\title{
Ricky Stadium 2040
}

Dawid Wojasz

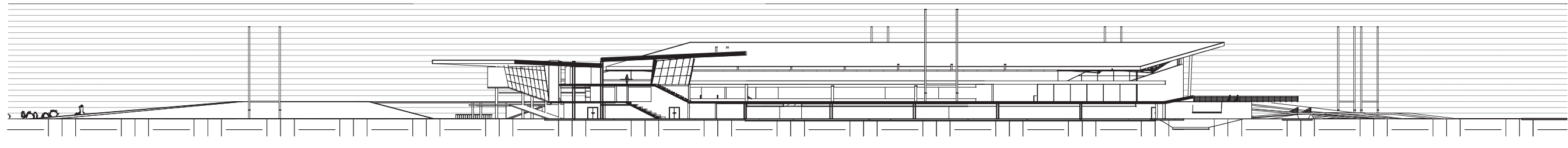





\title{
Ricky Stadium
}

BY

\section{Dawid Ryszard Wojasz}

\author{
A thesis \\ submitted to the Victoria University of Wellington \\ in fulfilment of the requirements for the degree of \\ Master of Architecture (Professional)
}

Victoria University of Wellington 



\section{Contents}

\begin{tabular}{|c|c|c|c|c|c|}
\hline \multirow[t]{2}{*}{ Abstract } & 7 & 04 Research Method (Approach) & 35 & Site Analysis & 92 \\
\hline & & Data Collection (Research for Design) & 36 & Personal Observations & 92 \\
\hline 01 Introduction & 9 & Analysis of Wainuiomata & 36 & 09 Design Development & 100 \\
\hline Problem Statement & 10 & Detailed Analysis of the Wainuiomata Rugby Club & 36 & 6 Month Review & 100 \\
\hline Research Aim & 10 & Research through design & 37 & September Critique & 105 \\
\hline Research Question & 10 & Data Interpretation (Design Trials) & 37 & & \\
\hline Scope of Research & 10 & Development of Brief (Refining \& Analysing Data) & 37 & Developed Design & 111 \\
\hline Summary of Chapters & 12 & $\begin{array}{l}\text { Design of Community Sports Facility (Application c } \\
\text { Findings) }\end{array}$ & of 37 & Discussion & 152 \\
\hline Conclusion & 12 & & & & \\
\hline & & 05 Wainuiomata & 39 & Conclusion & 155 \\
\hline 02 Literature Review & 15 & Wainuiomata & 40 & Appendix & 156 \\
\hline $\begin{array}{l}\text { Introduction } \\
\text { Diagrams in Architecture }\end{array}$ & 16 & Data Collection Process and Analysis & 44 & Appendix 1: Sources of Data & 156 \\
\hline Defining Diagrams & 16 & 05b Rugby Club & 61 & $\begin{array}{l}\text { Appendix 2: Financial accounts of Wainuiomata } \\
\text { Sports Clubs }\end{array}$ & 157 \\
\hline & & Development of Brief & 75 & Appendix 3: Income Sources & 161 \\
\hline 03 Case Studies & 21 & Project Brief & 77 & Appendix 4: Nga Purapura program comparison & 163 \\
\hline Seattle Public Library - OMA & 22 & & & & \\
\hline Nga Purapura - Tennent + Brown Architects & 26 & Design & 83 & References & 164 \\
\hline $\begin{array}{l}\text { tects } \\
\text { to }\end{array}$ & 30 & Design Trials & 86 & List of Figures & 170 \\
\hline
\end{tabular}





\section{Abstract}

The population of Wainuiomata (figure 1) is set to increase by $35 \%$ following Hutt City Council plans to build 2000 new houses. This increase has the potential to further erode a sense of community already weakened by the decline of traditional sources of community identity, notably Wainuiomata's Sports Clubs, Schools, and Churches.

This thesis reconsiders architectures relationship with sport and how architecture can help to enhance a sense of community identity. It employs an architecture derived from the formal and spatial qualities of a sports field to establish a range of programs and activities. Through a series of design iterations this thesis asks, how can Architecture's relationship with the Sports Field be reconsidered to intensify (social) connections between sport and community?

A mixed method research approach was used to obtain data from a broad range of sources including; historical resources, photographs, personal observations, statistical sources, council plans and documents, and local publications and through websites (see appendix 1). Data collected was interpreted into a series of diagrams, revealing relationships and links within the Wainuiomata Community, enabling it to be understood spatially. This data was analysed through a series of design tests which determined ways it could inform the design of a building. This analysis was used to develop a brief for the building which informed a series of design iterations, and ultimately a developed design. These designs developed an understanding of how a 'sports field' can be intensified as a spatial and programmatic proposition. The resulting design is a sport and education facility defined by overlapping surfaces which create a dialogue between sports field as a formal condition and a range of programs. Architecture, in this role, acts to connect a diverse range of community groups facilitating social interaction and enhancing local community.

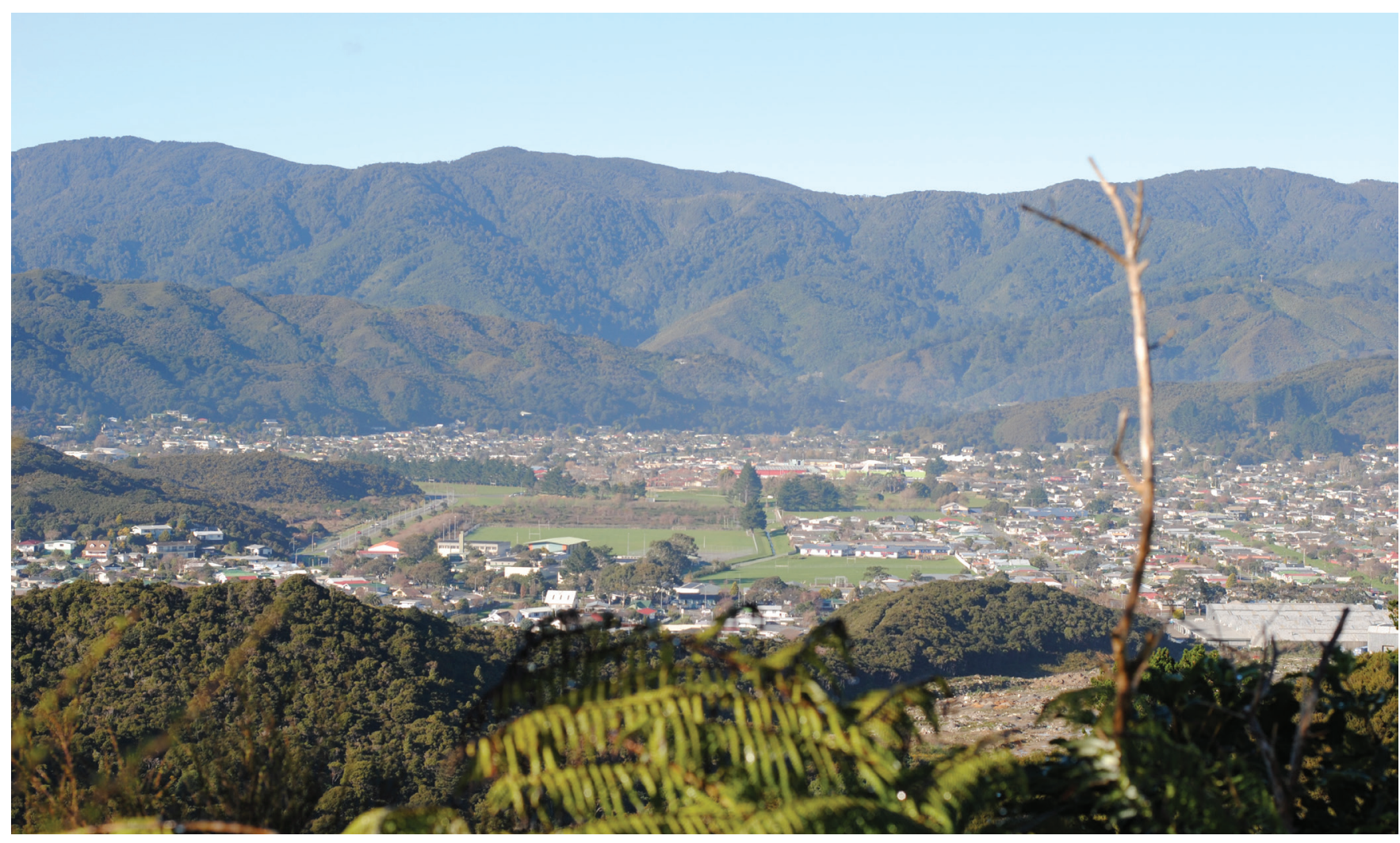

Figure 1: Central Wainuiomata and surrounding hills as viewed from the Wainuiomata Hill Road summit 



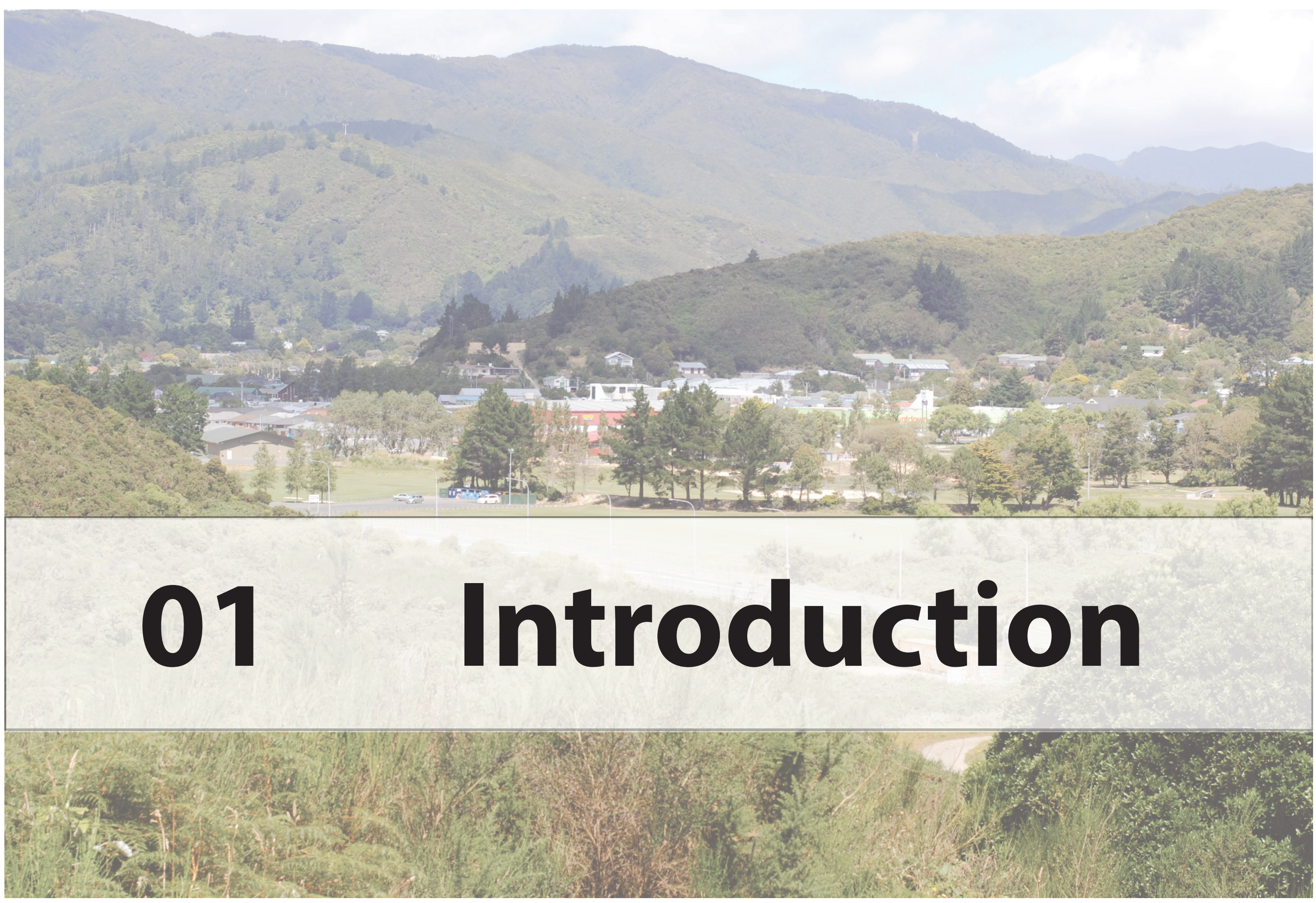




\section{Problem Statement}

Sport is a catalyst for a range of activities, interactions and connections within society which create social capital and contribute to a sense of local community identity (Putnam, 2001, p. 411). While the social effects of sport are widely researched, see (S. F. Brown, 2013; Hassan, 2013; Nicholson, 2013) the issue is the majority of this research has been conducted outside of architecture, consequently research is limited on how these effects can influence the design of buildings and spaces (Flowers,

2011, p. 1176). Books on sports architecture tend to focus on; the history, or technical and programmatic requirements for stadiums and other sports facilities see (Culley, 2009; John, 2013). While a few books such as, Sport, Space and the City (Bale, 2001), The Stadium: Architecture for the New Global Culture (Sheard, 2005), Stadium worlds: Football, space and the built environment (Frank, 2010), discuss the stadium as a social construct and environment. This discussion is limited by its focus on the stadium, an isolated container in which these relationships occur. There is little discussion on how sports environments connect to the wider community, discussions about social effects are limited to the stadium itself. The stadium has an indirect relationship with the city, what I am exploring is how a space can be designed so it has a more direct relationship with its context.

Papers on the spaces of sport either focus on sport as a social space (Tomlinson, 2003; van Ingen, 2003) or on developments in the way that spaces are designed (Bale, 1993) (Eichberg, 1993) or adapted in the city (Kural, 2010). Stadiums: Architecture and the Iconography of the Beautiful Game recognises the "intertwined social practices of sport and architecture" but has a focus on the stadium as an icon (Flowers, 2011, p. 1174). These papers have a tendency to focus on the stadium as an image/icon with little about context, or grass roots communities. Discussion on the social is focused on analysis of the stadium, rather than how these social effects might influence design. "The stadium is described as a lens which focuses on general social development trends and makes them recognizable"(Frank, 2010). There is little critical thought given to local community connections to sport and how they might influence the design of spaces. While the research discussed is valuable it has been limited in its exploration of the relationship between architecture, sport and community - as a way to strengthen community.

\section{Research Aim}

The aim of this thesis is to explore the relationship between architecture and sport (see figs $2 \& 3$ on pg 11). This is achieved through the design of a community building which capitalises on the social connectivity that sport produces to support additional community activities and functions. It does this through an examination of existing relationships and interconnections within the suburban community of Wainuiomata, which is used as a testing ground for design experiments - exploring opportunities for the 'sports field' to be intensified as a spatial and programmatic proposition.

\section{Research Question}

How can Architecture's relationship with the Sports Field be reconsidered to intensify (social) connections between sport and community?
Scope of Research

Research is restricted to a design related to the specific context of Wainuiomata ${ }^{1}$.

Given the subject of this inquiry it is necessary to clarify that unless otherwise stated what is meant by the term 'sports field' this is literally the field of play from which sporting activities are conducted, as opposed to the field of sport as an academic discipline or the understanding of field within architecture as espoused by Stan Allen as a continuous interconnected system (Allen, 2009a).

1 The suburb of Wainuiomata was chosen because I have a personal connection with the area. I have lived there all my life and identify strongly with it as a place. 
The Social Effects of Sport are Intensified Through an Overlap Between the Sportsfield and Architecture
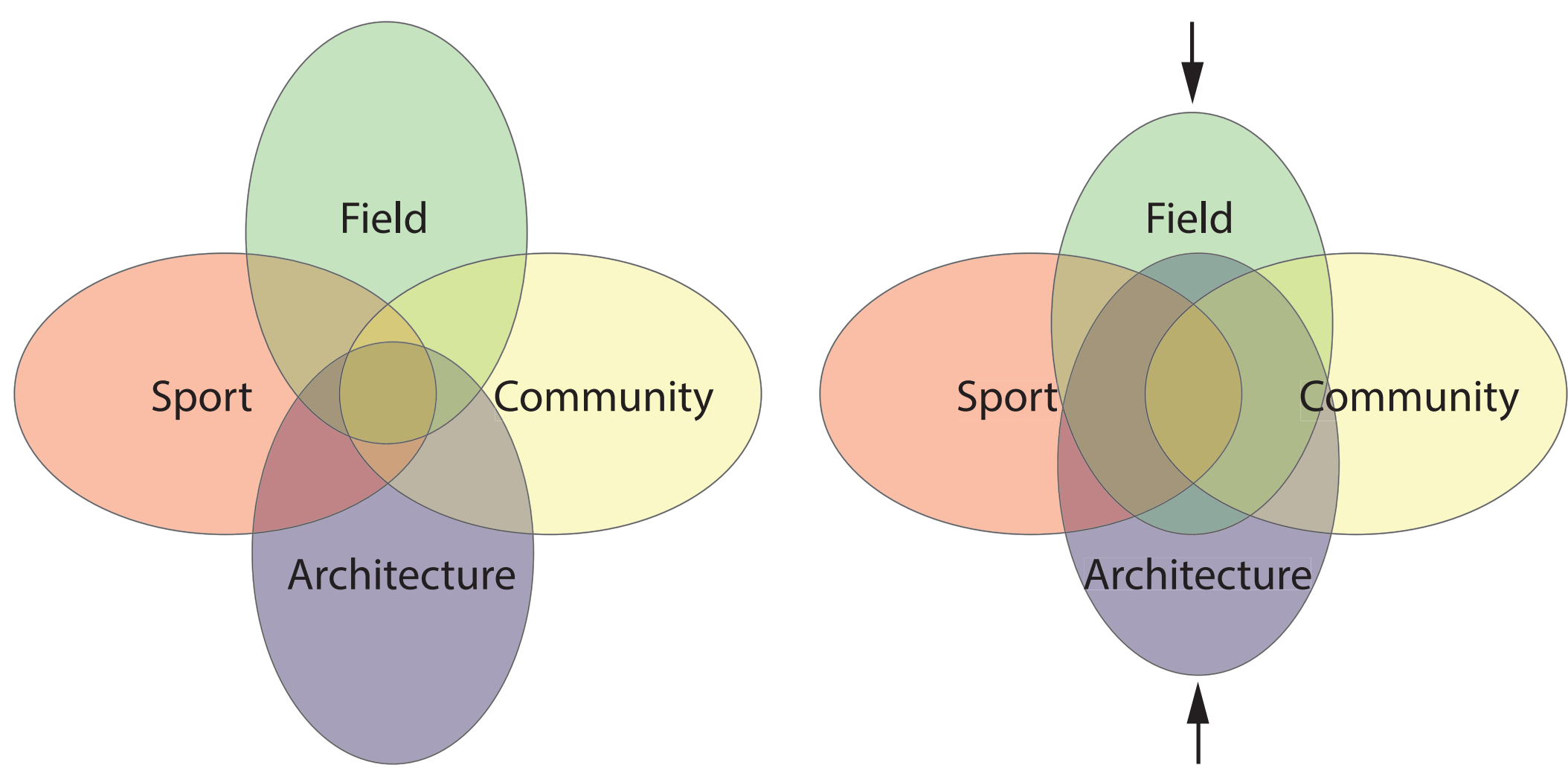

Figure 2: The sporting community is split between Architecture and the Sportsfield.

Figure 3: A closer relationship between architecture and the field will concentrate the sporting community, intensifying the social effects of sport. 


\section{Summary of Chapters}

This thesis consists of 6 chapters and is divided into two parts; Research for Design and Research through Design. A diagram of this research is shown in figure 4 on the next page.

\section{Part 1: Research for Design}

Discusses research conducted to aid in the design process.

\section{Literature Review}

Discusses the use of diagrams in contemporary architecture practice and how they can be used as a means of abstracting information and concepts in to allow a range of data to inform the design process.

\section{Case Studies}

Discusses three case studies which were used to understand how diagrams can be used at various stages of the design process and understanding the programmatic requirements of similar sports spaces to aid in the development of a brief.

\section{Research Method (Approach)}

This chapter outlines the research approach undertaken. It discusses methods used for obtaining and analysing data on the local community of Wainuiomata. This data was collected in two stages; the first stage had a broad focus collecting data on the wider community, the second was more detailed and focused on an analysis of Wainuiomata Rugby Football Union club.

\section{Part 2: Research through Design}

Discusses research conducted through the process of design.

\section{Pre Design}

This section presents data collected on the local community and discusses how this data has been interpreted through a series of diagrams and design tests and how this earlier research informed the development of a design brief.

\section{Design Development \& Discussion}

This chapter discusses the final design and the process of its development. It presents design iterations which formed part of the development process and documents the final developed design through a series of plans, sections, renders and diagrams.

\section{Reflection and Conclusion}

Reflects on the process of design research undertaken and how the focus of this research has changed throughout the process, how feedback from design reviews has influenced this process and limitations which were observed. The final design is related back to the initial research intentions and question and this is used to determine how successful the research was overall.

\section{Conclusion}

The resulting design is a sport and education facility defined by overlapping surfaces which create a dialogue between the sports field as a formal condition and a range of programs. Architecture, in this role, acts to connect a diverse range of community groups facilitating social interaction and enhancing local community. 
Research For Design

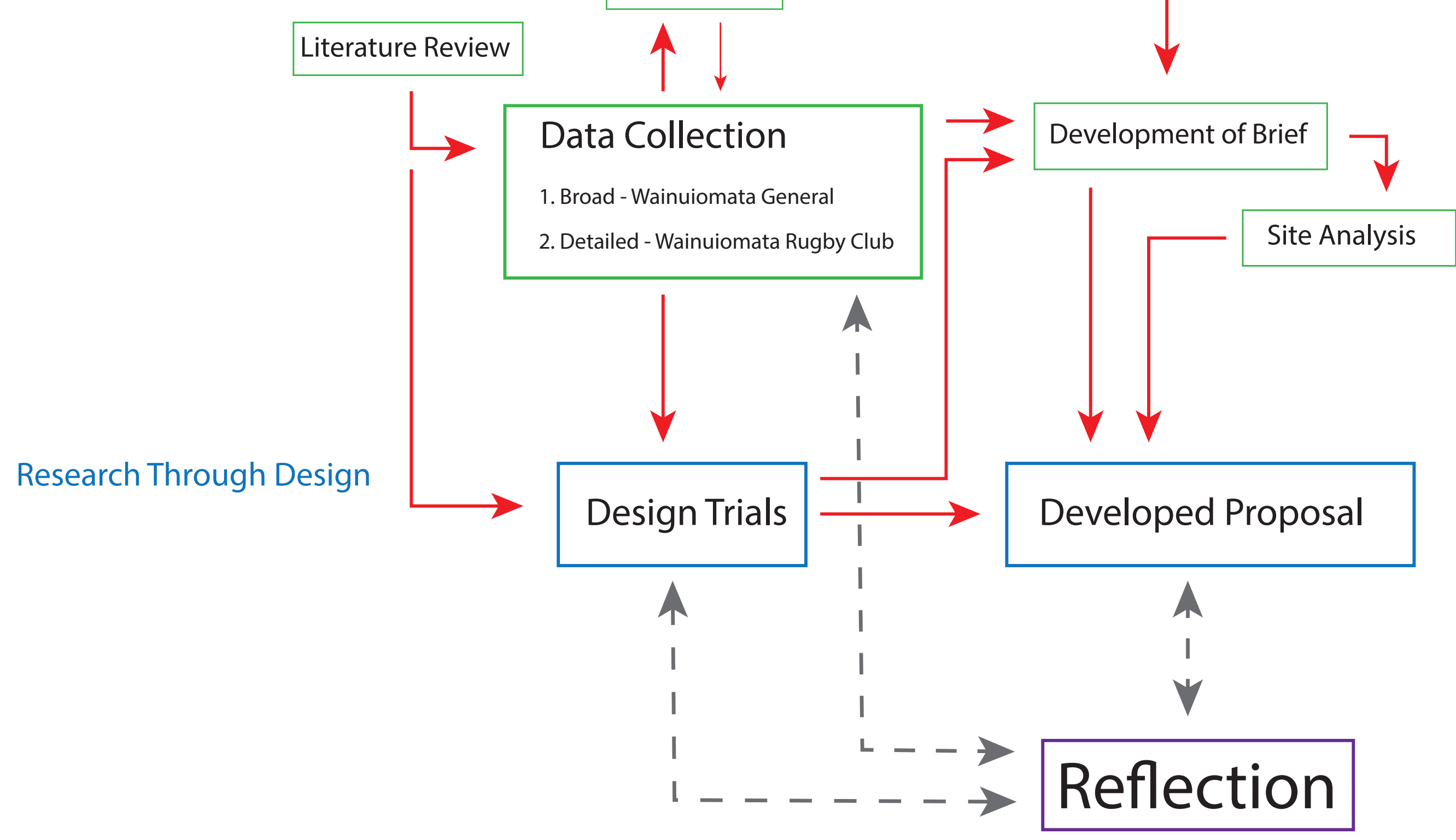





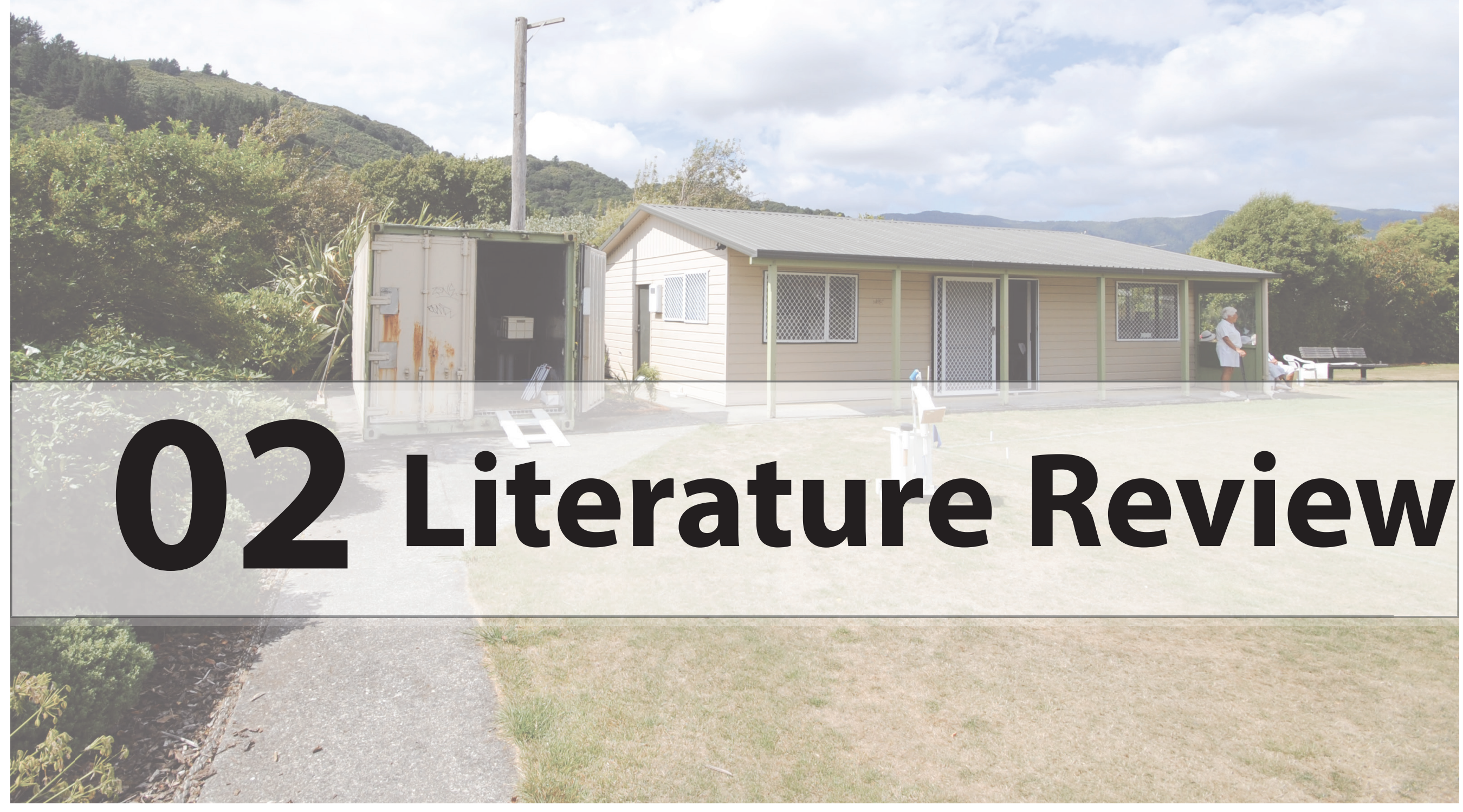




\section{Introduction}

This research uses an approach in which the design brief for a building is heavily contingent on an understanding of the forces at play in a local community sport environment. It seeks a closer relationship between architecture, sport and community to the point where these areas overlap and become indistinguishable from one another. This contextualises the research within a wider body of research related to the production of 'projective architecture' which is concerned with a closer engagement between architecture and forces traditionally seen as outside of the architectural discipline (Hight, 2009; R. Somol \& Whiting, 2002; Speaks, 2002). The use of diagrams, as a means of managing complex programmatic information, is seen as important for this pragmatic approach to practice. In this chapter I will briefly define the diagram then discuss the role of diagrams in the design process, how they have been used / understood in contemporary architectural practice, and concludes with how an understanding of diagrams has influenced my research process.

\section{Diagrams in Architecture}

Diagrams are valued by architects because they enable the reduction of complex information, through abstraction, enabling it to be more easily managed in the design process((UNStudio), 2010, p. 225; Garritzmann, 2010). This process of abstraction shifts the way the diagrams content is understood and opens up alternative opportunities to engage with the subject matter. Diagrams were investigated in this thesis as a means of engaging with the complexity of sport/community relationships in a spatial medium.

\section{Defining Diagrams}

There is a lack of consensus on an exact definition of a diagram. Understanding of the term has been complicated due to the diverse range of interpretations which exist across different disciplines (Garcia, 2010, p. 22). Most architectural theorists draw their understanding of diagrams from the works of Gilles Deleuze ${ }^{2}$, who argues that the diagram is an "abstract machine... a map of relations between forces" (Garcia, 2010, pp. 23-24). An abstract machine that for Deleuze and Guattari is:

...not physical or corporeal, any more than it is semiotic; it is diagrammatic (it knows nothing of the distinction between the artificial and the natural either). It operates by matter, not by substance; by function, not by form... The diagrammatic or abstract machine does not function to represent, even something real, but rather constructs a real that is yet to come, a new type of reality.

Gilles Deleuze and Félix Guattari, $A$ Thousand Plateaus p.141-142 as Cited in (Allen, 1998, p. 15)

This description of diagrams lends itself to multiple readings and has been interpreted (and expanded upon) in a number of different ways by architectural theorists and practitioners. Consequently this has resulted in a number of similar but different definitions, see: ((UNStudio), 2010, p. 224; Allen, 2009b, p. 51; Eisenman, 2010, pp. 94-95; Garcia, 2010, p. 18; Tschumi, 2010, p. 196) (Vidler, 2006).

2 The works of Charles Sanders Peirce, on semiotics, and Michel Focault on the Panopticon as a diagram of power relations are also highly influential(Garcia, 2010, p. 23).
Mark Garcia's definition of a diagram as “... the spatialisation of a selective abstraction and/ or reduction of a concept or phenomenon." (Garcia, 2010, p. 18) was the definition I found most useful for describing what a diagram is, while Allen's description of a diagram as "a graphic assemblage that specifies the relationships between activity and form" was more useful in describing how diagrams can be used and were used in this thesis (Allen, 2009b, p. 51).

What is similar across these definitions is that diagrams are defined by their function, as a spatial means of describing relationships. It has a spatial or graphic quality however the exact nature of what can constitute a diagram is quite open to interpretation. The power of the diagram is that through the processes of abstraction and reduction unnecessary information can be filtered out and key information can be transformed, allowing new understandings and associations to be developed(Garritzmann, 2010, p. 235). An important part of the diagramming process is selection of what should be diagrammed and how. The function of the diagram needs to be determined, which is where the designer comes in.

\section{History of Diagrams}

The use of diagrams has been a constant feature in architectures history ${ }^{3}$, although the perceived importance and understanding of the diagrams role in the design process has fluctuated over time (Garcia, 2010).

3 Garcia notes that some prehistoric buildings such as Stonehenge were diagrams of space and place and some of earliest architectural texts such as Vitruvius's Ten Books on Architecture contain a number of diagrams (Garcia, 2010, pp. 18-19) 
For modernist architects diagrams were understood as a means of introducing a functionalist, scientific rational to the design of architectural space (Pai,

2010). Bubble diagrams were used by modernists architects to describe the network of relationships and connections between the spaces of a building, aiding in organisation (Emmons, 2006, p. 441). The diagram understood in this way had a linear association with form(Pai, 2010, p. 74).

In the late 1970's and 80's a new understanding of the architectural diagram emerged based on the writings of Michel Focault ${ }^{4}$ and Gilles Deleuze ${ }^{5}$ on Jeremy Bentham's Panopticon as a diagram of power relationships in society (R. E. Somol, 1999, pp. $22-23)^{6}$. The diagram understood in this way offered new opportunities for architecture to engage the relationship between form and social program in a non linear way. During this period diagrams featured heavily in the works of architects such as Bernard Tschumi and Peter Eisenman, and Rem Koolhaas/ $\mathrm{OMA}^{7}$.

4 See Discipline and Punish (Foucault, 1975)

5 See Focault and A Thousand Plateaus (Deleuze, 1988; Deleuze, Guattari, \& Massumi, 1987)

6 Architects during this period were also influenced by 'deconstruction,' a movement which emerged from the theories of Jacques Derrida. Diagrams were used by deconstructivists to engage in formal experimentation removed from associations with function, and as a way to engage with traces of the past. - See Of Grammatology (Derrida, 1976)

7 All three submitted entries for Parc De La Villette design competition in 1982
Tschumi's 'Manhatten Transcripts' used diagrams to describe multiple characteristics of architecture at once recording action, movement and space (Architects, 1981; Tschumi, 2010, pp. 196-198). Tschumi's diagrams focused on multiple readings of a space, allowing it to be understood not only as a physical phenomenon but also a social one (fig 5). Eisenman's work with diagrams is associated with semiotics, describing architectural elements as 'motivated signs' that are both a formal object and a sign of their function. Eisenman used diagrams to conduct experiments with form which would remove these associations through a process of serial repetition and transformation. Koolhaas's framing of the Downtown Athletic Club in Delirious New York operates diagrammatically in the way that it describes the infinite possibilities for interaction between programs within the frame structure of the 'skyscraper-machine'(R. Somol \& Whiting, 2002, pp. 74-75).

In the 1990's the emergence of the digital led to a further expansion in the use of diagrams in architectural discourse. Gregg Lynn was highly influential during this period, his work involved the use of mathematical formula's to experiment with complex geometries and blob forms (Vidler, 2000, p. 6). Mathematical functions are diagrammatic in the sense that they describe formal, and other, relationships in a way which is not a direct representation of the forms they determine. The emergence of computers and the digital realm opened up opportunities to explore how manipulation of these mathematical relationships could be used to determine architectural form in an indirect way. This period also led to the development of what was termed 'diagram architecture' where the building takes on the spatial qualities of the diagram used in its design (Vidler, 2001, p. 89).

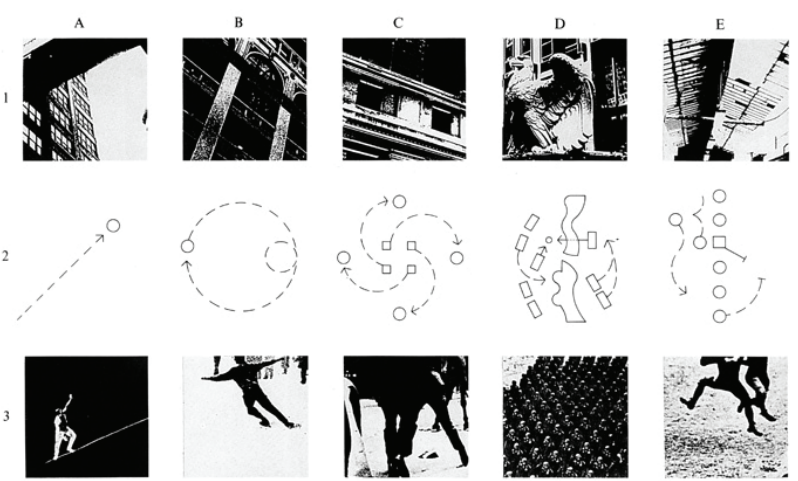

Figure 5: Manhattan Transcripts Diagrams (B.T. Architects, 1981) 
Other diagrammatic practices which were prominent during this period include: FOA, MVRDV, UN Studio, and again OMA.

Caroline Bos and Ben van Berkel from UN Studio and Alejandro Zaero-Polo from FOA have produced a number of writings on the role of diagrams in their designs, and architecture in general. Peter Eisenman's book 'Diagram Diaries' published in 1999 includes essays by Peter Eisenman which outline the development of diagrammatic process of design, and an introduction by Robert Somol which discuss the emergence of diagrams in contemporary architecture (Eisenman, 1999; R. E. Somol, 1999).

In contemporary architecture diagrams have become associated with projective architecture as a way to engage forces traditionally seen as external to the architectural design process. A number of architectural practices now employ diagrammatic techniques of design. UN Studio and Nox, OMA, Greg Lynn. The diagrams of OMA are largely based on the processing of information. OMA's process focuses on the visualisation of data, collected from a wide range of sources, diagrams are then used to explore the potentials to convert this data into a concept for design (Garritzmann, 2010, pp. 228-229). It is this process which initially influenced my research approach because of the potential to explore, how a wide range of sources might influence the design process.

\section{Limitations}

Diagrams operate through a process of selective abstraction and reduction. These qualities of diagrams which make them useful in architectural practice are also the subjects of negative critique. On this subject McCormack notes "Put simply abstraction is too quickly understood to be a technique of reductive simplification that fails to grasp the messy complexity of the space of the lived."(McCormack, 2012, p. 716)

Garcia also lists a number of criticisms with diagrams (Garcia, 2010). One important criticism is that they are by their very nature reductive, they simplify the complex to a few key ideas or concepts and inevitably detail is lost in the translation process. Similarly the use of diagrams can exaggerate the importance of different types of information giving it a disproportionate influence on the outcome of the design. Other criticisms he discusses focus on the aesthetics of diagrams, and the way in which they used in the design process. These criticisms relate more to the circumstance in which the diagram is used rather than the diagram in general.

\section{Conclusion}

Diagrams have emerged as an important part of the design process over recent years, as a way to engage with forces which have an effect on architecture.

This research uses an approach which prioritises an understanding of the relationships between sport and community in the design process. The use of diagrams was explored as a way to enable a wide range of data on these relationships to be incorporated into the design. Diagrams became more useful in the design process once a more concrete design agenda was established through the development of a brief. 
Diagrams Were Used To Engage Community Relationships In The Design Process

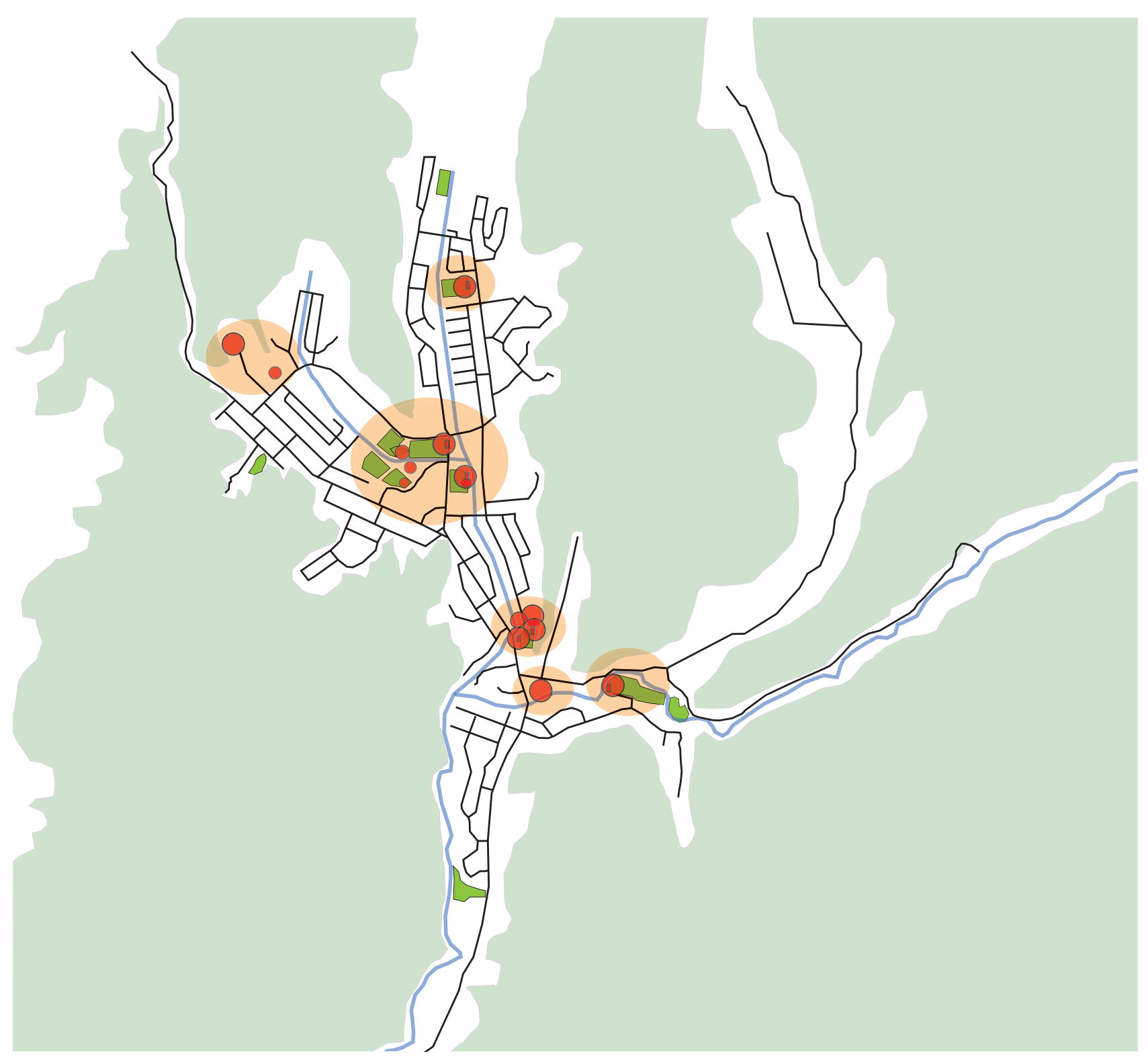

Figure 6: Nodes of Sporting Activity in Wainuiomata 



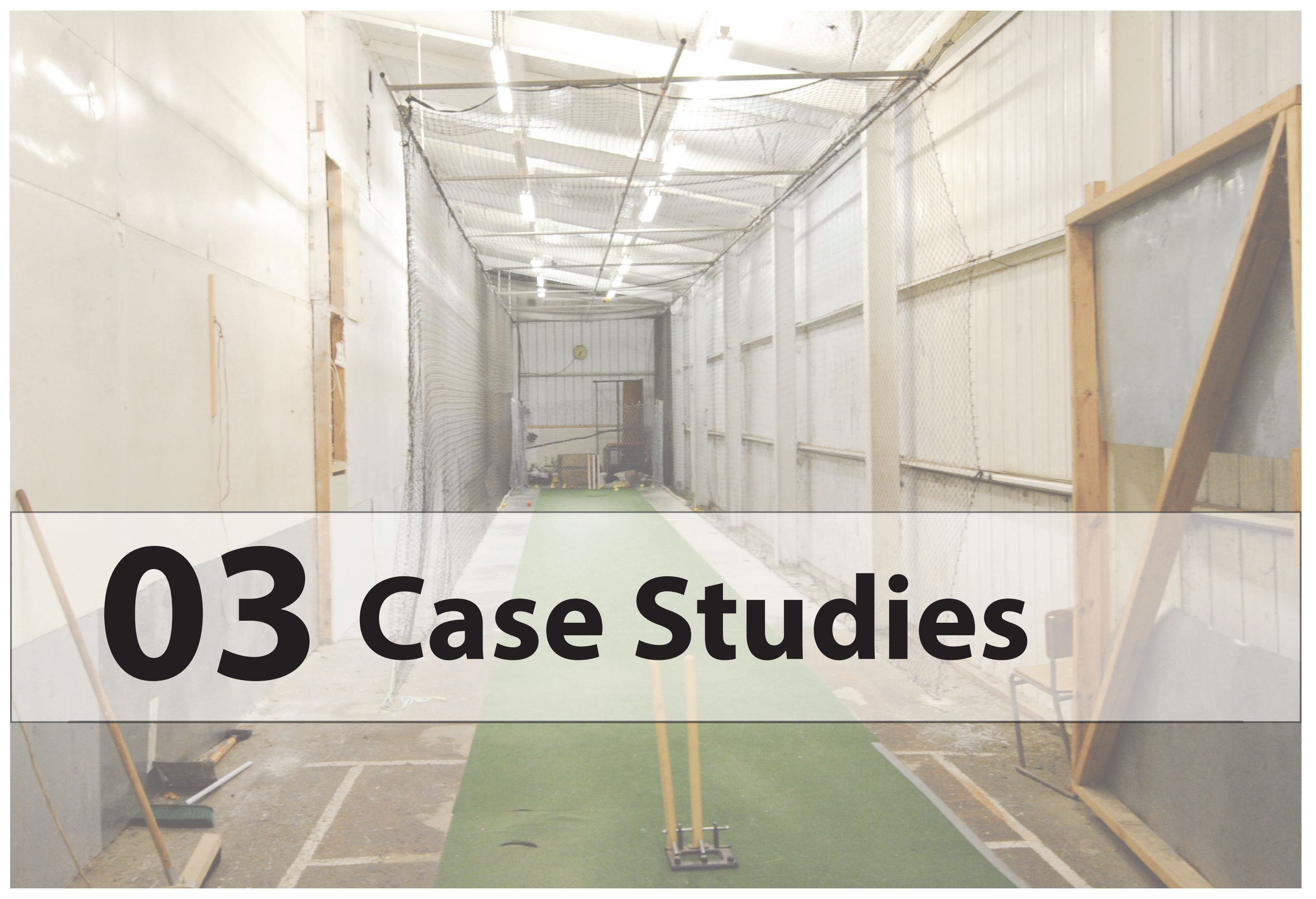


Following the literature review the use of diagrams in the design process was examined through the analysis of a number of case studies. Seattle Public Library by OMA and Yokohama Terminal by FOA were both analysed to develop a better understanding of the diagramming process, for brevity only Seattle will be discussed). The designs of existing sports buildings were also analysed through several local case studies to develop an understanding of program, organisation and how these spaces are used, these include, Nga Purapura and ASB Sports Centre by Tennent + Brown (Plans for new sports hubs in Fraser Park and Walter Nash Stadium were also examined but are not included in this discussion).

\section{Seattle Public Library - OMA}

This case study looked at how diagrams can be used, from an early stage in the design process, as a way of; communicating key ideas about the project, developing an organisational strategy, and managing the organisation of program and its distribution throughout the building. OMA's process began with background research on the physical and social/cultural changes which effect how libraries are used and designed. As a result of this research OMA identified that books now compete with a range of media and that the role of the library, rather than being solely tied to physical books, is changing parallel to this with an expansion of social program. This was represented in two diagrams showing a parallel expansion of media types (Fig 7) and the social program of the library (Fig 8) over time. The representation of this information in a timeline diagram suggests a pattern of expansion which will continue into the future, it also makes clear that this expansion will give an increasingly equal importance to the various media and social program in the library (Kubo \& Prat, 2005, pp. 10-11). As a response to these revelations OMA established a design intent, to redefine the library "as an information store where all potent forms of media - new and old - are presented equally and legibly"(Kubo \& Prat, 2005, p. 11). OMA Identified that flexibility of open planning in a library is a potential threat to this equality due to the tendency of collections to expand and "inevitably come to encroach upon public space"(Kubo \& Prat, 2005, p. 14). A response to this problem is demonstrated through a pair of diagrams. The first presents the problem by depicting an opening scenario, with an equally distributed space, and a future scenario in which public space has been taken over by collections (Fig 9). The second repeats the earlier diagram but shows how a strategy of compartmentalising 'stable' spaces can prevent encroachment "tailored flexibility remains possible within each compartment, but without the threat of any one section hindering the approach of others"(Kubo \& Prat, 2005, p. 15) (Fig 10). Used in this way the diagram informed an organisational strategy for the building which achieves equality between programs. The detail of how this strategy was to be implemented is further explored through a series of diagrams which represent the program of the library spatially in coloured bands (Figs 11 \& 12). This allows the program to be organised, consolidated into categories of similar function and then reshuffled to suit the organisational strategy of compartmentalisation into stable and instable zones.

A critique of this method of design is that while the library's design responds to a global historic context, regarding the role of the library, it does not appear to have much connection to the local context, urban environment or history of the city, it is a clean slate. The finished building occupies an entire city block but has little interaction with the street itself. Another critique is that reduces the complexity of a library to a few images and through the process gives the problems presented an exaggerated importance in the design process. In the case of OMA this exaggeration is an intentional part of the design process, a strategy used for generate new ideas (Garritzmann, 2010, p. 235).

This project is limited also as an example of the diagramming process because, while it presents a coherent line of development from diagram to finished building, only the diagrams that were ultimately relevant in the design are presented. There is no indication of alternate solutions or strategies of organisation explored which may have led to alternate designs. These diagrams present a logical progression but following this logic could lead to a number of design outcomes, not limited to the one finally developed.

This case study is useful for understanding how diagrams can be used as part of the research process as well as understanding some of their limitations. The use of diagrams by OMA shows how they can aid in understanding and interpreting data. In summary the process of designing the library diagrams were used to; present a scenario, develop the design intent, identify a problem and through repetition present a solution to the problem, and finally implement an organisational strategy which led to a developed design. 


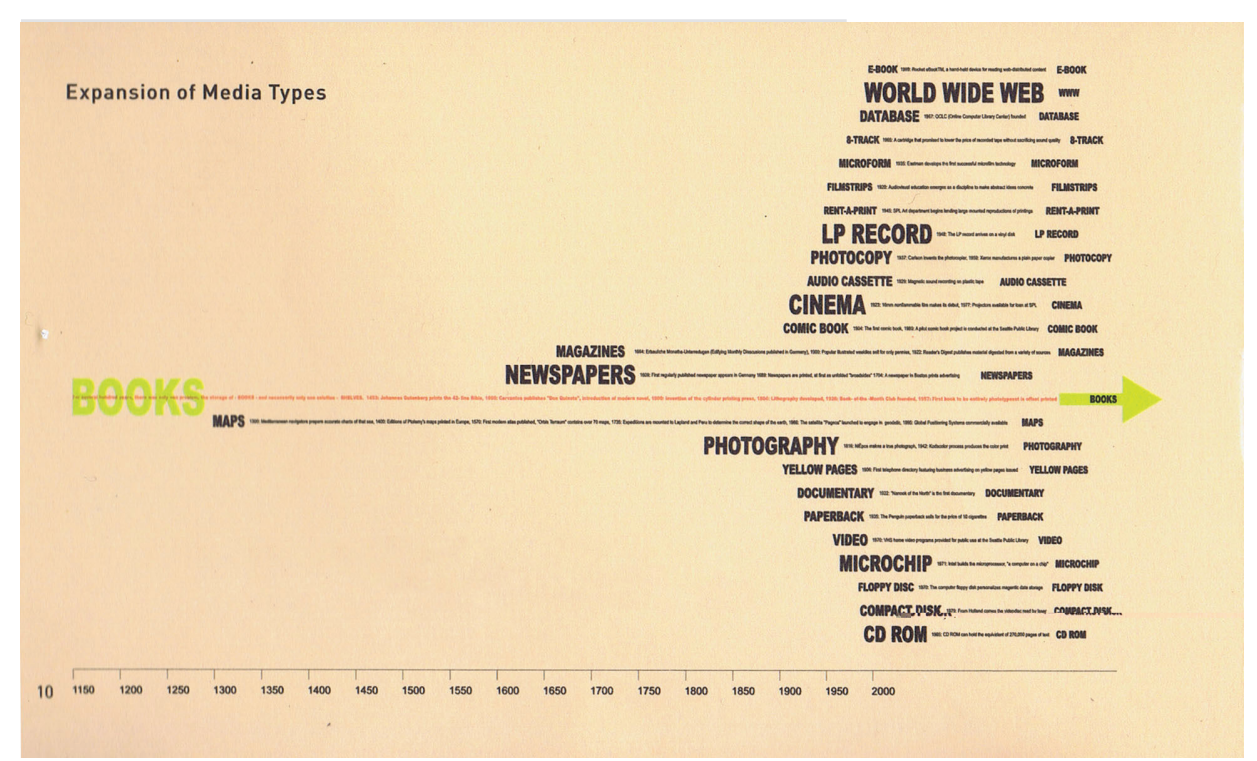

Figure 7: Books now compete with an expanded range of media types (Kubo and Prat, p. 10)

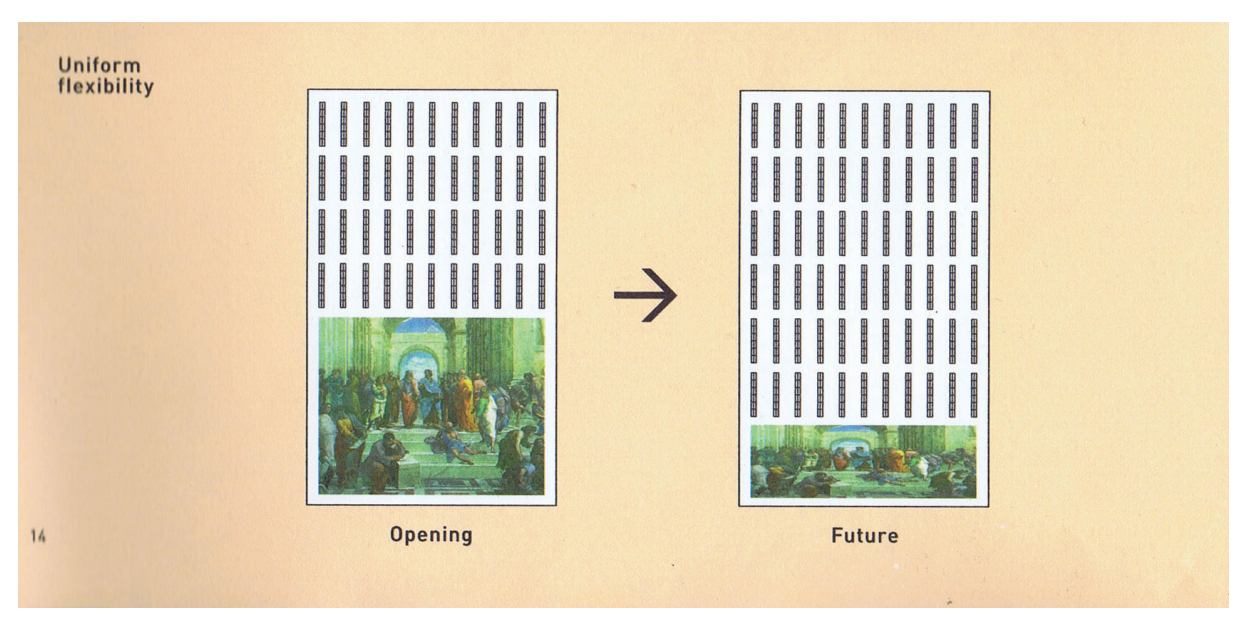

Figure 9: Uniform flexibility allows collections to encroach upon public space (Kubo and Prat, p. 14)

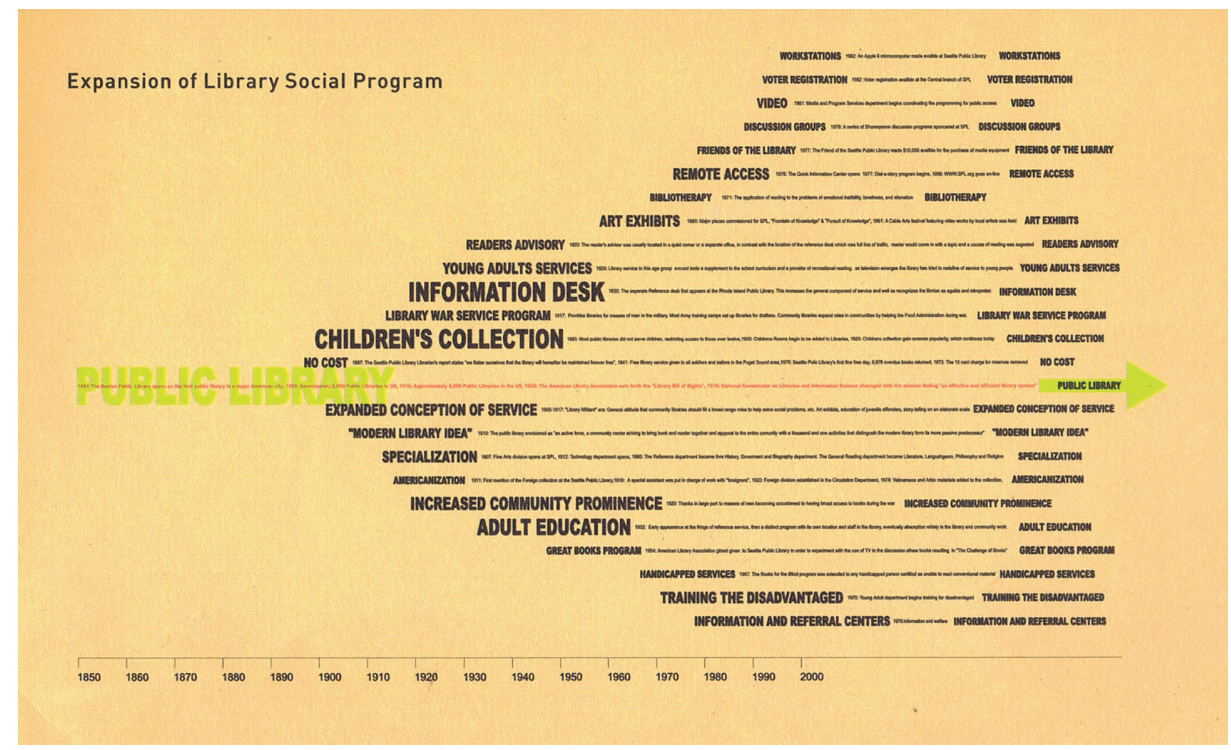

Figure 8: The social program of the library is also expanding (Kubo and Prat, p. 11)

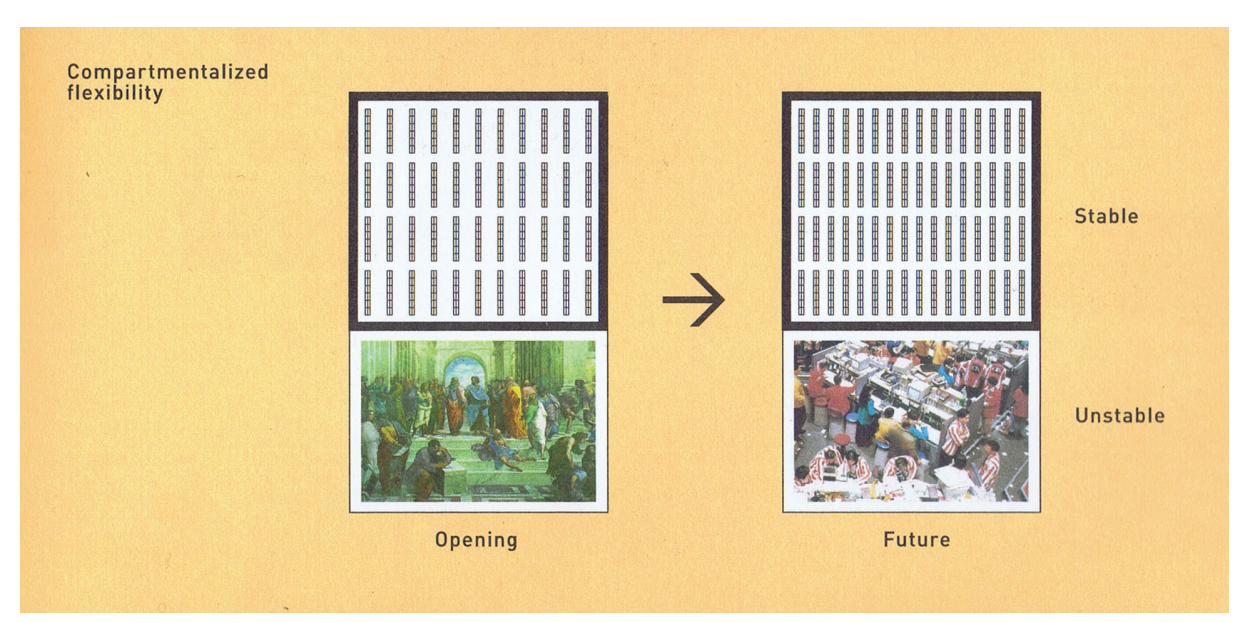

Figure 10: Compartmentalised Flexibility contains expansion to defined areas (Kubo and Prat, p.15) 


\section{Diagrams Enable OMA To Organise, Consolidate, And Reshuffle Program}

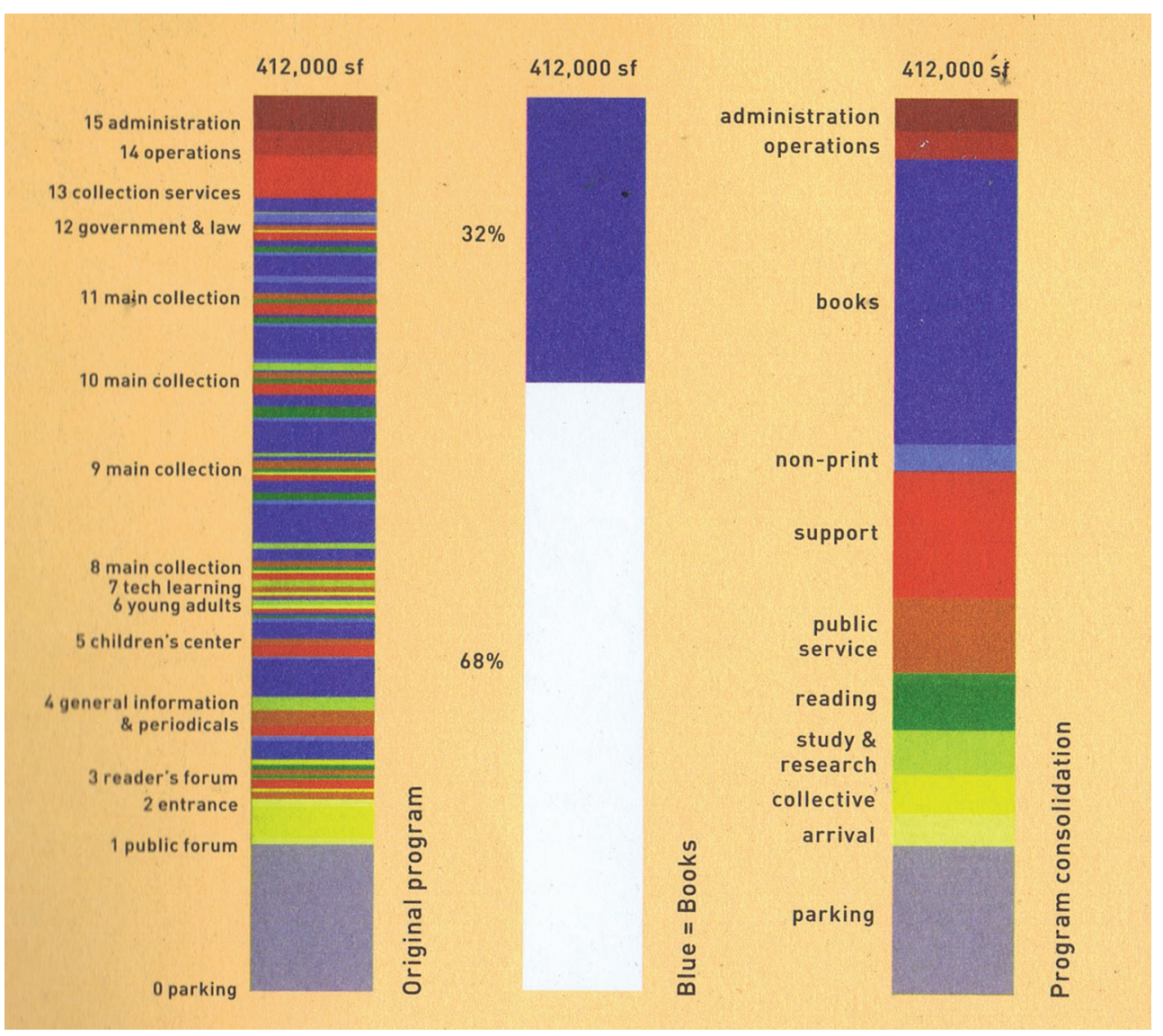

Figure 11: Program is categorised spatially in coloured bands and consolidated (Kubo and Prat, p. 18)

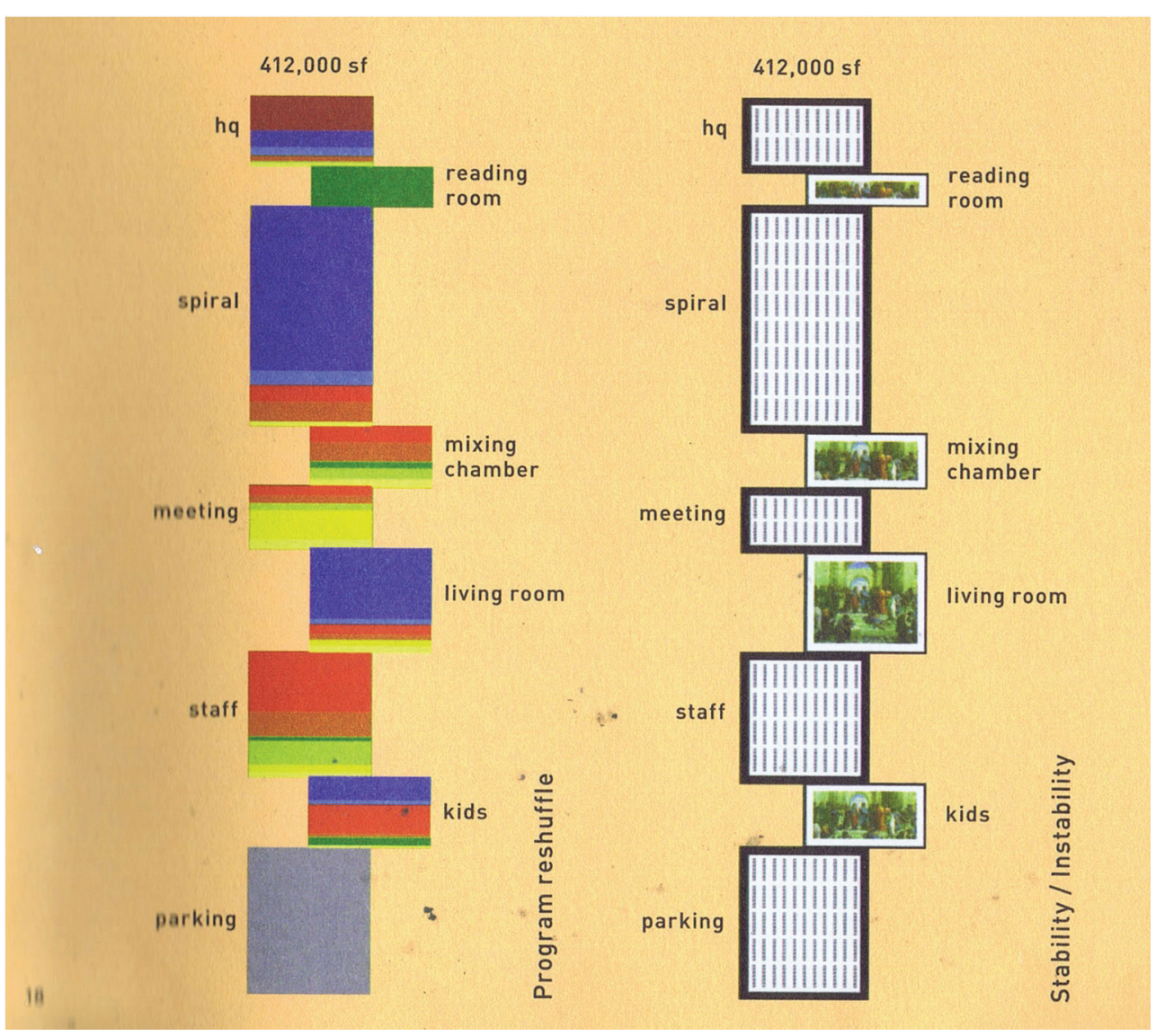

Figure 12: Program is reshuffled into compartments of stability and instability (Kubo and Prat, p. 18) 


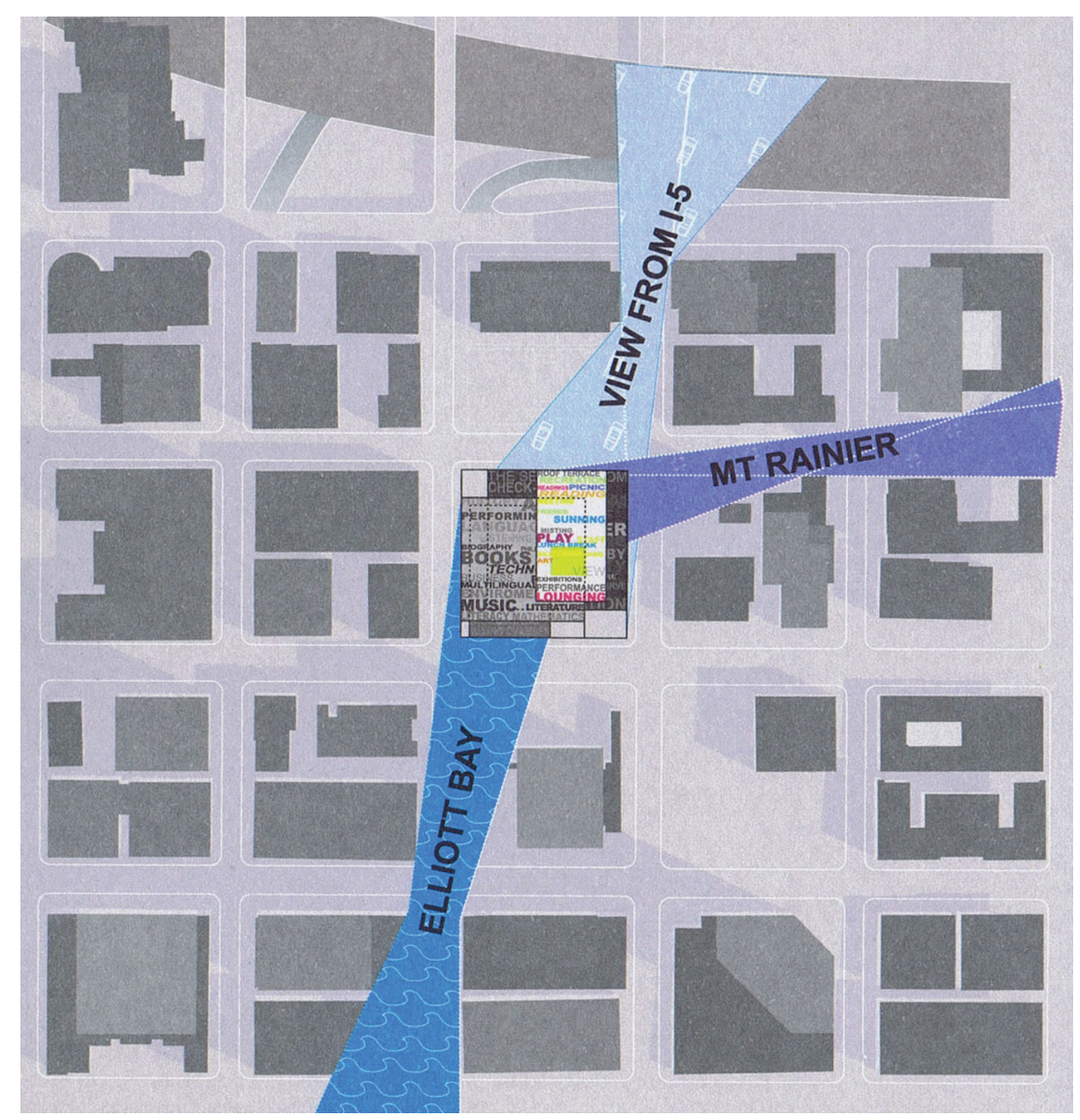

Figure 13: Diagram of View Shafts Determines Alignment of Spaces (Kubo and Prat, p. 30)
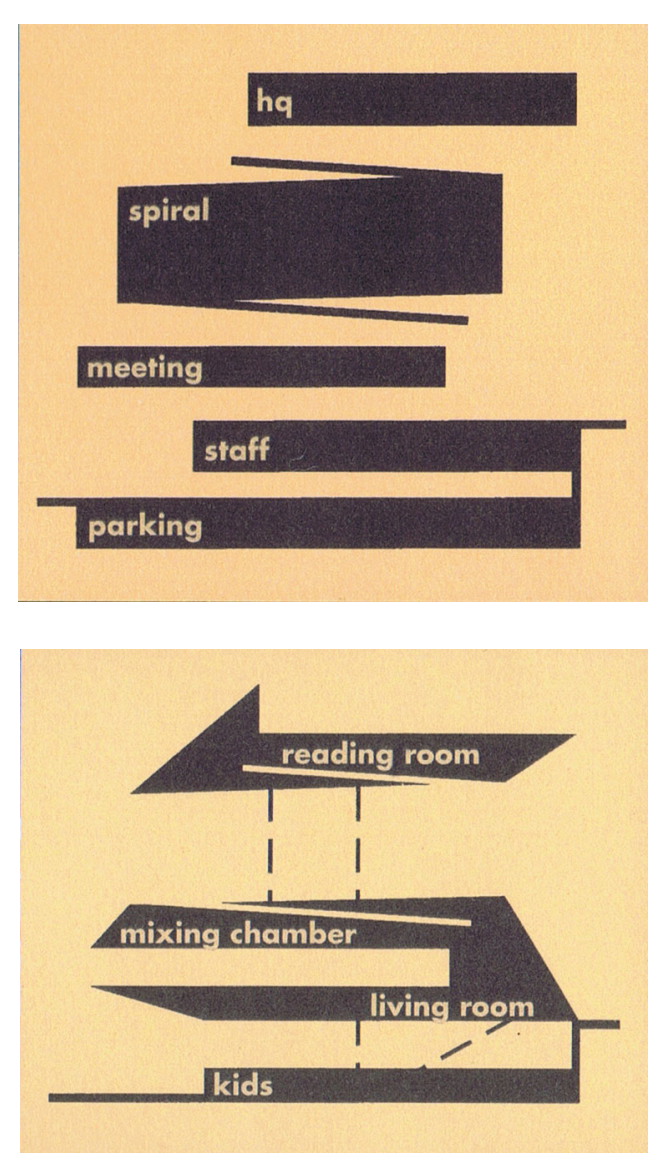

Figure 14: Final Composition of Program (Kubo and Prat, p. 22 \& 26 ) 
Nga Pura Pura was used as a case study because it is a local building recently built with a similar brief to the one which I was developing for my design. Nga Purapura was built in 2012 as an addition to Te Wananga - O - Raukawa, a tertiary education provider in Otaki. It is designed to house programmes focused on improving Maori physical wellbeing, while also being open to the public providing a means for the school to engage with the wider community ( $T$. Brown, 2012). This project is useful as an example of how an organisational strategy has been developed and used to inform the design. It also provides a recent local example of the types of spaces needed in a sport and educational facility (see figs 15-24).

\section{Organisational Strategy}

The design of Nga Purapura is based around "the holistic model of Maori health - Te Whare tapa Wha' (the four sides of the house)"(T. Brown, 2012). Programme is categorised into four functional groups, physical (tinana) - the gym, mental and emotional (hinengaro) - class spaces, spiritual (wairua) - atrium and 'kakano', and Social (whanau) - sports hall, in accordance with this model(T. Brown, 2012). These groups of spaces are arranged around the central atrium in a way which ensures a good flow between spaces and further enables the atrium to function as the spiritual heart of the building (fig 15). A wooden pod, the kakano - seed, in the centre of the atrium also aids circulation and serves as a reference point which can be seen throughout the building.

\section{Programme}

The design of Nga Purapura combines the programmes of a tertiary education institute with that of a sports facility. The allocation of space in this building was analysed to aid in developing a brief for my design. Measurements of the plans revealed the following sizes of space:

- Entrance

- Reception $6 \times 3 \mathrm{~m} \mathrm{18m^{2 }}$

- Atrium (Kakano sits within this space) $12 \times 16 \mathrm{~m}$ $192 \mathrm{~m}^{2}$

- Kakano ('Seed' Multi use space) $5 \times 9.5 \mathrm{~m} 47.5 \mathrm{~m}^{2}$

- Sports hall (space for two courts) $37 \times 42 \mathrm{~m}$ $1554 m^{2}$

- Warm up \& Viewing Platform $11 \times 4.549 .5 \mathrm{~m}^{2}$

- Toilets 1 (male + female) $5.75 \times 11.5 \mathrm{~m} 66.125 \mathrm{~m}^{2}$

- Teaching Spaces (2 rooms $8 \times 7 \mathrm{~m} 56 \mathrm{~m} 2$ each) $112 m^{2}$

- Showers (male + female including toilets) $14.5 \times 7 \mathrm{~m} 101.5 \mathrm{~m}^{2}$

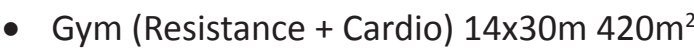

- Nutrition Class $10 \times 10 \mathrm{~m} 100 \mathrm{~m}^{2}$

- Cafe $3.5 \times 3.5 \mathrm{~m} 12.25 \mathrm{~m}^{2}$

- Admin $6 \times 11 \mathrm{~m} 66 \mathrm{~m}^{2}$

- Office (4 offices $4.4 \times 2.5 \mathrm{~m} 11 \mathrm{~m} 2$ each) $44 \mathrm{~m}^{2}$

- Plant $158.5 \mathrm{~m}^{2}$

- Total $3203.5 \mathrm{~m}^{2}$

It is worth noting that Nga Purapura has a relatively small amount of classroom space for an educational facility. This is justified because the building is a part of a larger campus and has a curriculum is also more hands on. A larger, independent, campus would necessitate an appropriate increase in some areas.

\section{Flexibility}

The use of retractable seating in the sports hall allows the space to be used for events, while allowing more space when seating is not needed. Nga Purapu$r a$ is also serves as an example of how a sport centre can connect to the local community by providing facilities which are open to the public to use for training, sports and social activities(Purapura, 2013).

This case study was useful to demonstrate how a complex program can be arranged simply and effectively by organising spaces into functional groups. It also shows how an atrium can be used as a central point to aid circulation around a building. Finally it provides an example of the type/size of spaces needed for such a building which was useful for developing a brief. 


\section{Nga Purapura - Distribution Of Program And Circulation}
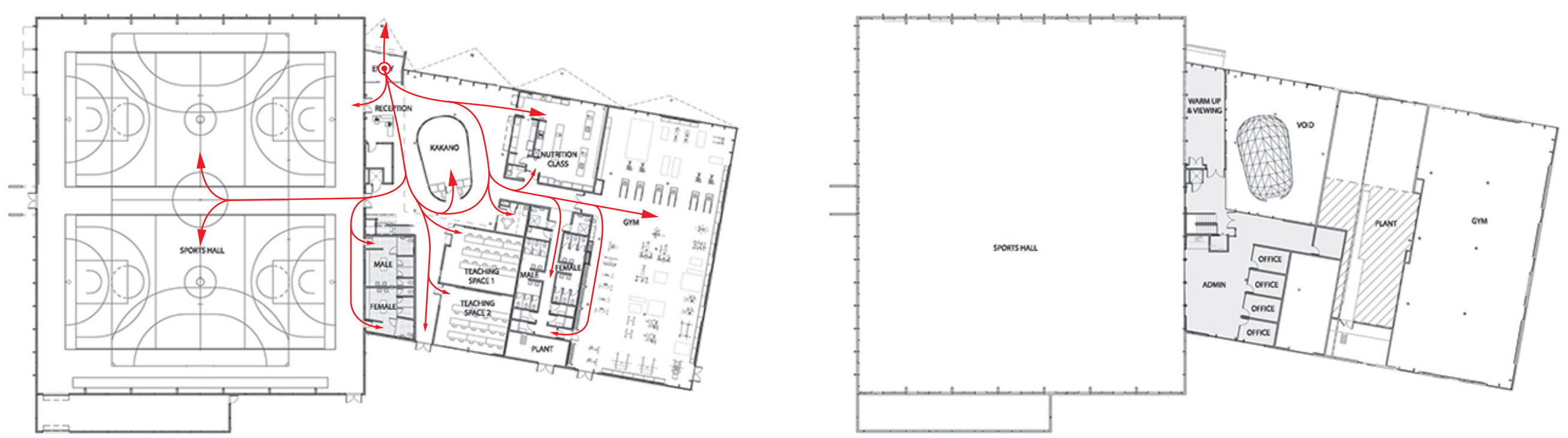

Above

Figure 15: Ground Floor Plan - Circulation branches from central atrium.

Image adapted from (Architects, 2013g)

\section{Top Right}

Figure 16: Mezzanine Plan - Viewing platform and

Admin area overlook Sports Hall and Atrium space.

(Architects, 2013h)

Right

Figure 17: Site Plan - Landscape elements act as a

threshold separating the building from the main road.

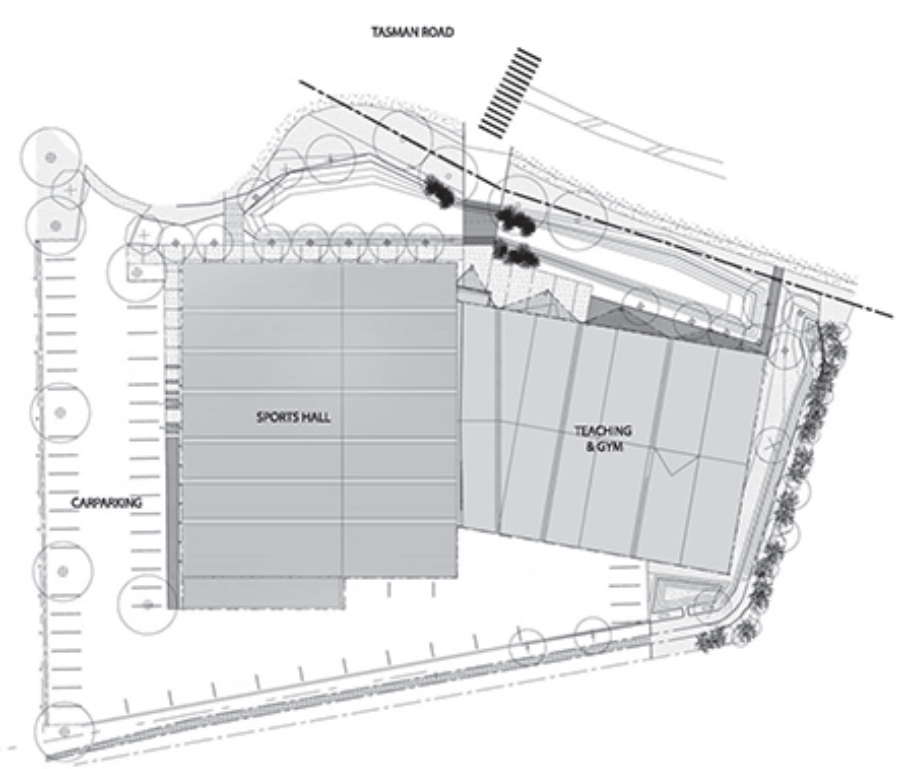

(Architects, 2013i) 
Nga Purapura - Physical Attributes And Qualities of Space
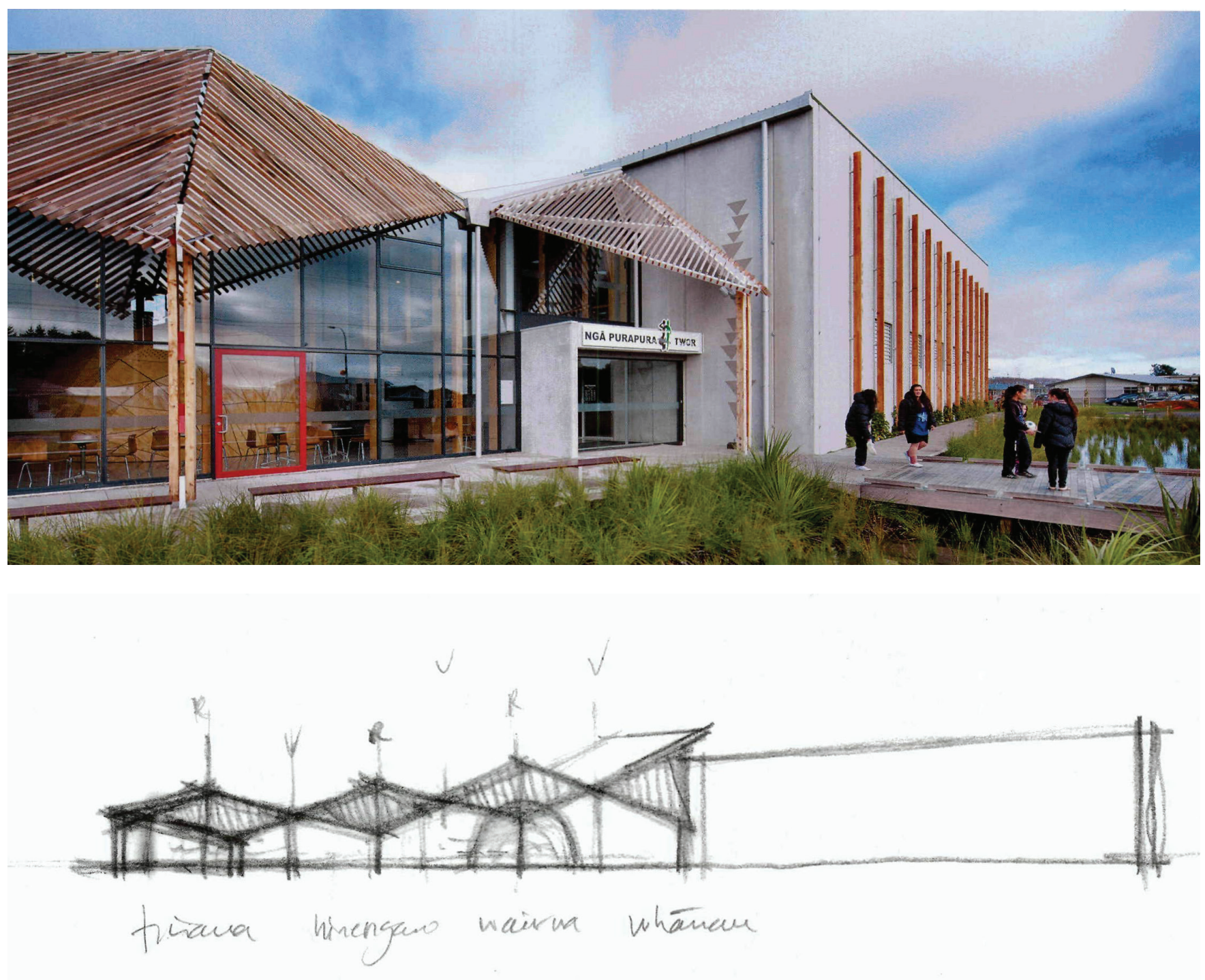

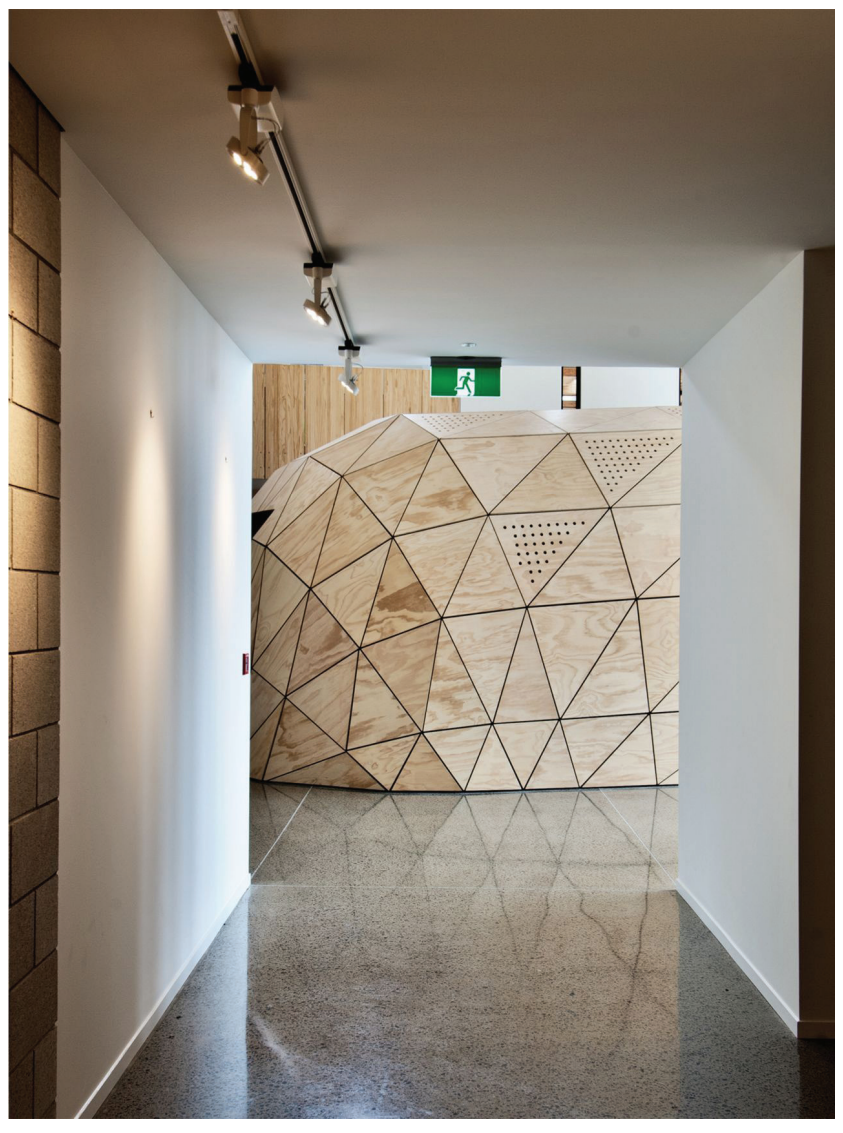

Top Left

Figure 18: Main Entrance - Bridge crossing wetland facilitates transition between street and building. (Brass, 2012a, p. 61)

Left

Figure 19: Conceptual Sketch - Building organised into functional areas in accordance with Te Whare Tapa Wha holistic model of Maori health. (Wood, 2012, p. 64)

Above

Figure 20: Spaces throughout the building link back visually to the central Atrium aiding in orientation. (McCredie, 2013f) 


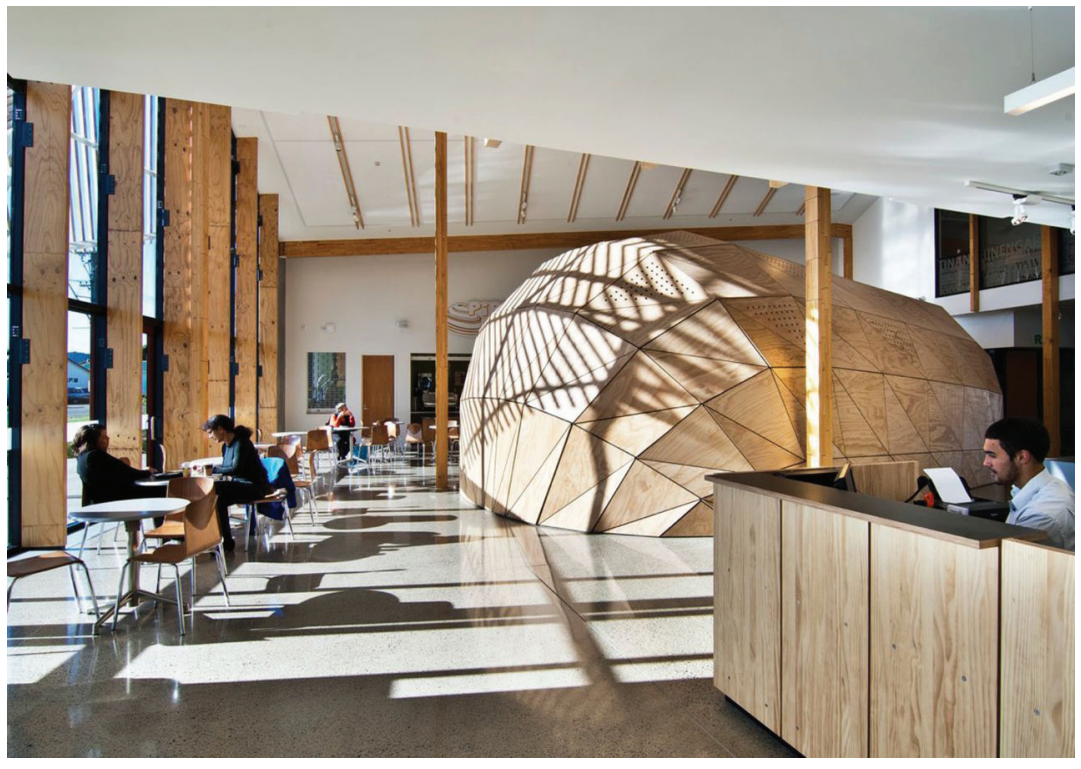

Figure 21: Tall atrium contains a pre fab 'Kakano' reflection space with a distinctive form which helps orient visitors to the building (McCredie, 2013e)

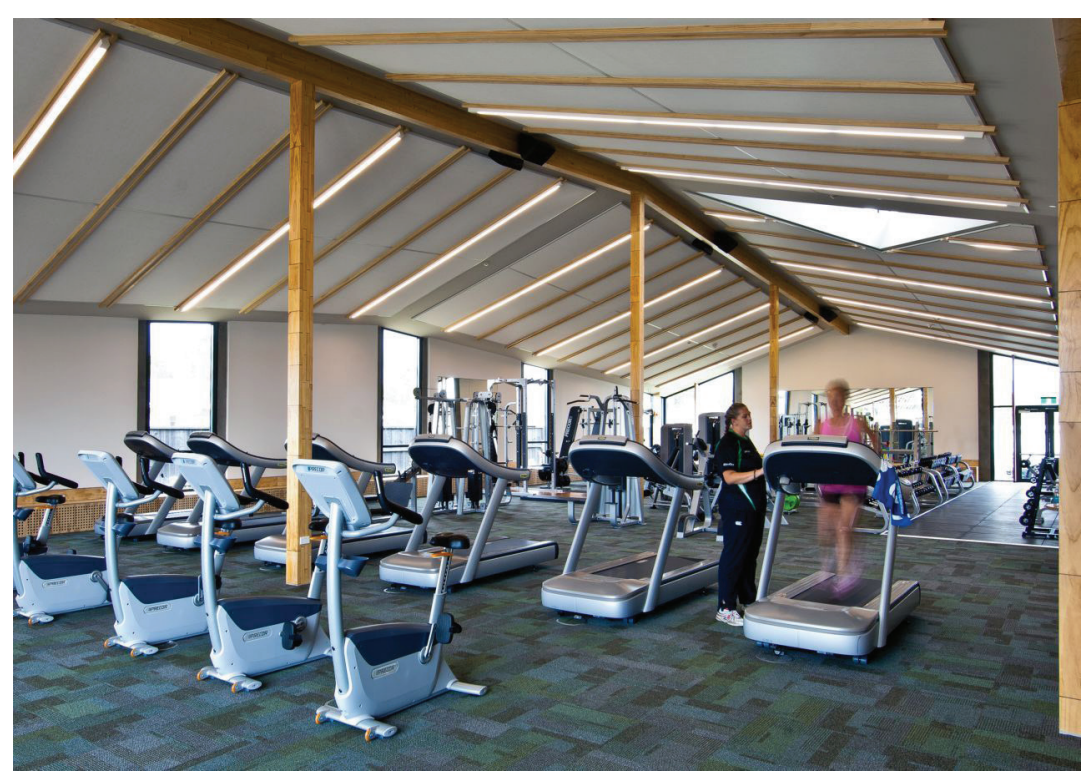

Figure 23: Gym provides open space for a range of training activities. (McCredie, 2013h)

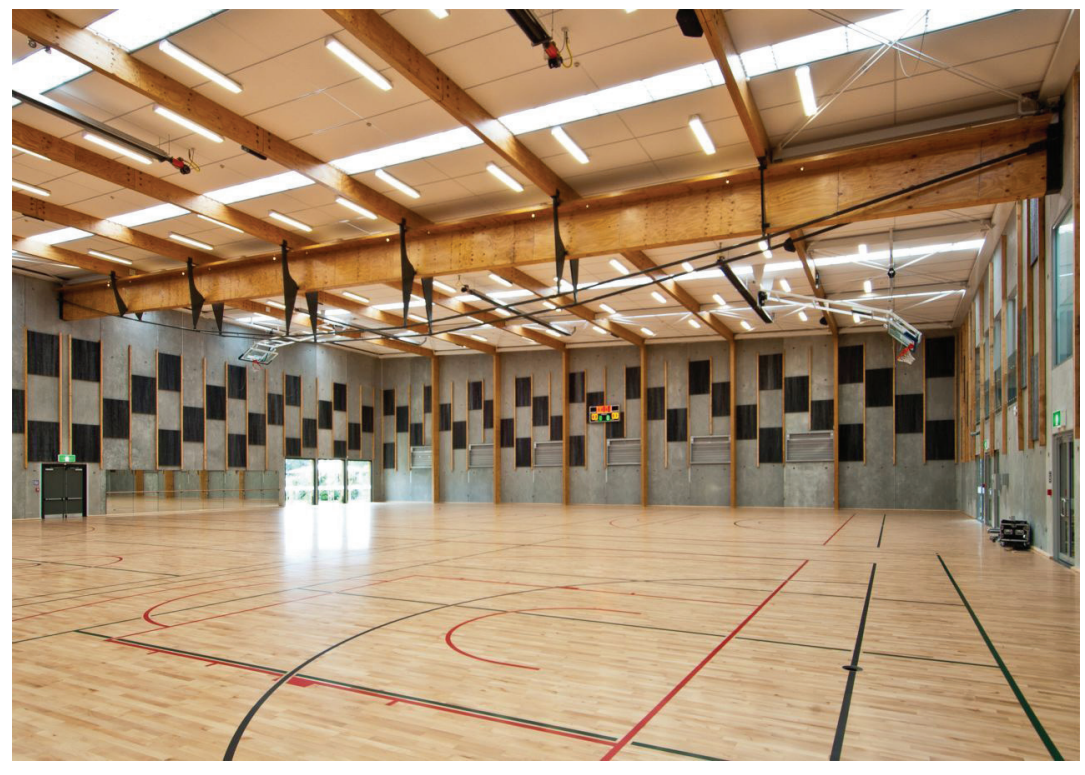

Figure 22: Colour coded markings in Sports Hall accommodate a range of sports. Suspended basketball hoops prevent obstruction at ground level. (McCredie, 2013g)

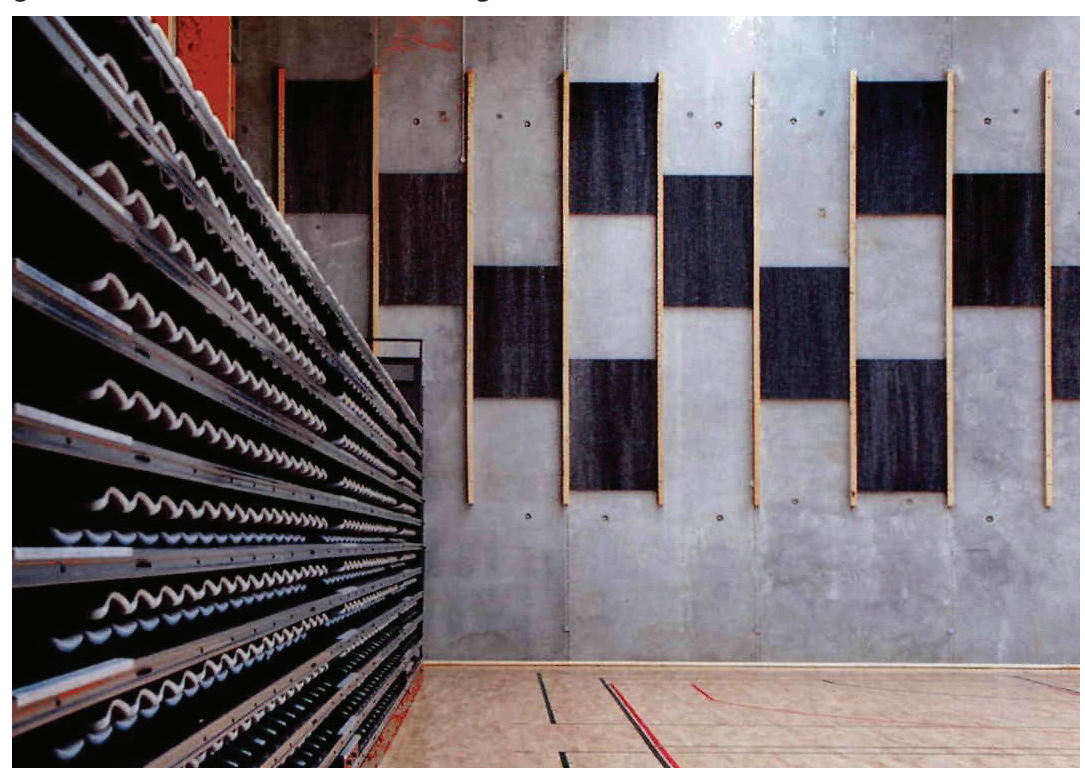

Figure 24: Retractable seating in Sports Hall enables flexible use of space. (Brass, 2012b, p. 62) 
ASB Indoor Sports Centre - Tennent + Brown Architects

ASB Sports Centre is as a case study which shows how additional programs can supplement a sports facility and how space can be designed to accommodate a range of different layouts for sports activities and scenarios. It also demonstrates how a sports field can be developed to increase its use throughout the day and value to the local community. (See figs $25-36)$

In addition to its primary role, as a sports hall, the building integrates a number of supplementary programmes into its design. These programmes include a cafe, meeting rooms, function rooms, changing rooms with ice baths for recovery, as well support services for athletes which include a training centre for high performance New Zealand, Wellington Sports Medicine Clinic and Pacific Radiology (Wellington City Council). These additional programmes allow the building to act as a hub, attracting a range of activities, not limited to those directly related to sports games.

Another aspect of the building which is of interest is its flexible use of space. The playing area of the building is organised into two large hall spaces with a central viewing platform between them. This has the duel benefit of dividing the space, allowing the two areas to operate independently from each other, and concentrating the space for spectators and amenities into a central location which afford views to all the activities going on. A range of layouts for different sports activities and scenarios is accommodated within these two areas (figs 28-31). Colour coding is used to allow a range of sports courts to be marked out at the same time, allowing the space to flexibly accommodate a range of sports (figs $34 \& 36$ ). This flexible layout is further supported by; basketball hoops suspended from the roof structure which can be raised and lowered when needed allowing the hall below to remain unobstructed, retractable seating which can be arranged to suit a range of games and events, and nets which can be raised between courts to prevent sports from interrupting each other.

This project is also of interest because the site it was built on, Cobham Park, previously contained space for two rugby fields (fig 32). The building occupies the space of these field, but where sports fields are typically unoccupied for much of the week ASB is used throughout the day, it is open from 7am to

$10 \mathrm{pm}$, by a range of users school groups, athletes, casual sports matches, holiday programs etc (Wellington City Council). This development serves as an example of how additional programs can be introduced to the space of a sports field to increase its use and appeal to the public. In this circumstance the field itself has been replaced with an indoor sports environment however a sports field could be similarly supplemented with additional programme while retaining the field itself. One issue with this is that intense use of sports fields can damage them making them unsuitable for play, artificial turfs are suited to this kind of use and provide a surface which can be used in any weather.

While overall the design appears to be successful at accommodating a range of sports and sports related activities the planning of some of the spaces is awkward, the main entrance does not have a very good flow to the sports hall spaces and supplementary program occupies leftover space at the ends of the sports halls, resulting in some oddly shaped rooms.
This case study was useful for showing how a range of programmes can supplement a sports facility and how these spaces can be arranged to accommodate a wide range of uses.

\section{Conclusion}

The three case studies looked at in this chapter were used to understand; in the first case study, Seattle Public Library, how diagrams can be used in the design research process to interpret data and explore/ solve problems spatially; and in the second and third case studies the functional requirements, organisation and programme of local sports buildings. Nga Purapura and ASB each show different ways that a sports facility can be designed to incorporate a range of programme and activities, encouraging use throughout the day by a diverse range of people. This is something which is notably missing from many community sports facilities. Information about the types, organisation and qualities of space required in these sports facility as well as an understanding of the limitations of these projects aided in the development of a design brief which responds to the local Wainuiomata community. 


\section{ASB Indoor Sports Centre}
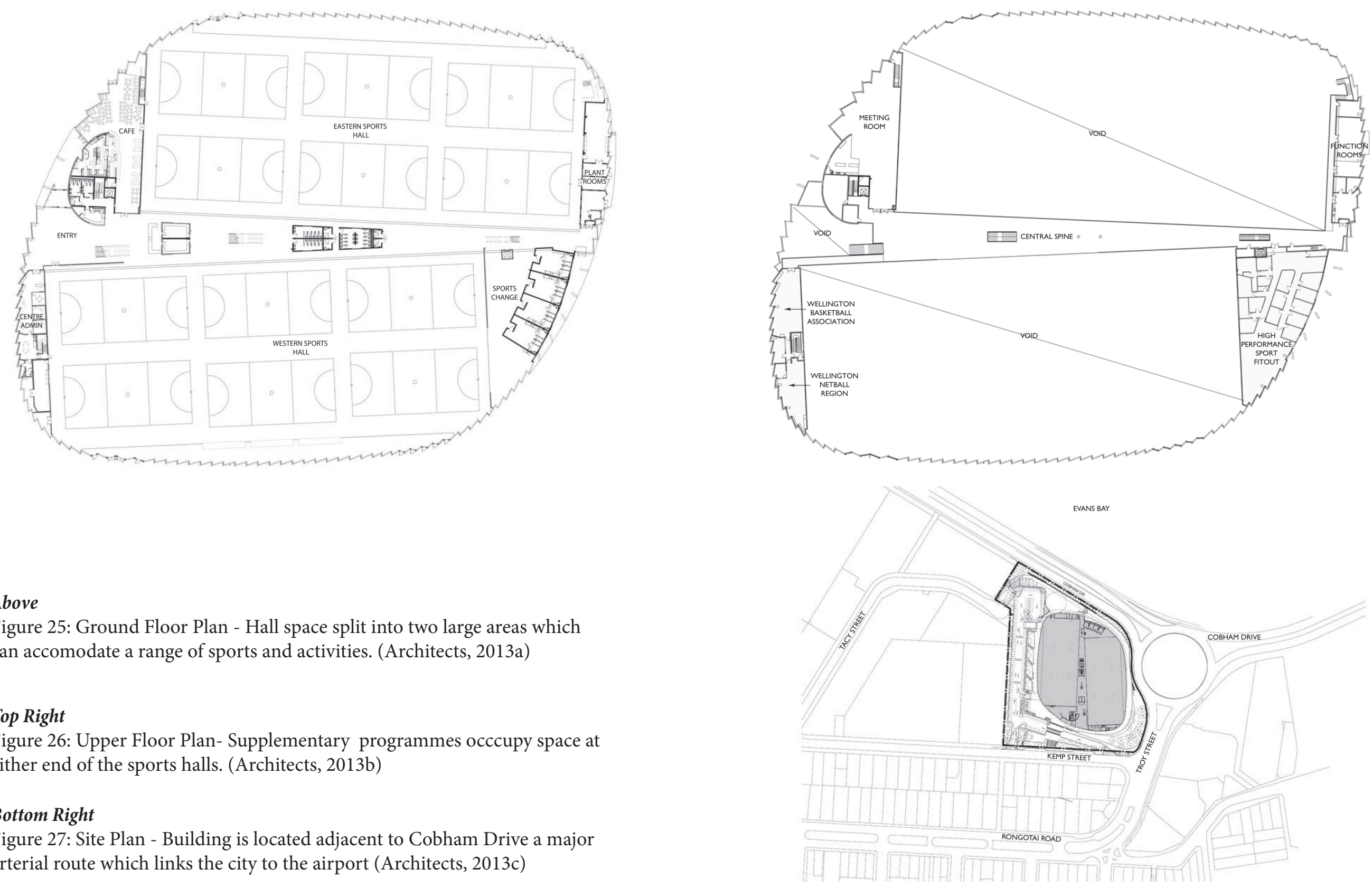

Above

Figure 25: Ground Floor Plan - Hall space split into two large areas which can accomodate a range of sports and activities. (Architects, 2013a)

\section{Top Right}

Figure 26: Upper Floor Plan- Supplementary programmes occcupy space at either end of the sports halls. (Architects, 2013b)

\section{Bottom Right}

Figure 27: Site Plan - Building is located adjacent to Cobham Drive a major arterial route which links the city to the airport (Architects, 2013c) 
The ASB Sports Centre Can Accommodate a Wide Variety of Sporting Activities and Events

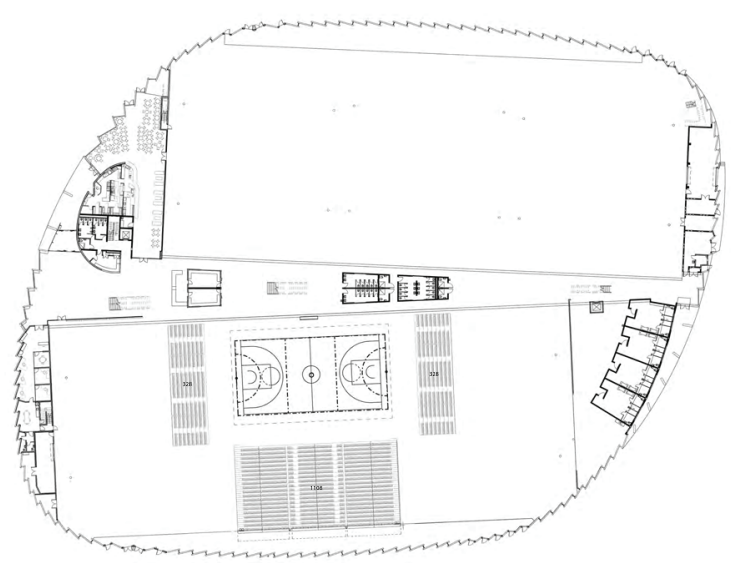

Figure 28: Exhibition Court Layout - Retractable seating can be arranged to provide viewing areas for games and events (Architects, 2013j)

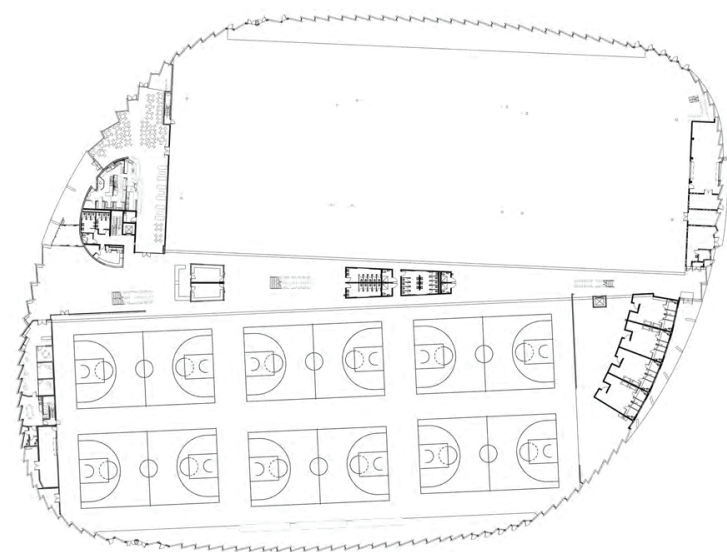

Figure 30: Basketball Court Layout (Architects, 2013d)

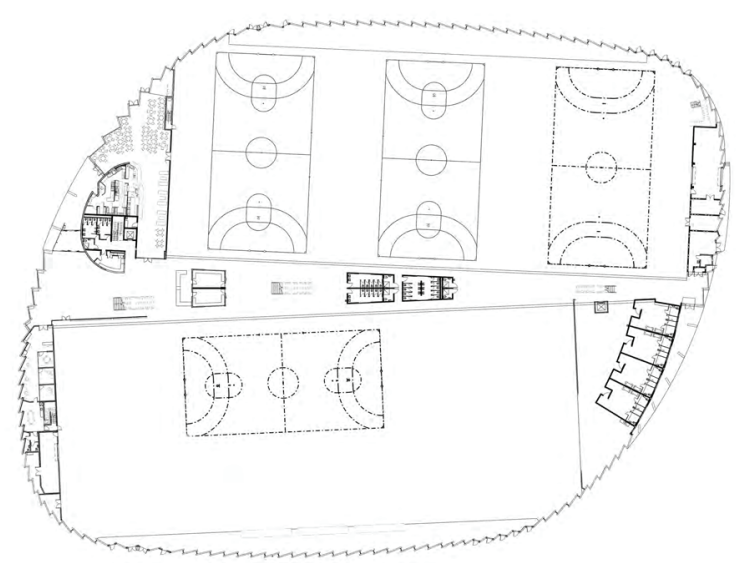

Figure 29: Futsal, Handball and Korfball Court Layout (Architects, 2013e)

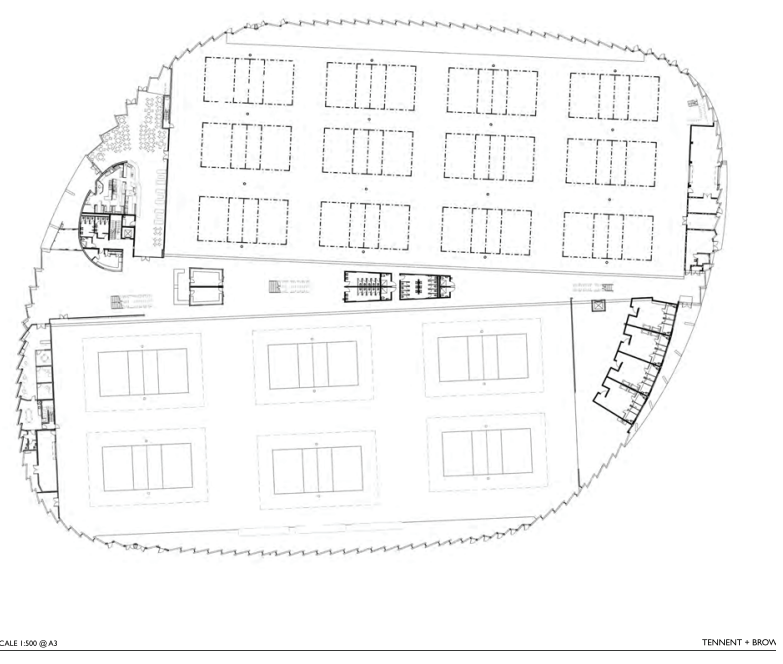

Figure 31: Volley Ball Court Layout (Architects, 2013f)
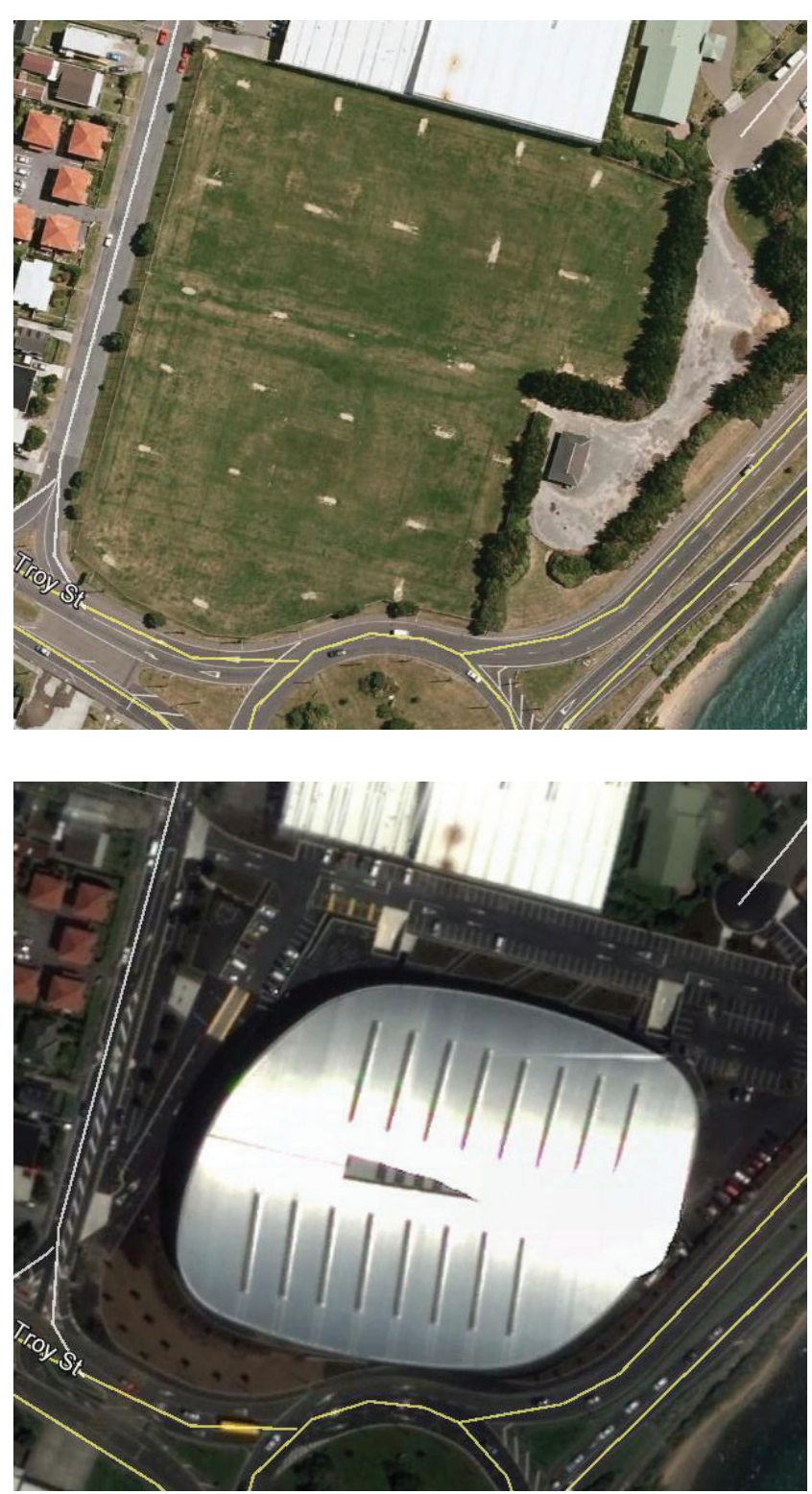

Figure 32: Development of the sportsfield intensifies its use by the public. (Google Earth. 2009, 2012) 


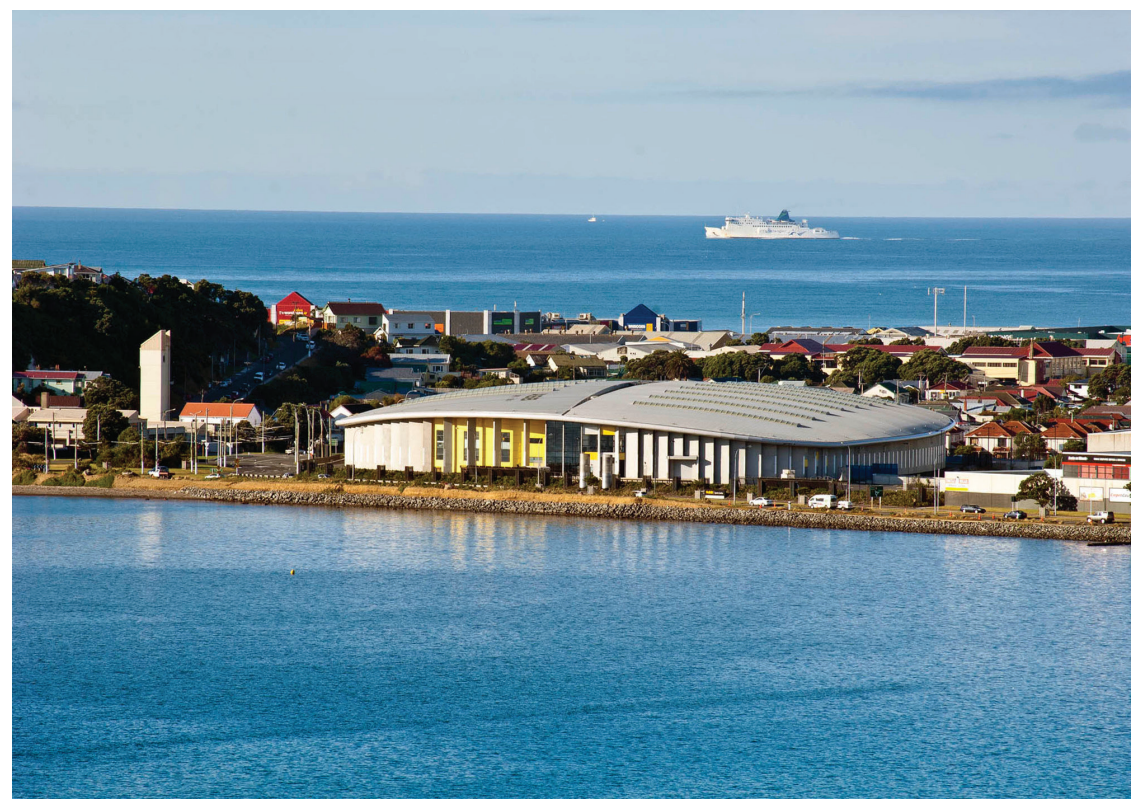

Figure 33: ASB occupies a prominent position at the end of Evans Bay and is visible from accross the harbour (McCredie, 2013b)

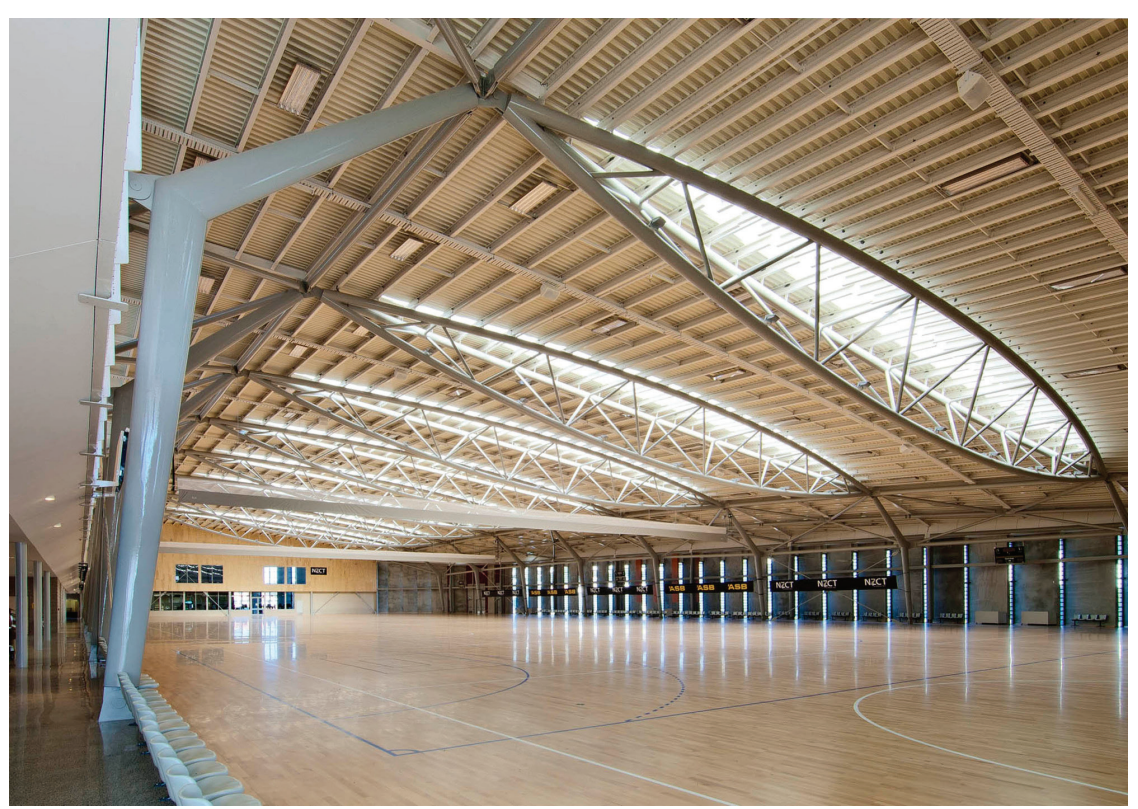

Figure 34: Eastern Sports Hall - The use of allows for large unobstructed playing areas. (McCredie, 2013d)

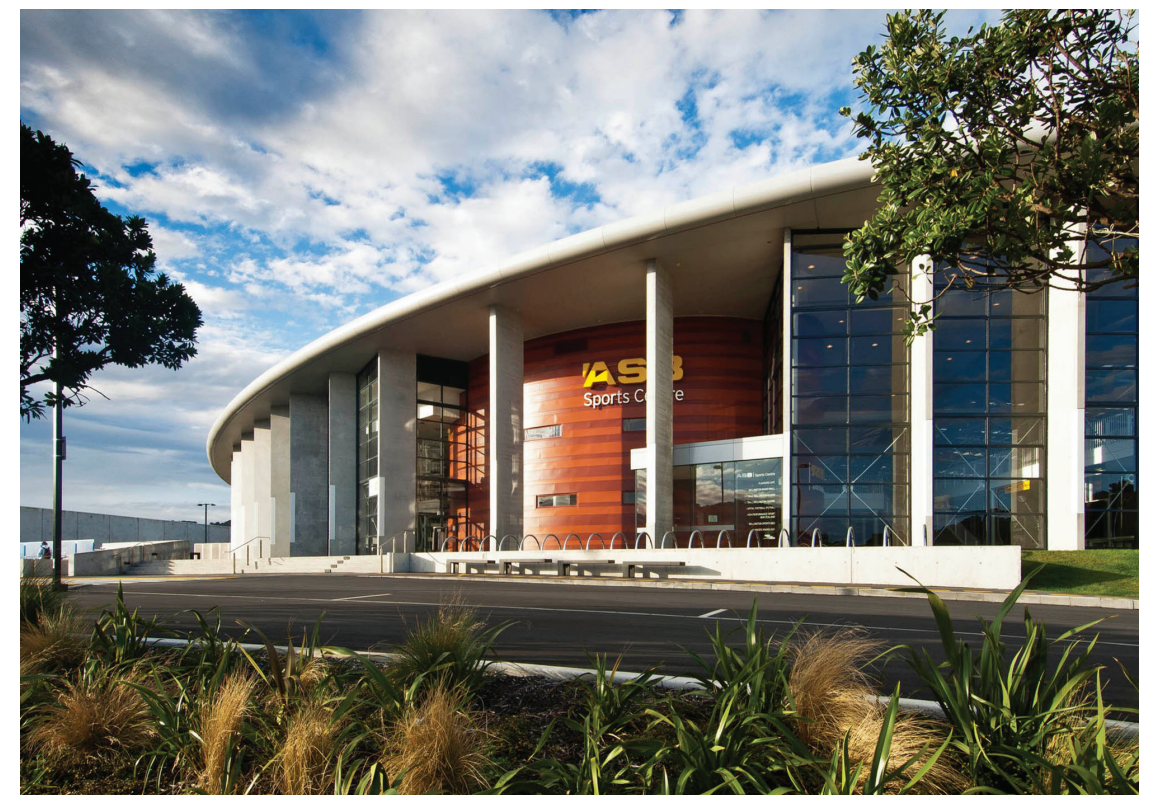

Figure 35: Main Entrance - The concrete panels of the facade open out to reveal the entrances to the sports halls and cafe. (McCredie, 2013a)

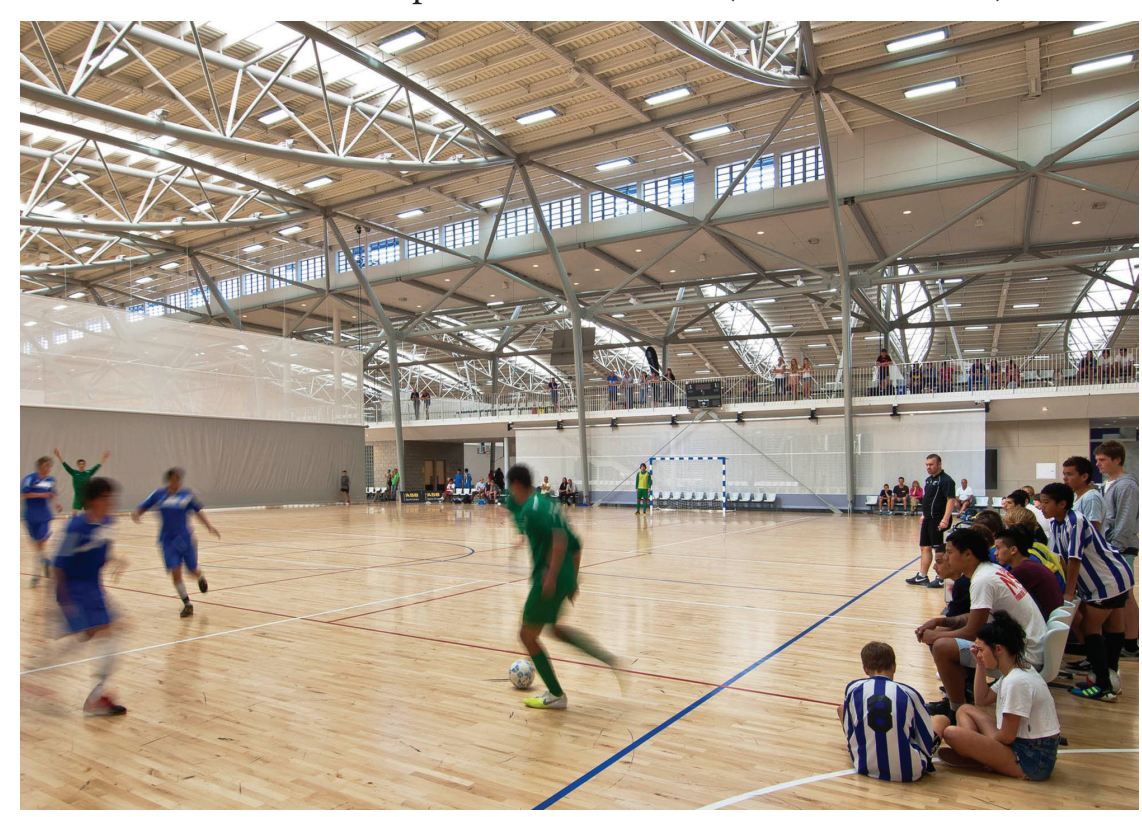

Figure 36: Sports Hall - Nets and colour coded markings allow the space to accommodates a range of sporting activities. (McCredie, 2013c) 



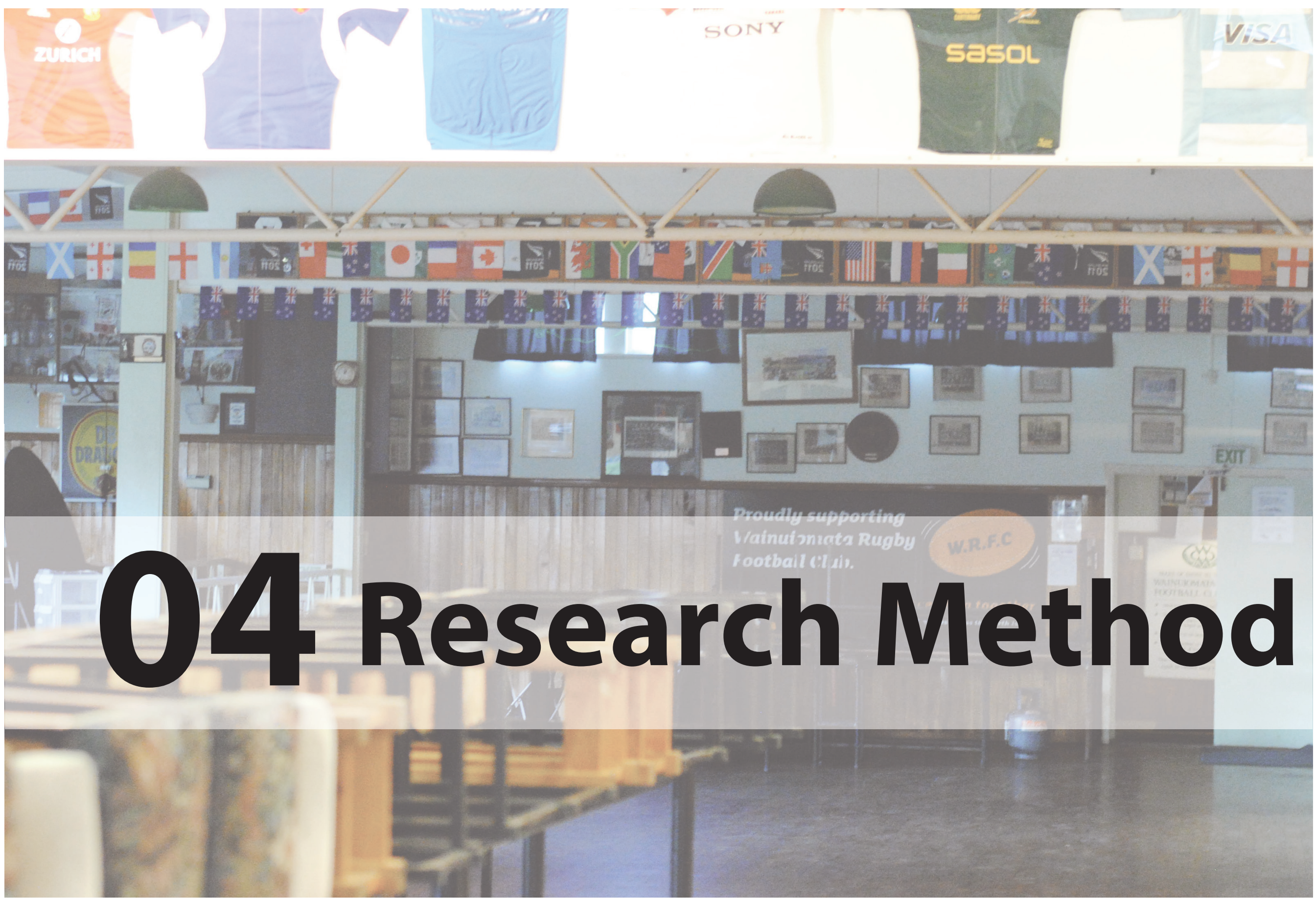


My research approach was conducted in two parallel phases, the first consisted of contextual research used to aid the design process, what Peter Downton refers to as 'Research for design'(Downton, 2003, pp. 16-33), the second part consisted of a series of design tests which explored how data collected could be translated into an architectural medium to aid in the design process - 'Research through design' (Downton, 2003, pp. 91-109).

My approach to research for design was a mixed method approach, employing both qualitative and quantitative methods for the collection of data (Creswell, 2003, pp. 18-20). The mixed method approach was adapted from the 'Concurrent Transformative Strategy' outlined by John W. Creswell in his book Research Design (Creswell, 2003, p. 219). In this approach qualitative and quantitative research are carried out concurrently, the different types of data are given either equal or unequal priority dependant on the researcher's theoretical perspective, which is based on the research question (Creswell, 2003, p. 219). This approach was chosen to allow a diverse range of data to inform the design process and brief.

The nature of this study and the limited sources of qualitative and quantitative data available on the local community restricted direct comparisons between individual data sources. Because of this data was combined at the interpretation phase of the research, as opposed to the collection or analysis phases, where the diverse nature of the sources would have complicated the process.

Data collected was analysed to determine how it might be used to inform the research through design process, aspects of the data which were deemed relevant or useful were interpreted as diagrams and used to inform a series of design tests, these were developed in parallel to data collection. Data collected and the design test were analysed and interpreted to form a design brief for a community sports building in Wainuiomata, which would form the basis of more complex design explorations which reconsider Architecture's relationship with the Sports Field in accordance with the original research question.

\section{Data Collection (Research for Design)}

This section discusses the process of collecting data on the local community of Wainuiomata and the methods used for this. Data was collected in two stages which were conducted in parallel with design tests which explored how it could inform design. These stages were: 1 . Analysis of Wainuiomata, 2. Detailed Analysis of the Wainuiomata Rugby Club. ${ }^{8}$

\section{Analysis of Wainuiomata}

The aim of the first stage of research was to gather a wide range of information about the local sports clubs and their relationship with the Wainuiomata community. This was used to build a knowledge base that more detailed investigations could build upon and to inform initial design iterations. In this initial stage data was collected from a broad range of quantitative and qualitative sources.

8 Data collected for this thesis is intended as an aid in the development of a design brief and for grounding design tests in a the local context. The primary inquiry is a spatial one which is made through the process of design itself. The application of data collected is therefore the focus rather than the perceived accuracy of the studies undertaken to obtain the data.
Quantitative data sources included: Statistics NZ National Census data from 1986-2006 (Statistics New Zealand, 2009, 2013), http://www.societies.govt. $\mathrm{nz} /$ for Financial Statements of local sports clubs (Appendix 2), Department of Internal Affairs website for 'Gaming' machine numbers and locations (Department of Internal Affairs, 2012).Qualitative data sources included: Personal observations and photographs of existing sports club buildings and grounds, Web pages for local sports clubs (Wainuiomata AFC, 2012; Wainuiomata Rugby Football Club, 2013b; Wainuomata Lions Rugby League Club, 2012), Literature concerning the history of Wainuiomata and its sports clubs (Alexander, 2000; Associates; Keneally, 1982; Miskell, 2012; O'Hara, 2002; Pickering, 1984; Wainuiomata Rugby Football Club, 1996), Hutt City Council documents and Plans(Hutt City Council, 2012, 2013a), Historic aerial photographs (Digital NZ, 2014).

Detailed Analysis of the Wainuiomata Rugby Club

Following the initial data collection phase it was determined that while the breadth of data collected was useful for understanding the general context and history of sport in Wainuiomata a closer study would be needed to build an understanding of the sporting environment at a more intimate scale. The Wainuiomata Rugby Club was chosen for analysis due to its role as the largest and one of the oldest sports clubs in Wainuiomata. In a similar fashion to the first stage data was collected from a range of Quantitative and Qualitative sources. Quantitative data was obtained from: Plans held by the Rugby Club (Wainuiomata Rugby Football Club, 2013a), and the clubs 50 year anniversary publication(Wainuiomata Rugby Football 
Club, 1996). Qualitative data was obtained through: Personal Observations, Informal Discussions, and Photo Analysis.

\section{Research through design}

This section discusses the process of developing a design based on data collected on the local community of Wainuiomata. This was conducted in stages which were, in part, conducted in parallel with data collection. These stages, outlined below, were: 1 . Data Interpretation, 2. Development of Brief, 3. Design of Community Sports Facility.

\section{Data Interpretation (Design Trials)}

A series of design trials were conducted in parallel with the collection of data to explore how the information collected could inform the design of architecture. These tests primarily took the form of a series of charrette models which responded to observed relationships between architecture, sport and the community and explored how these conditions could be altered to improve the relationship between built form, sporting activity and the community. These tests explore; how the facade of the rugby clubrooms could be made more permeable, improving access and visual connections. How the programme of a sports club could be rearranged to better relate to the field. How views of the field could be used to influence the arrangement and design of spaces. How the relationship between the sports field and architecture can be improved. Although these tests responded to a specific context, an understanding of how a design can begin to respond to these relationships was developed. Through this process an idealised model, which acted as a diagram, describing how a closer relationship between building and field could be established was developed, this was used to inform further design developments.

\section{Development of Brief (Refining \& Analysing} Data)

Data gathered throughout the earlier studies was analysed to determine how an architectural design might best respond to the future needs of the local community. This analysis revealed opportunities for a design to respond to gaps in the local community including a lack of all weather facilities for training and playing a lack of education opportunities within Wainuiomata. This analysis was also used to determine a suitable site for a new sports facility. It was determined that there was an opportunity to integrate the programme of a tertiary education campus with that of the sports club, enabling the design of a facility which would throughout the day for a range of training, education, and fitness related activities. A programme for this was developed through an analysis of a number of case studies and through reference to the book 'Neufert Architect's Data'(Neufert \& Neufert, 2000). Data gathered through the detailed analysis of the rugby club and design tests was used to determine specifics about the relationships and qualities of spaces required. This information was all refined into a brief which formed the basis for more detailed site specific design tests and ultimately a final design.
Design of Community Sports Facility (Application of Findings)

The first stage began with an analysis of the site which recorded both the existing conditions of site as well as the sites potential to connect with a wider community context through photographs and diagrams. It was observed that despite its central location there were poor connections through and within Wise Park. Activity on the site was also concentrated towards the periphery, leaving large areas relatively unused.

A series of design developments were then conducted through an iterative process consisting of a series of negotiations between; orientations of the site; ideal connections through the site; program of sports facility and its relationship to the field; relationship between landscape, artificial landscape and building; visual connections to the surrounding landscape and community. These designs were evaluated at various stages, coinciding with design reviews where feedback was given by design professionals. At these stages the process of design development at that point in time was reflected upon and the design reevaluated to better respond to; criticisms; the focus of the research; local context and issues identified in earlier stages of research. Following a review in October a final design was determined and developed in more detail. 



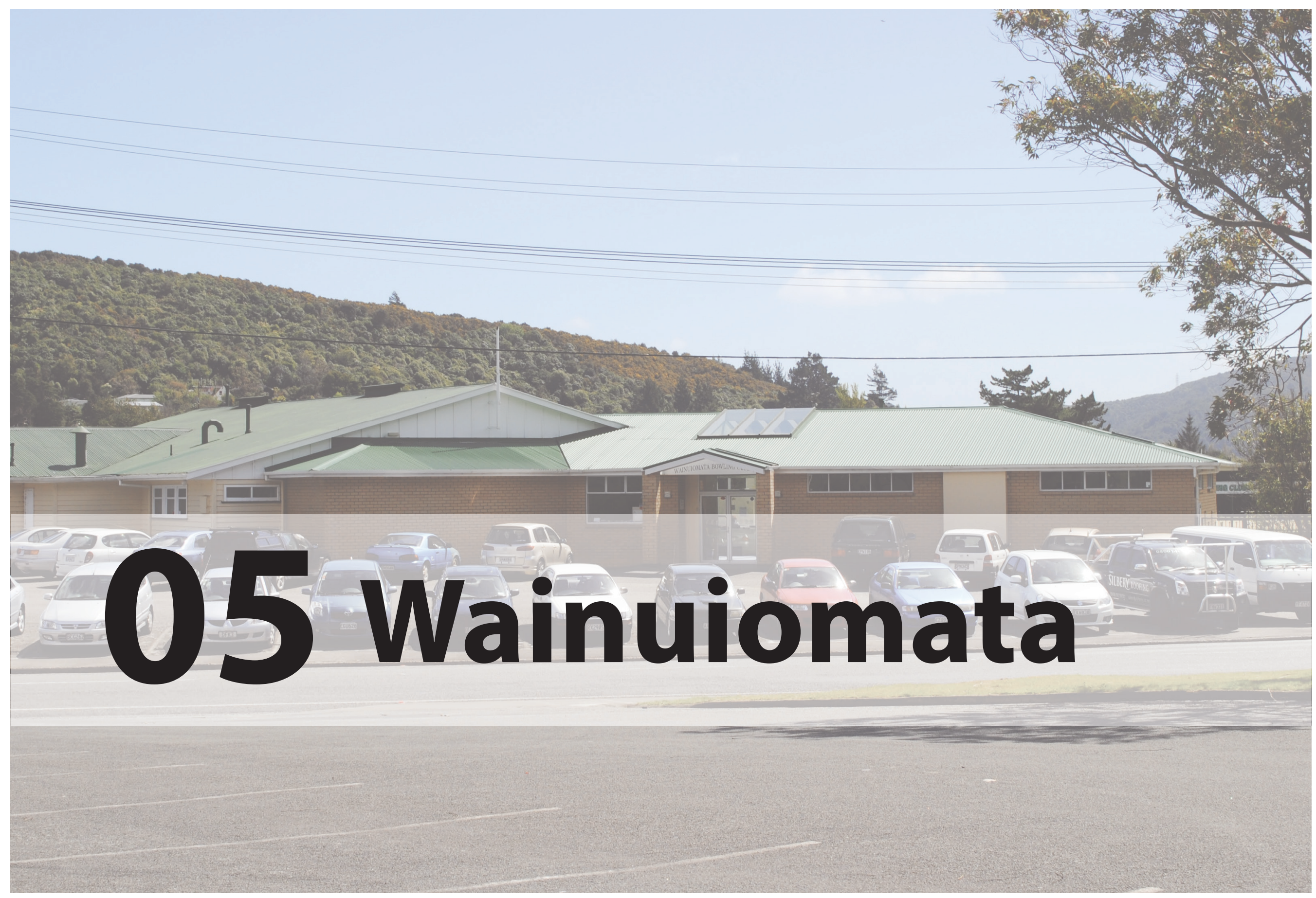


This chapter discusses quantitative and qualitative information collected on the sporting community of Wainuiomata and demonstrates how this information informed the development of a design brief and selection of a site for the design of a community sports building. It begins with a description of Wainuiomata and some of its history then goes into detail on data collected on the local community.

\section{Wainuiomata}

The name Wainui-O-Mata translates to Water Big of Mata which is thought to either be in reference to a women's name or an abbreviation of the word Roimata which means tears - Big Water of Tears. (Alexander, 2000, p. 297)

Wainuiomata occupies a valley to the east of Wellington harbour over 'the hill' from Seaview/ Gracefield in Lower Hutt (fig 37). The Wainuiomata Valley was originally settled around 1844, after the area was surveyed by the New Zealand Company (Keneally, 1982, p. 5). Initial settlement was based around the Homedale Village area to the south, with local industry based around sawmilling and farming (Keneally, 1982). In 1927 Wainui-O-Mata Development Limited was formed to buy and develop land options in Wainuiomata (Alexander, 2000, p. 91). The company ran into financial difficulty due to the recession limiting bond payments and large investments put into building a tunnel to the Hutt Valley which was never fully realised (Alexander, 2000, p. 266). Development stalled until the 1940's when bond holders took control of the company (Alexander, 2000, pp. 266-267). Wainiuiomata began to expand rapidly following the purchase of 1000 properties by the government in the late 1950's (269-70). Since the

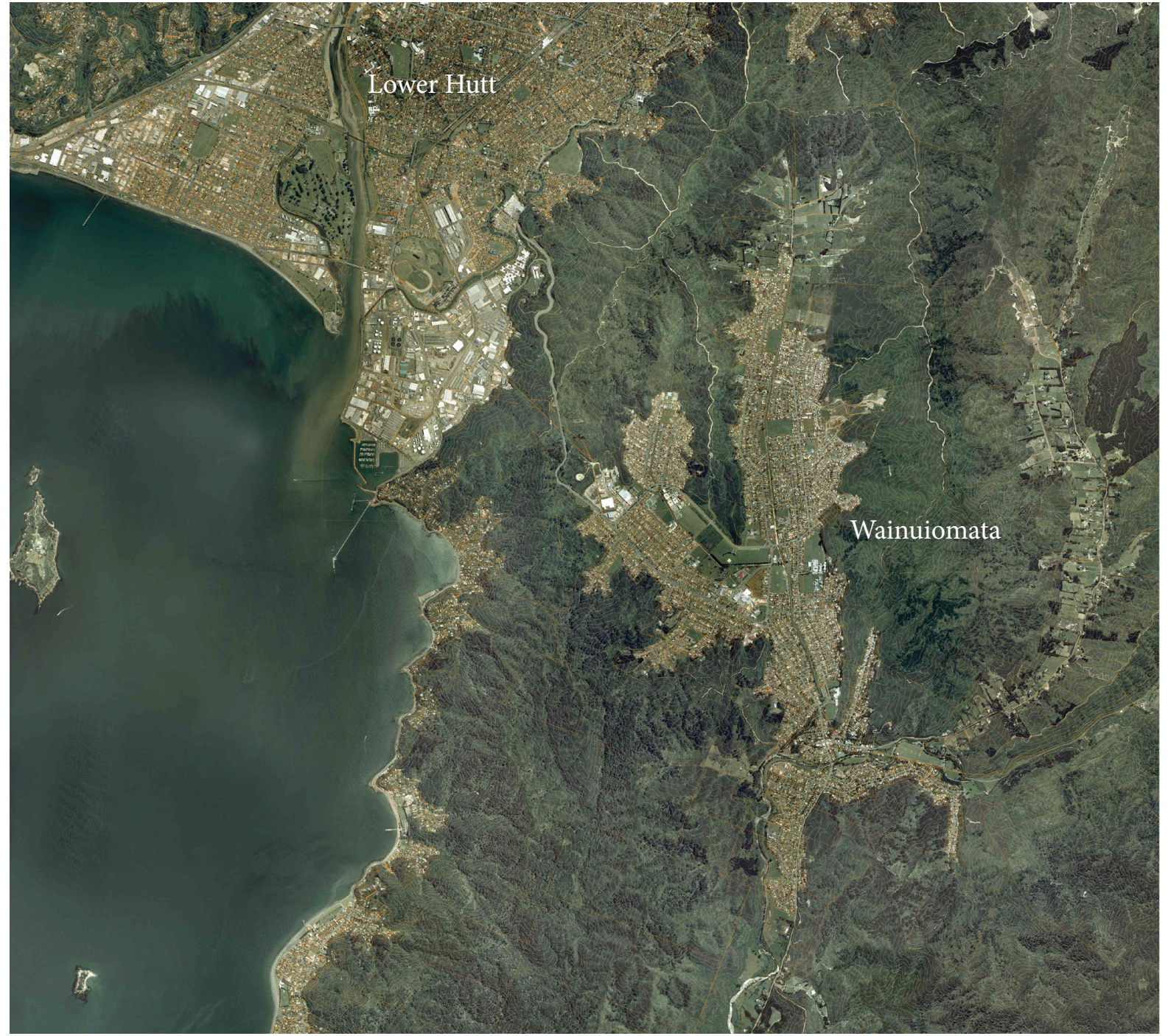

Figure 37: Location of Wainuiomata - The Wainuiomata Valley is defined by a network of hills which separate it from the rest of the Hutt City (LINZ, 2011) 


\section{Wainuiomata's Shifting Centre}

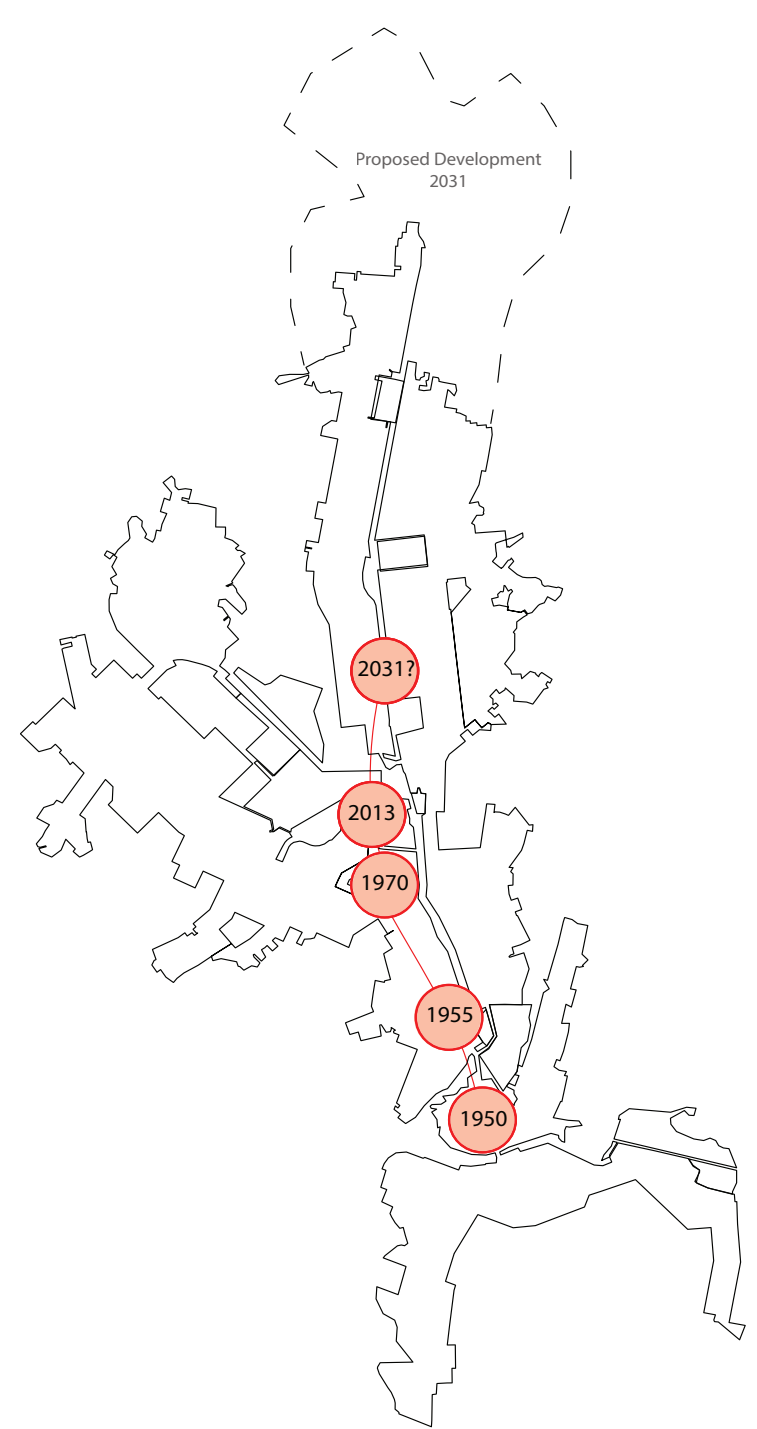

Figure 38: The centre of Wainuiomata has shifted North over time 1950's Wainuiomata's pattern of growth has seen the centre of town shift progressively north of the original settlement in Homedale Village (fig 38).

\section{Landscape, Isolation and Community}

The local landscape has had a strong impact on the development of Wainuiomata, the local community, and the perception of Wainuiomata from the outside. Wainuiomata has a mixed relationship with the landscape. The hills surrounding Wainuiomata have historically made access difficult. This has had an isolating effect on the local community, despite its close proximity to the neighbouring Hutt Valley. Settlers originally accessed Wainuiomata via a bush track from Lowry Bay. (Alexander, 2000, p. 12). Later a narrow road was built over the hill. This has since been widened to accommodate four lanes of vehicles. The hill still has an impact on access, which is largely dependent on motor vehicles. Historically, isolation from the Hutt Valley led to the development of a strong sense of independence, cooperation and local identity within Wainuiomata due to limited contact and support from the outside. This has contributed to the development of a strong sense of community.

Wainuiomata's pattern of development has been greatly shaped by the surrounding hills and its waterways, artificial and natural, resulting in a distinctive morphology. Much of the land to the north was initially wetland prior to being drained by early settlers through a series of drainage ditches which allowed these areas to be developed. Landscape has had a major effect on the development of the local built environment (fig 39).

\section{Built Environment}

The built environment of Wainuiomata predominantly consists of single storey suburban houses.

The majority of these houses are built on the valley floor however some occupy the surrounding hillside. The centre of Wainuiomata is defined by a central shopping area which consists of a mall as well as shops along Queen St and The Strand. A number of sports grounds and facilities add contrast to the built environment and are a focus for community activity in Wainuiomata.

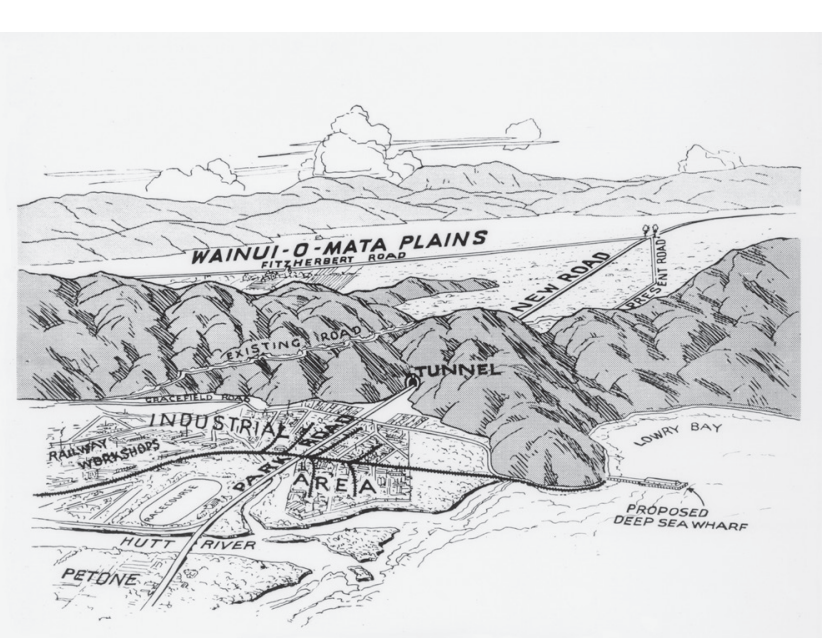

Figure 39: Plan of proposed new tunnel and development for Wainuiomata area (Alexander, 2000, p. 91) 


\section{Sports in Wainuomata}

Sport has played an important role in Wainuiomata providing a platform for recreational activity and social interaction. Historically Wainuiomata's isolation has meant that contact with surrounding areas was limited, particularly for young people with no means of transportation. Participation in organised sports provided a means for people to travel to other places in the Wellington region and expand their horizons by having contact with people from other areas. Sports clubs also helped to develop a sense of local identity through competition between clubs from different areas and through socialising with other members of the community on an equal setting.

As Wainuiomata's population has grown so has the number of sports clubs along with associated grounds and facilities. New grounds were established for sports clubs, as required, from farmland on the fringes of developed areas. As the town expanded these fringes were pushed back from the original centre resulting in sports grounds being scattered throughout Wainuiomata, see pages 50- 1 and 53-5. The nature of this expansion has meant that clubs such as the Rugby and Football clubs which were initially quite central now in more isolated positions as the centre of town has moved further north.

The relationship between sport and community in Wainuiomata was investigated further to see how it could inform the design process. The next section outlines the process of collecting data on these relationships and their analysis.

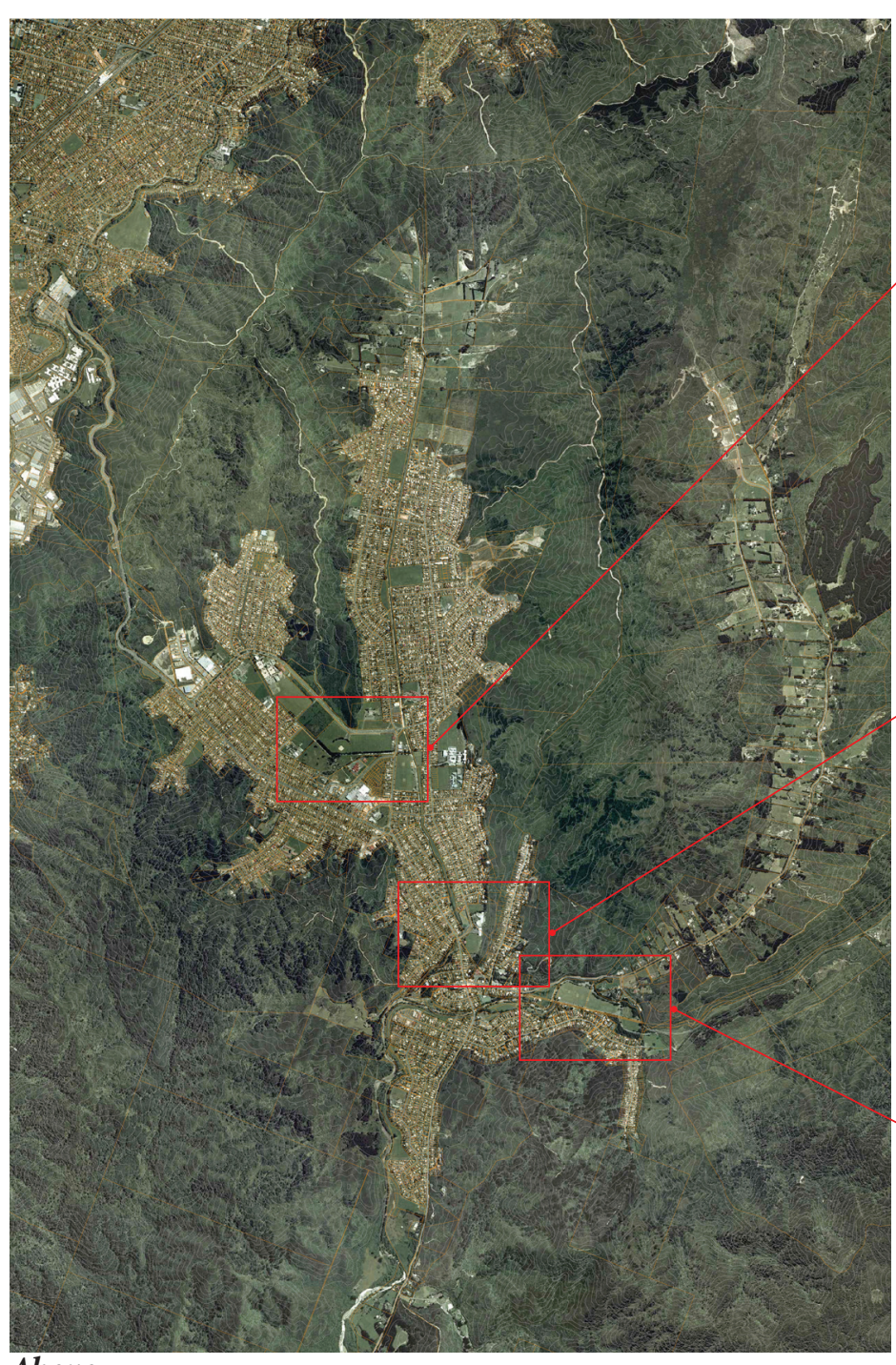

Above

Figure 40: Map of Wainuiomata - Sports Clubs are clustered around three main areas; Wise Park and Brian Heath Park, William Jones Park, and Brian Heath Park. Images obtained from(LINZ, 2011)(Hutt City Council, 2013b)

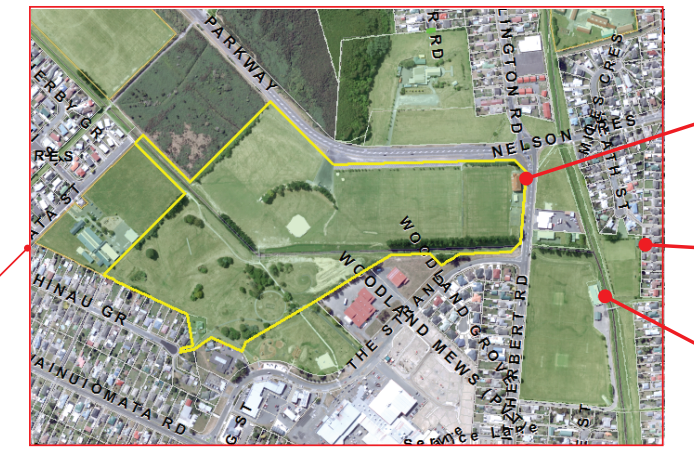

Frederick Wise Park

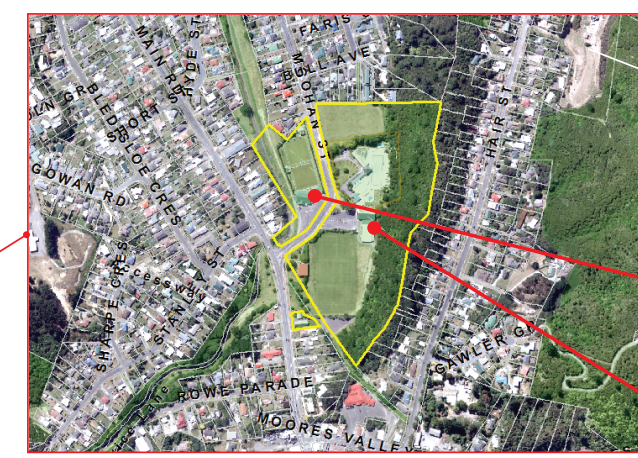

William Jones Park

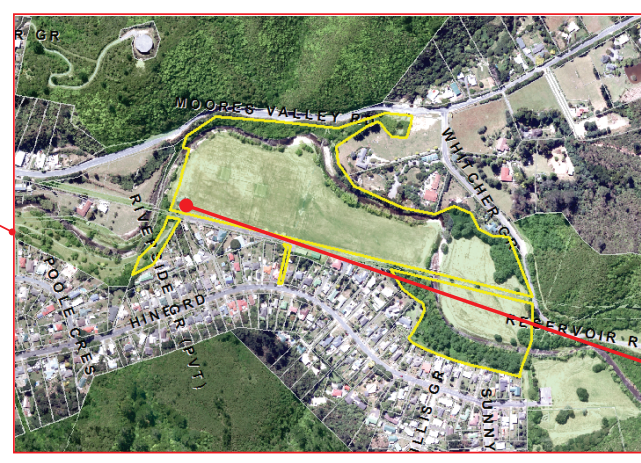

Richard Prouse Park

\section{Opposite}

Figure 41: Photo Survey of Sports Clubs Facilities and Grounds in Wainuiomata. 


\section{Data Collection Process and Analysis}

The process of data collection began with site visits to the local sports clubs (figs 42-47). The focus of these visits was to observe existing facilities and grounds and document them through photographs. The locations of these clubs were recorded and their relationships with associated sports ground were mapped in a diagram (fig $48 \& 49$ ). Photographs taken inside these spaces revealed display areas for trophies, and historic memorabilia, social spaces where people could gather and storage spaces, and indoor training spaces.Sponsorship signs and displays were very prominent inside the rugby club. The extent of these economic links was explored through a process of mapping sponsors ${ }^{9}($ fig 50$)$. This process revealed connections to businesses, gaming trusts, and local politicians; Ray Wallace, the mayor of Lower Hutt; and Trevor Mallard, MP for Hutt South. This line of inquiry was expanded further by mapping the sites and quantities of pokie machines in the local community ${ }^{10}$ (fig 51).

Financial records for local sports clubs were compared ${ }^{11}$ (Figs 52-57). Bar trading was found to have a significant impact on the design of spaces and is a major source of income for many clubs. Societies. govt.nz was also used to obtain dates that sports

9 List of sponsors were obtained from the websites of the three largest sports clubs, Wainuiomata Rugby Football Club (Wainuiomata Rugby Football Club, 2013b), Wainuiomata AFC (Wainuiomata AFC, 2012), and Wainuiomata Rugby League Club (Wainuomata Lions Rugby League Club, 2012).

10 Most of the grant money given to sports clubs is obtained through charitable gaming trusts

11 These were obtained via the societies.govt.nz website clubs were registered, and deregistered. This was used to create a diagram showing how the number of sports clubs has expanded over time.

Historic aerial photography was analysed and used to map growth of Wainuiomata and its sports grounds over time (fig 58). This revealed a pattern in which the town has expanded in a predominantly northerly direction. As the town has expanded sports grounds which were initially quite central have become more isolated from the centre of population.

A review of local literature on the history of Wainuiomata and its sport clubs aided in understanding the local context and conditions which led to the development of Wainuiomata's existing sporting environment ${ }^{12}{ }^{13}$. This history was recorded in a series of diagrams which mapped these changes over time (Figs 59 \& 60)

12 The existing facilities in Wainuiomata were largely community driven projects, often built by locals. Because of this the older generation feel a connection to the build ings and spaces that their family had a hand in building. These kinds of projects served to unite the community in the past with Wainuiomata having little support from the outside.

13 Anniversary publications by the Wainuiomata Rugby Club and Wainuiomata AFC provided information about the histories of the clubs and grounds which revealed how facilities and grounds have been developed and expanded over time as clubs have grown. They also provide details about the community involvement in fundraising, working bees, and the construction of buildings. These publications also reveal a history of interrelationships and sharing of facilities between clubs, this has been particularly important for the establishment of new clubs.
A review of Hutt City Council documents and plans revealed plans; to develop community sporting hubs and promote a sharing of resources between sports clubs via 'Sportsville' partnerships(Hutt City Council, 2012); and encourage the development of 2000 'low cost' houses in Wainuiomata, which would increase the local population by 35\%(Hutt City Council,

2013a). These documents suggest that there will be significant changes to the local community in the near future, which reaffirms the need to examine how the design of sports facilities can better respond to the local community.

Census data for the Wainuiomata Ward from 1986 2006, showed that; the average age is increasing and the population is becoming more ethnically diverse and less religious (figs 61-69). This data also revealed low levels of education in the local community, $22 \%$ of Wainuiomata outside of high school have no qualifications at all.

The data collected in this initial study was useful for understanding a range of relationships which exist between sport and the local community of Wainuiomata. This information is valuable for understanding context and how a design could respond to local conditions on an urban scale. A closer study was needed to understand how these relationships could influence design at the scale of a building. Diagrams produced using this data are shown on pages 46-59 and are followed by discussion of the collection of detailed data at the Wainuiomata Rugby Club from page 61. (see apendix 1 for more infromation on sources) 
Wainuiomata Sports Clubs

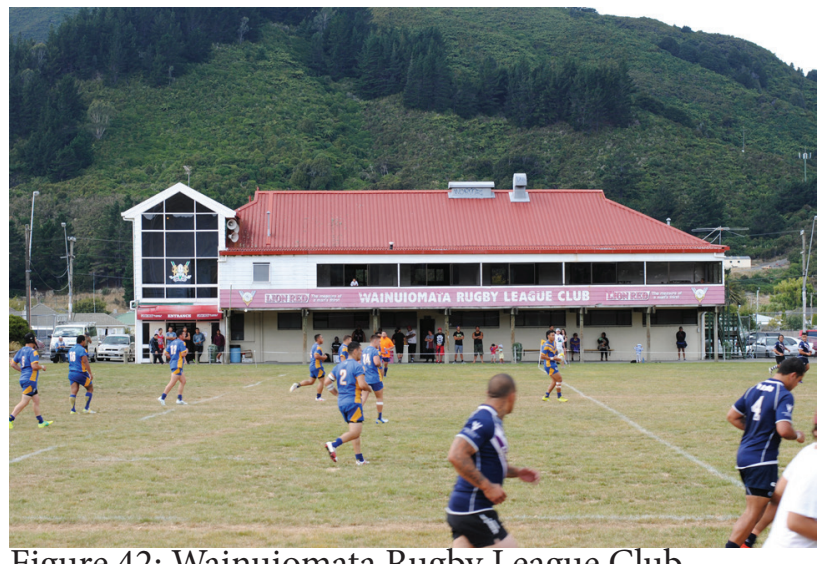

Figure 42: Wainuiomata Rugby League Club

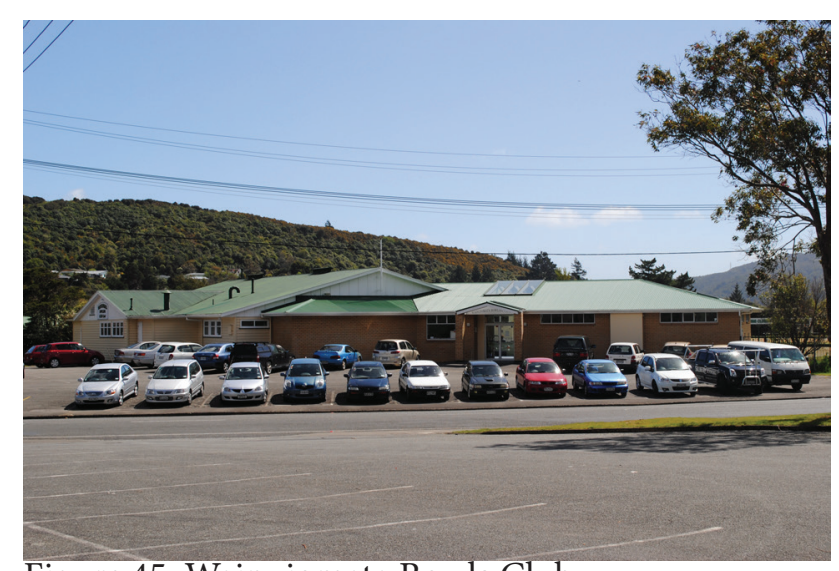

Figure 45: Wainuiomata Bowls Club

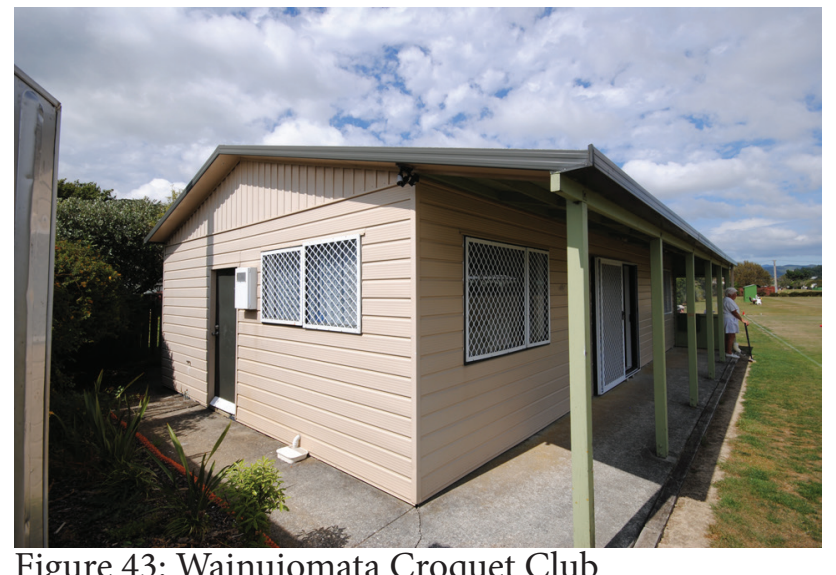

Figure 43: Wainuiomata Croquet Club

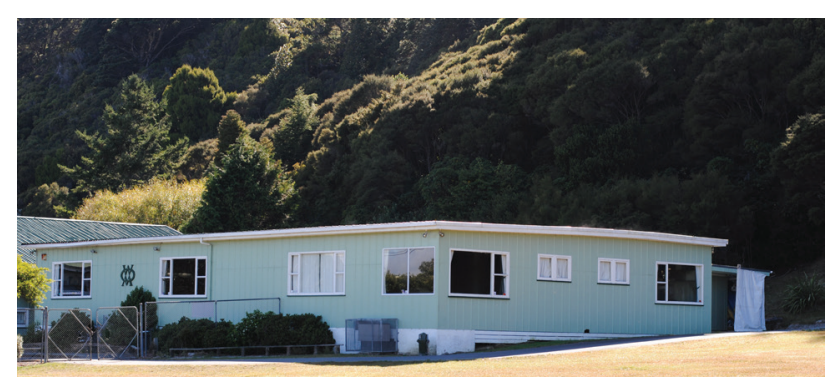

Figure 46: WainuiomataRugby Football Club

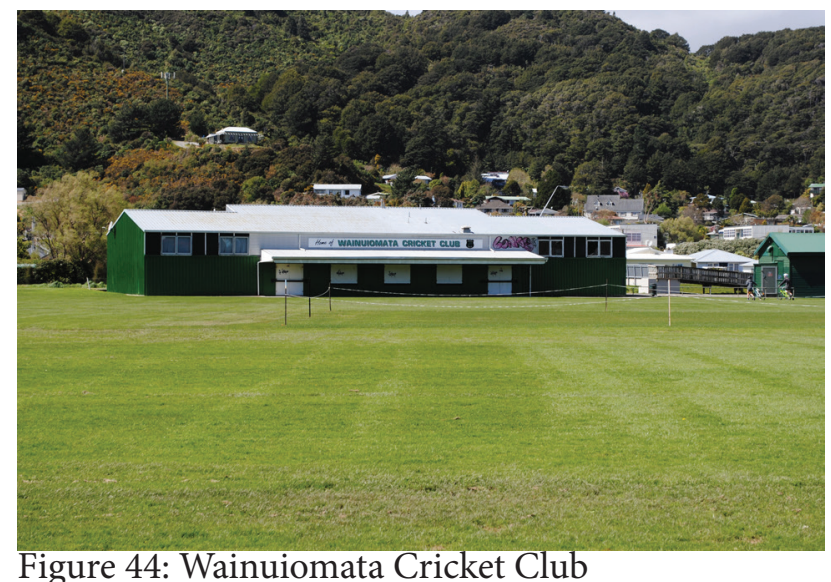

Figure 44: Wainuiomata Cricket Club

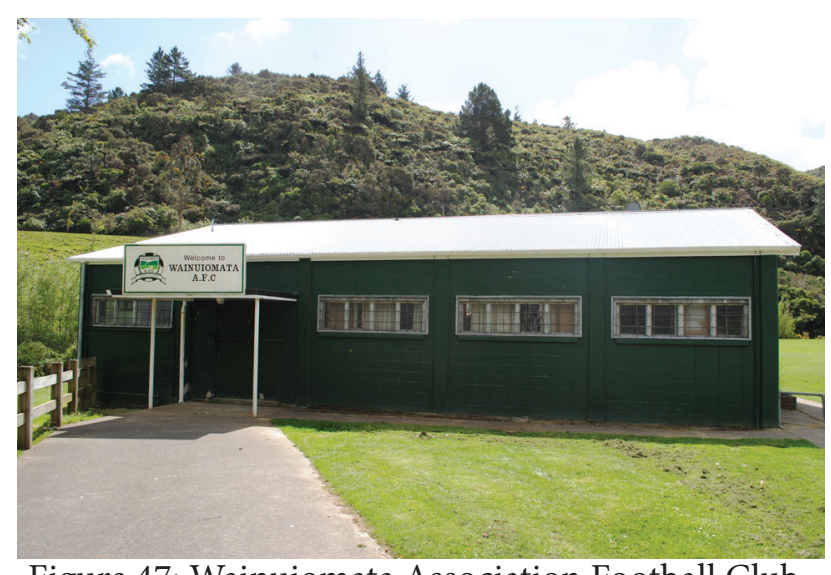

Figure 47: Wainuiomata Association Football Club 


\section{Links Between Sports Clubs And Sports Grounds}

Softball, Touch, Junior Rugby

Football, Cricket

Junior Rugby

Rugby, Touch, Sevens

Figure 48: The activities of Sports Clubs are split between a number of associated sports grounds - a number of these clubs also have an association with each other through the Wainuiomata SportsVille programme.

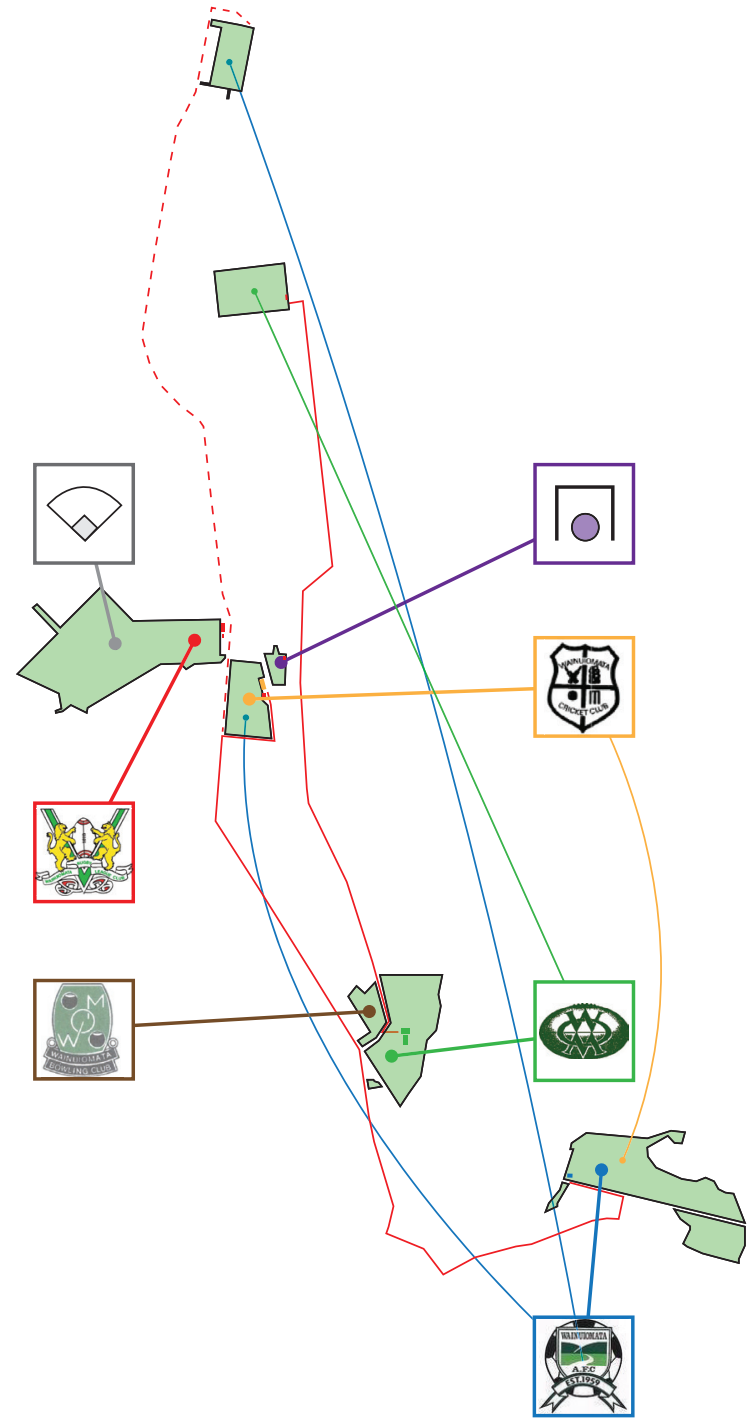

Figure 49: Diagram of club Relationships with Sports Grounds- Sports activities are distributed geographically throughout Wainuiomata, there are three clusters where activities of a number of clubs are concentrated. 


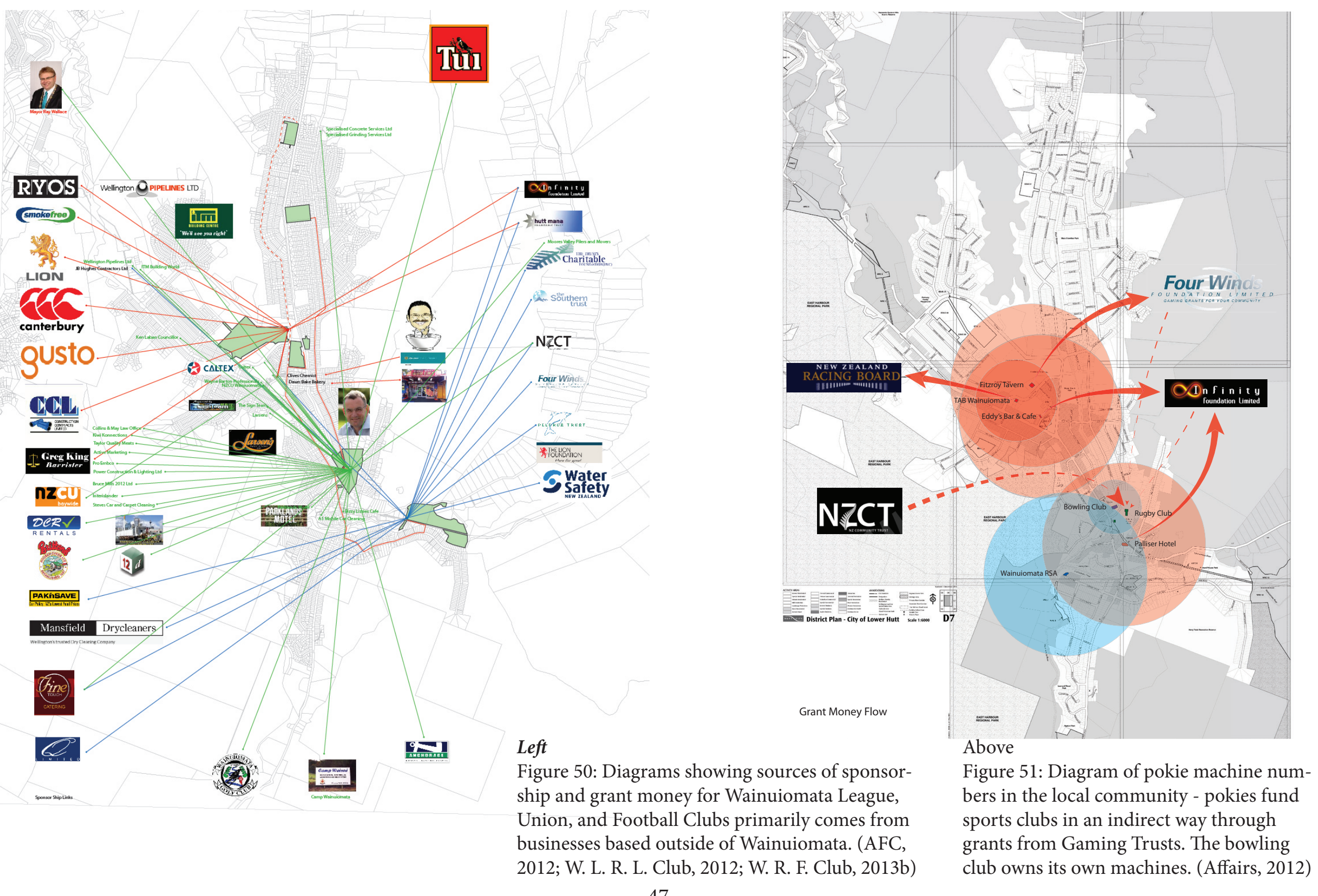




\section{Comparative Income Sources Of Wainuiomata Sports Clubs}

\section{Rugby League}

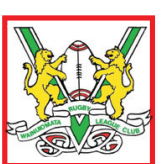

Rugby League Club
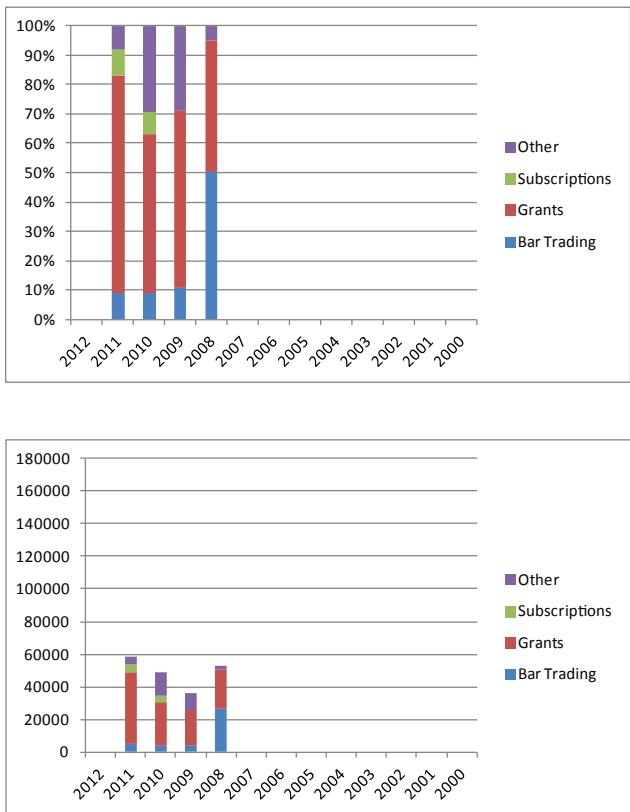

Figure 52: Rugby League Income Sources - The majority of the clubs income comes from grants.

\section{Croquet}

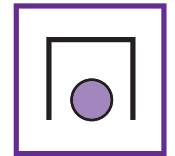

Croquet Club
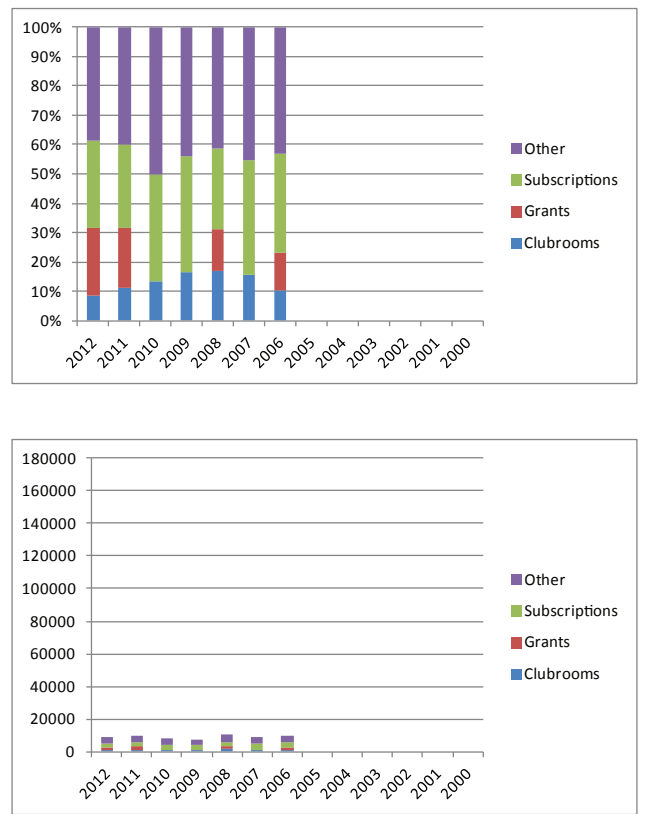

Figure 53: Croquet Income Sources - The Croquet Club operates on a very low budget and is mainly financed through fundraising and subscriptions.
Cricket
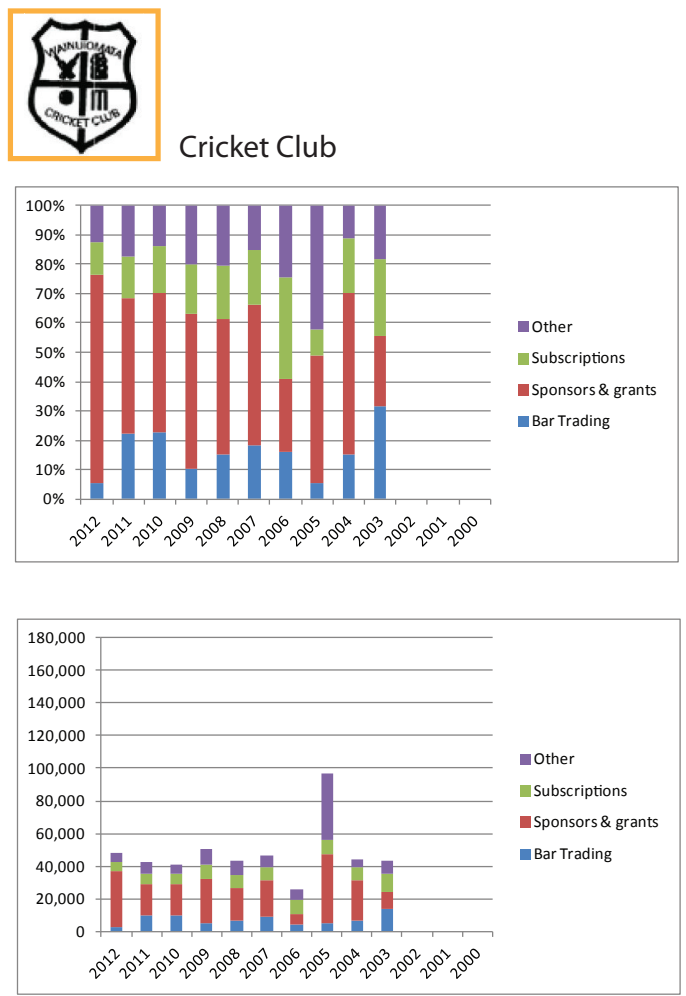

Figure 54: Cricket Income Sources - The Cricket Club gets the majority of its income from grants, which is supplemented by bartrading, subscriptions and other sources 

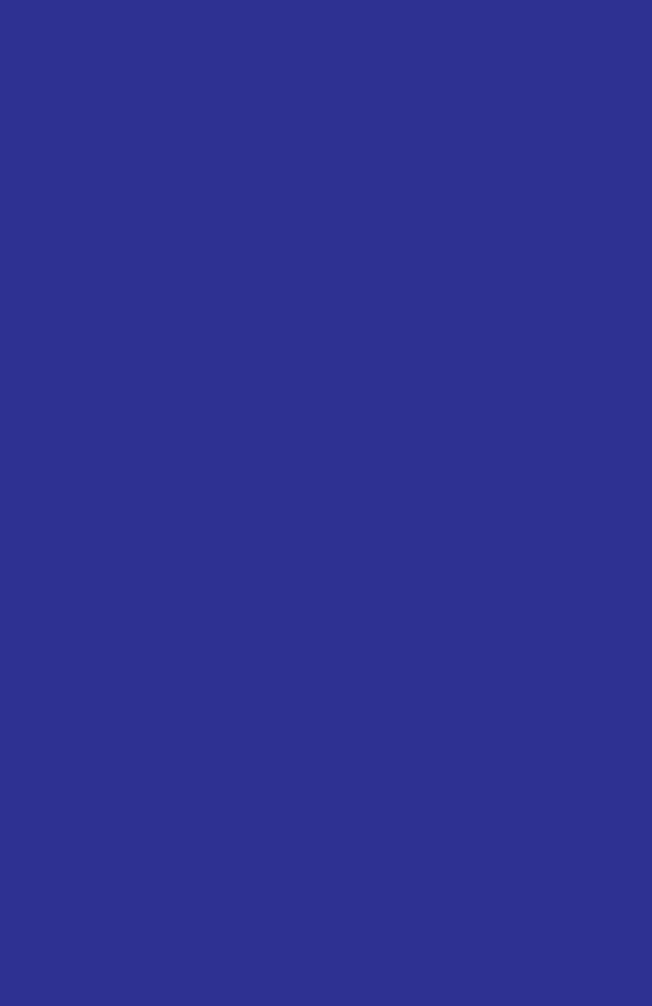

\section{ex}

Rugby Football Club
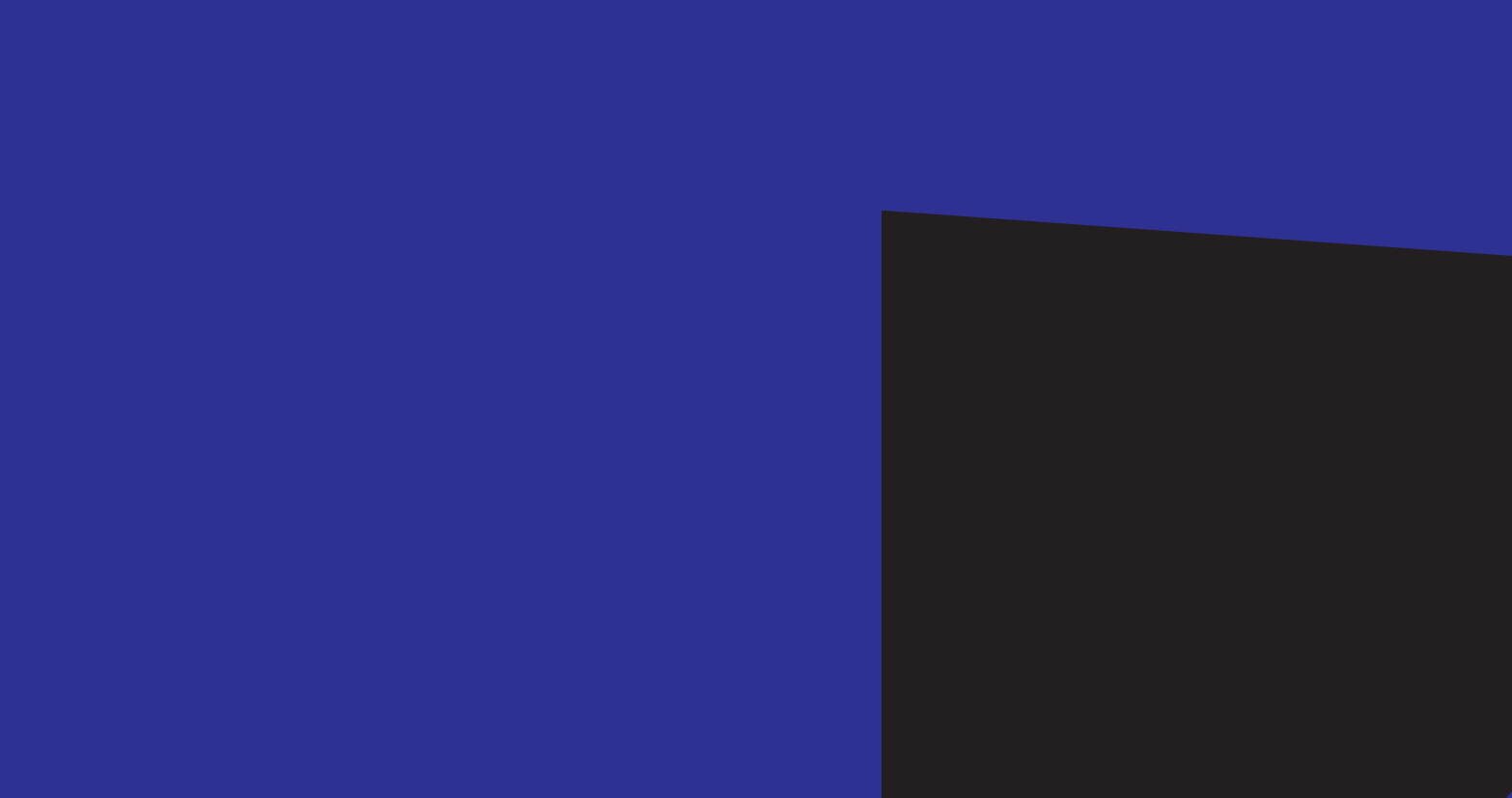


\section{Development Of Wainuiomata Over Time}

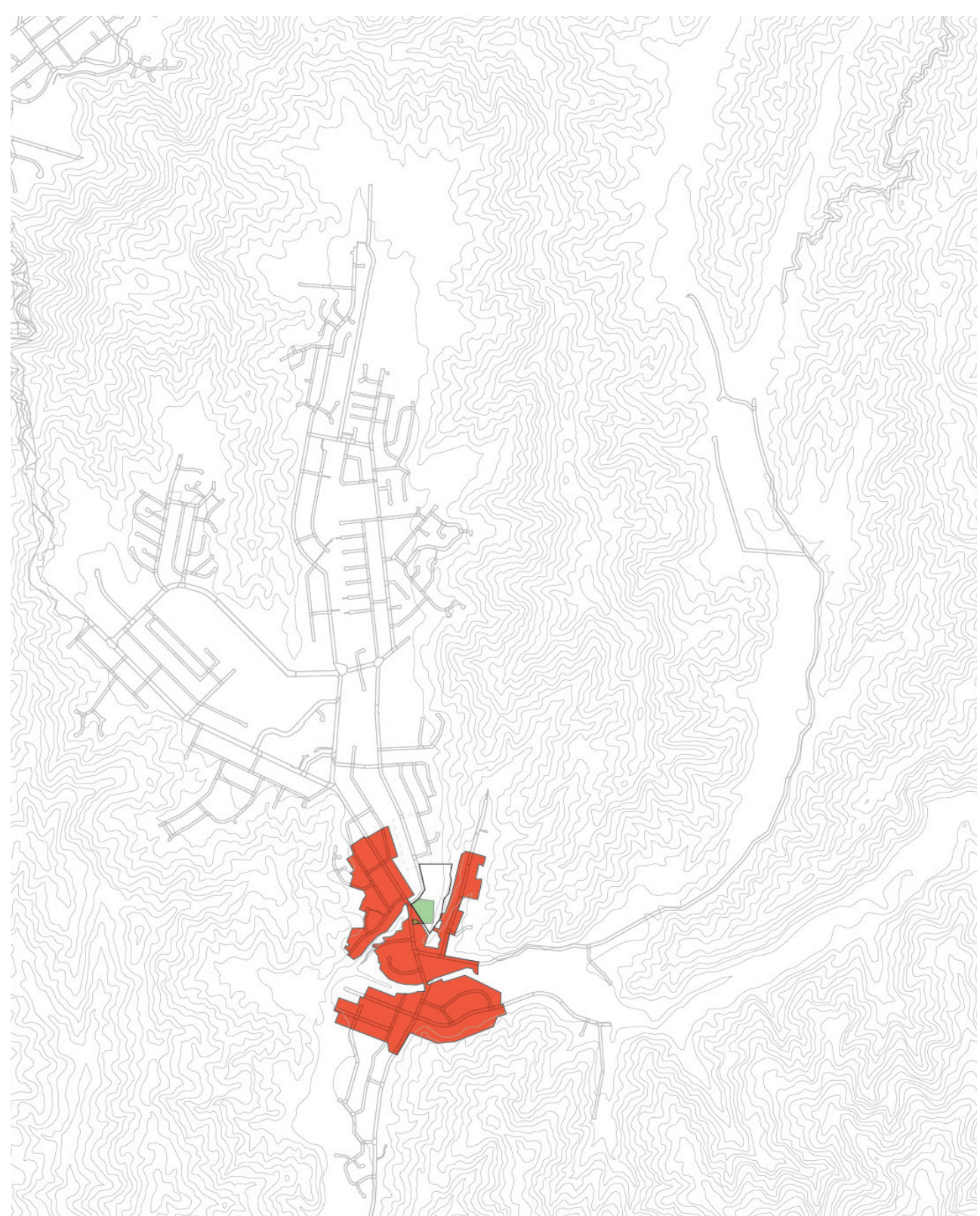

1950 - Original settlement in Wainuiomata, Homedale Village, was based around solid land at the junction of Black Creek and the Wainuiomata River.
Figure 58: Diagram of Wainuiomata’s stages of development as it has progressively expanded from the original settlement in Homedale Village. (Continued page 51)
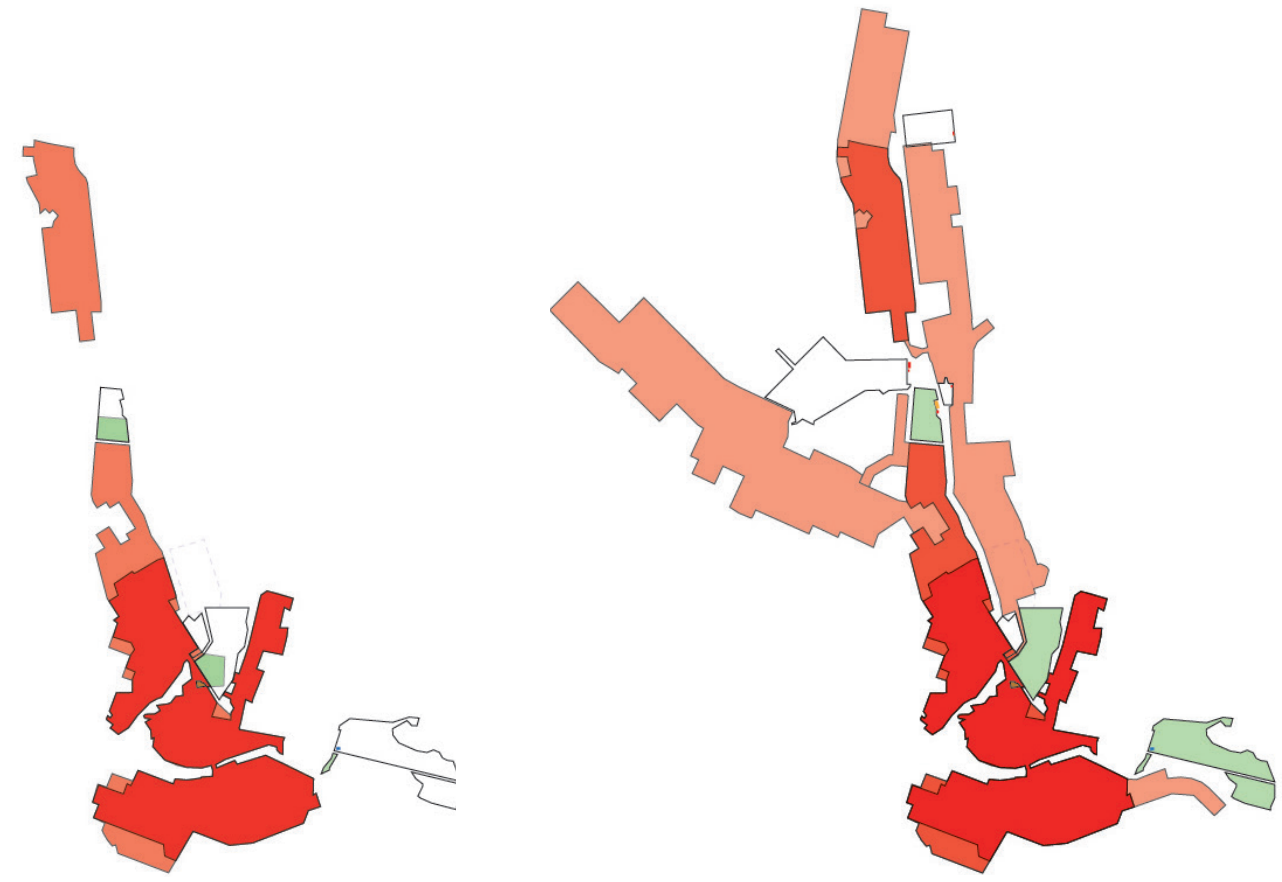

1955 - Drained Wetland to the north developed into new housing. New sports grounds are developed on the fringes

1960 - Housing development expanded. Richard Prouse Park developed, William Jones and Brian Heath Parks expanded. 


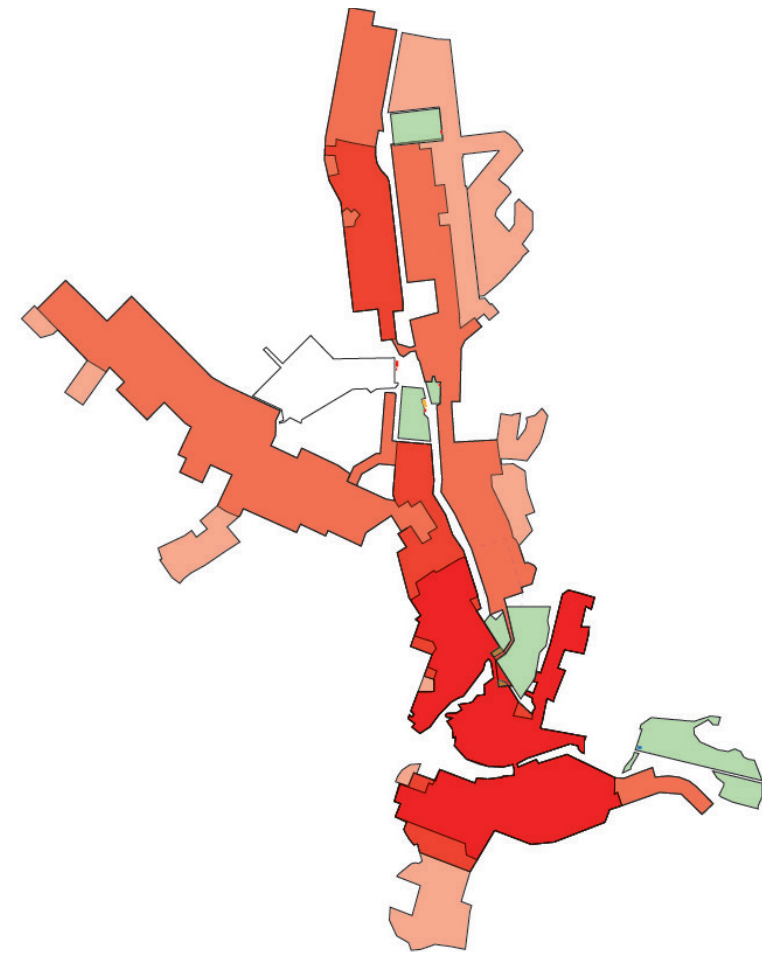

1965 - Further expansion is accompanied by development of Mary Crowther Park to the north and Bowling Grounds by the Rugby Club.

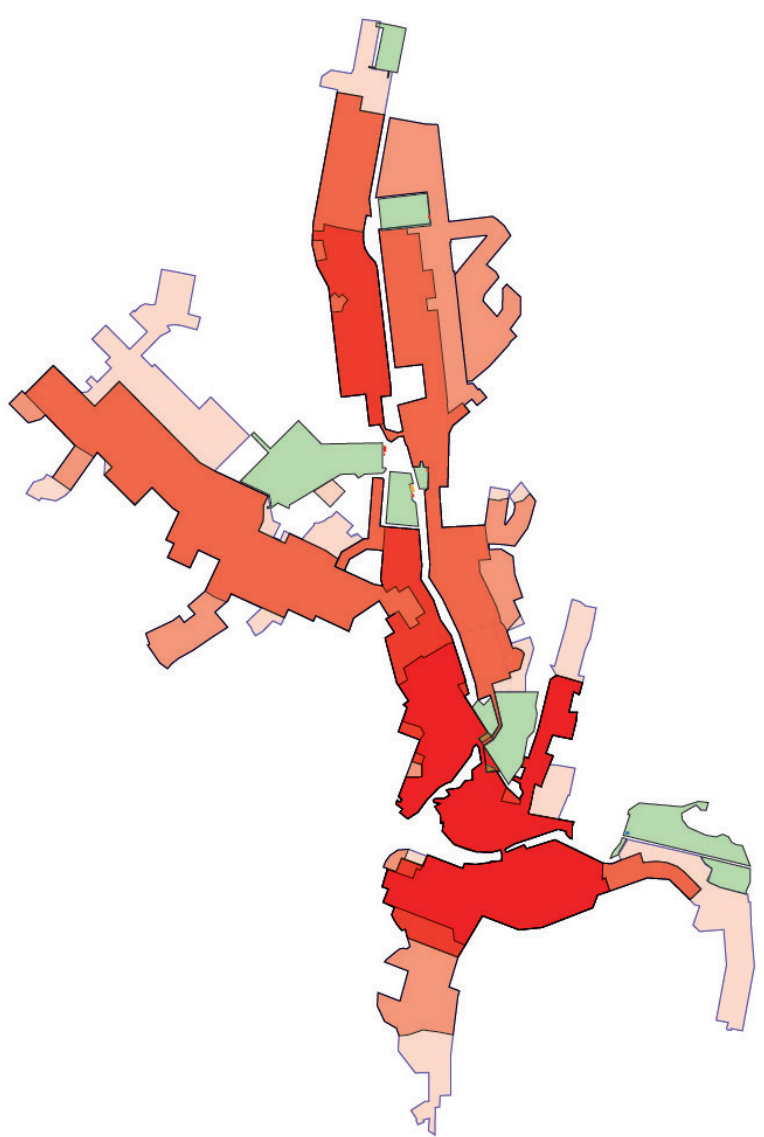

1970 - Development around the fringes in accompanied by the development of the Wainuiomata Mall, and Wise Park in the centre of town, and Arakura park to the north

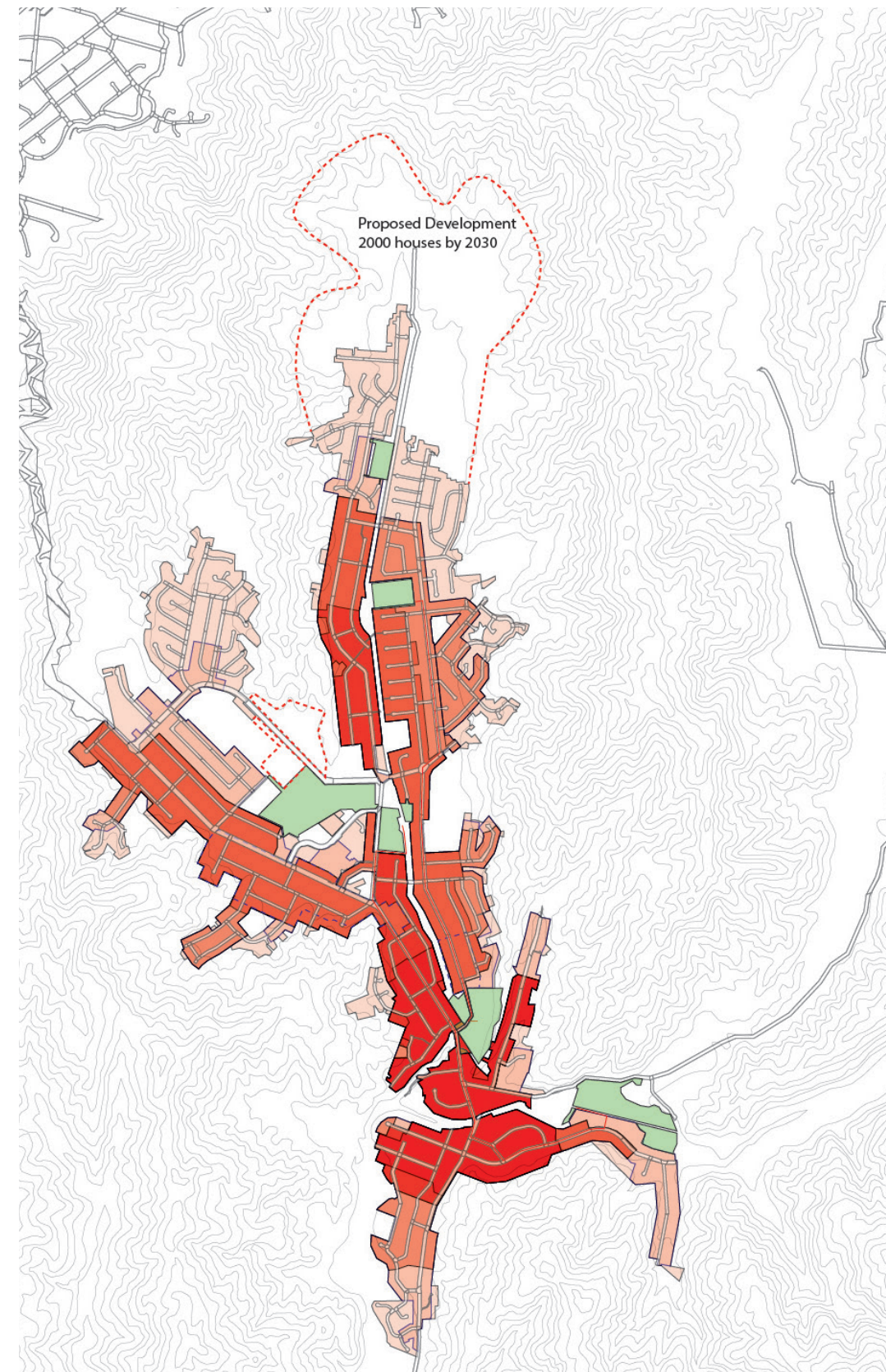

2013 - Growth stabilised with some further development to the north around the Parkway and Arakura areas. Development of the Upper Fitzerbert area to the North is being discussed. 


\section{Sports Clubs Registered In Wainuiomata Over Time}

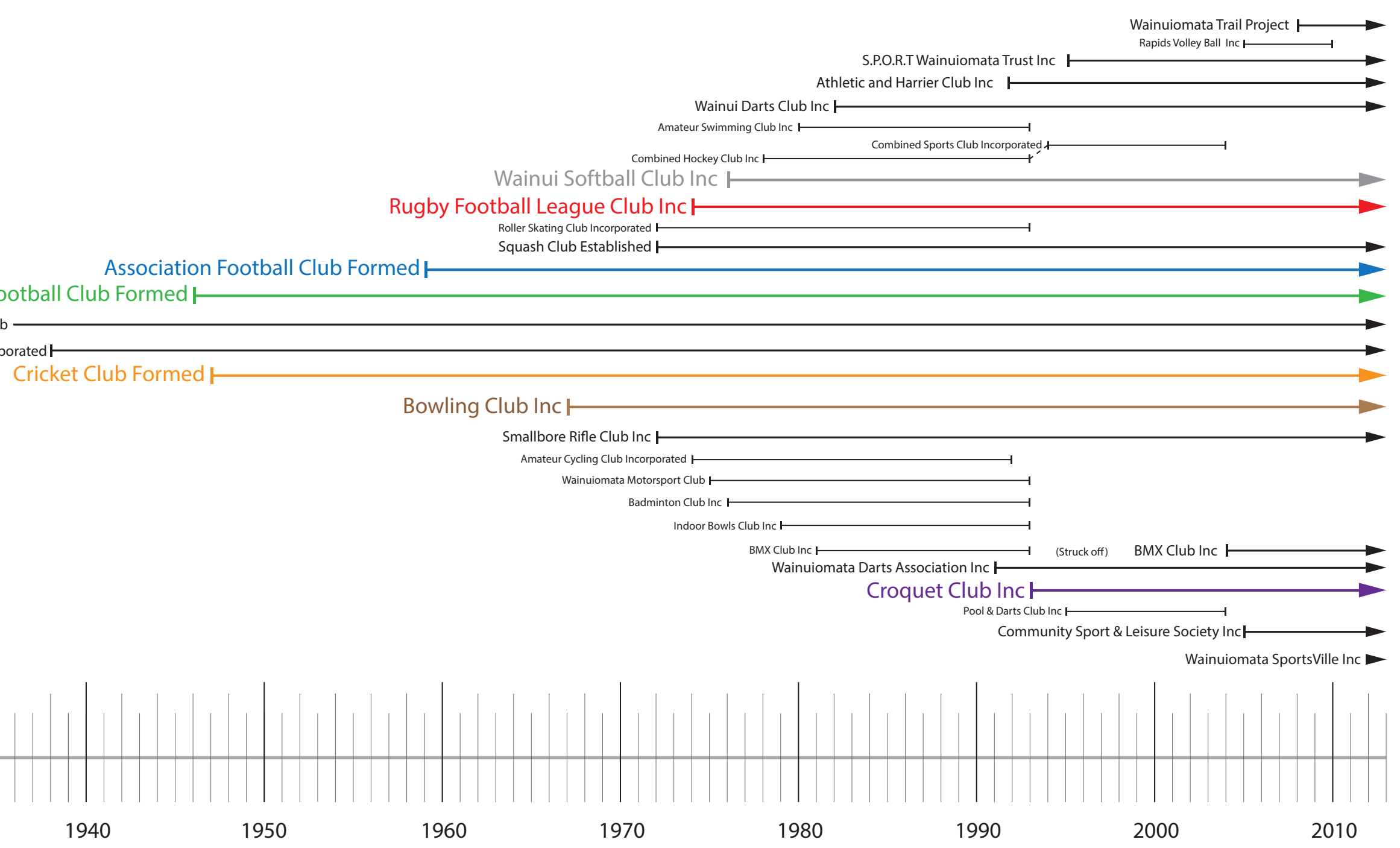

Rugby Union F

Golf Club Incorporated
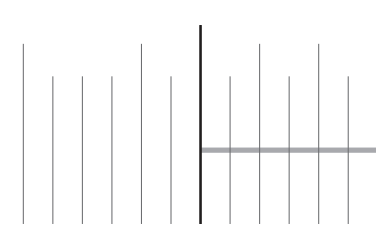

1930

1950

1960

1970

1980

1990

2000

2010

Figure 59: The number of Sports Clubs registered in Wainuiomata has expanded over time resulting in increased competition for members and the division of the sporting community. 


\section{Graphic History Of Wainuiomata In Relation To Its Sports Clubs}

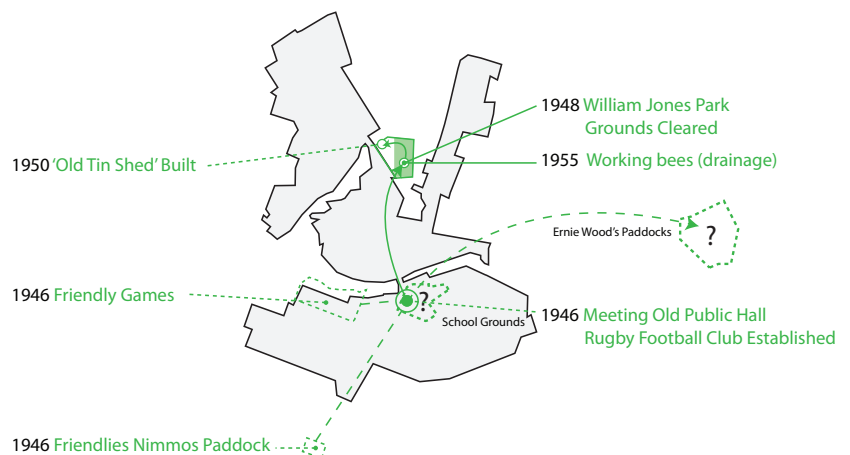

1950 - The Rugby was formed in a meeting at the Old Public Hall, games were played in nearby fields until grounds were cleared at the site of William Jones Park. The 'Old Tin Shed' was built as a club house.
Figure 60: A social and developmental history of the Wainuiomata Rugby Club, Association Football Club, and the Wainuiomata Pool were mapped spatially over time, in reference to the simultaneous expansion of Wainuiomata. (Continued on page $54 \& 55$ )

1955

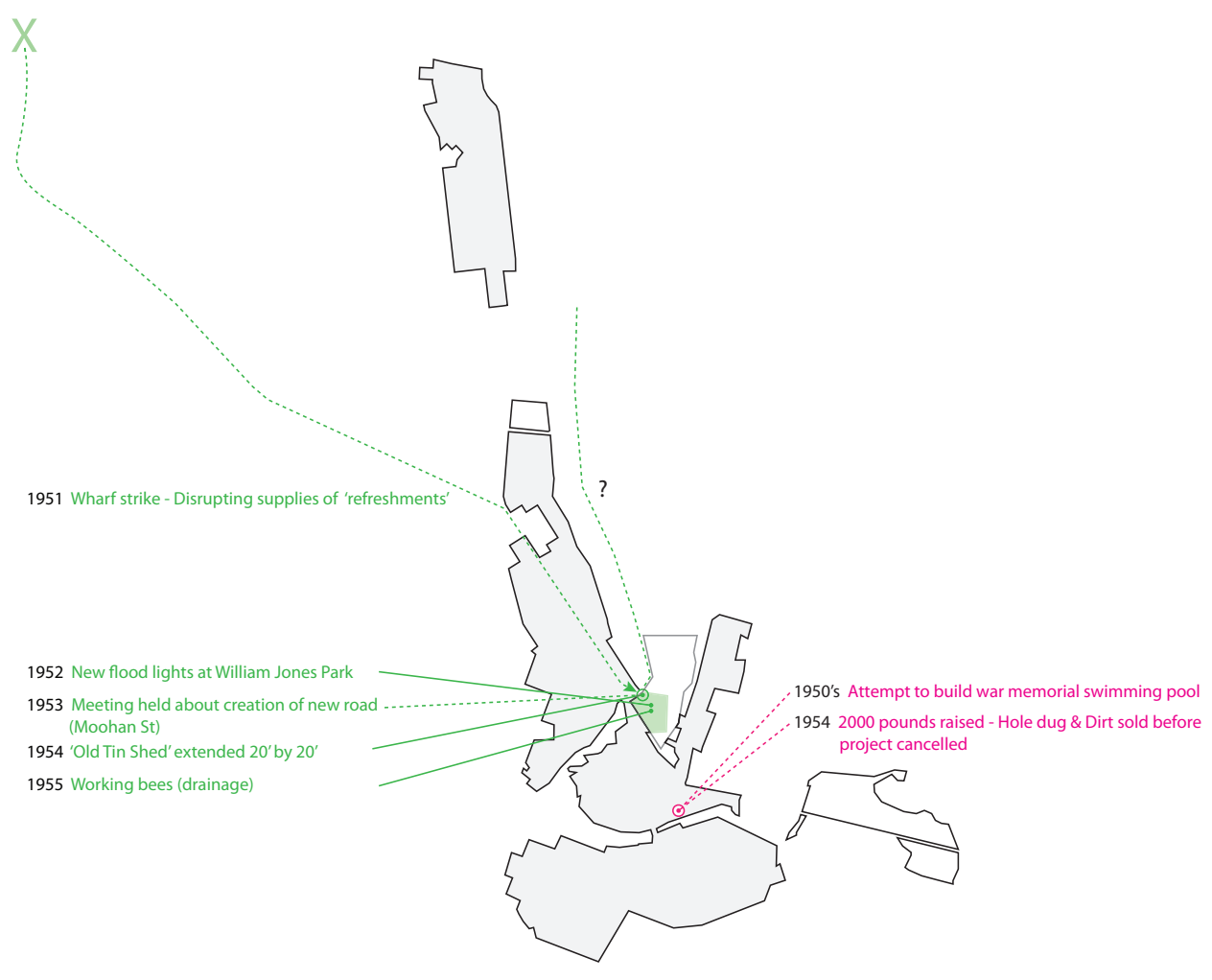

1955 - Several improvements were made to William Jones Park including the provision of flood lights, extension of the 'Old Tin Shed' and working bees to improve the grounds. An attempt to build a swimming pool was made which was eventually cancelled but not before a large hole was dug at the current site of the Tennis Club. 


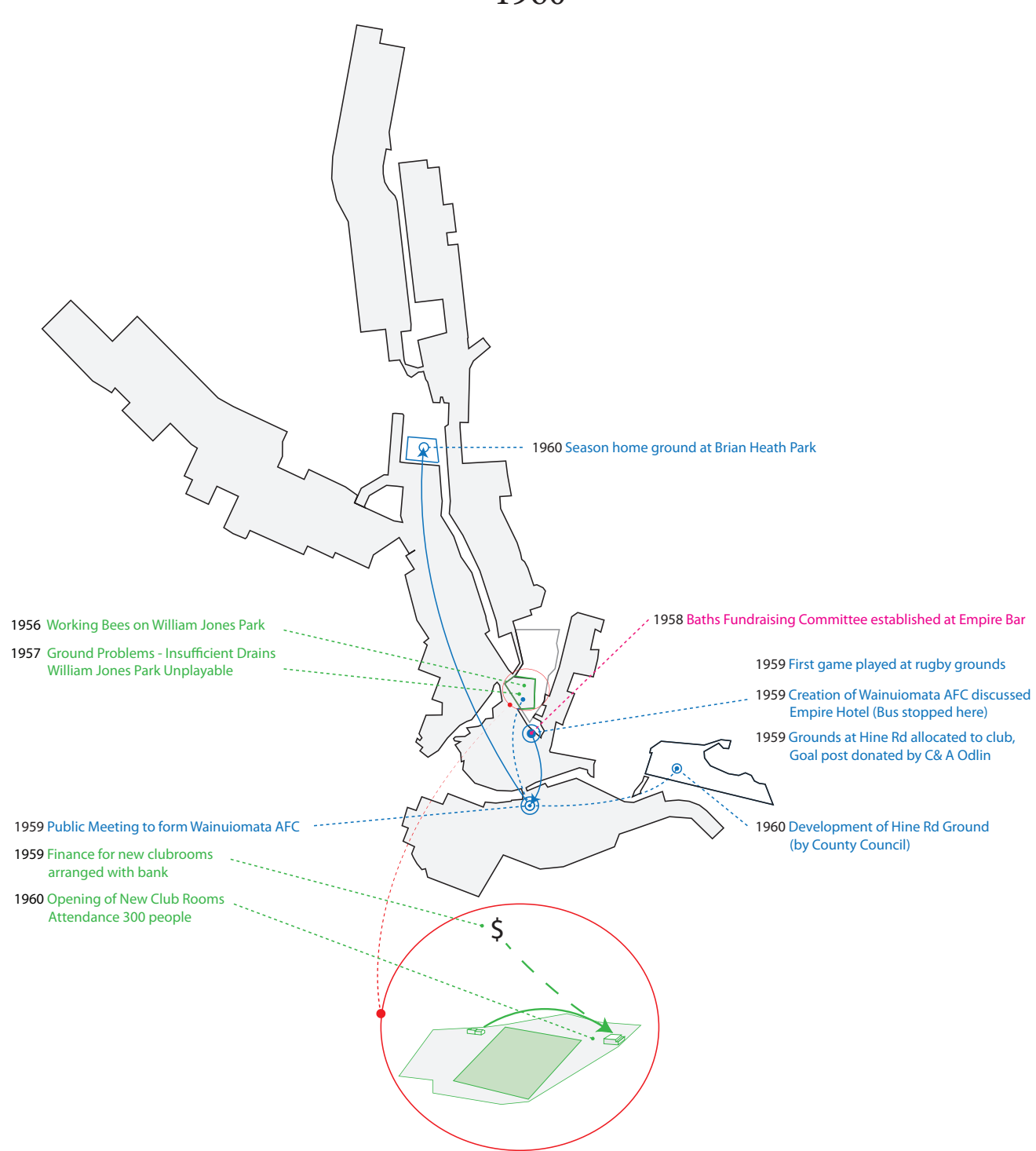

1960 - The Wainuiomata AFC was formed, spending a season at Brian Heath Park while grounds at Richard Prouse Park were being developed by the council. The Rugby Club built and financed new club rooms at William Jones Park.

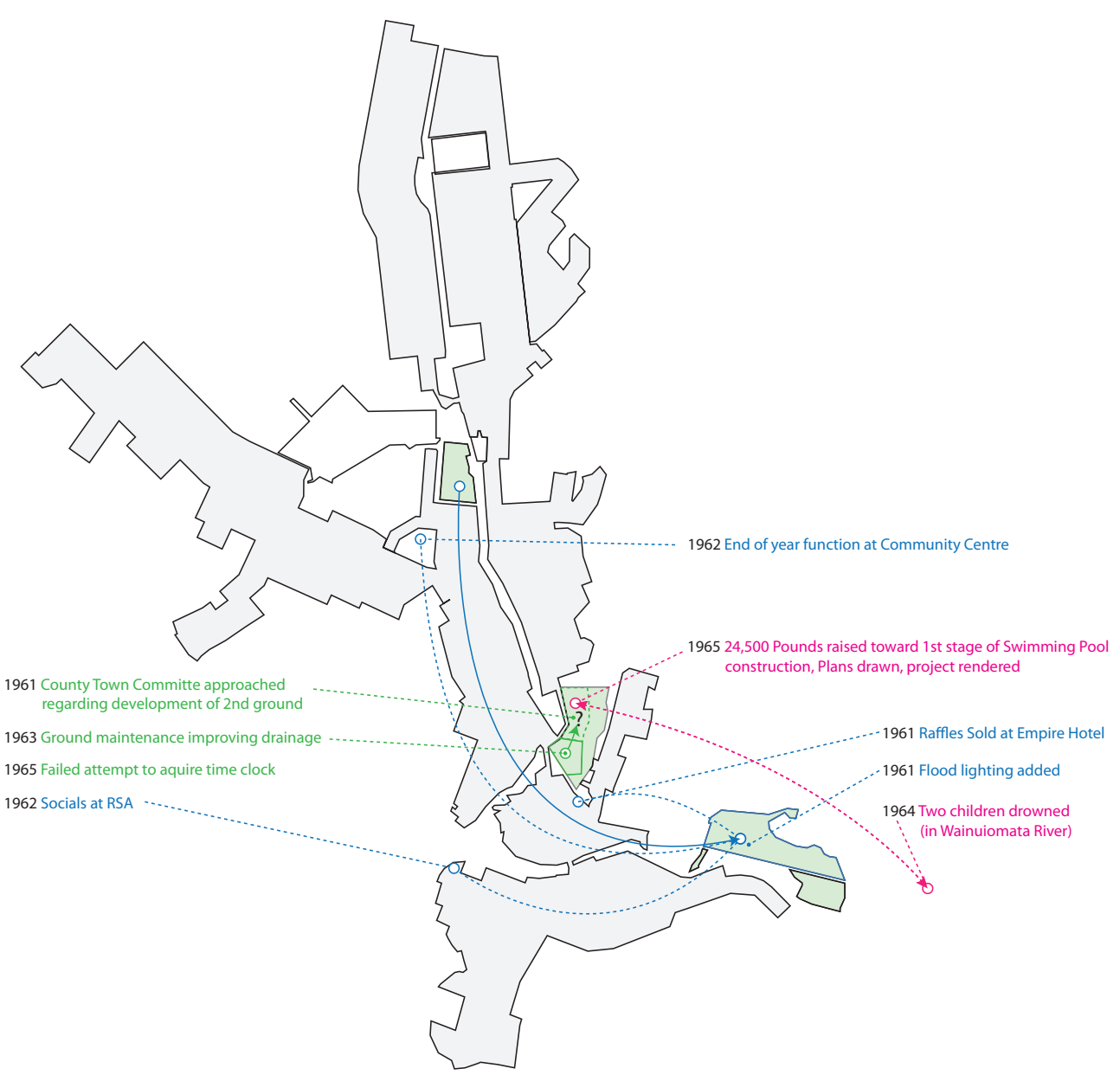

1965 - Development of a second ground at William Jones Park was considered before a decision was made to build a pool at the site. The Football Club moved its home ground to Richard Prouse Park, with social events dispersed around Wainuiomata. 


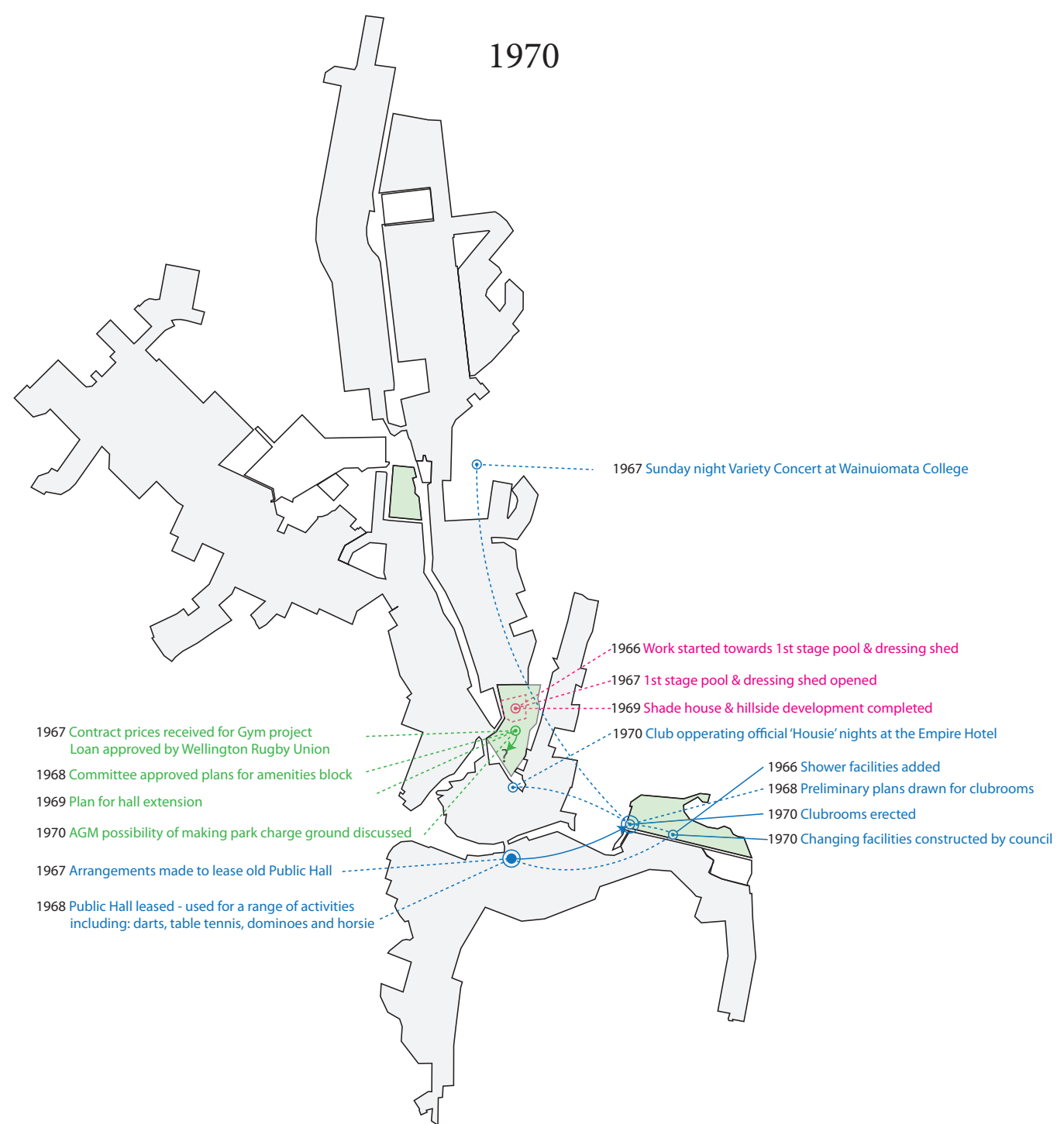

1970 - Plans were made for extensions to the Rugby Club. Work started on swimming pool at William Jones Park. The Football Club continued to organise social events throughout Wainuiomata before construction of club rooms at Richard Prouse Park.

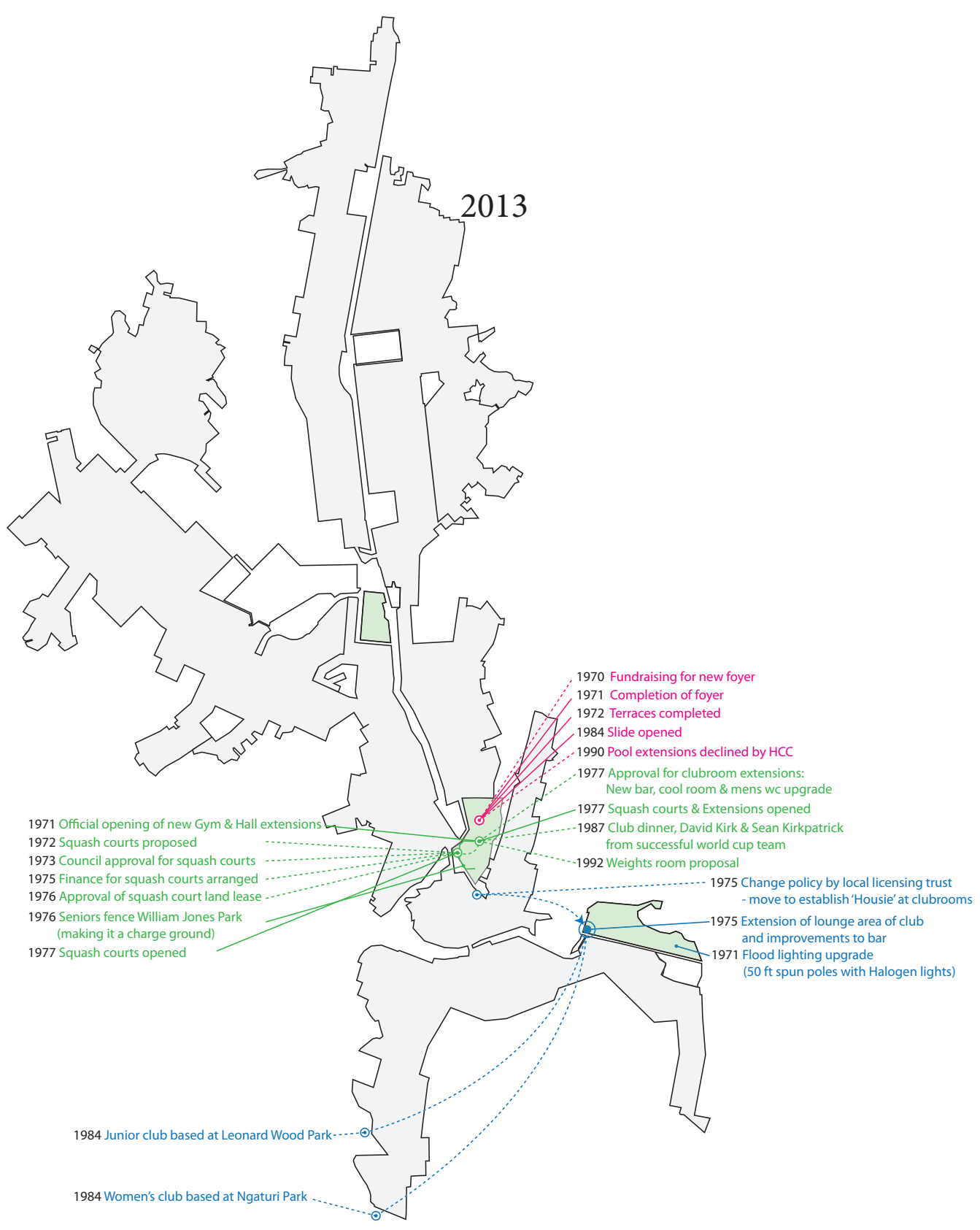

2013 - Extensions to Rugby Club were completed and further extensions were made. A Squash Club was also developed by the Rugby Club at William Jones Park. The Pool was completed with the inclusion of a slide. Extensions were made to the Football Club. 


\section{Demographic Trends in Wainuiomata}

\section{The (changing) Demographic Profile of Wainuiomata}

Recently there have been demographic shifts in age, ethnicity, and religion have affected the Wainuiomata community. As a result of these changes a growing number of community buildings in Wainuiomata, most notably schools and churches, have become redundant and their benefits to the community as a platform upon which groups of people can network and meet others have been have been lost. A community facility will need to be designed to accommodate these shifting demographics and user numbers if it is to be responsive to changes effecting Wainuiomata.

\section{Population}

Between the 1956 and 1971 census's Wainuiomata's population increased dramatically as a result of large scale development of cheap housing. From 1986 to 2001 the population was in decline but has since begun to rise again with both the 2006 and 2013 Census's showing increases to the population which currently stands at 17,304 (Statistics New Zealand 2009, 2013). Recently the Hutt City Council has proposed to encourage the development of 2000 'low cost' houses in Wainuiomata by 2031 which would increase the local population by 6000 people, a $35 \%$ increase (Hutt City Council, 2013a).

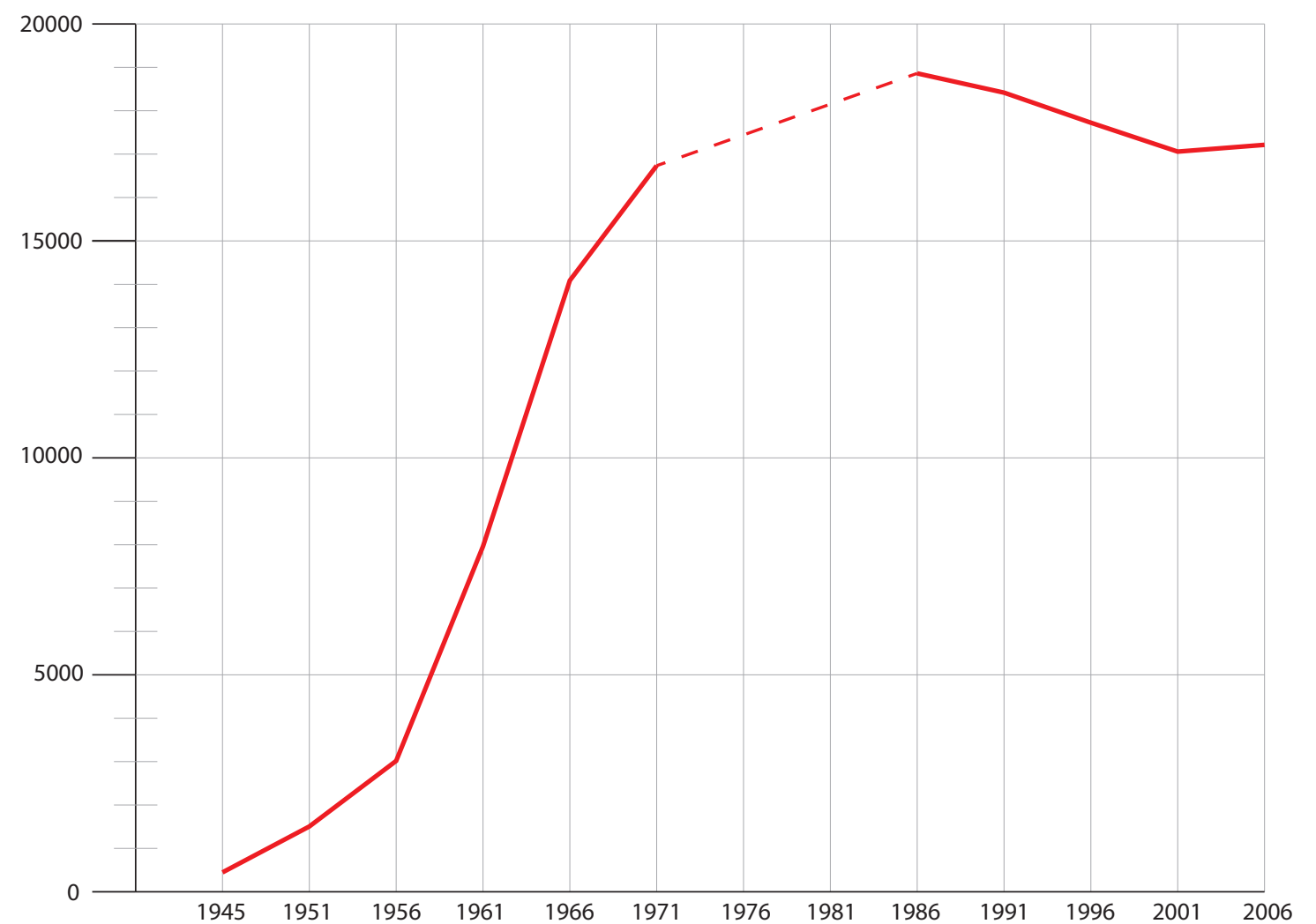

Figure 61: Wainuiomata Population Growth - Figures taken from Boffa Jackman Study (Associates, p. 6) + Census data from 1986 to 2006 (Zealand, 2009, 2013). 
Age Of Wainuiomata Over Time

Population Distributed by Age Group

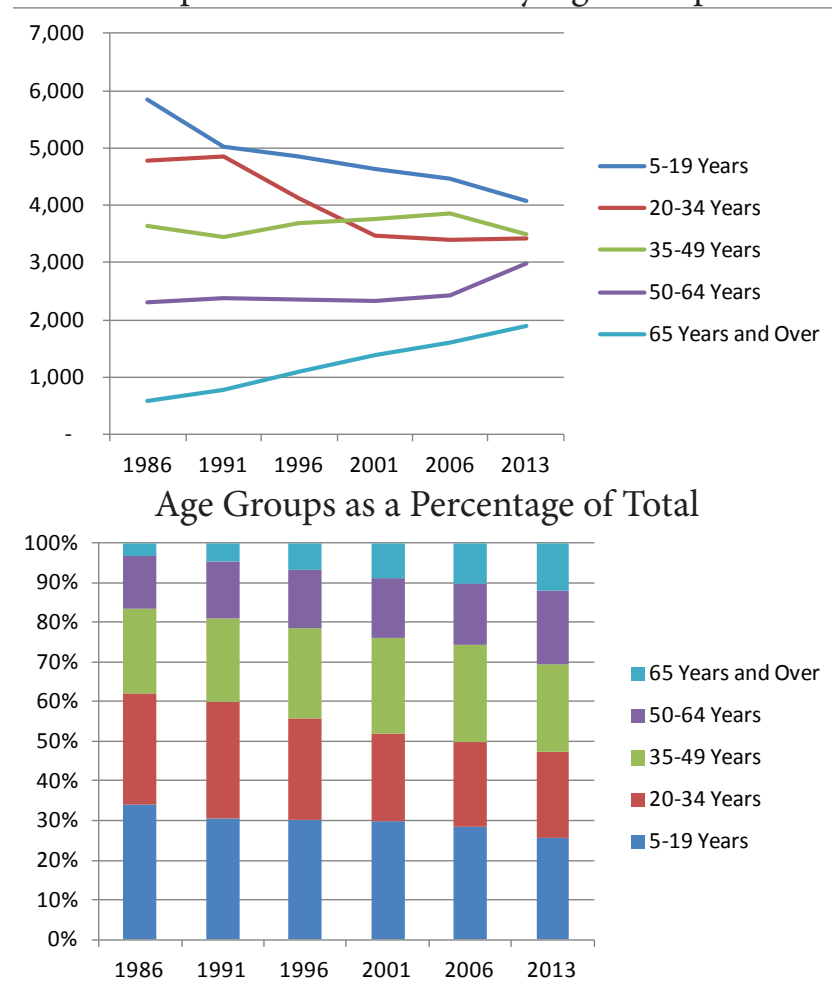

Figure 62: The average age of population is increasing Age

The average age of the population in Wainuiomata is increasing. The effects of this were seen in 2002 when, due to declining roles, the total number of schools was decreased from 14 to 9 through a series of mergers leaving just 1 high school, 1 Intermediate and 7 primary schools. Schools have a number of benefits beyond education, facilitating a range of activities and interactions within the community. Consequently the loss of a number of school sites has a negative impact on the wider community.
Population Distributed by Ethnicity
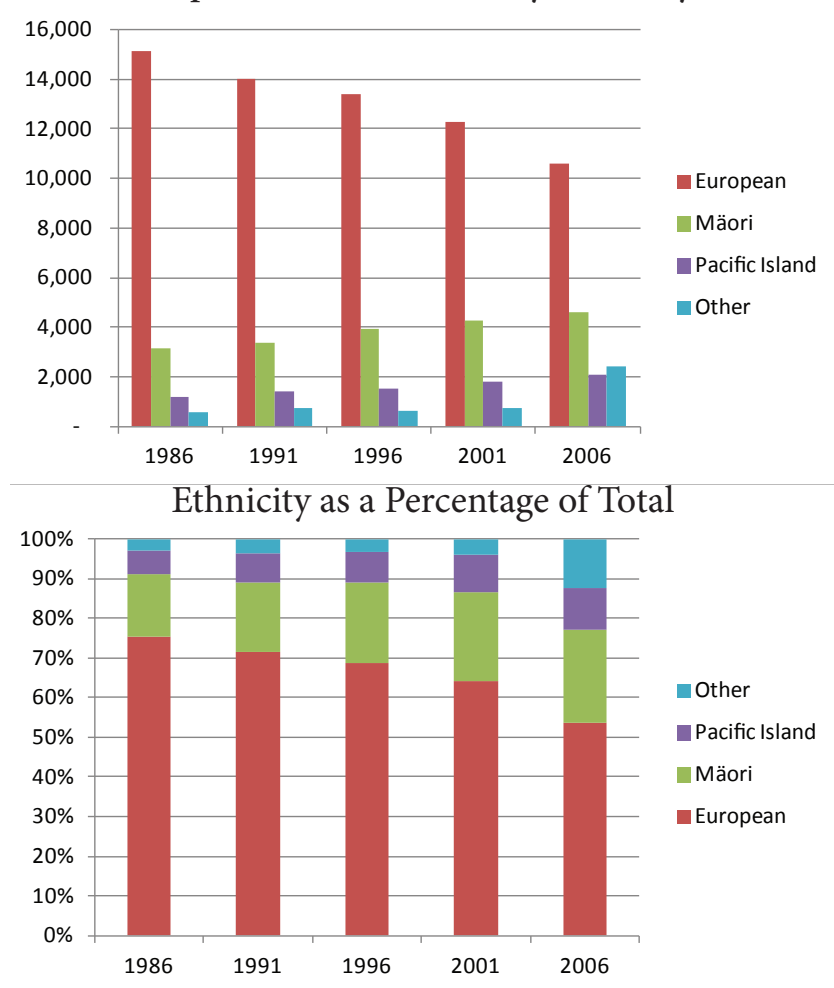

Figure 63: Wainuiomata is becoming more Ethnically Diverse

Ethnicity

The population of Wainuiomata is predominantly European however this proportion has been steadily falling alongside a notable rise in Maori, Pacific and other ethnic groups. Consequently the ethnic makeup of the local community is becoming increasingly diverse. Cultural differences between ethnic groups can present a barrier for participation in community activities.
Population Distributed by Religion
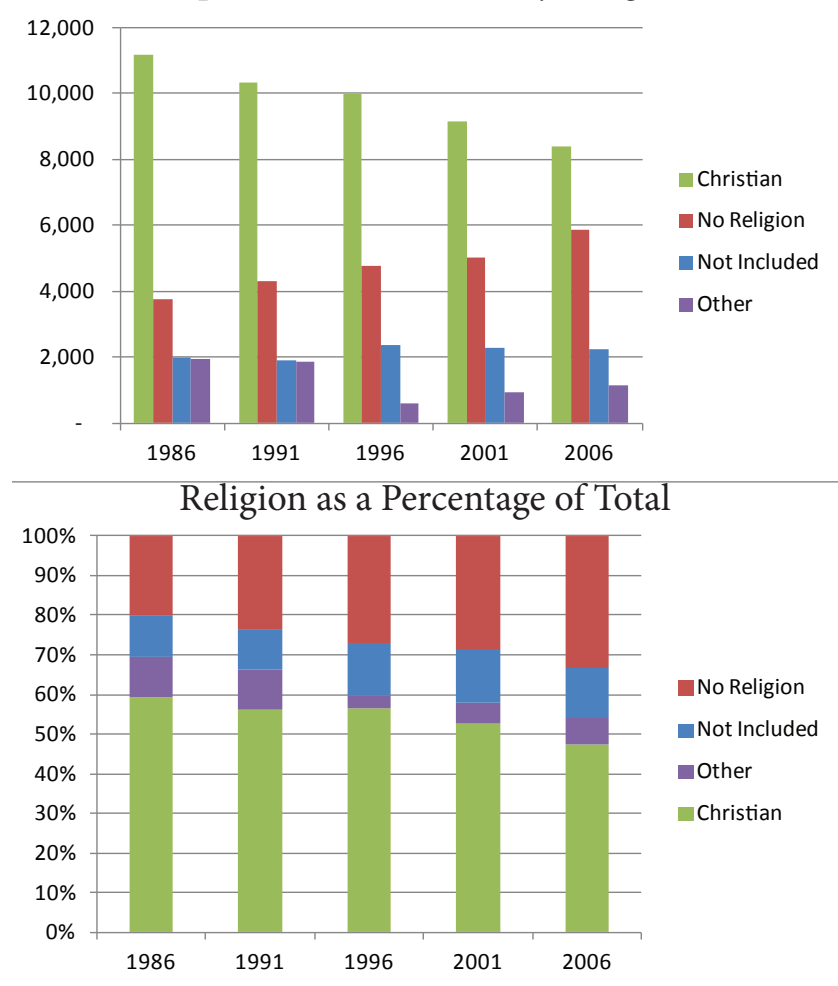

Figure 64: Wainuiomata is becoming less religious

\section{Religion}

The population of Wainuiomata is becoming increasingly less religious, which is consequently having an effect on church attendance and the ability for these buildings to remain viable in the long term. Churches have traditionally played a community role bringing together people that otherwise would have little interaction. 


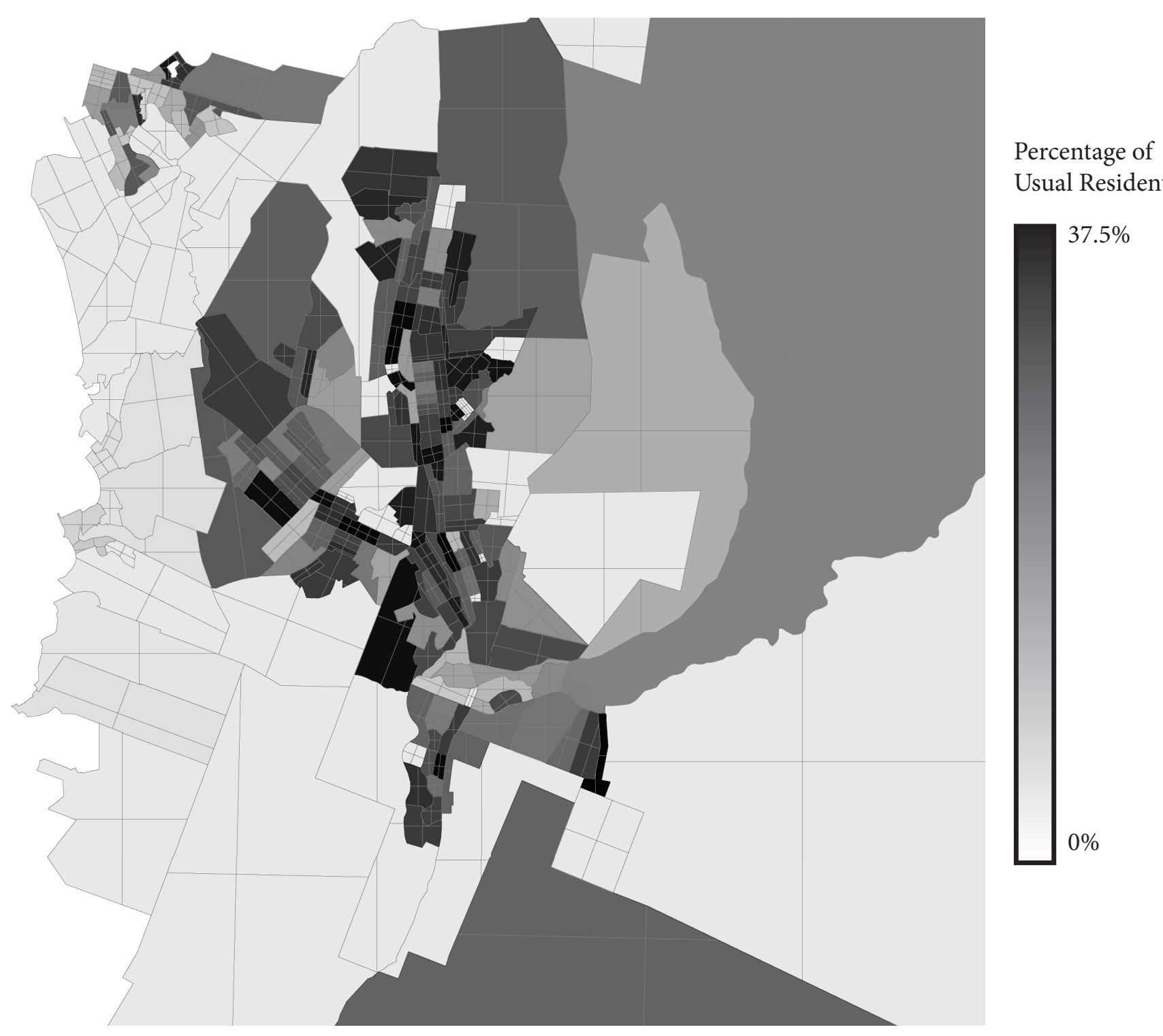

Figure 65: The percentage of population above 15 with no qualifications varies throughout different areas of Wainuiomata, reaching as high as $37.5 \%$ in some cases (Zealand, 2009).

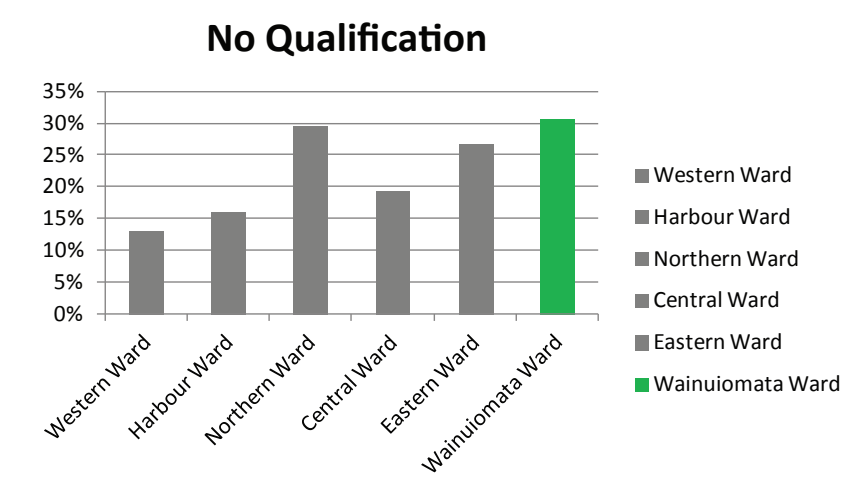

Figure 66: Wainuiomata has a high proportion of population above 15 with no qualifications of any kind, even compared to other Lower Hutt suburbs (Zealand, 2009).

\section{Census, Study Participation}

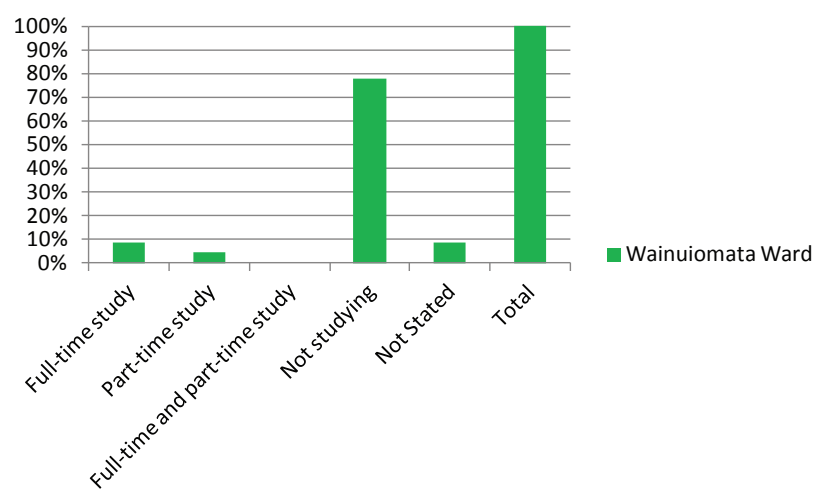

Figure 67: The majority of Wainuiomata residents are not currently engaged in full or part time study (Zealand, 2009). 


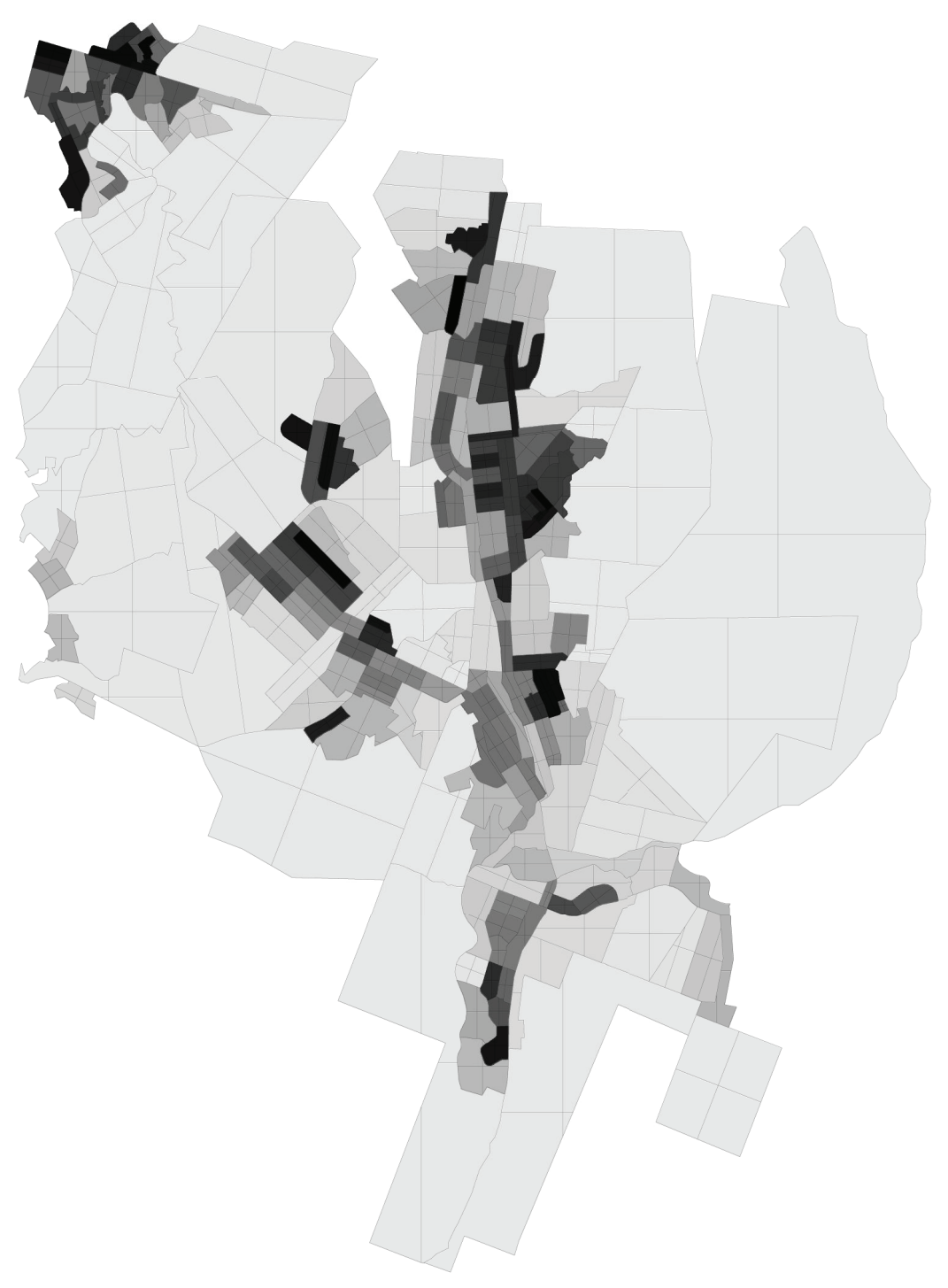

Figure 68: Population density in Wainuiomata is fairly low, however there are several clusters, generally towards the fringes and more recently developed areas, where the population is higher than in other areas.

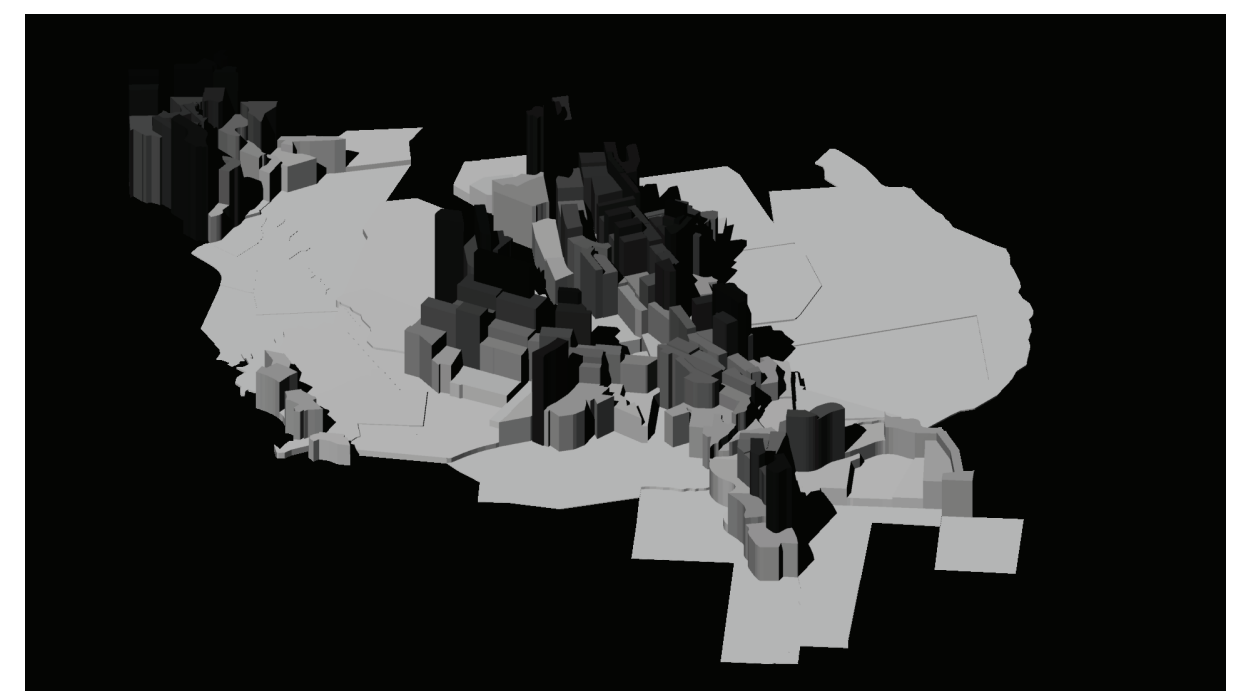

Figure 69: 3D representation of population density in Wainuiomata.

Education levels and Population Density in Wainuiomata were mapped using Meshblock data for the 2006 Census obtained from Statistics New Zealand (Zealand, 2009) Images were created in Rhino using the Grasshopper plugin with Meerkat GIS Components 



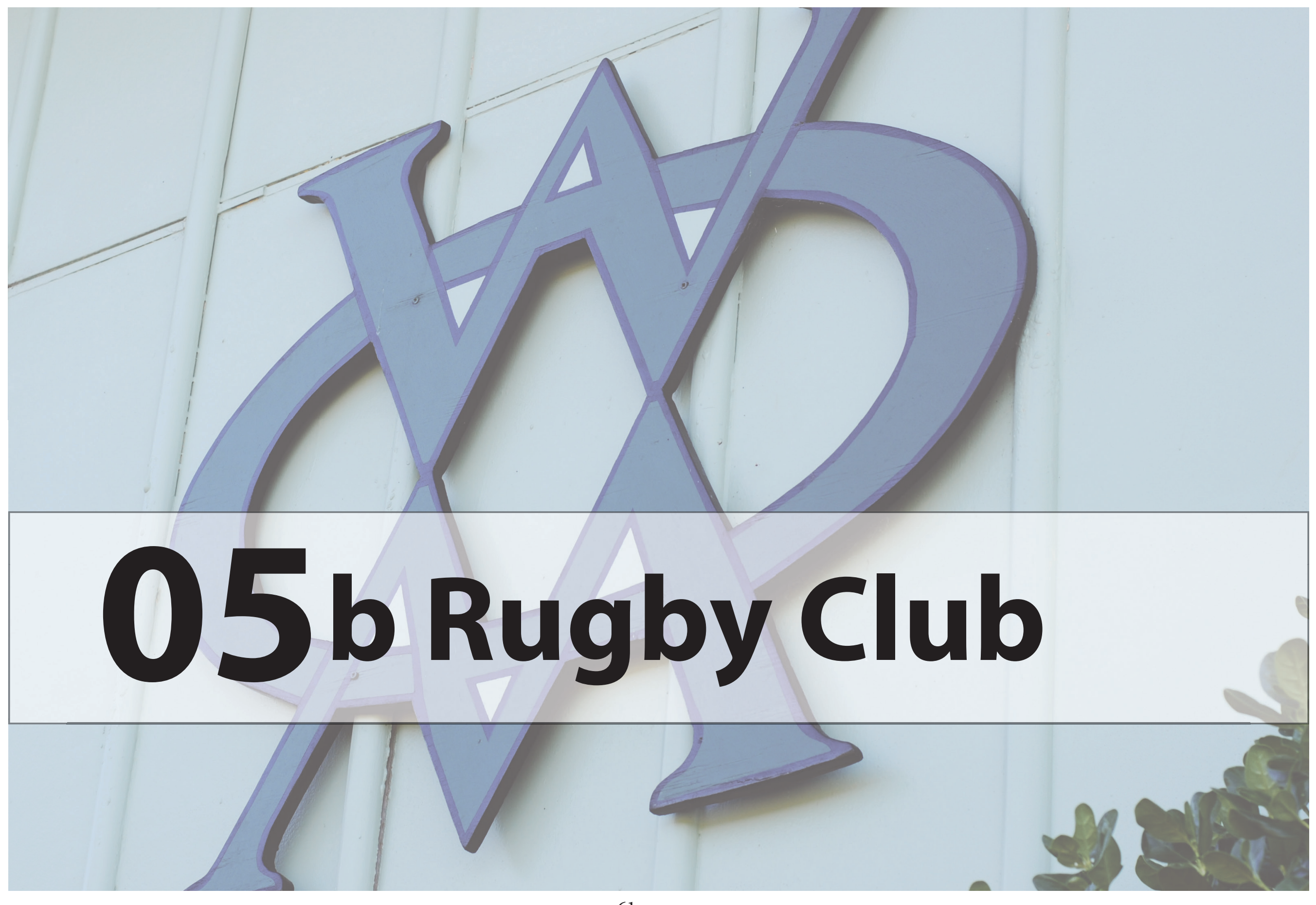




\section{Rugby Club Analysis}

Following on from the last chapter the scale of exploration was shifted from wider community down to the scale of the rugby club (fig 70). Detailed analysis of the rugby club began with a photographic survey which recorded physical characteristics and qualities of the exterior and interior of the building, and the adjacent sports field (figs 71-74). This survey revealed that there is a poor visual connection between the club and the street as well as the sports field itself. From the outside the rugby club has quite an introverted appearance. It is set back on the site and separated from the street by a large car park, access to the field is provided via a gate just in front of the clubrooms. The club is raised off the ground making its windows above eye level which prevents people from outside from seeing whether there is activity within (figs $71 \& 72$ ). I found this lack of visibility a little intimidating because there was little indication of what was going on inside or whether the club was closed, or being used for a private event. The main entrance is approached through a 'tunnel' space which is also used to access an indoor training gym and changing rooms. The inside appearance of the club is quite vibrant in contrast to the outside, the walls of main social area of are covered in an array of sporting memorabilia and photographs. There are several traces of alterations which have been made to the space, the most significant being a split in floor level which differentiates the space of the original club which is now used as a dance floor from later extensions. Despite being one open area the main social space is divided into three parts because of this split.

A series of personal observations were then conducted during which time I assumed the roles of both participant observer and complete observer when appropriate (Creswell, 2003, p. 186). The club was visited on multiple occasions including days when; premier games were being played, club meetings were being held, games were not being played, and special occasions such as preseason 'senior team camp' and Old Timers day and Prize Giving. A series of photographs and sketches were made during these events recording changes of layout to the space, patterns of use and occupation (figs 75-85). During these visits the rugby club supplied me with copies of archived plans, and a publication made for the Rugby Clubs 50th Anniversary. Information about the size and types of spaces in the building over time was obtained from an analysis of these plans which revealed a number of alterations over time, demonstrating how the building has been physically adapted to accommodate changes in occupation. The clubs 50 year anniversary publication provided Information about the changing numbers

of teams over time. This provided information about the expansion of programme over time in relation to the growth of the club. Diagrams of these changes helped to develop an understanding of why the rugby club is organised the way it is and led to investigations of how this programme could be reshuffled on the site to better relate to the clubs current needs (figs 86-91).

Informal discussions with members of the Wainuiomata Rugby Club committee provided non-sensitive factual information about the different groups using the facilities, issues affecting the operations of the club and provided information about seasonal change in use 14 . These discussions, in addition to 14 As per the Victoria University Human Ethics Policy section 4.8(a) (i) No ethics approval is required where the interviewee's name will be kept confidential and the my own observations, revealed that two of the main problems affecting the use of the rugby club facilities were related to alcohol licensing and weather. These discussions also indicated that there were reduced numbers of people returning to the clubrooms after the match compared to previous years.

On several occasions there were police present at games to ensure that alcohol was not taken outside of the club by people watching the game ${ }^{15}$. Part of the appeal of watching grassroots rugby is the ability to enjoy a few beers while being close to the action. The location of the club on site and positioning of its windows mean there are only limited views of the field from inside which consequently these issues impact on the sale of alcohol during a game.

Weather had a large impact on the use of grounds by both players and spectators. Extreme weather conditions in the form of droughts early in the season and heavy rains later in the season resulted in restrictions on use of the field as well as a number of transfers away from the club, this has a significant financial impact on the club "Each match transferred away from the club caused a loss of $\$ 1000$ to $\$ 3000$ of spending" (Easton, 2013). Rain also affects spectator turnout in part due to a lack of sheltered areas that the game can be watched from. Wainuiomata has no all weather sports fields so when games are transferred revenues are lost from the community all together. Weather also has an effect on the number object of the interview is merely to seek non-sensitive factual information(Victoria University: Research Policy Group, 2007, p. 6).

15 The irony of this was pointed out to me by members of the public, who noted that there is no liquor ban in place at the park so people can consume drinks bought from elsewhere while watching the game. 


\section{Wainuiomata Rugby Football Club Site Plan And Context}

of spectators attracted to a game. It was observed that there were limited areas of shelter to watch the game from which people would huddle under, making staying dry a difficult prospect while watching a match.

It was observed that a large number of people would immediately leave after a match was concluded In-

stead of staying to socialise. Although their path back to the car park took them past the clubrooms activity within the club was not visible along this route, due to high windows and a lack of permeability in the facade, meaning the opportunity to entice people inside to socialise was lost.

Detailed data collected on the rugby club was useful for revealing a range of information related to people and their interactions within the spaces of sport. The Club, despite its close proximity to the field is not well connected to activities of the sports field. There is a poor visual connection into and out of the club. The club is also positioned towards the back of the site, with entrances towards the back which means that people arriving and leaving a game flow around the club rather than into it. Observations of patterns of occupation revealed information about the way people inhabit sports facilities. It also highlighted some key issues which affect the operation of sports clubs, spectator numbers, weather, and alcohol sales. This analysis was important to reveal and understand these relationships, allowing my design, developed in the following chapters, to respond to these issues.

The following pages show; photos of external \& internal conditions of the club and park 55-58; Diagrams of Patterns of Occupation 59-60 \& 64 and the growth of the rugby club 61-63.

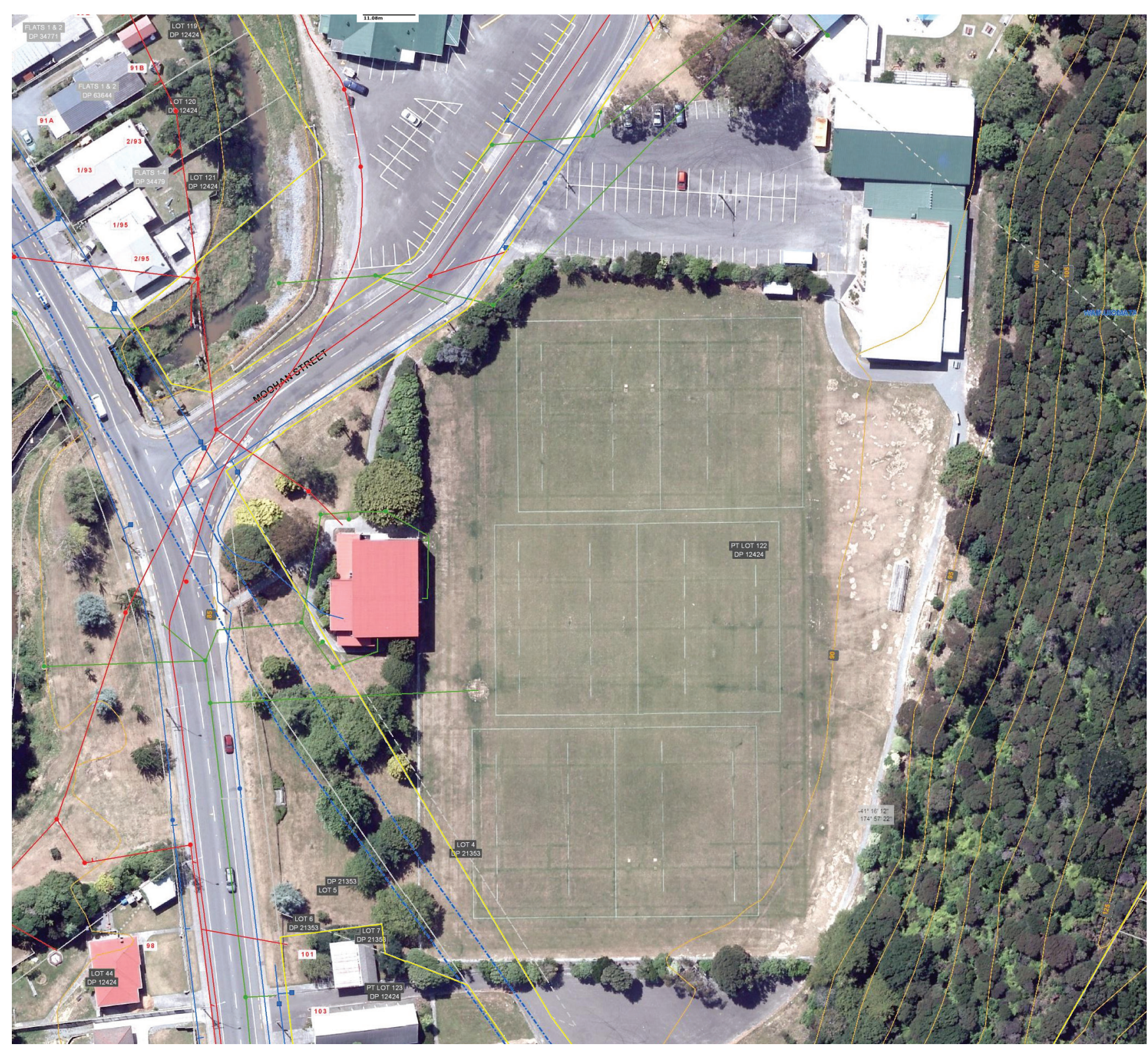

Figure 70: Site 1:2000 Showing the Rugby Club top right and adjacent William Jones Park centre. West of the park is the Wainuiomata Squash Club. The Swimming Pool and Bowling Club are north of the Rugby Club. (Hutt City Council, 2013b) 


\section{Wainuiomata Rugby Football Club Context and External Appearance}

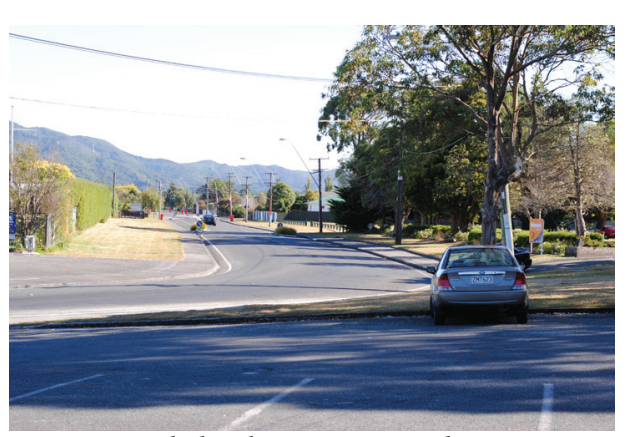

View North looking up Moohan St.

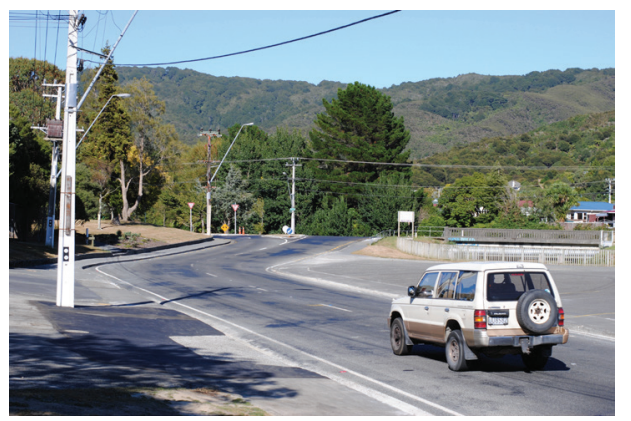

View South West towards Main Rd.

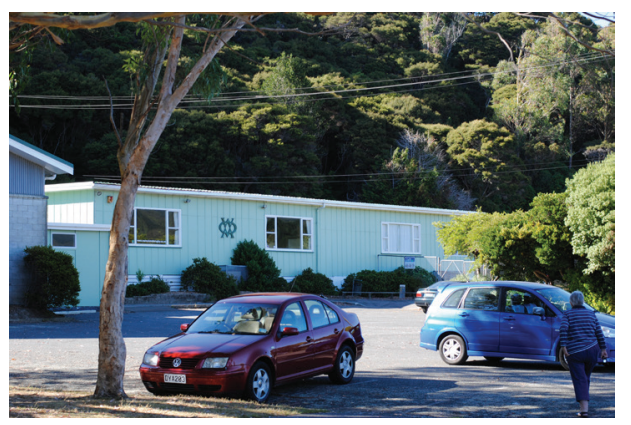

View of Rugby Club from Moohan street.

Above

Figure 71: Photos - Connection to Immediate Context

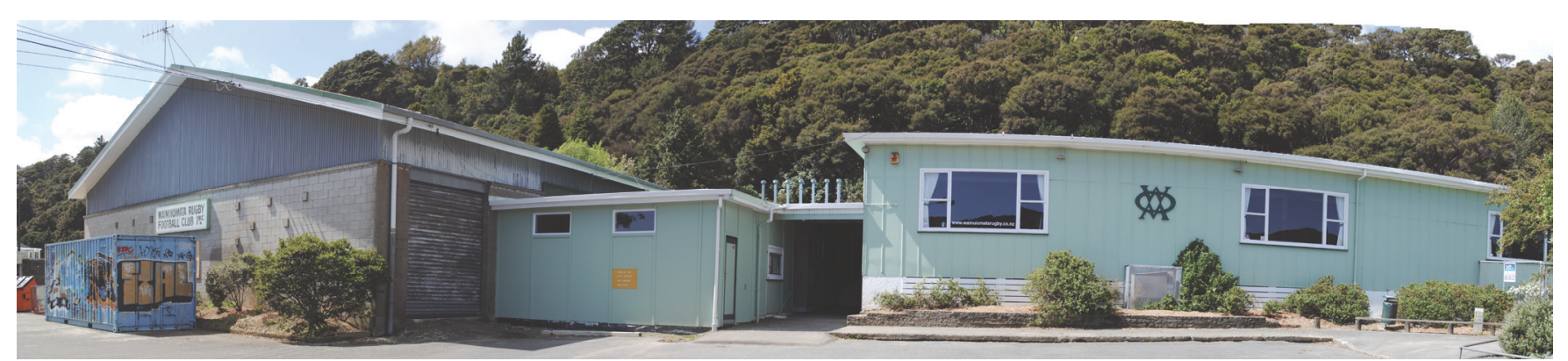

The Wainuiomata Rugby Club - Left Training Gym, Middle Changing Rooms, Right Clubrooms.
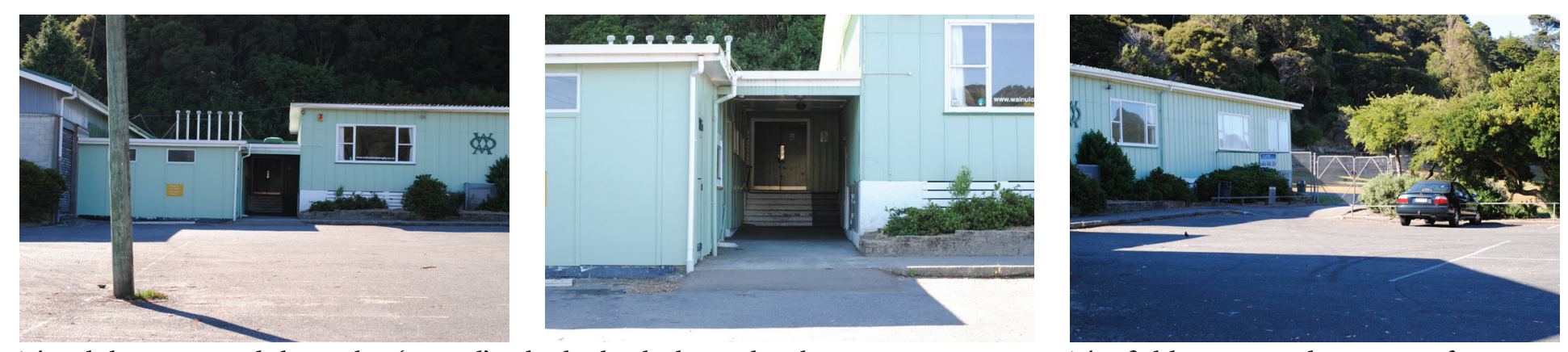

The field is accessed via a gate from

The club is accessed through a 'tunnel' which also links to the changing rooms and training gym.

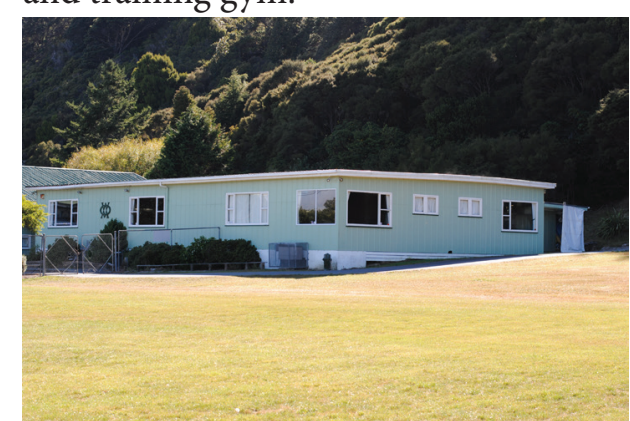

It's difficult to see into the club from outside.

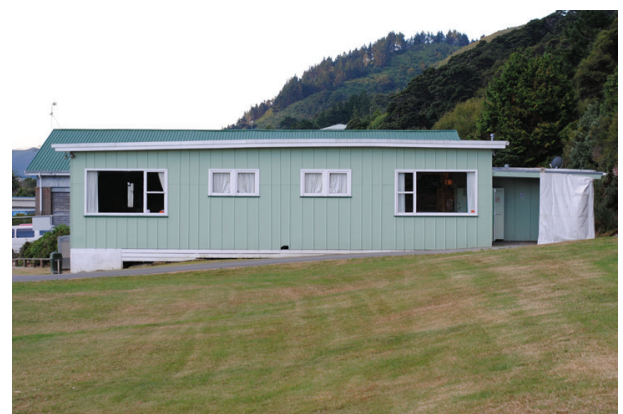

A secondary entrance opens onto the grounds.

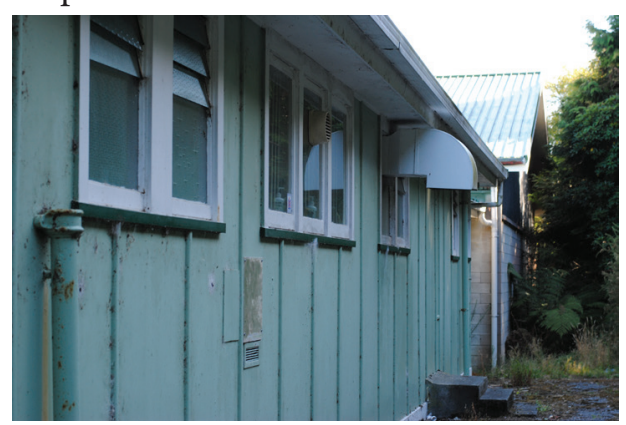

Rear of Clubrooms show signs of alterations.

\section{Above}

Figure 72: Photo Survey of External Appearance 


\section{William Jones Park}

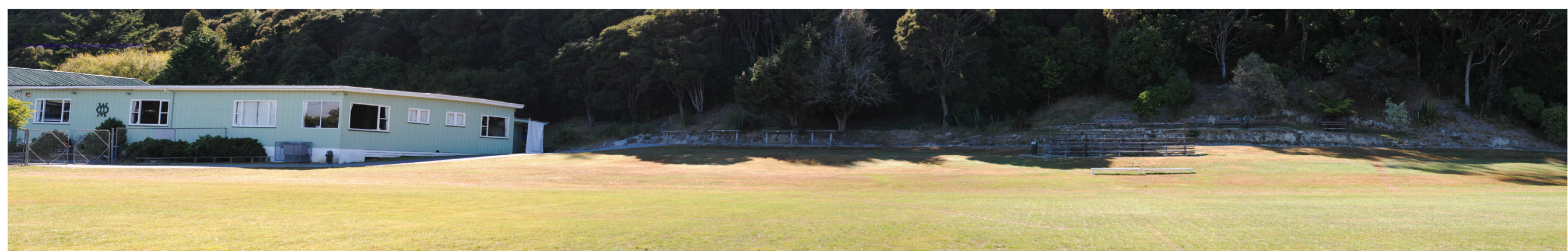

A hill adjacent to the field acts as the main viewing area spectators, It provides elevation for viewing and connects to the side entrance of the club rooms.

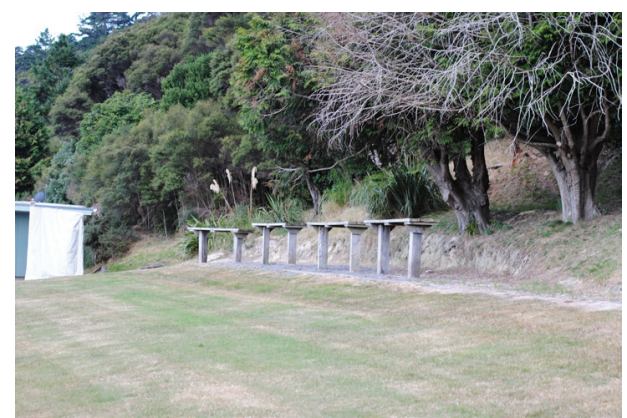

'Leaners' are positioned adjacent to the rugby club entrance.

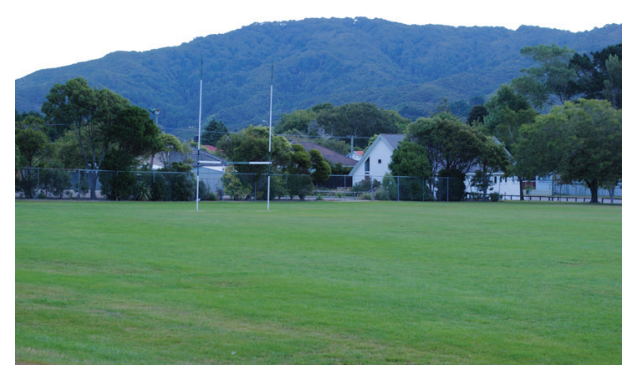

The surrounding hills provide a backdrop to the field.

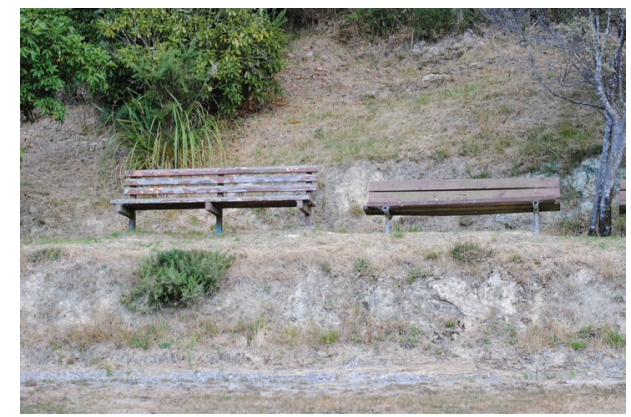

Benches are nestled into the hills.

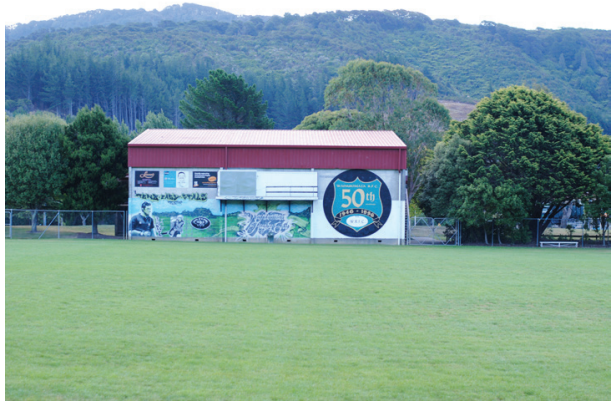

Sponsors and the scoreboard are displayed on the rear of the squash club.

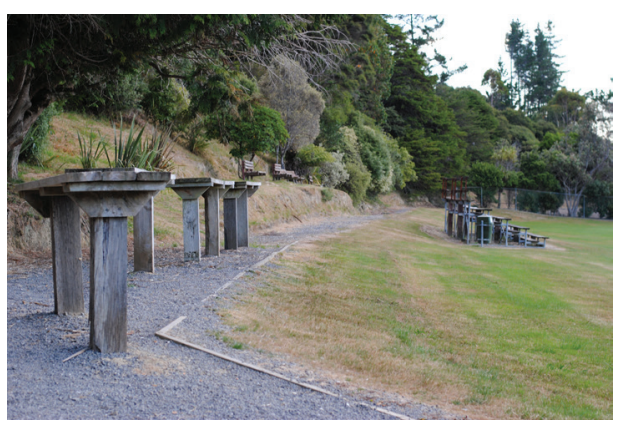

A gravel path at the top of the hill.

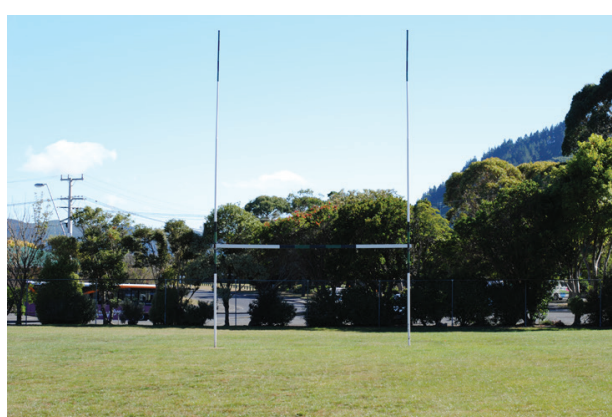

Trees shroud the field from the carparking area.

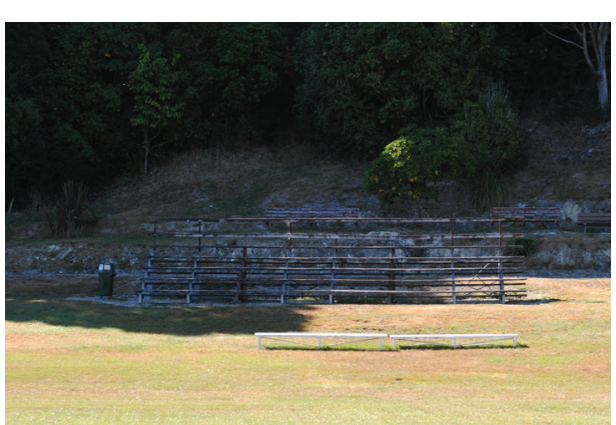

Viewing stands are placed in a central position.

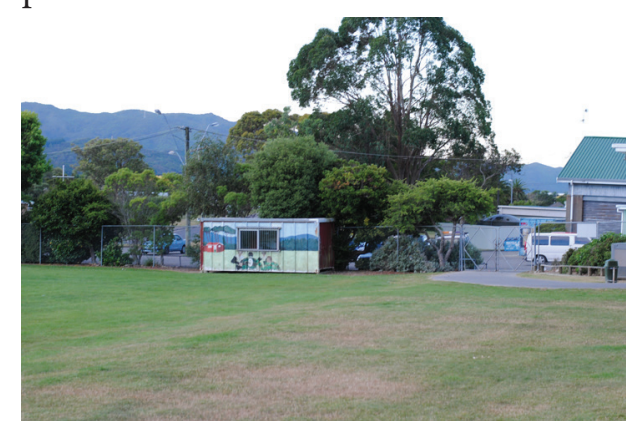

A container is used to store equipment for games and training.

Above

Figure 73: Photo Survey of the rugby grounds at William Jones Park 


\section{Internal Layout and Appearance}
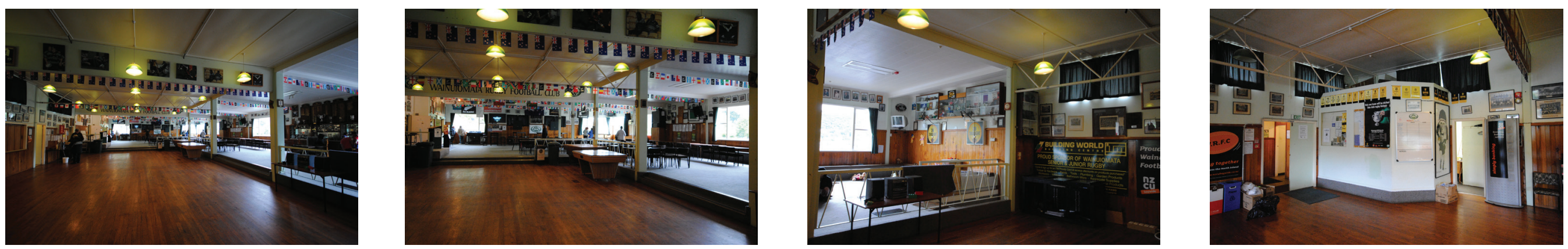

A hill adjacent to the field acts as the main viewing area spectators, It provides elevation for viewing and connects to the side entrance of the club rooms.

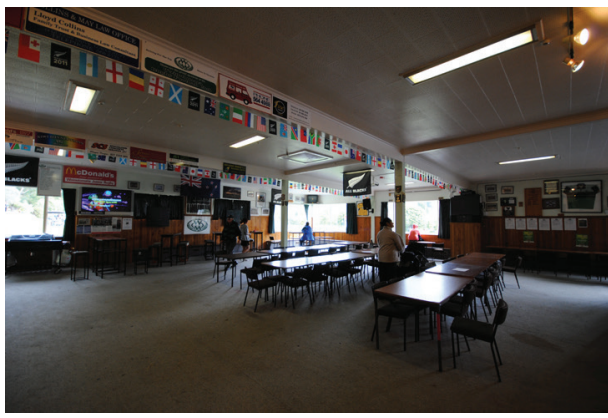

'Leaners' are positioned adjacent to the rugby club entrance.

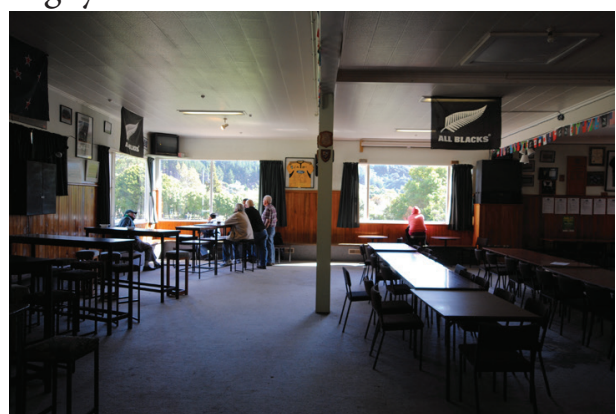

The surrounding hills provide a backdrop to the field.

Above

Figure 74: Photo Survey of the rugby grounds at William Jones Park

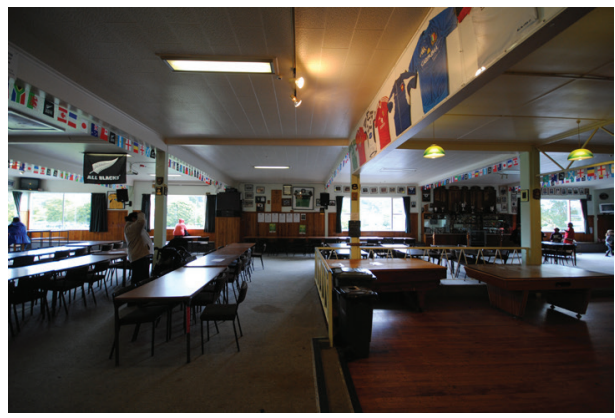

Benches are nestled into the hills.

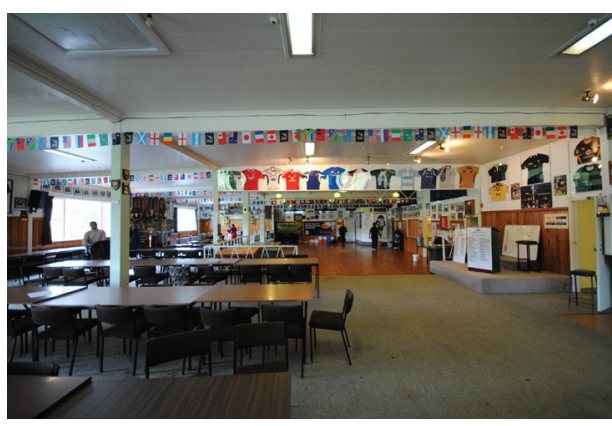

Sponsors and the scoreboard are displayed on the rear of the squash club.

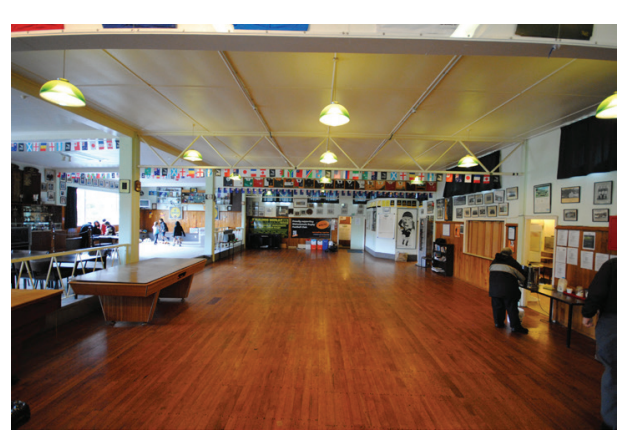

A gravel path at the top of the hill.

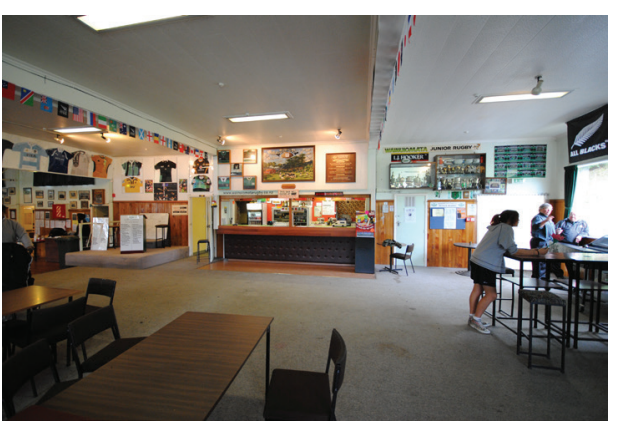

Trees shroud the field from the carparking area.

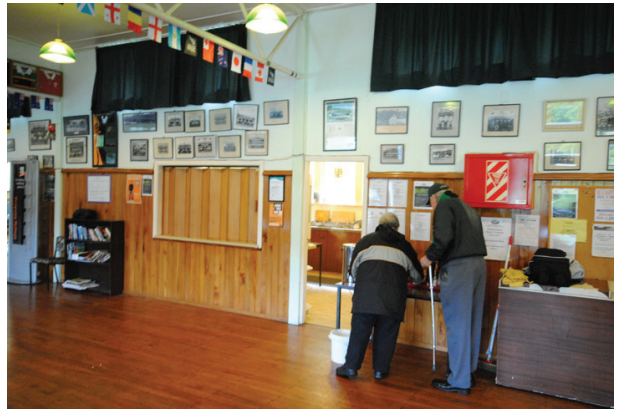

Viewing stands are placed in a central position.

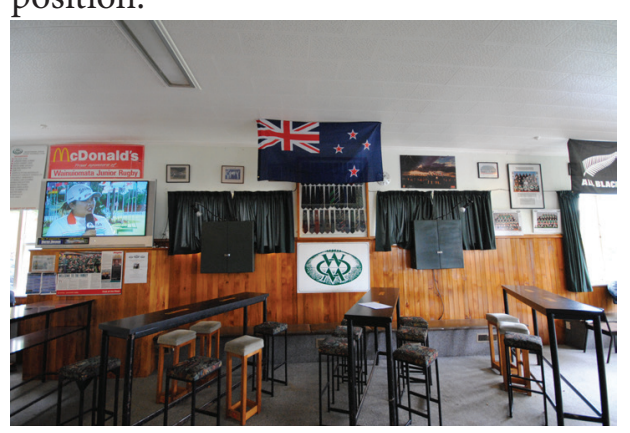

A container is used to store equipment for games and training. 
Game Day Activity In Clubrooms
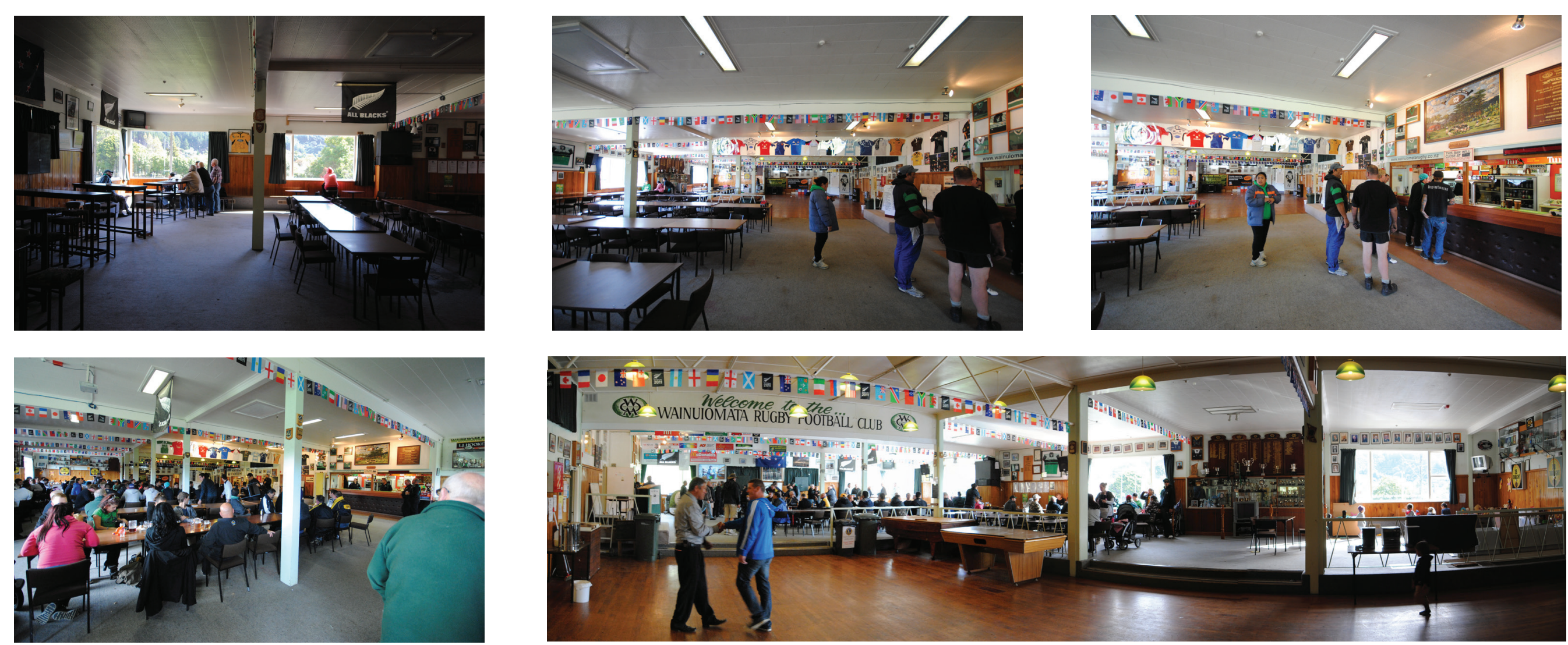

Figure 75:

Top Row: Activity during game limited to small num bers of people by the corner window, at the bar, and in the childrens area.

Middle Row: After game people are seated for announcements.

Bottow Row: Later more people arrive from other games etc.

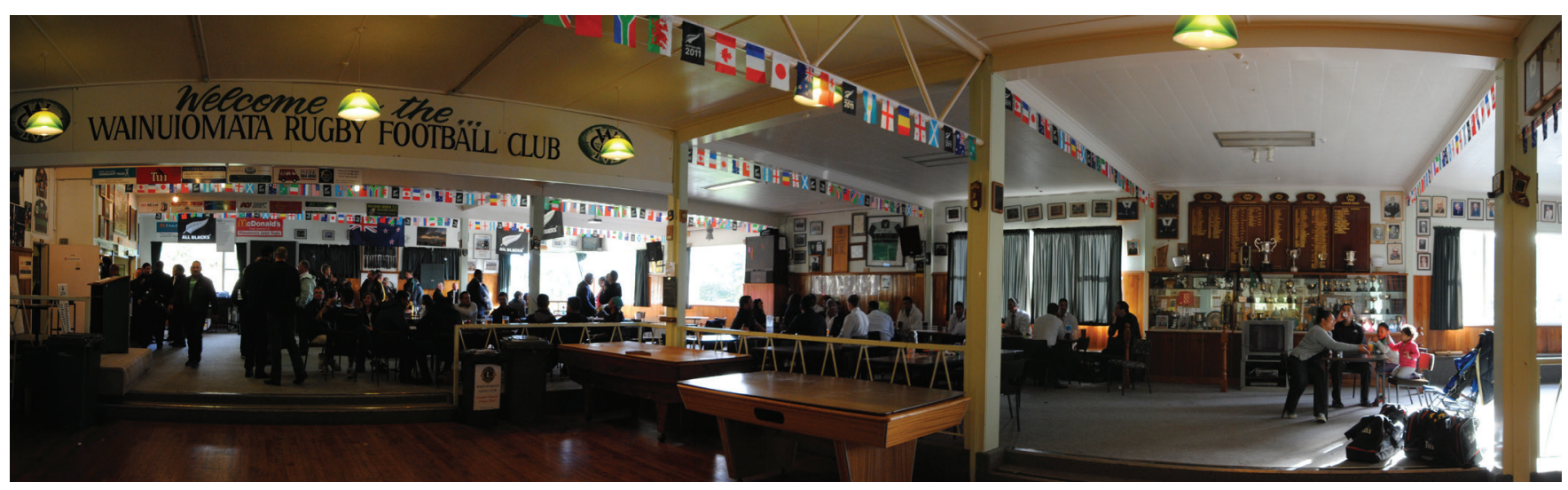




\section{Changing Layouts Of Rugby Club Rooms}

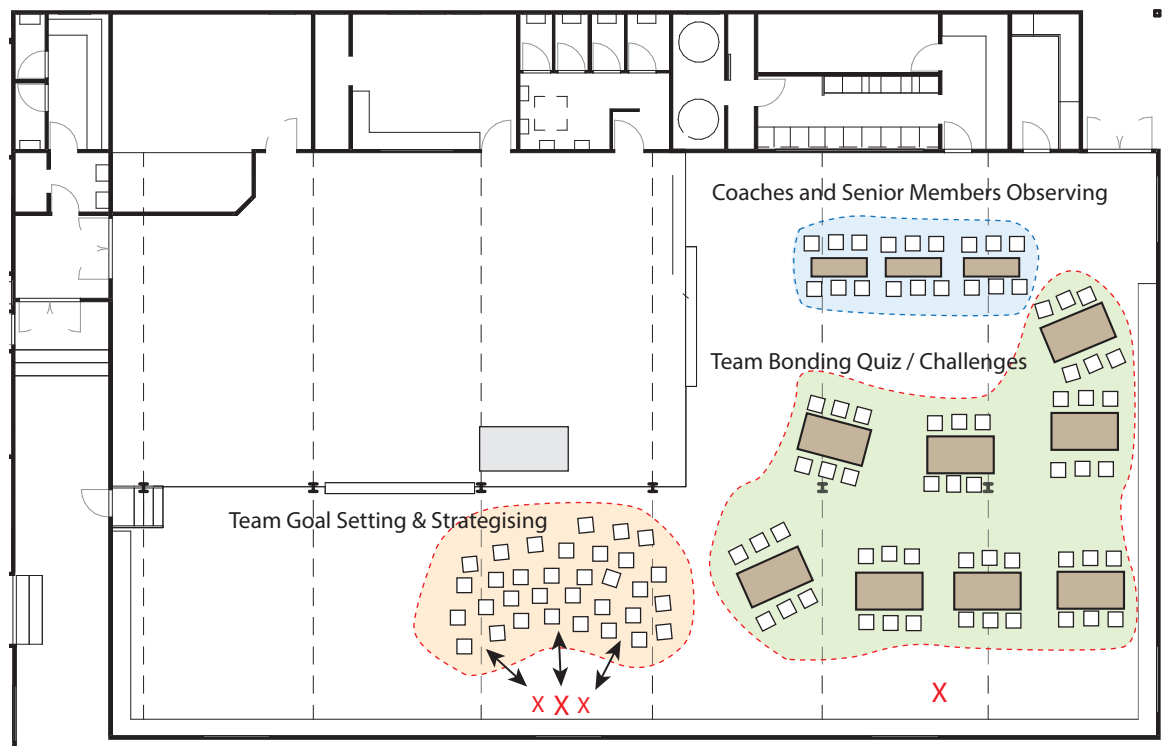

Figure 76: Senior Team 'Camp' - Informal layout of chairs and tables

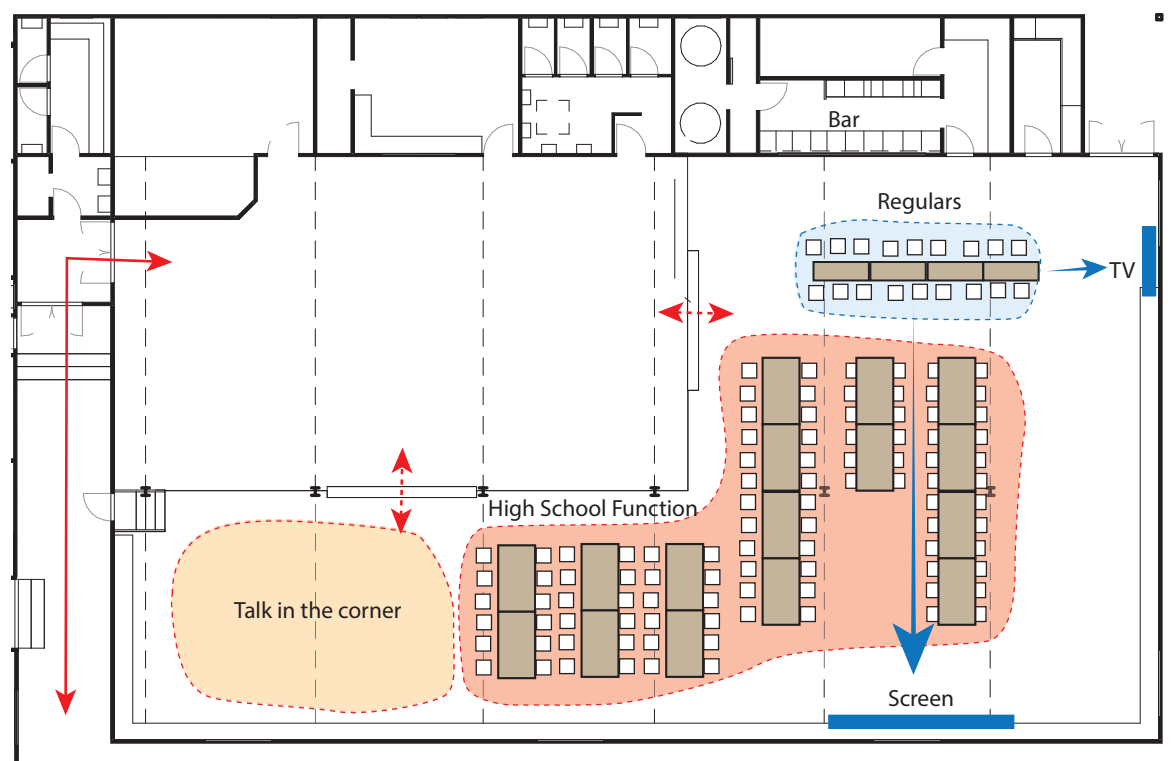

Figure 78: High School Function - Space maintained for regulars by the bar while the rest of the area is organised for highschool dinner

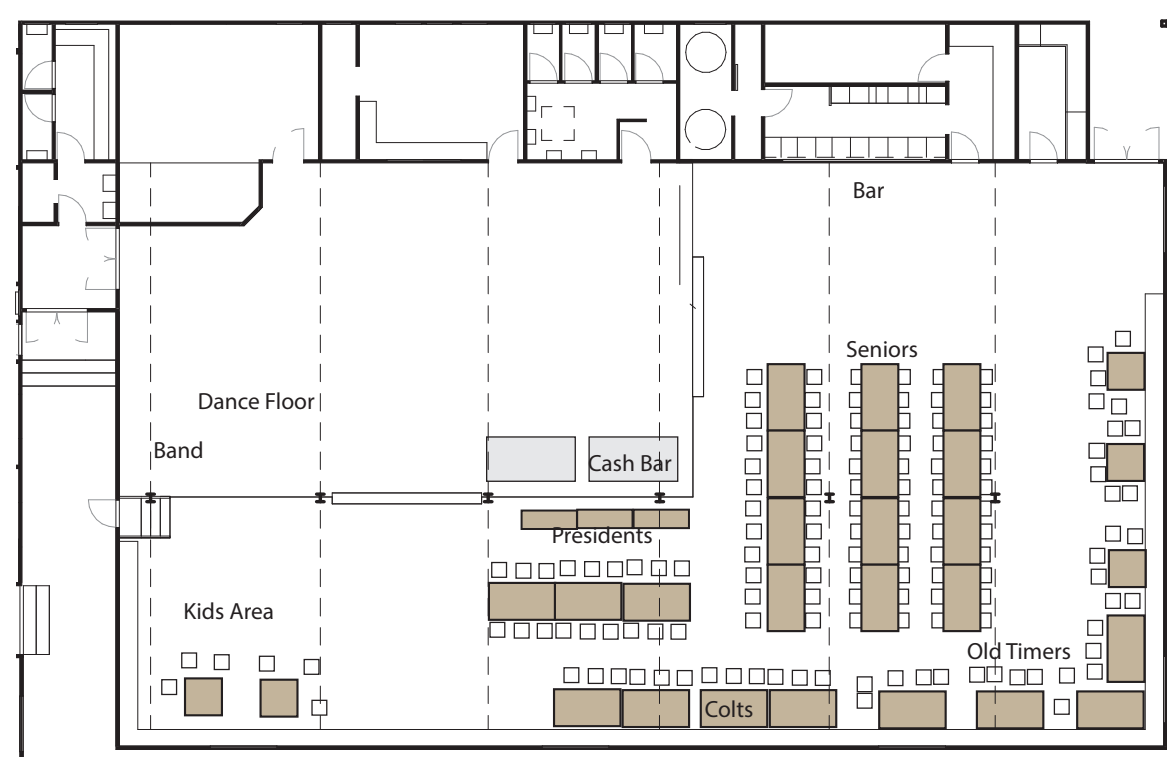

Figure 77: Old Timers Day - Dense arrangement to accomodate more people

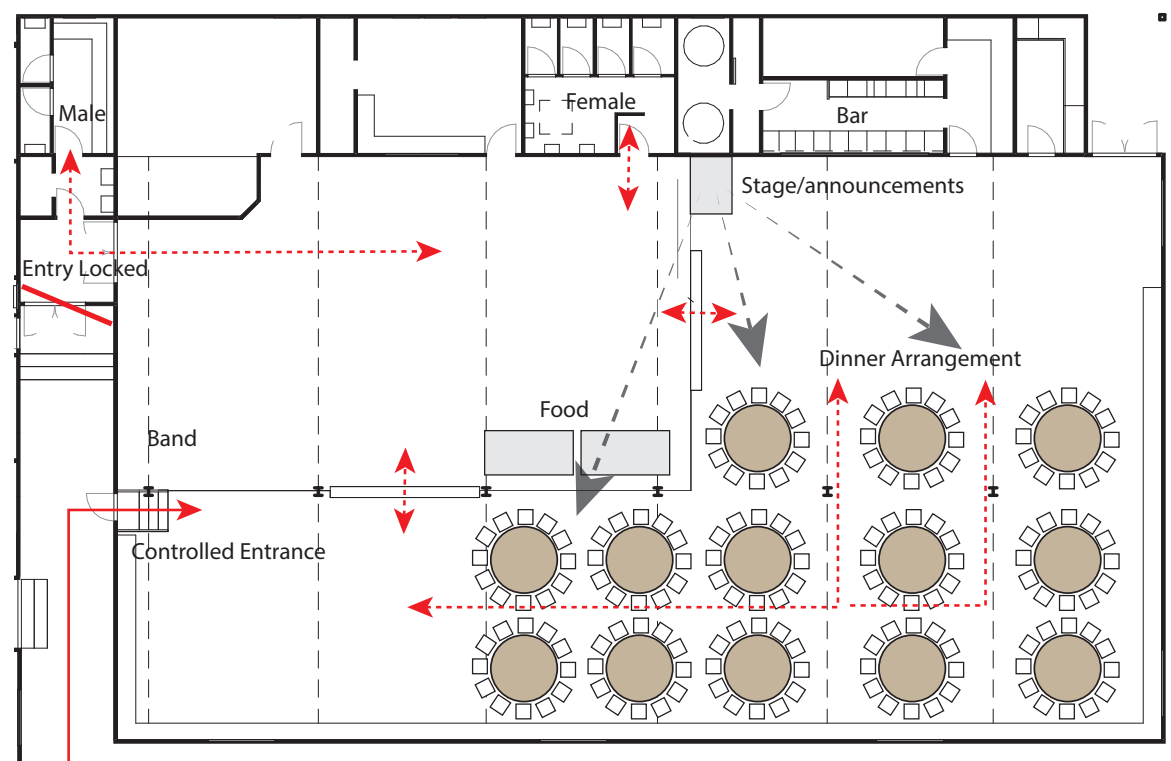

Figure 79: Senior Prize Giving - Formal Dinner Arrangement - Entrance to club controlled by bouncer 


\section{Old Timers Day Patterns Of Spatial Occupation}

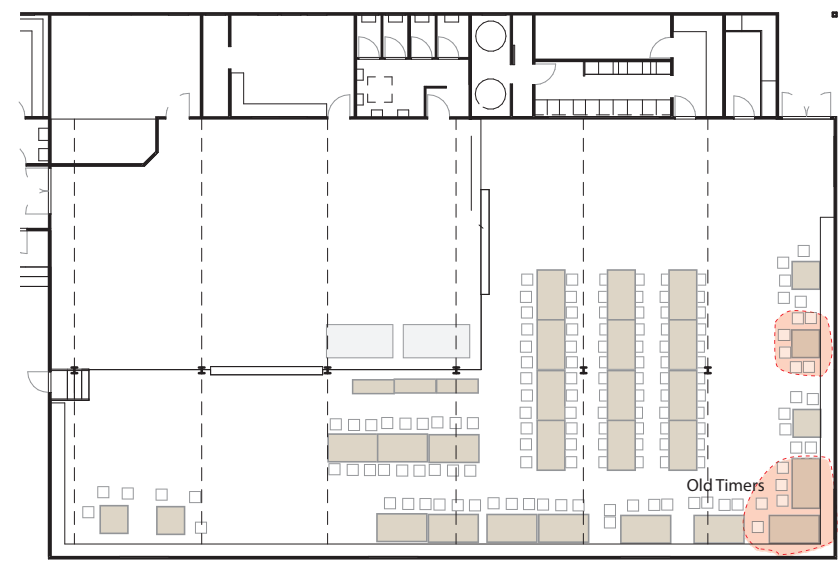

Figure 80: Before Senior 1st Game: Tables by corner windows occupied

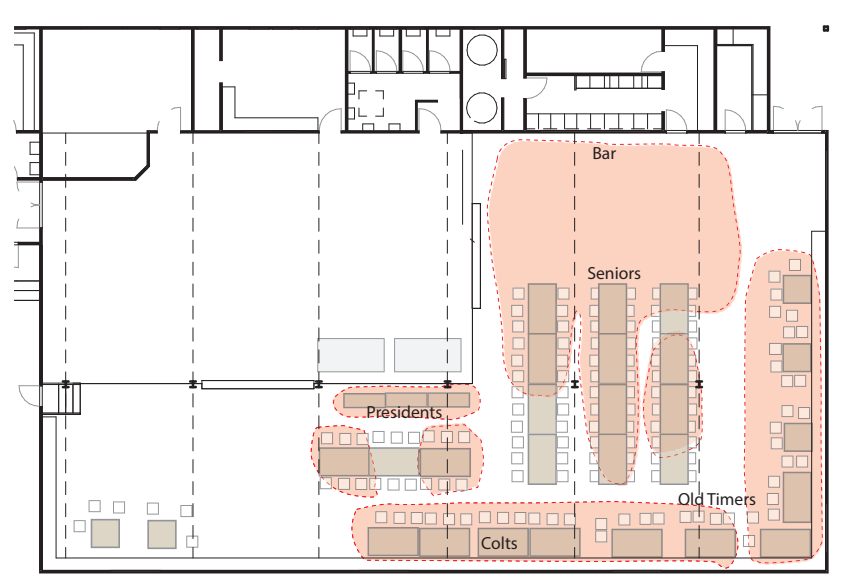

Figure 83: Seniors Players Return: Tables towards the centre begin to be used.

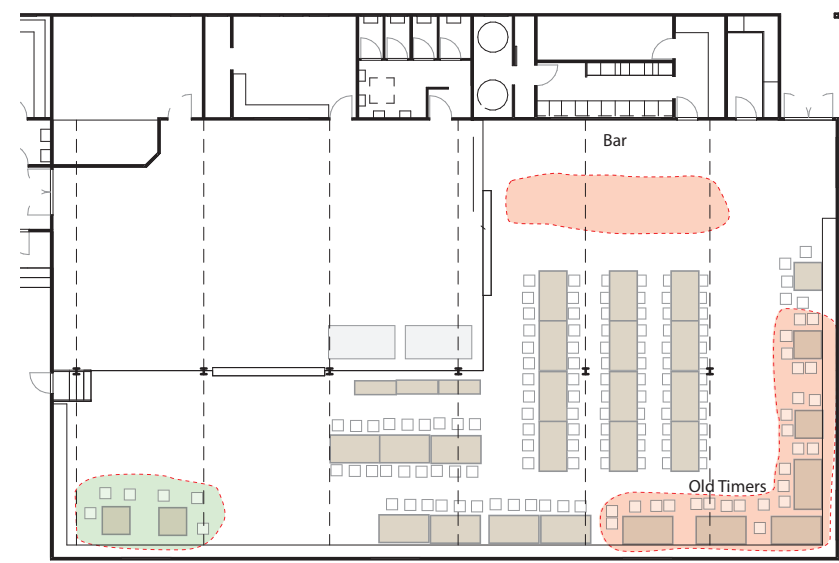

Figure 81: After Senior 1st Game: People concentrated around bar, corner windows, and childrens area

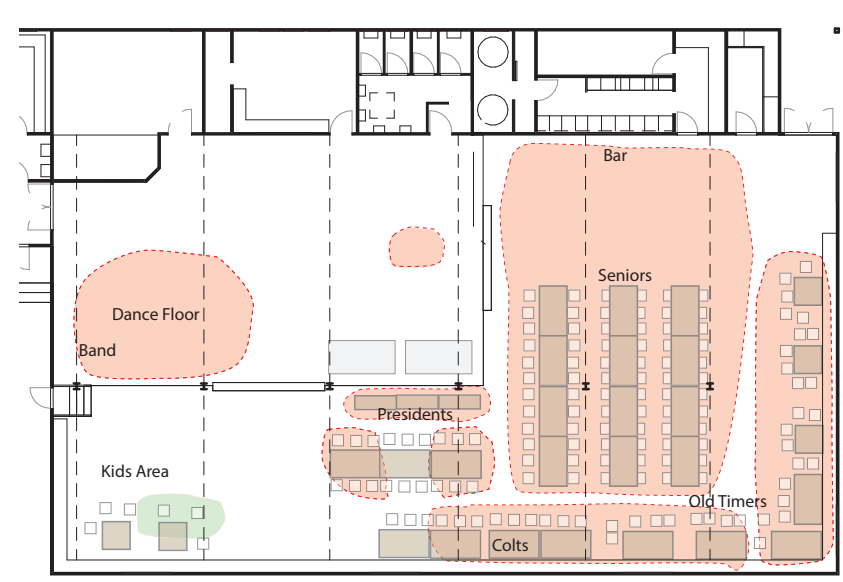

Figure 84: Later in the night: Majority of tables occupied, band playing and dance floor in use

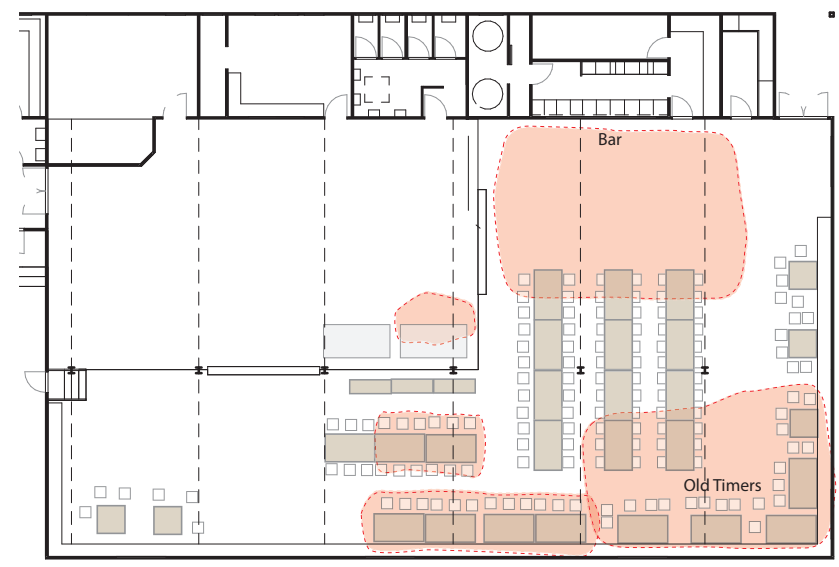

Figure 82: After Premier Game: Large amounts of people around bar, edges of seated areas occupied

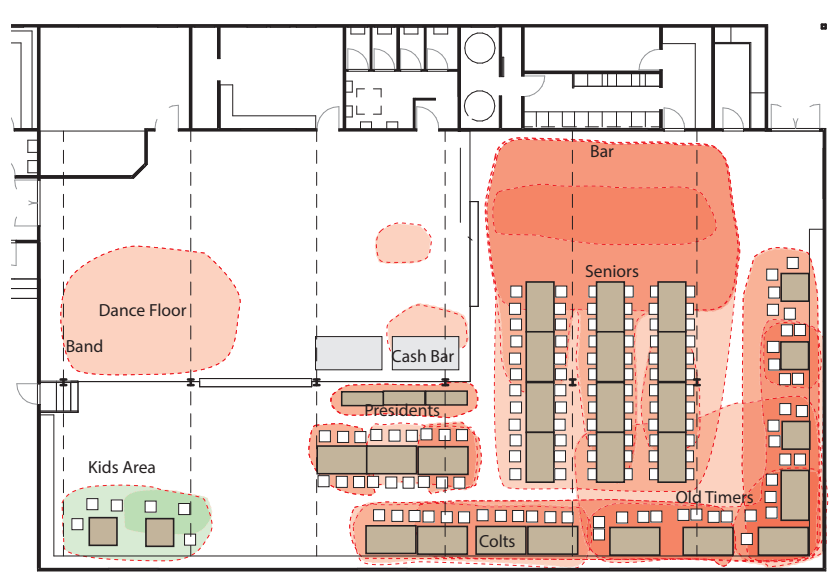

Figure 85: Density of Occupation Throughout the Day 
1950

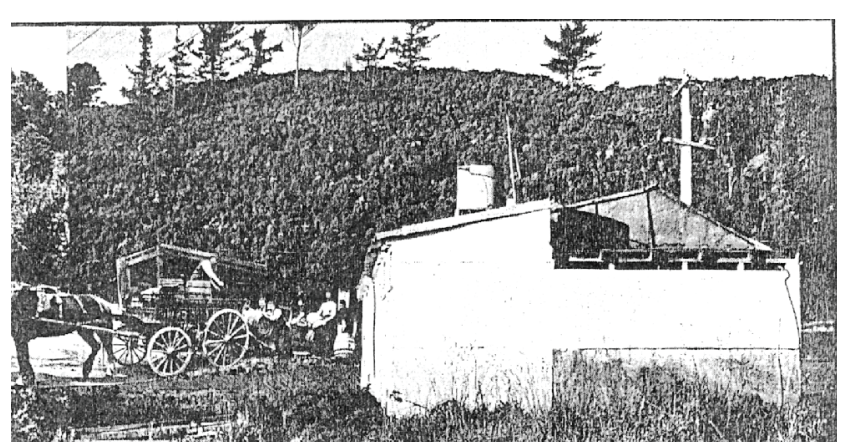

Original Clubrooms the 'Old Tin Shed' built.
Evolution of Rugby Club

1960

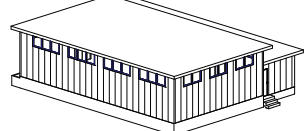

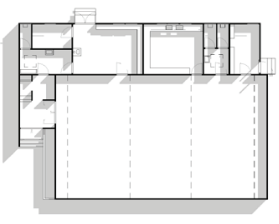

1955

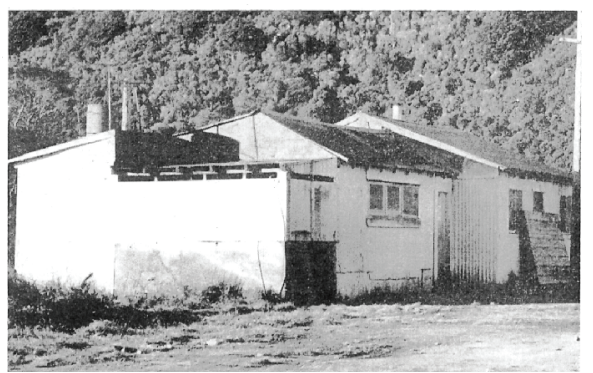

'Old Tin Shed' extended

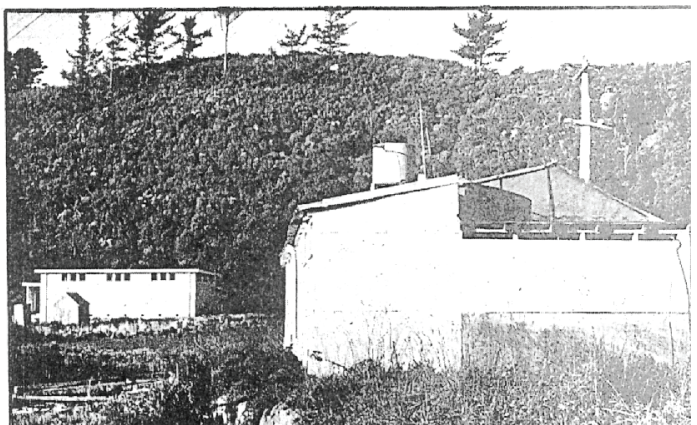

New Club Rooms built
Figure 86: Graphic Evolution of the Ruby Club (Continued page 62)

1965
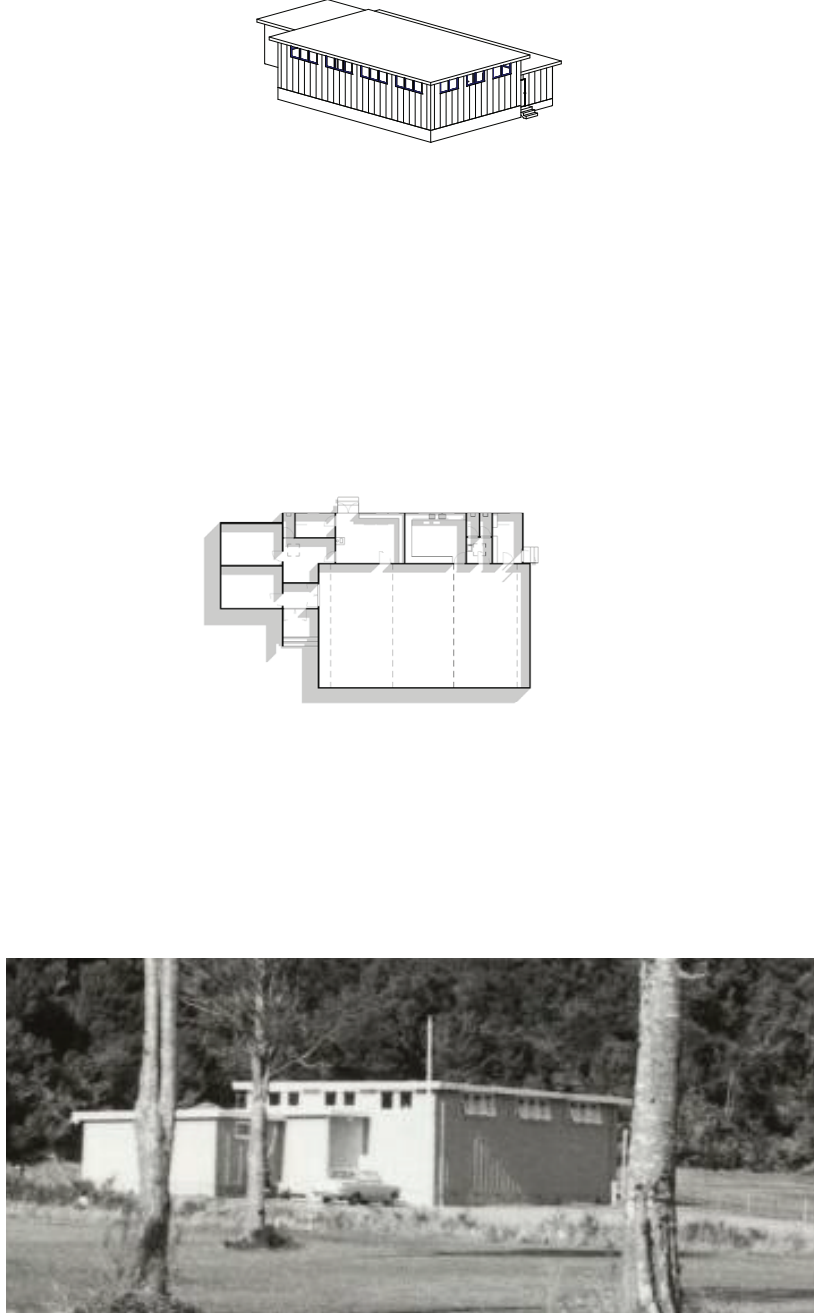

Changing Rooms Added 


\section{Evolution of Rugby Club (Continued)}

1970
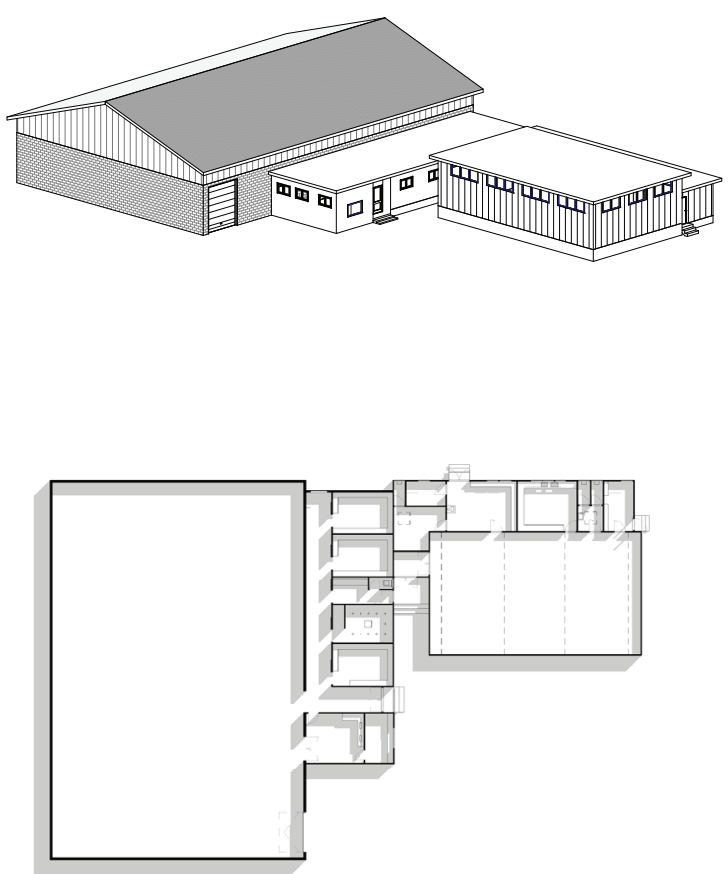

Clubrooms extended, Training Hall and additional amenities added
1970

$1977-2013$
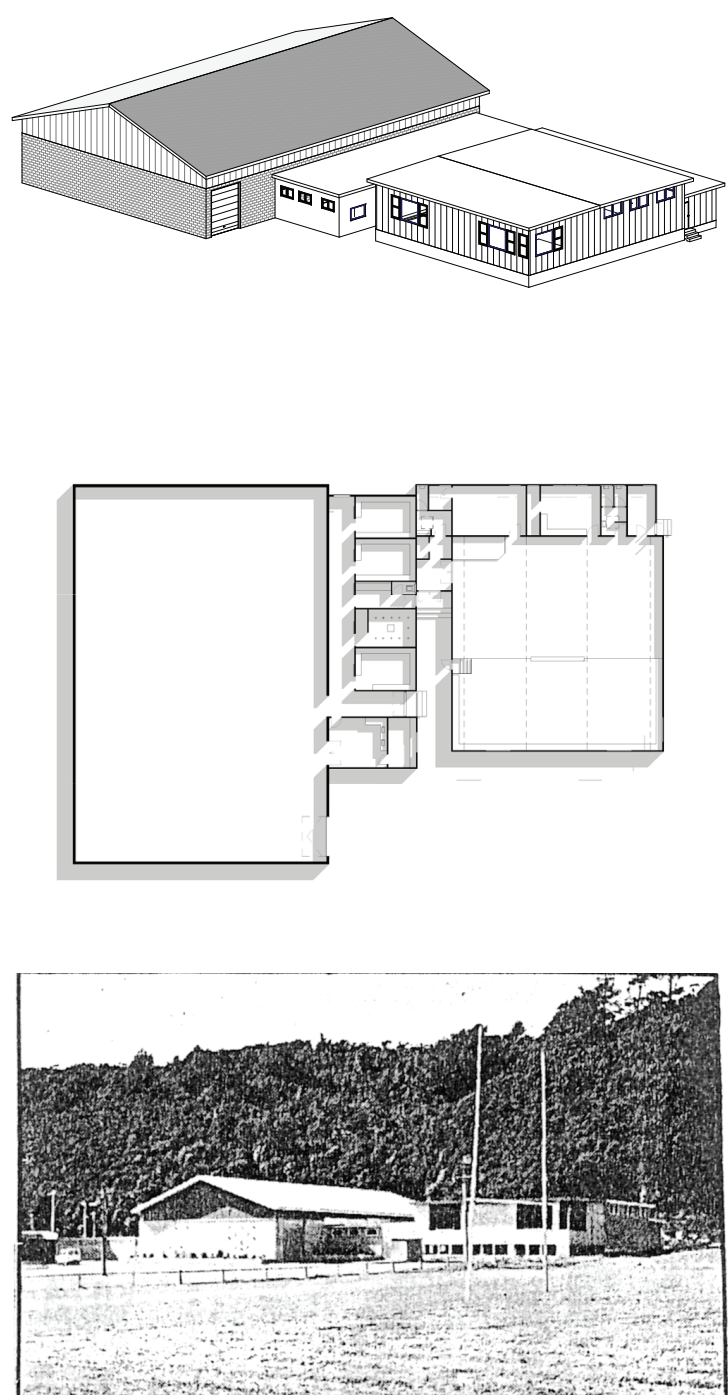

Clubrooms extended again.
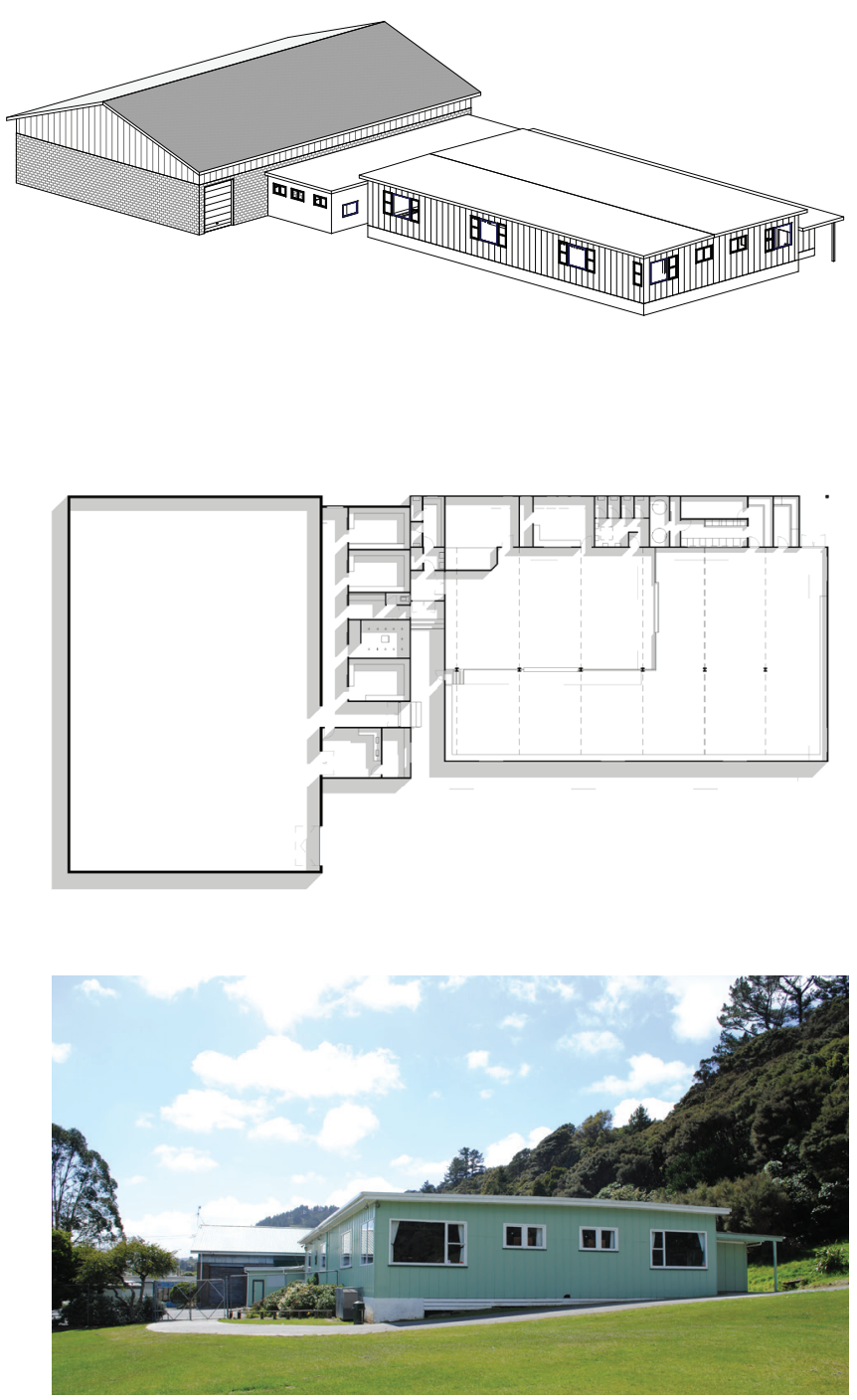

Clubrooms extended again, minor alterations to interior resulting in current layout. 


\section{Expansion of the Rugby Club Program}

1960

1965
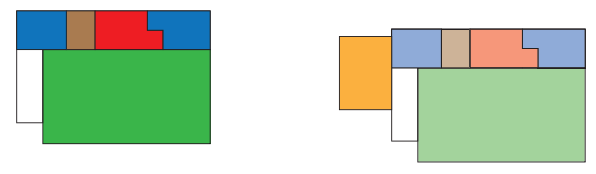

Figure 87: Expansion Of Program Over Time.

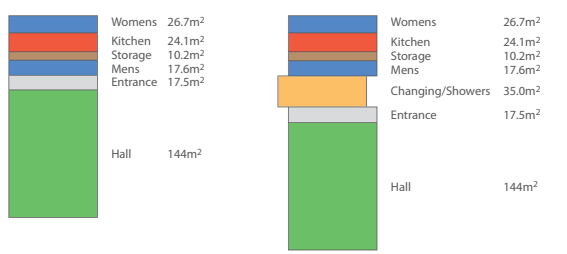

1975
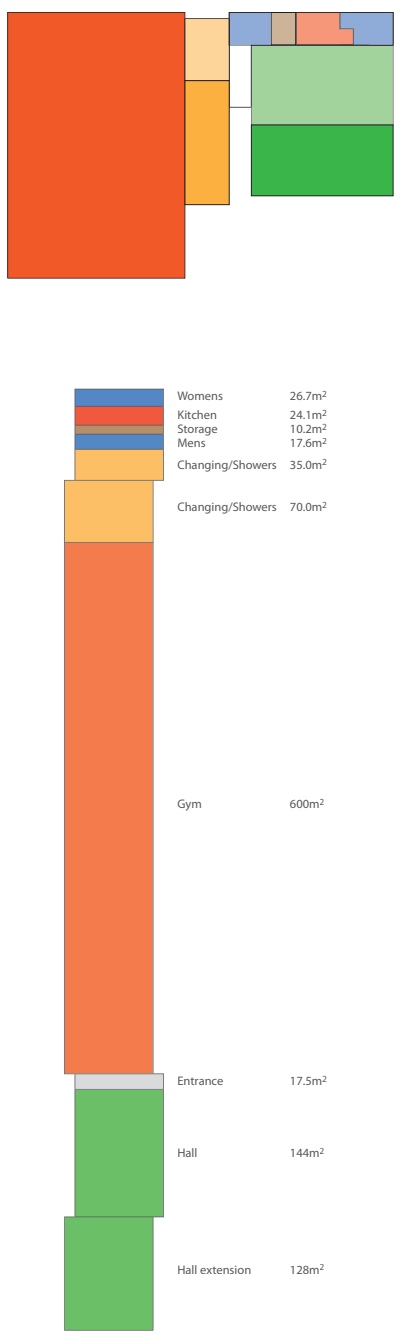

1977
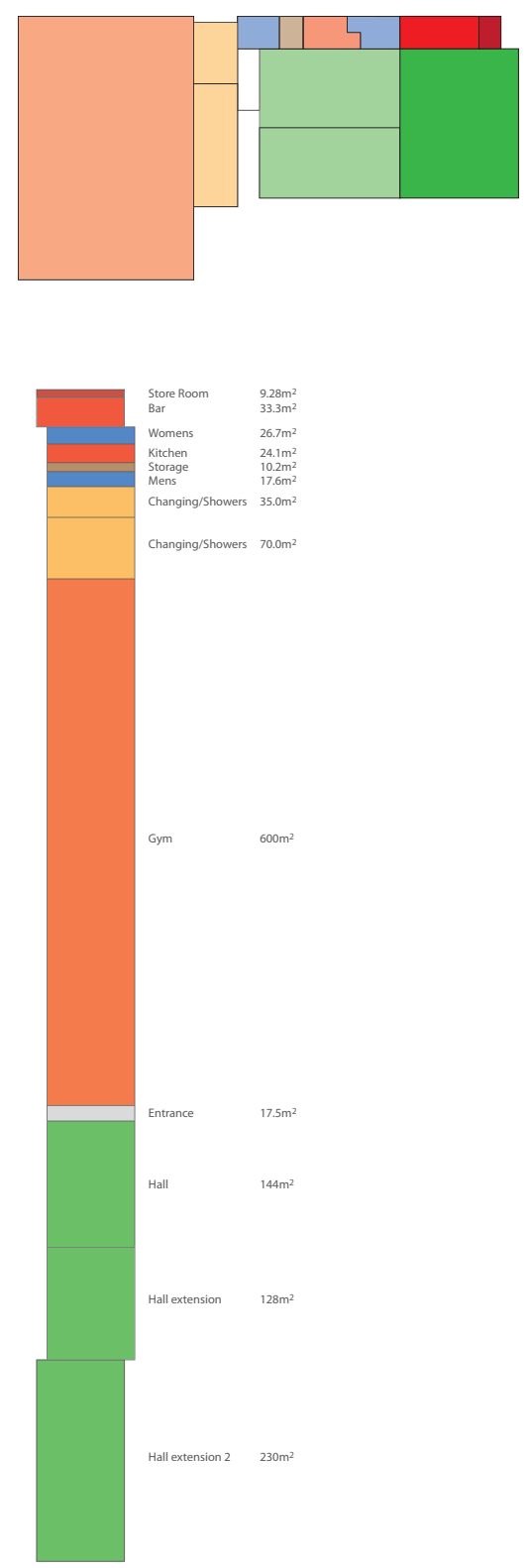

72

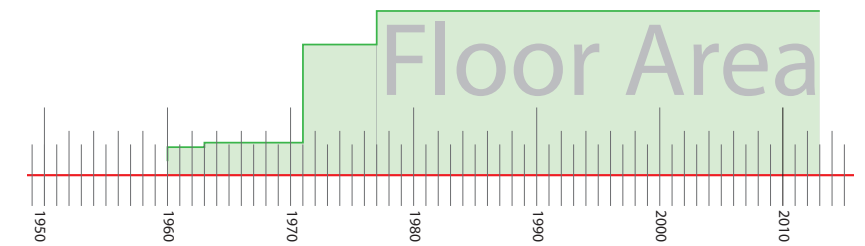

Figure 89: Rugby Club Expansion Over Time

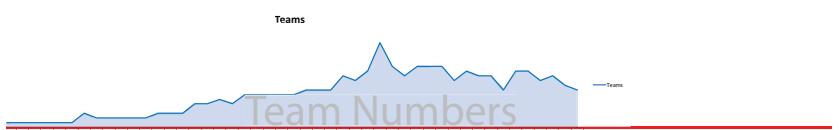

Figure 90: Growth In Team Numbers Over Time

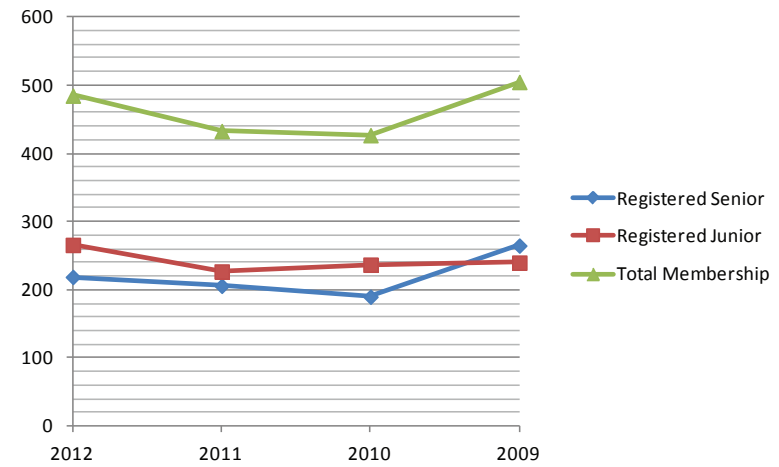

Figure 91: Registered Rugby Players 2012, 2011, 2010 \& 2009 
Views and Spectator Behaviour
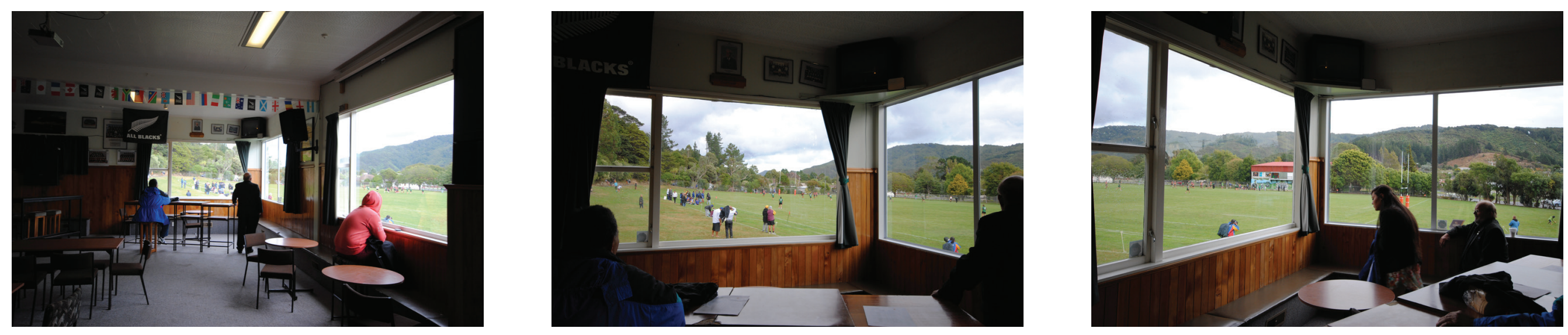

Top Row

Figure 92: Corner windows provide views of the field from within the rugby club.

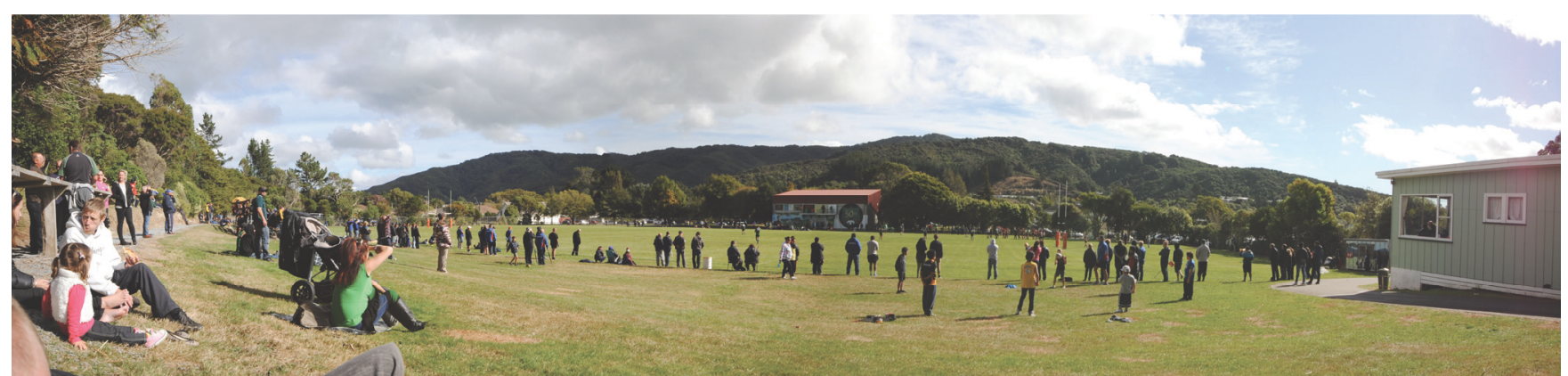

Figure 93: Typical distribution of spectators observing premier team

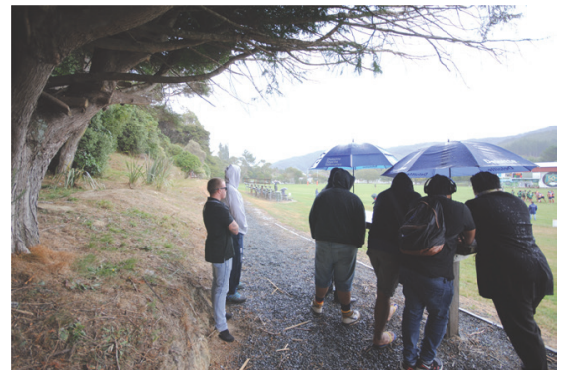

Figure 94: Trees provide natural shelter during games

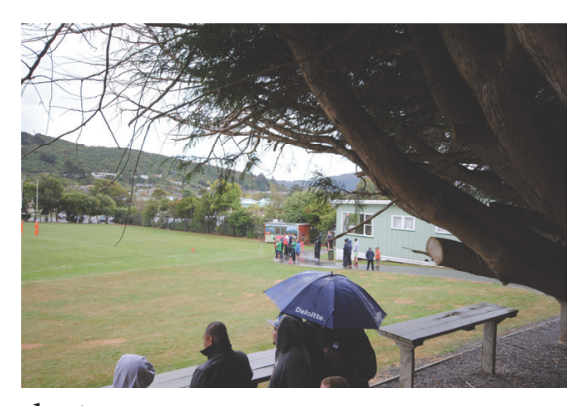

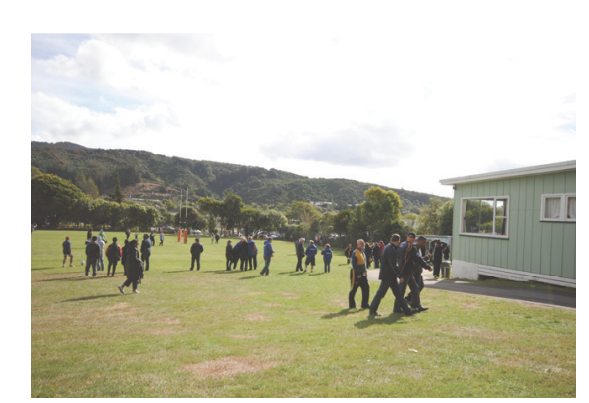

Figure 95: Post match spectator movements

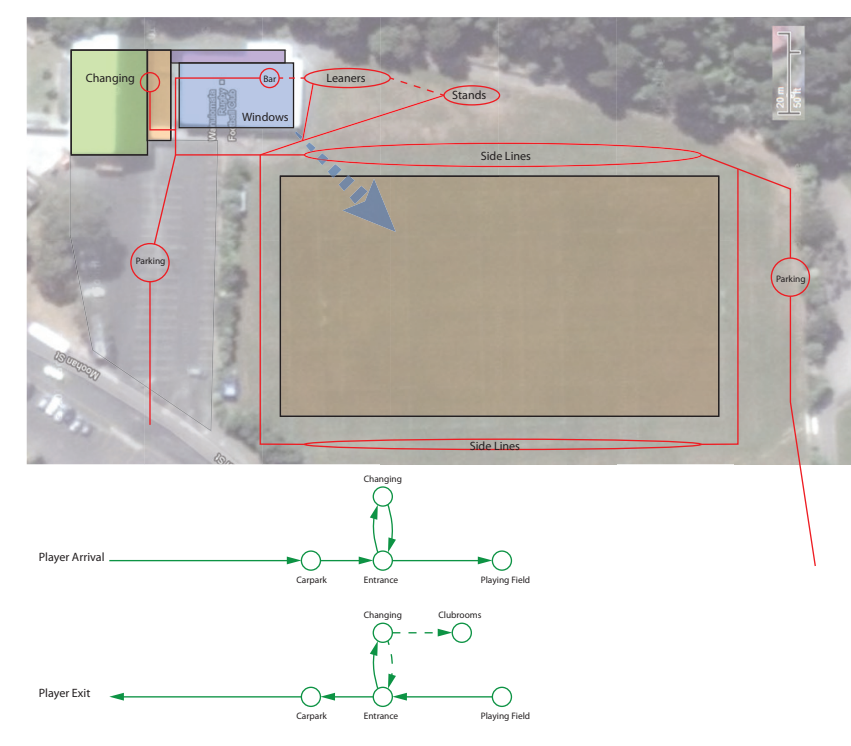

Figure 96: Diagrams of player and spectator behavior in relation to site. 



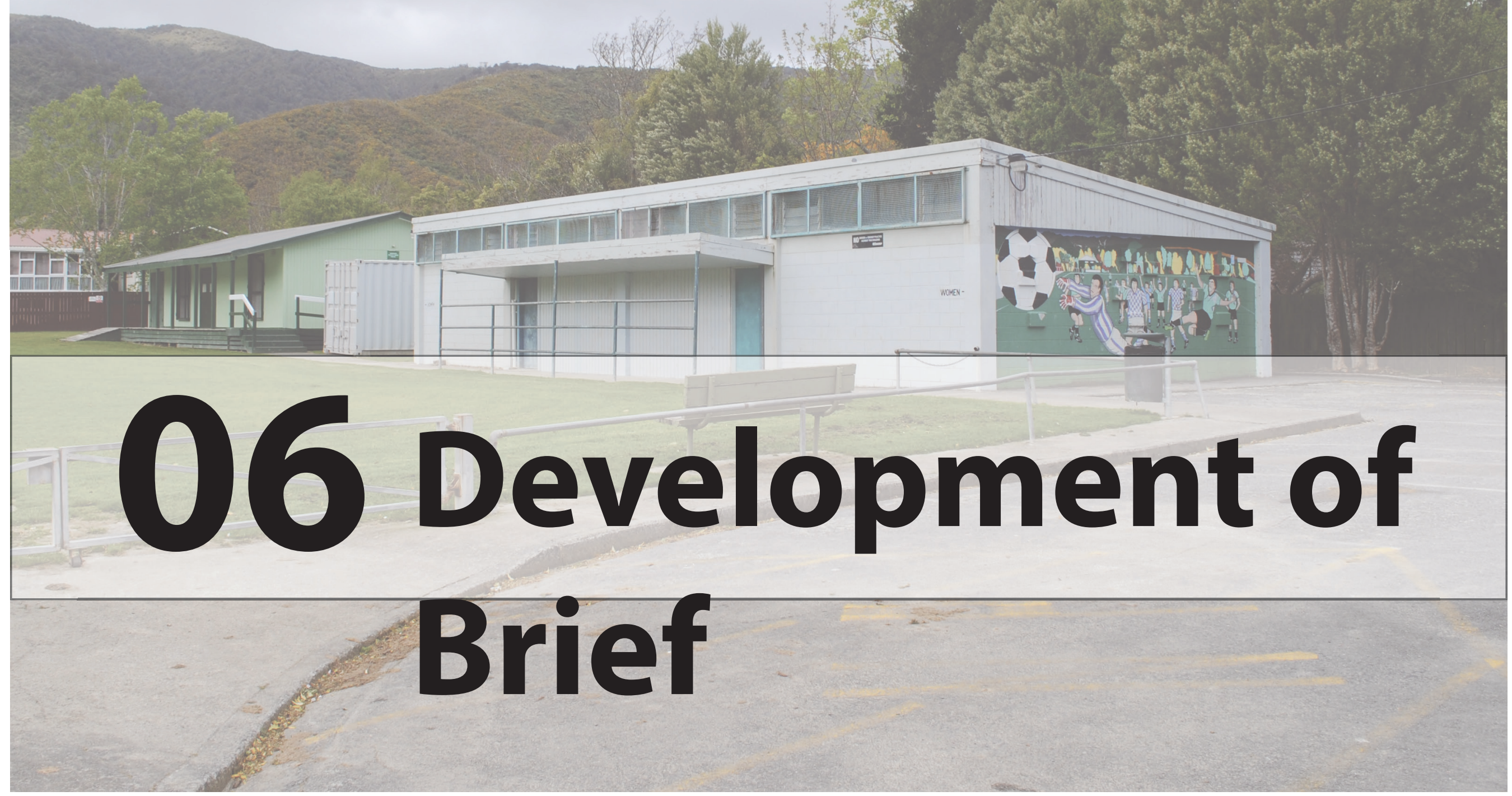


Based on the research presented in the previous chapters $5 \mathrm{a}$ and $5 \mathrm{~b}$ a brief was developed.

This chapter discusses the development of this design brief based on analysis of the sporting environment of Wainuiomata. This study revealed information about the relationships between the activities of sport, the built environment, and the local community. It also highlighted several gaps / problems with these existing relationships. Analysis of this information was used to determine the programmatic requirements of a new community sports facility in Wainuiomata. It was also used to determine how elements of program should interact to achieve a closer relationship between architecture and the sports field, and intensify the connections between sport and community.

Initially the intention was to combine the programs of a range of Wainuiomata sports clubs into a single design which would capitalise on the seasonal nature of sports to allow spaces to be shared between clubs allowing for a more efficient use of space. Additional supplementary programmes could then be introduced which would could operate at other times when clubs are unused throughout the day. Early in the research process it became clear that this strategy would not be an adequate response for a range of reasons. This research is in part a response to problems with the existing sports facilities of Wainuiomata, simply combining the existing programs of these clubs has the potential to just compound the problems facing these clubs into a single design rather than addressing them. This would also ignore the existing built environment and the connections between clubs and their individual fields of play, in short, it would assume a clean slate. The focus of this research was shifted, as a response to these revelations, to use an analysis of the existing sporting environment and its relationship to the community to closely inform the design of a sports facility which intensifies these social connections. This analysis, summarised earlier in chapters $5 a \& 5 b$, revealed a number of 'gaps' in the existing environment which could be addressed through an architectural design. These include:

- A shortage of all weather facilities for training and games, leading to cancelations and restricted use during poor weather. An artificial turf in Wainuiomata would allow games to be played in any weather and allow more intensive use.

- Poor visual connection into the club room (public appearance) and between the clubroom and the field of play

- Increased scrutiny concerning the consumption of alcohol outside of clubrooms.

- Reduced numbers of people returning to the clubroom after the match

- Sports clubrooms are unoccupied during the day for most of the week, there is a potential for them to be used for other activities during this time.

- A low level of qualifications and study participation in the existing community. There are currently no tertiary education providers within the valley to address this issue. An educational facility would bring activity during the day.

- Proposed development which will significantly increase the local population, increasing the demand for community spaces.
As a response to these gaps a brief for the project was developed for a sports facility which, instead of replacing the existing clubs, provides alternative all weather facilities for training and playing games which can be used by a range of groups. This would supplement existing sports clubs and also provide an environment to host and foster the growth of new sports clubs. To counter the lack of activity during the day in traditional sports facilities this program is integrated with that of a tertiary education campus, with a focus on developing skills related to the activities / performance of sport. This facility helps to address the low level of qualifications in Wainuiomata by providing a link between education and sporting activity, making participation in higher education more accessible and appealing to the local community. This facility would provide additional benefits to local business and the wider community by attracting people from neighbouring areas to Wainuiomata and encouraging increased activity throughout the day.

In addition to programmatic requirements several requirements of performance for the building were developed as a response to observations of the current environment. The building needs to:

- Encourage people to use and socialise within the clubroom / social area.

- $\quad$ Establish a strong relationship between sports facility and the wider community.

- Prioritise a strong visual connection between social 'clubroom' space and the sports field, establishing a controlled environment for the sale and consumption of alcohol, which has a good visual connection to sporting activities. 
A general program for this facility was developed through reference to the book 'Neufert Architects' Data' and through analysis of a similar project in Otaki, Nga PuraPura by Tennent + Brown Architects, as well as a number of local case studies16. The spatial requirements of Nga PuraPura were used to provide a realistic starting point, these were the then adjusted to take into account differences in population between Wainuiomata and Otaki, as discussed in chapter 3 . This program was then adjusted to suit the specifics of this project. The sizes of educational spaces were based on an estimated population of between 17300 and 23000 for Wainuiomata in 2031 which would give an estimated 250 to 400 students(Neufert \& Neufert, 2000).

\section{Project Brief}

The brief developed for a Community sport and Education centre in Wainuiomata, specifying elements of program and an estimate of spatial requirements, is outlined below.

\section{Program}

\section{Workout $420 \mathrm{~m} 2$ total}

Resistance Training (Weights Room) 245m2 3m clear room height

\section{Cardio/Fitness $175 \mathrm{~m} 2$}

Showers, Changing and WC 100m2

16 These include designs for Nga Purapura, Fraser Park Sportsville Redevelopment, Walter Nash Stadium, ASB Indoor Sports Centre, Wainuiomata Ruby Football Club, Wainuiomata Rugby League Club.
Recovery $51 \mathrm{~m} 2$ total

Hot-Cold Room (4.8m x 3.5m) 17m2

Hot Spa (6-7 person spa pool) $230 \mathrm{~cm} \times 230 \mathrm{~cm} \times$ $106 \mathrm{~cm}$

Cryotherapy Pool $150 \mathrm{~cm}$ x $200 \mathrm{~cm}$

Massage / Physio Room (3.5m x 4m) 14m2

Recovery Lounge (5m x 4m) 20m2

\section{General Teaching 650m2 total}

A mix of General $50-60 m 2$ and Small $40-50 m 2$ classrooms

1x Computer Lab

\section{Lecture \& Seminar $355 \mathrm{~m} 2$ total}

Lecture

200 seat Lecture Theatre $180 \mathrm{~m} 2$

Ancillary Spaces 75 m2 (30m2 WC)

- Seminar

- Seminar Room $2 \mathrm{~m} 2$ seat 50 seats $-100 \mathrm{~m} 2$

Library $360 \mathrm{~m} 2$

Shelf Space $(10 \mathrm{~m} \times 18 \mathrm{~m}) 180 \mathrm{~m} 2$

Reading \& Checkout Spaces (10m x 18m) 180m2

Seminar $100 \mathrm{~m} 2$
Plant 270m2

Offices \& Admin $350 \mathrm{~m} 2$

Staff Room 85m2

- Meeting Spaces

- Administration

- $\quad$ Offices $12 \mathrm{~m} 2$

\section{Indoor Sport/Training 3080m2}

Indoor Court (40m x 70m) 28000m2 - Multiuse with provisions for the following layouts:

4 Netball / Basketball Courts (for training)

2 Netball / Basketball Courts (for games)

Retractable Seating for 400 people

Ancillary Spaces $280 \mathrm{~m} 2$

Entrance Area 45m2

$4 x$ Changing Rooms (2 for each game court) $80 \mathrm{~m} 2$

- $4 x$ Shower Rooms $60 \mathrm{~m} 2$

- $\quad$ Toilets 1 per changing room \& 1 male 1 female by entrance

- 2 Instructors rooms (12m2 each) $24 \mathrm{~m} 2$

- $\quad$ Equipment room (3m depth) $60 \mathrm{~m} 2$

- $\quad$ Cleaning Equipment Room 5m2

- $\quad$ Caretakers Room 10m2 
Viewing Platform

\section{Outdoor Sport/Training}

1 Main Artificial Field for Football

Spectator Stands

Additional Fields for Training

Changing Rooms

Storage $30 \mathrm{~m} 2$ per field

Atrium $700 \mathrm{~m} 2$

- Entrance

- $\quad$ Atrium Space

- Reception

- $\quad$ Cafe

Clubrooms/Social Space total $870 \mathrm{~m} 2$ - round to 900m2

- $\quad$ Clubrooms/social space need to be flexible and able to support a wide range of groups and events of different sizes. Social spaces also need to have a good visual connection with the field and the wider community.

Social and event space $16 \times 30 \mathrm{~m} 480 \mathrm{~m} 2$

Storage ( $2 \times 4$ at rugby club) $10 \times 20 \mathrm{~m} 200 \mathrm{~m} 2$

Toilets $50 \mathrm{~m} 2$

Office $40 \mathrm{~m} 2$
Kitchen/Bar 100m2

\section{Parking $5000 \mathrm{~m} 2$}

Parking area for 250 cars $5000 \mathrm{~m}^{17}$

Conclusion

The brief outlined in this chapter is developed based upon earlier analysis of the sporting environment of Wainuiomata. It responds to observed relationships, gaps and problems in the existing environment.

These issues, as well as local precedents were used

to determine programmatic requirements and to

inform how elements of program should interact to achieve a closer relationship between architecture and the sports field, and intensify the connections between sport and community.

17 Wise Park currently has approximately $5400 \mathrm{~m} 2$ of car parking which is filled when there are games on. Additional facilities will increase this demand during peak periods. 




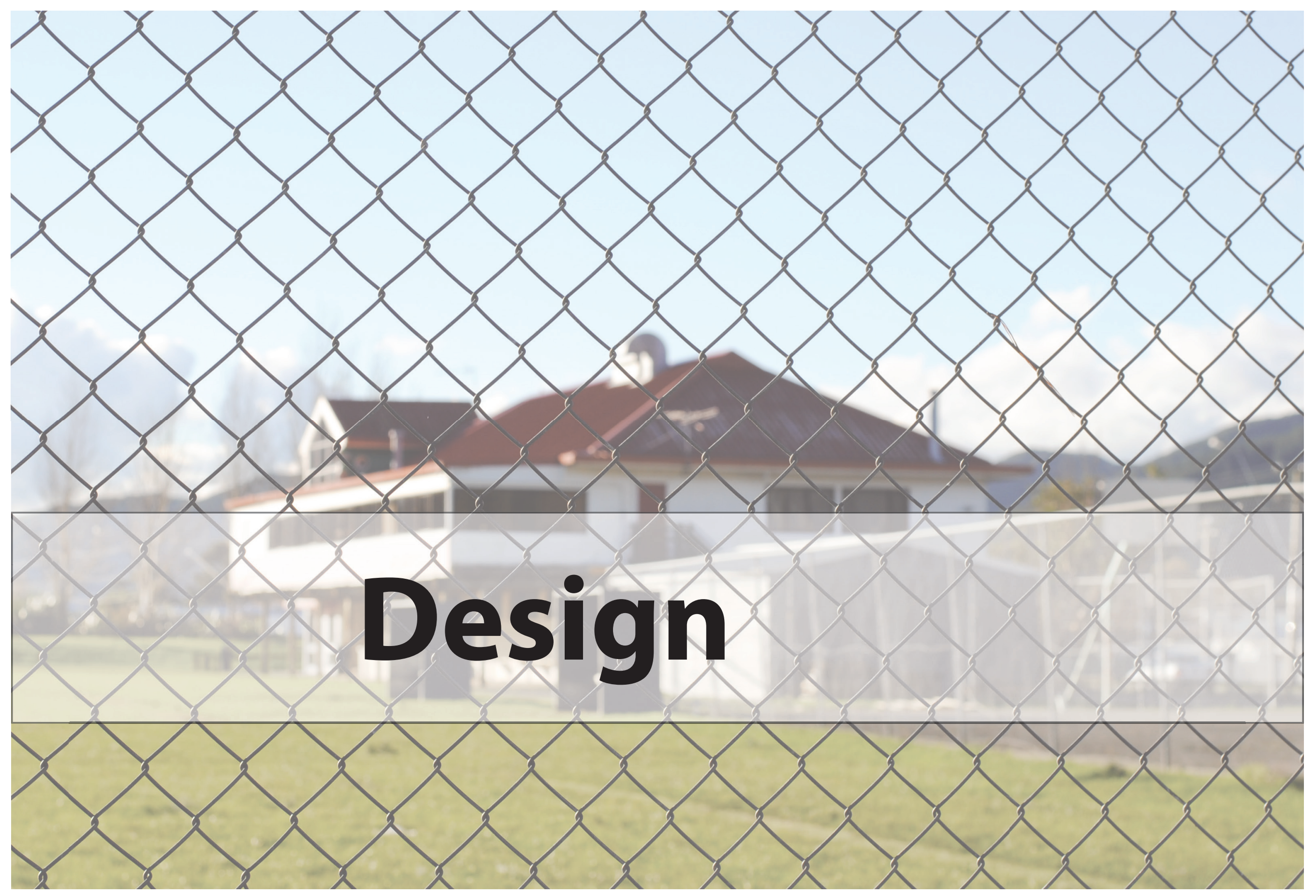





\section{Design}

This chapter describes the 'research through design' process and the results of the design research.

This section is broken into four parts:

\section{Initial design trials}

This part descibes initial design trials which were developed as a response to observed conditions in the existing Wainuoimata sports environment.

\section{Site Analysis of Wise Park}

This part discusses the existing conditions of the site chosen for design iterations through images and text

\section{Design Development}

This part discusses the design at various stages of development and reasoning behind changes.

\section{Developed Design}

This part describes the final design through images and text, ending with discussion and reflection on the research process undertaken. 



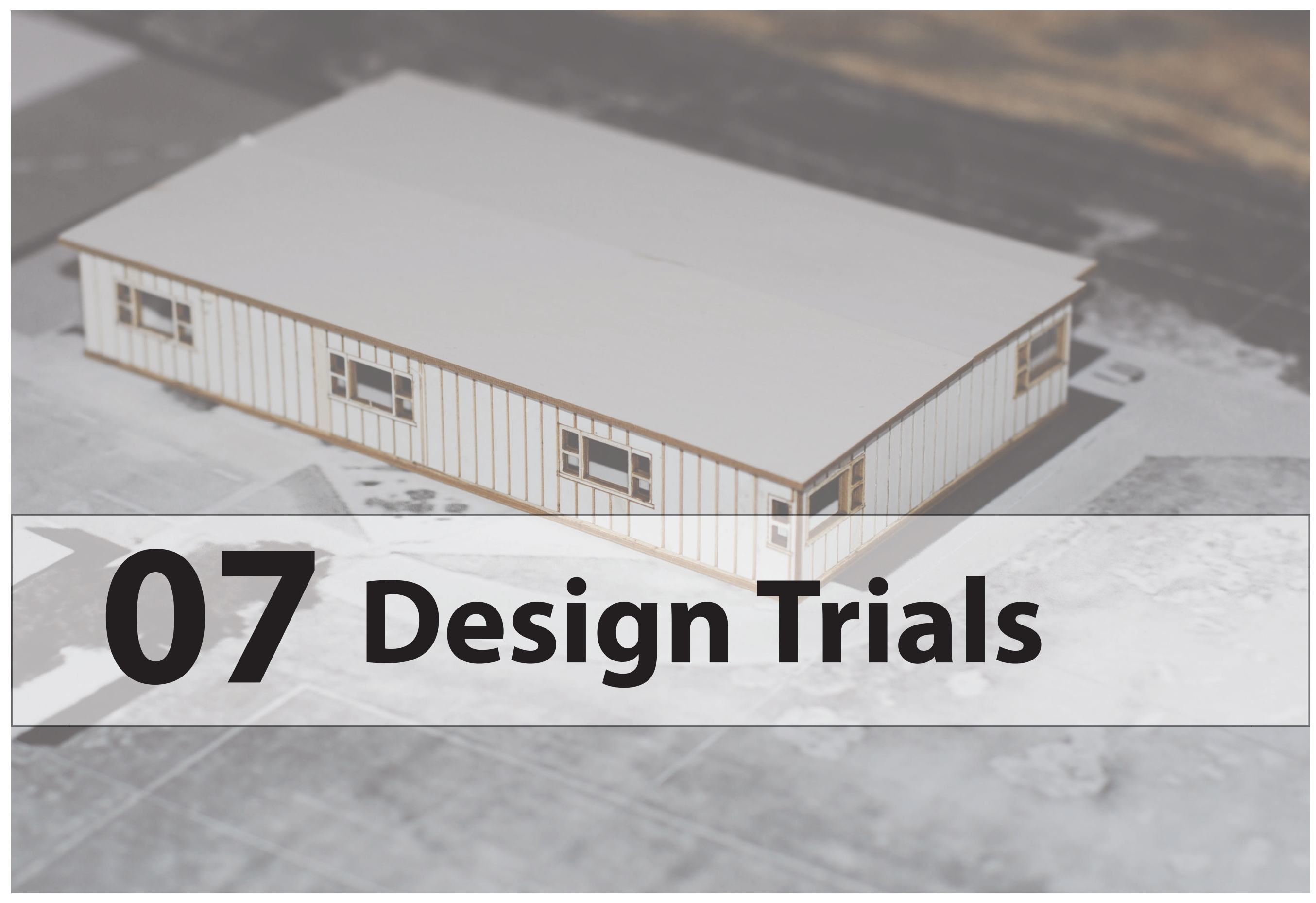




\section{Design Trials}

Initial design trials consisted of a number of charette models, developed in response to observed relationships between architecture, sport and the community. These trials explored how existing conditions could be altered to improve these relationships and interactions within the community. These trials can be organised into three broad categories in accordance to themes explored; Permeability in the Facade; Relationship between Building and Sports Field; and Rearrangement of Program.

\section{Permeable Facade}

The first set of charettes explored how the exterior facade of the Rugby Clubrooms could be altered to open up the building, making it less introverted and more inviting to the general public (Figs 97,98 \& 99). These charettes also explored how these openings might allow a better visual connection to activities on the field and create a stronger relationship between the performance of the sports game on the field and the activities within the building itself ${ }^{18}$. A more permeable facade would allow people glimpses inside and facilitate an ease of transition into the building so that people would be less inclined to leave immediately and might slip inside to experience the vibrant atmosphere within. While this experiment showed some promise it was limited, as a response to existing conditions, and not necessarily conducive to the design of a new type of sports building. This design was nevertheless useful as a way to begin

18 A disconnect between these two was identified through observations and discussion with the bar manager who noted that only $1 / 3$ people coming to a home game would later come back to the club to socialise.

\section{Permeable Facade Formal Explorations}
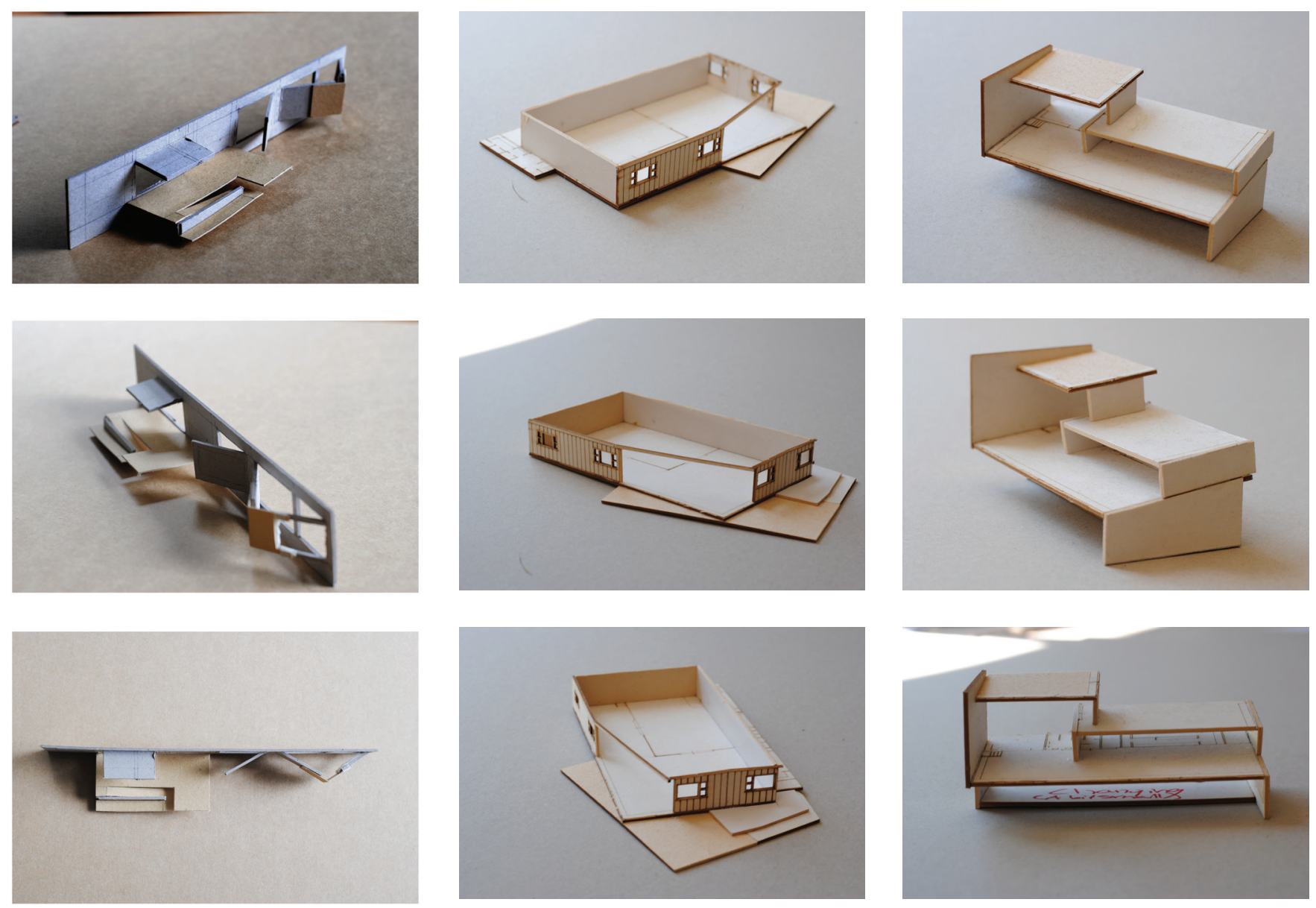

Figure 97: Permeable Facade
Figure 98: Corner Opening to Field
Figure 99: Mezzanine Floors 
exploring a physical means to respond to some of the issues identified related to the disconnection between the activities of the sports club as a social institution and those of the sports field itself.

Relationship between Building and Field

The second set began by investigating the existing visual relationship between the building, the street, and the field by mapping sightlines in and out of the rugby club rooms (fig 100). This revealed a very limited area of club which could be seen from outside, as well as limited views out and only a very small area where the majority of the field could be seen. A few quick models, included in the earlier set (figs $98 \& 99$ ), looked at how the current building could be altered to improve viewing from the clubs current site positioning. (These models, discussed earlier, weren't very successful and were not conducive to the creation of a new design). I then looked at how sight lines to the field could be used in a more productive way to influence the design of a viewing area. An alternative placement for a clubroom in relation to the field was explored and a kind of topological terrain was generated based on views to the field (Fig 101), with the intention that a similar surface could be used in the floor of the club. A mild slope would allow better views of the field from within the clubroom itself and a contoured sloping floor would allow a better flow in and out of the building and enable viewing space to be maximised. The relationship of building with surface was explored further in another model which tested how the mass of the rugby club could be blended into the surrounding landscape, creating a direct relationship with the surface of the field while allowing the roof of the club to be occupied by spectators (fig 102).

\section{Relationship Between Building And Field}
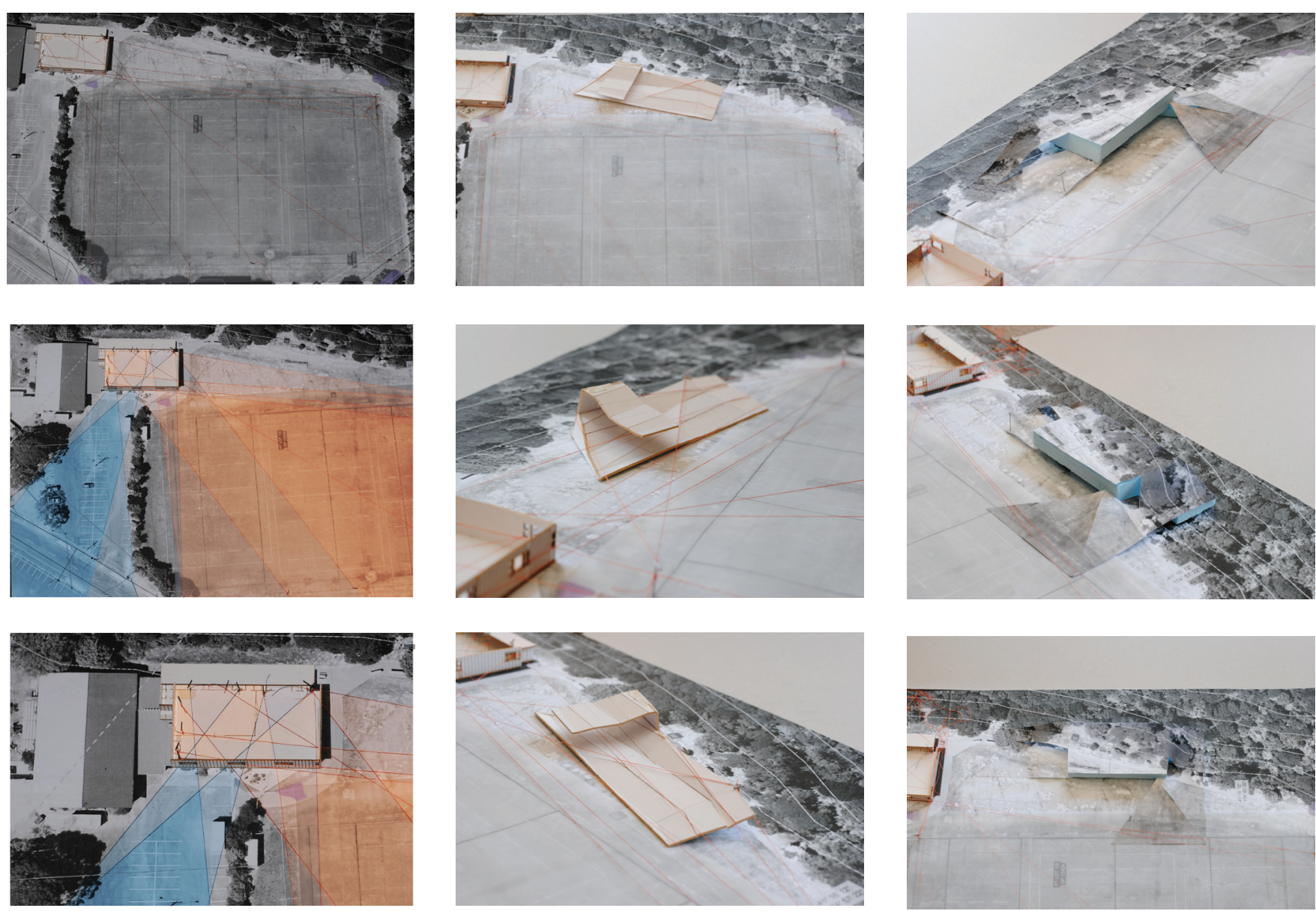

Figure 100: Visual Connections

Figure 101: Surface developed from views of field

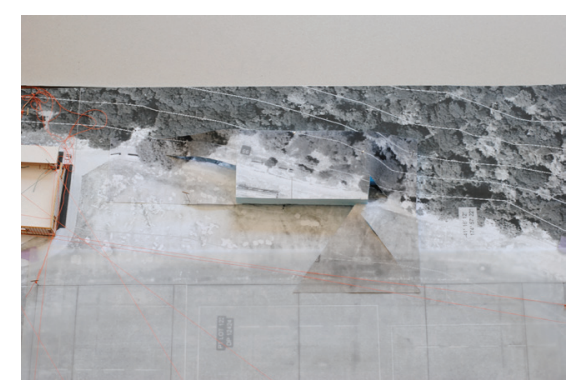

Figure 102: Club blended into landscape 


\section{Rearrangement of Program}

The third set of design tests began as a formal comparison of the space taken up by sports clubs in Wainuiomata compared to the space used by a single rugby pitch. A rough quality scale model of the facilities of each sports club involved in the Sportsville initiative ${ }^{19}$ was created to aid in this comparison. Through this process it was made apparent that the area required by these clubs was much less than that needed for the operation of a single sports game. Rearrangement of these forms revealed the potential for the programme of these sports clubs to be reestablished as a continuous element along the length of a field in a way which fostered a closer relationship between the two programmes. While this was a simple exploration it opened up a line of exploration of ways in which a crossover between different clubs and their associated activities could be explored.

This line of investigation was continued by applying this same logic to the program of the rugby club. It was observed that while the 'social' area of the Rugby Club occupies one open space there are internal barriers and a split in floor level which restrict how the space is be used. While formally one volume the space operates in a more linear fashion, a $U$ shape within a rectangle. As an experiment a diagram was made which explored how this space could literally be unfolded allowing the program of the sports club to occupy the length of the field. This quick study was effective at revealing the potential for a linear sports club building to have a closer relationship with

19 Sportsville is a platform which is being promoted by the Hutt City Council to get Sports Clubs to work together and share resources. the field space by rearranging the program from a more traditional arrangement to one that occupies the length of the field itself. This understanding of the buildings relationship with the field was expanded through a model which explored how lifting up the field, itself, would open the space beneath to accommodate additional activities. This model identified a potential way for the social space of a sports field to be intensified allowing further simultaneous activities within the same area of land / public space.

This common ground between a linear building and the linear nature of the sideline led to further examination of a common ground shared between building and sports field. The planar nature of the field is comparable to the floors of a building. Through this comparison an idea was conceived of an intersection between the building and the plane of the field on multiple levels. A raised field would free space underneath for other functions, allowing an intensification of the field space itself.

\section{Conclusion}

These early trials examined how design could respond to observed relationships between architecture, sport and the community and explored ways in which these relationships could be improved. Ideas taken from these initial tests were explored in further design developments. The programmatic model developed consisting of three fields with bands of program concentrated between them was particularly important in this regard, functioning as a diagram of the relationship between social program and field that I wished to establish, informing future developments (fig 105).

\section{Re-arrangement Of Program}
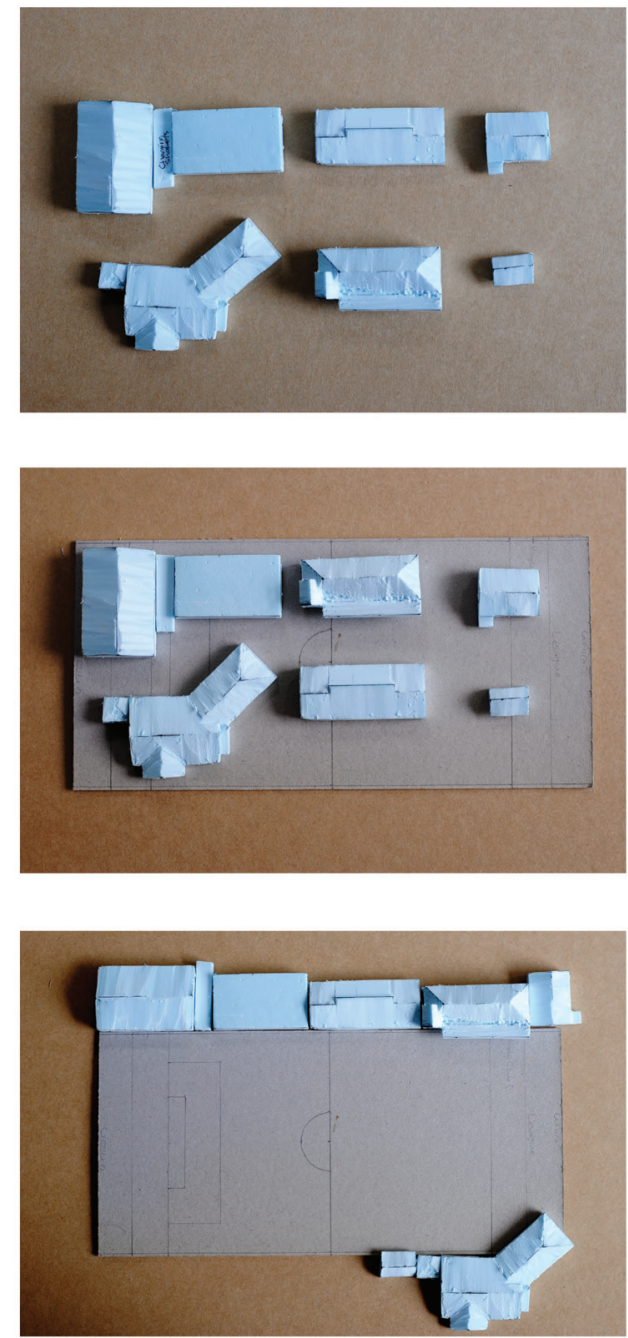

Figure 103: Sports club masses re arranged to occupy length of field 


\section{Re-Arrangement Of Program - Continued}
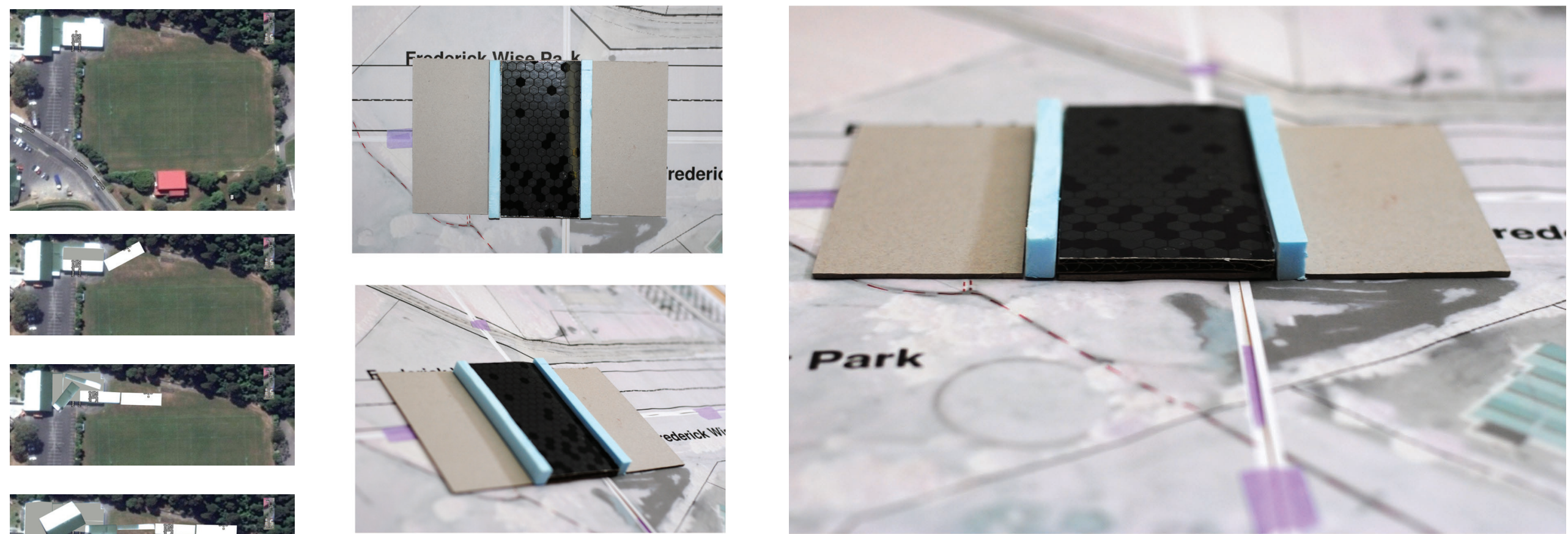

Figure 105: Organisational strategy - Three fields with program concentrated in between - intensifying social space and multiplying views.

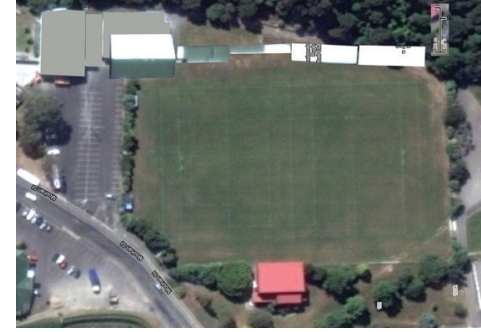

Figure 104: Unfolding of rugby club program. (Google Earth)

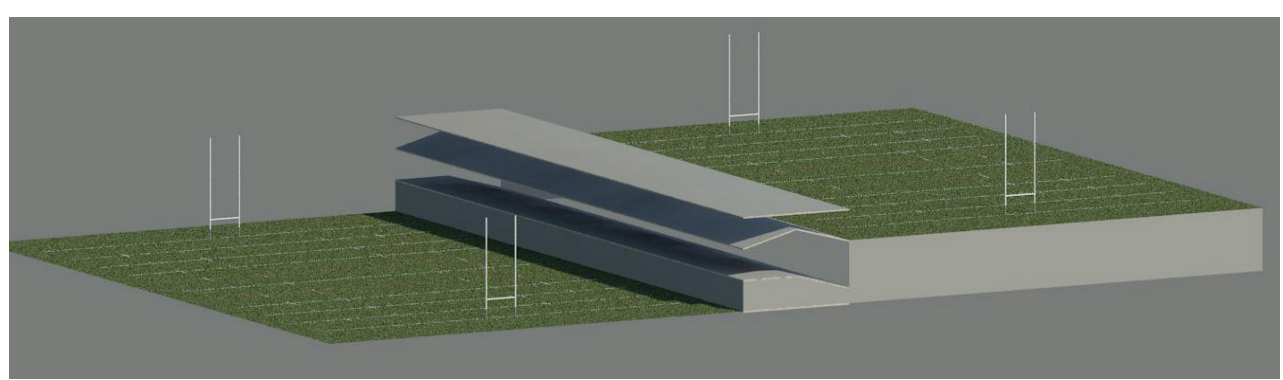

Figure 106: Space above field used for additional program
Figure 107: Raised field allows additional program underneath 


\section{Development of Concept}

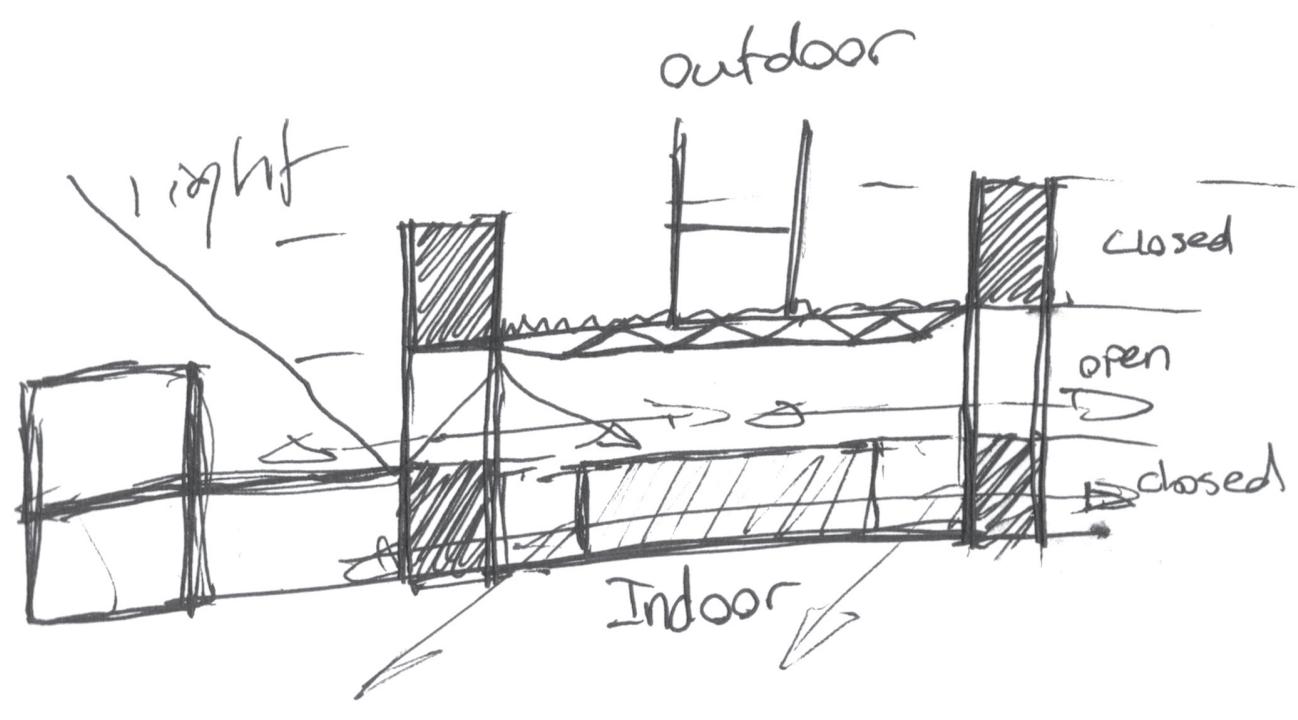

Figure 108: Sketch of 'three fields' organisation strategy, utilising the space beneath the field.

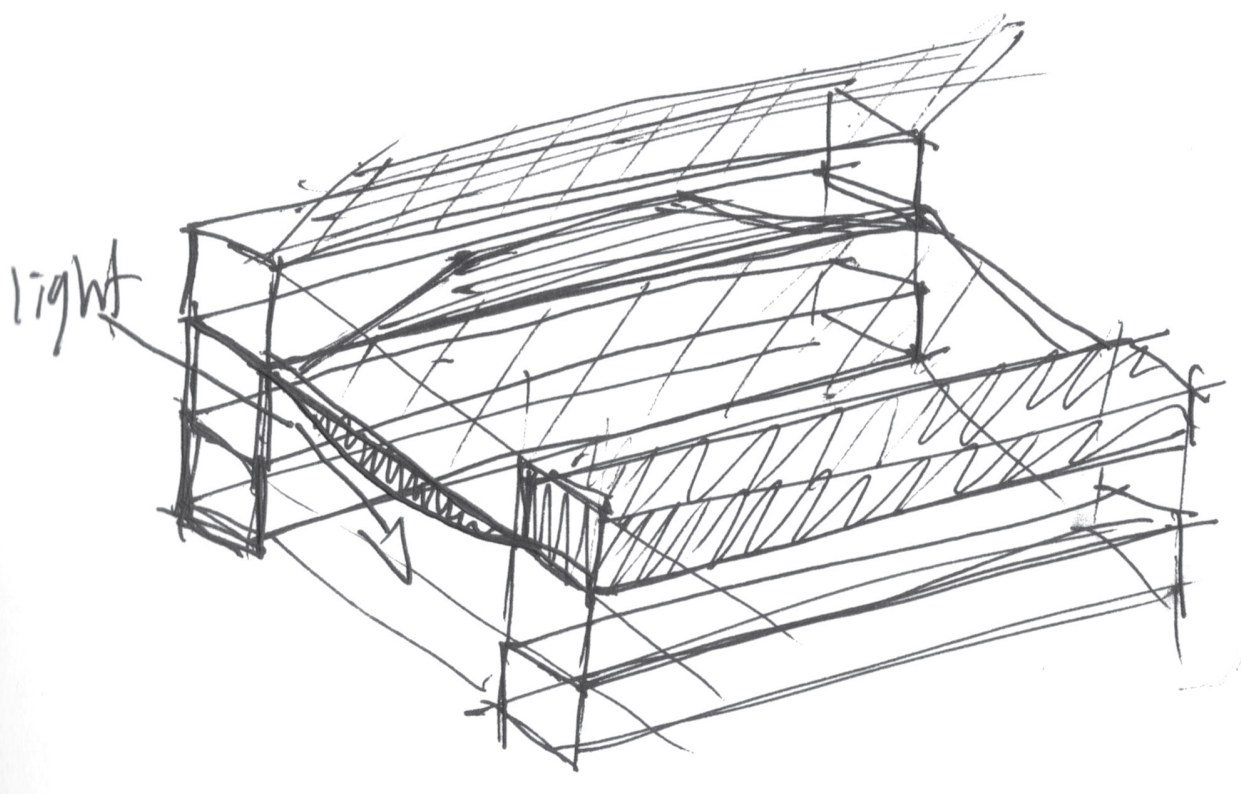

90 


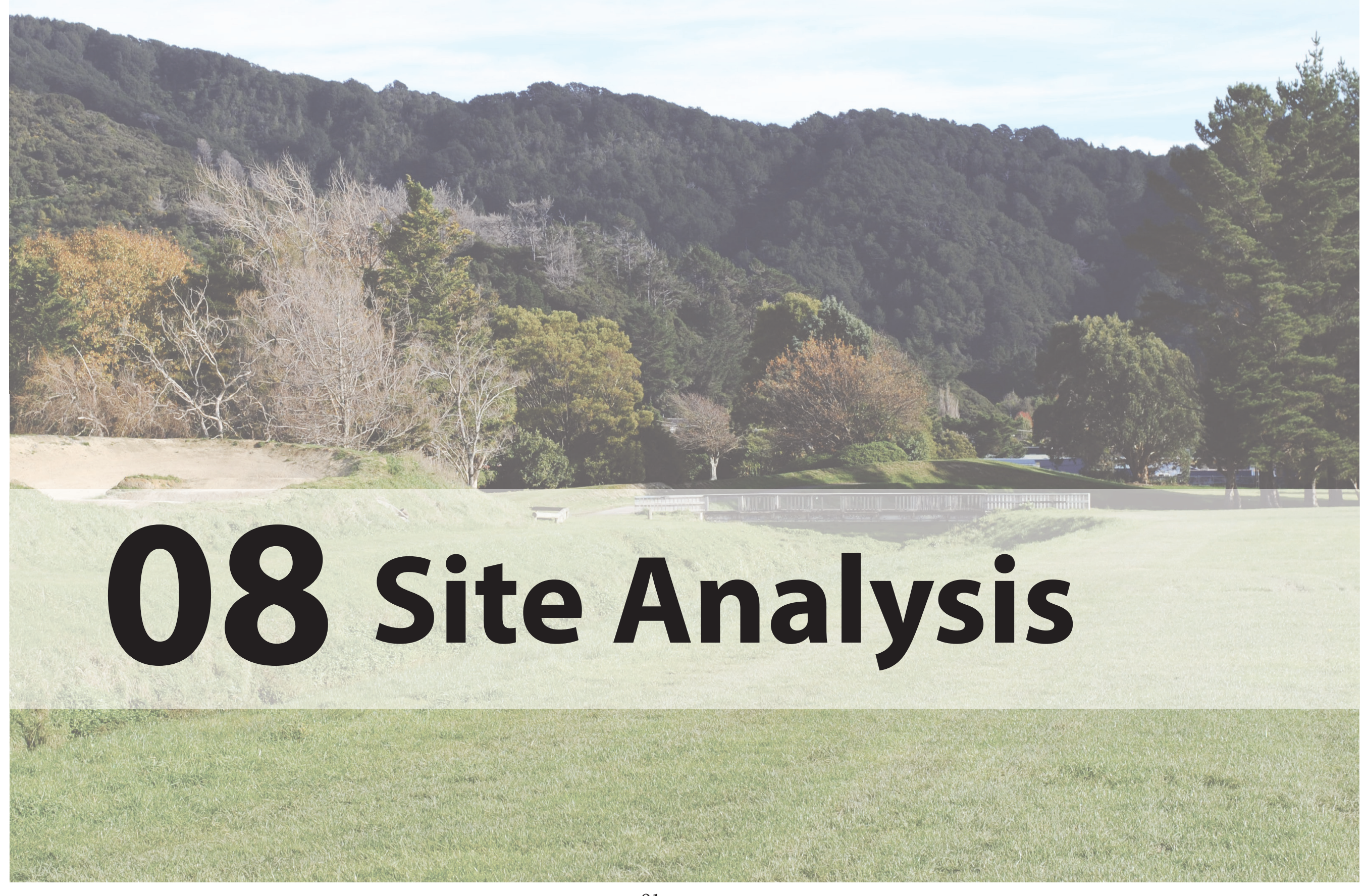




\section{Site Analysis}

This section briefly outlines the site selected for the design proposal, Wise Park. The boundaries of the site are defined and the outcomes of a site analysis conducted are discussed. This analysis includes a review of the sites history and council documents related to the site, Personal observations recorded through photographs and sketches.

\section{Site Selection}

Three sites were initially considered for the proposed design; Frederick Wise Park, Richard Prouse Park and William Jones Park (fig 109). Wise Park was chosen as a site due to its unrealised potential to provide a quality public space for the Suburban community of Wainuiomata. The Park occupies a large area of land $-154,238 \mathrm{~m} 2$ making it the largest piece of public land in Wainuiomata. Wise Park occupies a very central location with several schools and the local Marae within close proximity, it is also across the road from the local mall and shops and is accessible from all sides (fig 110). Despite these factors it is underutilised as a public space ${ }^{20}$. The local community would benefit from development to increase the quality of this area and encourage increased activity in the park throughout the day.

20 Recently there has been a proposal to sell an 'underutilised' area of the park to allow for the development of a retirement home (Hutt City Council Policy Comittee, 2013). I believe that it is more prudent to look at the reasons why people do not use the area as and propose a solution to improve this public space.

\section{Defining Wise Park}

At this point it is probably useful to define the site in question. Frederick Wise Park which shall henceforth be referred to as Wise Park is for the purposes of this thesis defined as the area bounded by the Parkway

Extension Fitzherbert Road and the Strand, and Hinau Grove. Included in this definition is the Fitzroy Tavern and the Rural Bush fire service.

\section{History of the park}

In 1973 the Wainuiomata 'Baths and Civic Fund' made the decision to develop Wise Park as a passive recreational area.(O'Hara, 2002, p. 20) Preliminary plans for this proposal were started by the Lincoln College Landscape Consulting Service and Frank Boffa \& Associates in 1974. These were continued by Boffa Jackman \& Associates which published a report outlining their evaluation of the local landscape and resulting proposals for Wise Park.(Associates, p. 2) These proposals were never realised. (see fig 118)

\section{Personal Observations}

The most striking feature of the site is its sense of openness, the parks central location places it in the widest part of the Wainuiomata, at a point where the various branches of the valley meet. Consequently the park has views of, and can be viewed from, the surrounding hills which define the valley. The low lying nature of the suburb, typically single storey residential housing, means that any large building located in the park would similarly have the potential to view, and be viewed by, most of Wainuiomata, providing an opportunity to act as a landmark to which visitors could orient themselves while also highlighting the town.

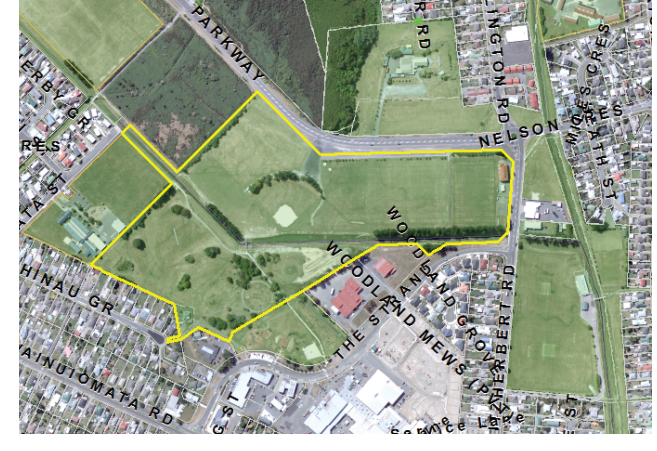
Frederick Wise Park

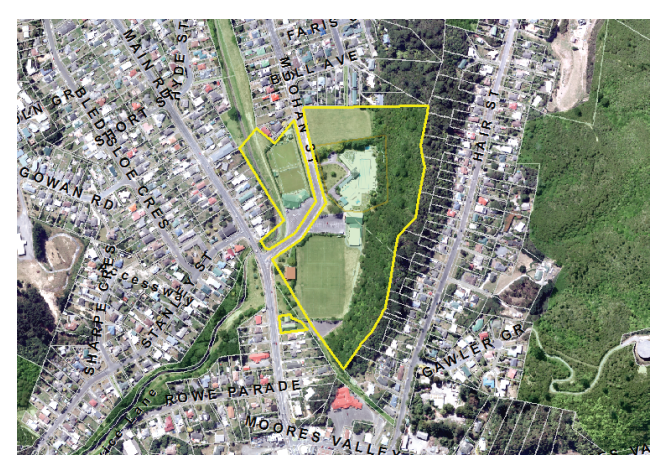

William Jones Park

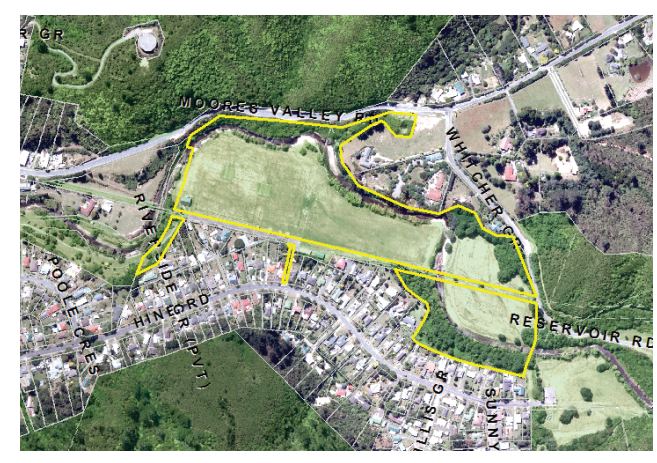

Richard Prouse Park

Figure 109: Sites considered for design Source: (Hutt City Council, 2013b) 


\section{Wise Park Site And Context}

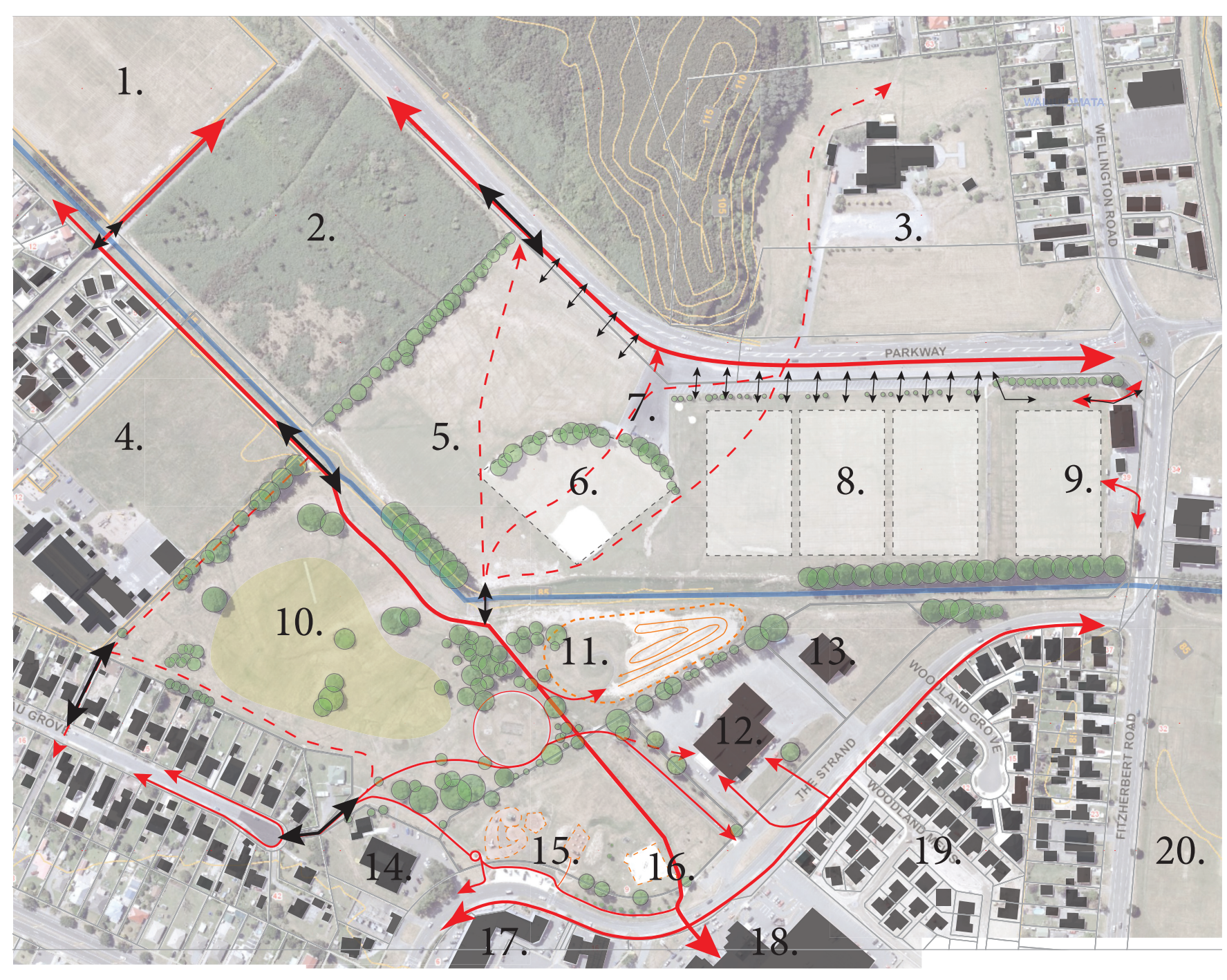

1. Wainuiomata High School

2. Undeveloped land intersected by waterways

3. Wainuiomata Marae

4. St Claudine's Thevenet School

5. Training Field - with flood lights

6. Softball Diamond

7. Recycling Centre

8. Rugby Fields

9. Wainuiomata Rugby League Club

10. 'Swampy' underutilised land

11. BMX Track

12. The Fitzroy Tavern \& Super Liquor Wainuiomata

13. Wainuiomata Bush Fire Service

14. Whai Oranga O Te Iwi Health Centre

15. Playground

16. Skate Park

17. Local Shops

18. The Wainuiomata Mall

19. Semi-Retirement Village

20. Brian Heath Park

Figure 110: Pedestrian routes through and around Frederick Wise Park - A 'river' splits the park into two sections North and South, this divide is crossed by a single bridge which creates a bottle nexk withing the park.

Background image source (Hutt City Council, 2013b) 


\section{Mapping Of Site}

Opportunities for the park to connect with the surrounding landscape have been largely unrealised. As has the potential for the park to provide North-South cross site links for pedestrians, currently a drainage 'stream' splits the park into two parts, North and South. The Northern area of Wise Park contains four tightly packed sports fields predominantly used for Rugby League (although only two are used regularly), a Softball Diamond, as well as a smaller secondary diamond, and a training pitch with lights. The Southern part contains a small skate park (which was not very well designed), a BMX track built recently which has proved popular and a playground. These areas of activity are focused towards the perimeter of the park, where they are easily accessible. Other areas of the park are more isolated, less visible and often 'swampy' consequently these are not well used.

There appears to be a real lack of consideration given to the connection with water. Water plays an important role in the history of Wainuiomata large areas of Wainuiomata were wetlands prior to the land being drained to allow it to be used for agriculture and later, housing. The old path of waterways was mapped from historical photos as well as existing rivers surrounding site, link back into landscape and help to integrate further recreational possibilities on site

The sites central location affords views to much of Wainuiomata and the surrounding hills, these views were identified as a way to connect with the local context and allow the facility to become a visible hub of community activity (fig 112). These observations were taken into consideration and responded to as part of design developments.
A bottle neck caused by a river was identified as a problem restricting access through the site. In response to this a diagram of desire lines through the site was created by linking nodes of activity and main routes of access into the site (fig 114). A series of spatial explorations were also conducted, which looked at the site in relation to the spatial requirements of a number of sports field arrangements, and tested a range of spatial orientations and layouts.

Wise Park was chosen as a site because it has unrealised potential to be a quality public space. The existing site presents a number of challenges and its position at the centre of Wainuiomata provides opportunities to engage with the wider community.

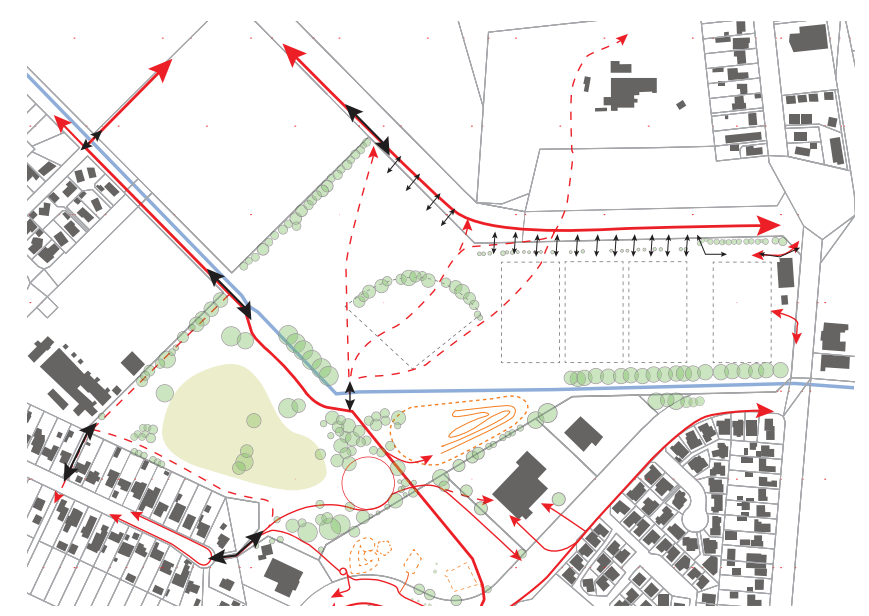

Figure 111: Figure Ground - with pedestrian paths

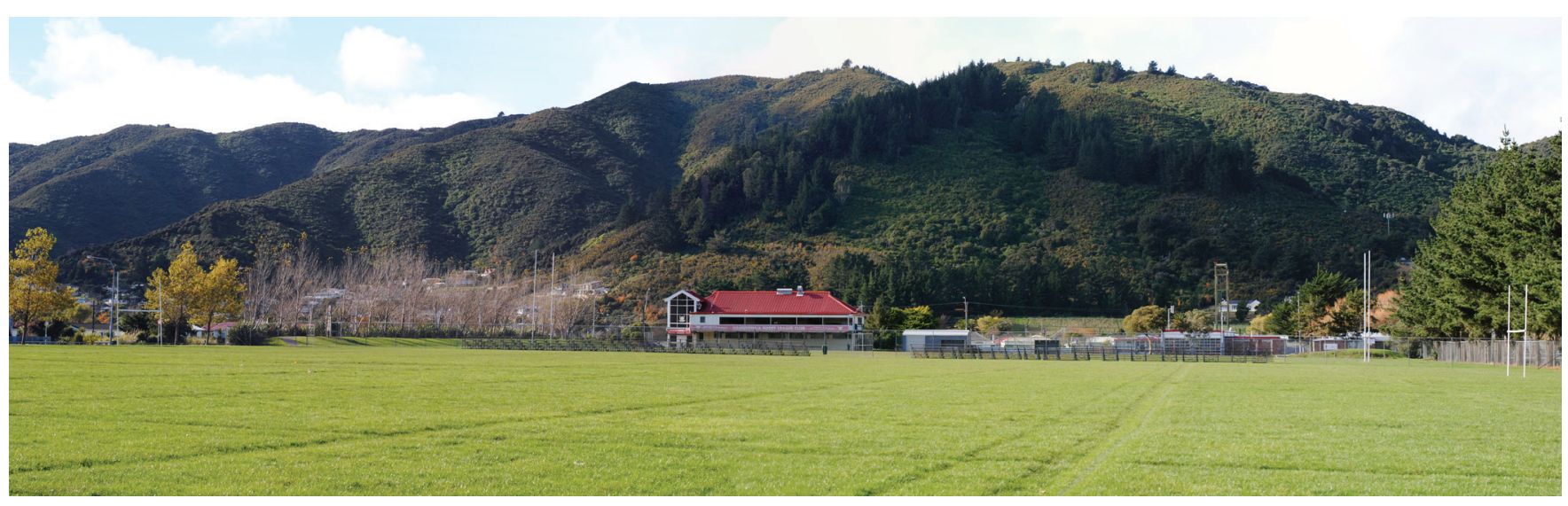

Figure 112: View East towards Rugby League Fields and Club Rooms, framed by surrounding landscape. 


\section{Mapping Of Site (Continued)}

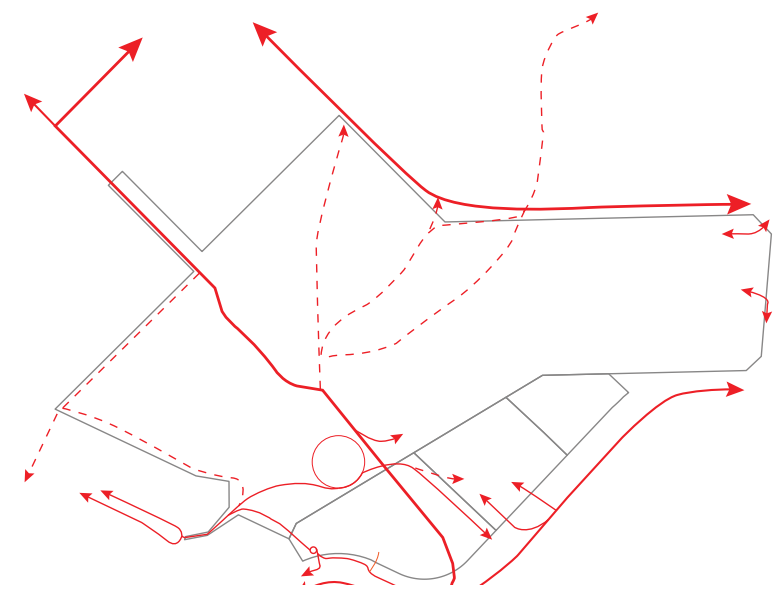

Figure 113: Pedestrian Routes - through and around the site.

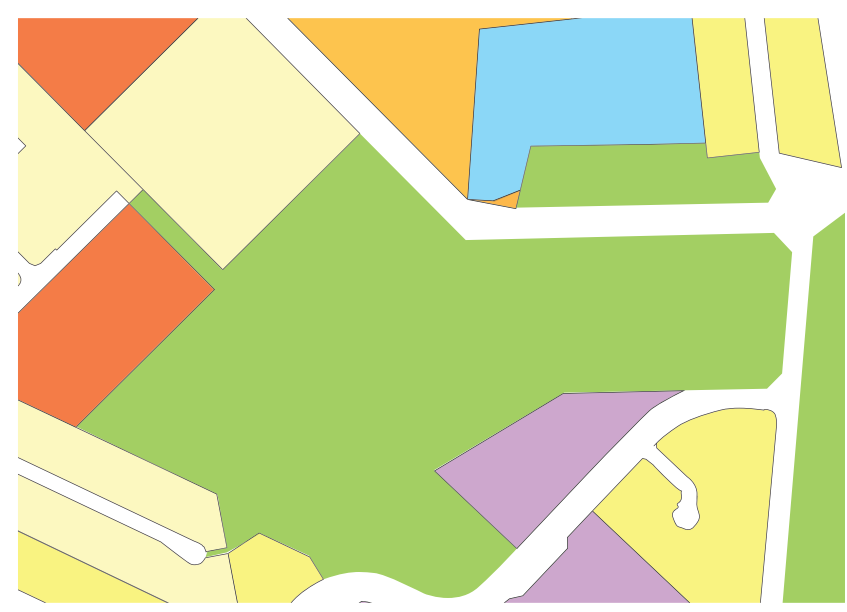

Figure 116: Zones

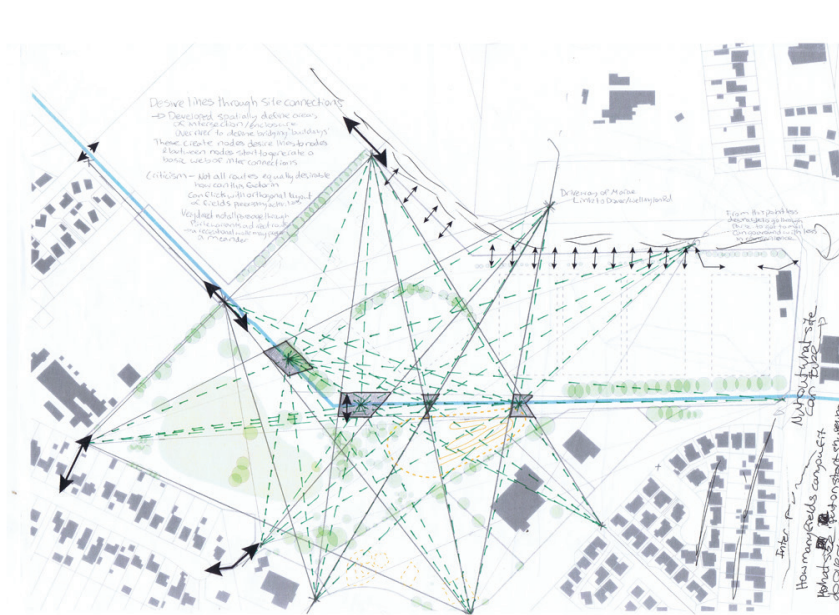

Figure 114: Diagram of ideal connections / desire lines through Wise Park

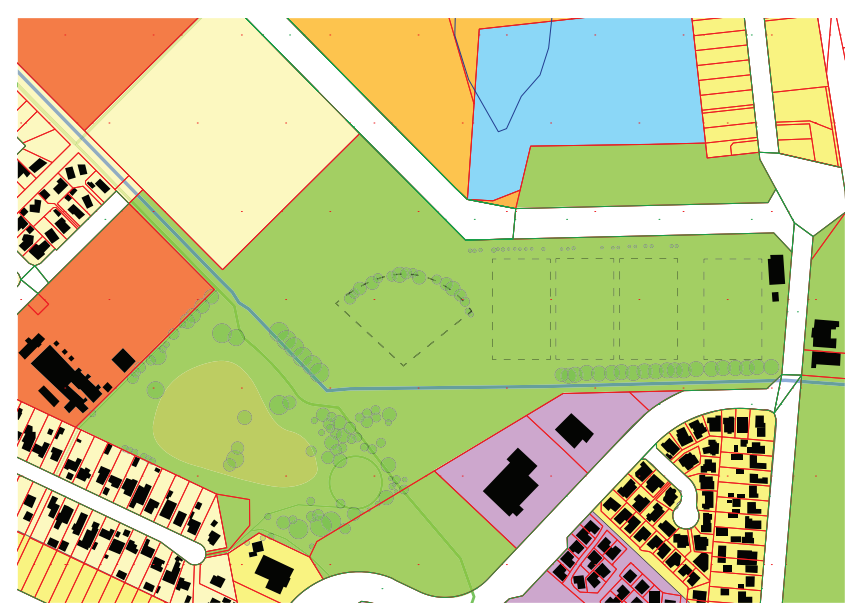

Figure 117: Zones with figure ground

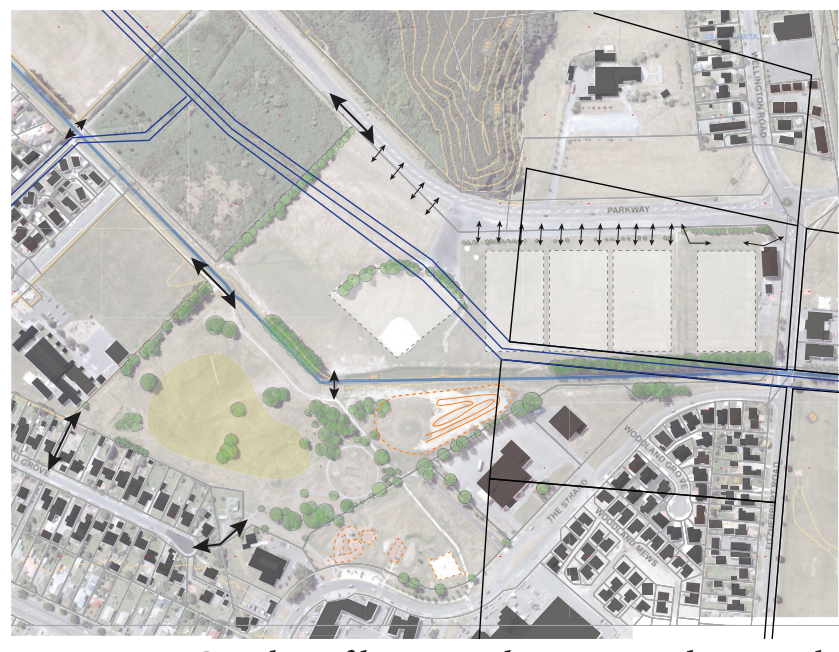

Figure 115: Overlay of historic plot areas and original river course.

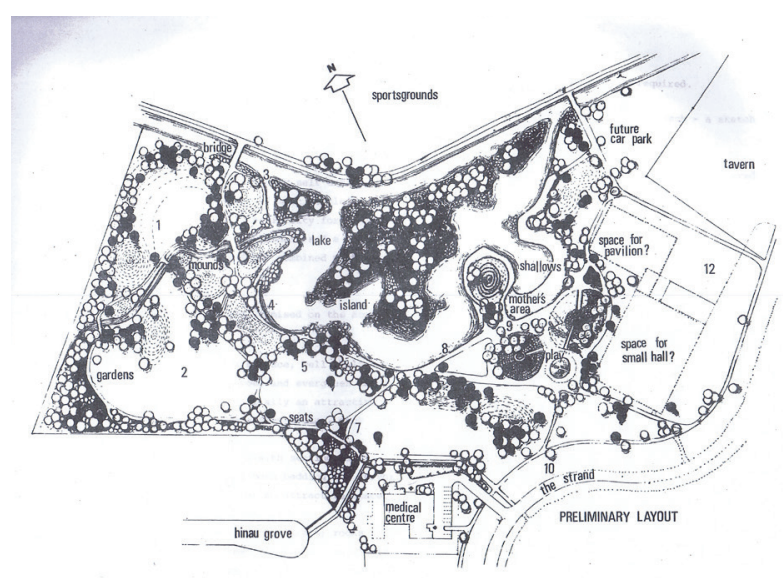

Figure 118: Boffa Jackman \& Associates proposal for wise park. (Associates, p. 25) 


\section{Panoramic Views Of Wise Park}

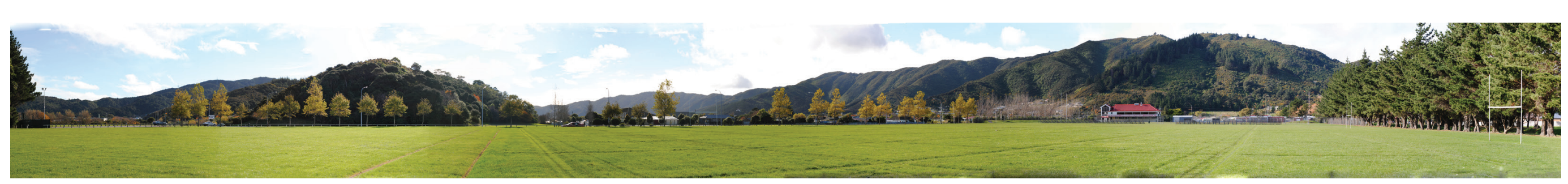

Figure 119: Panorama of sports fields on North side of river

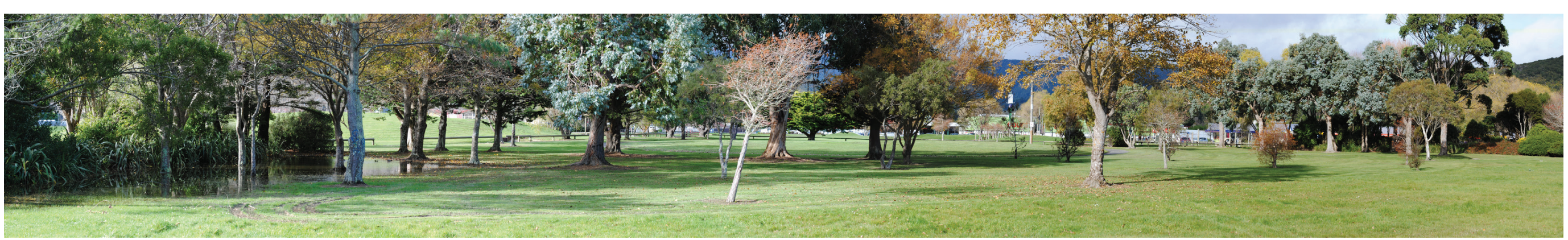

Figure 120: Panorama of 'under utilised area'

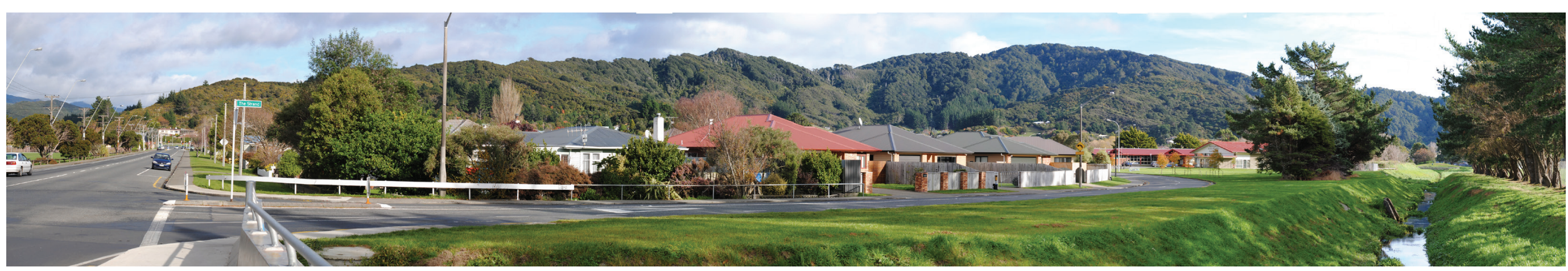

Figure 121: Panorama from Fitzherbert road bridge - looking west with Semi-Retirement Village to the left, River/Stormwater drainage centre, Rugby League Club, Basketball Court and Sports Fields to the right. 

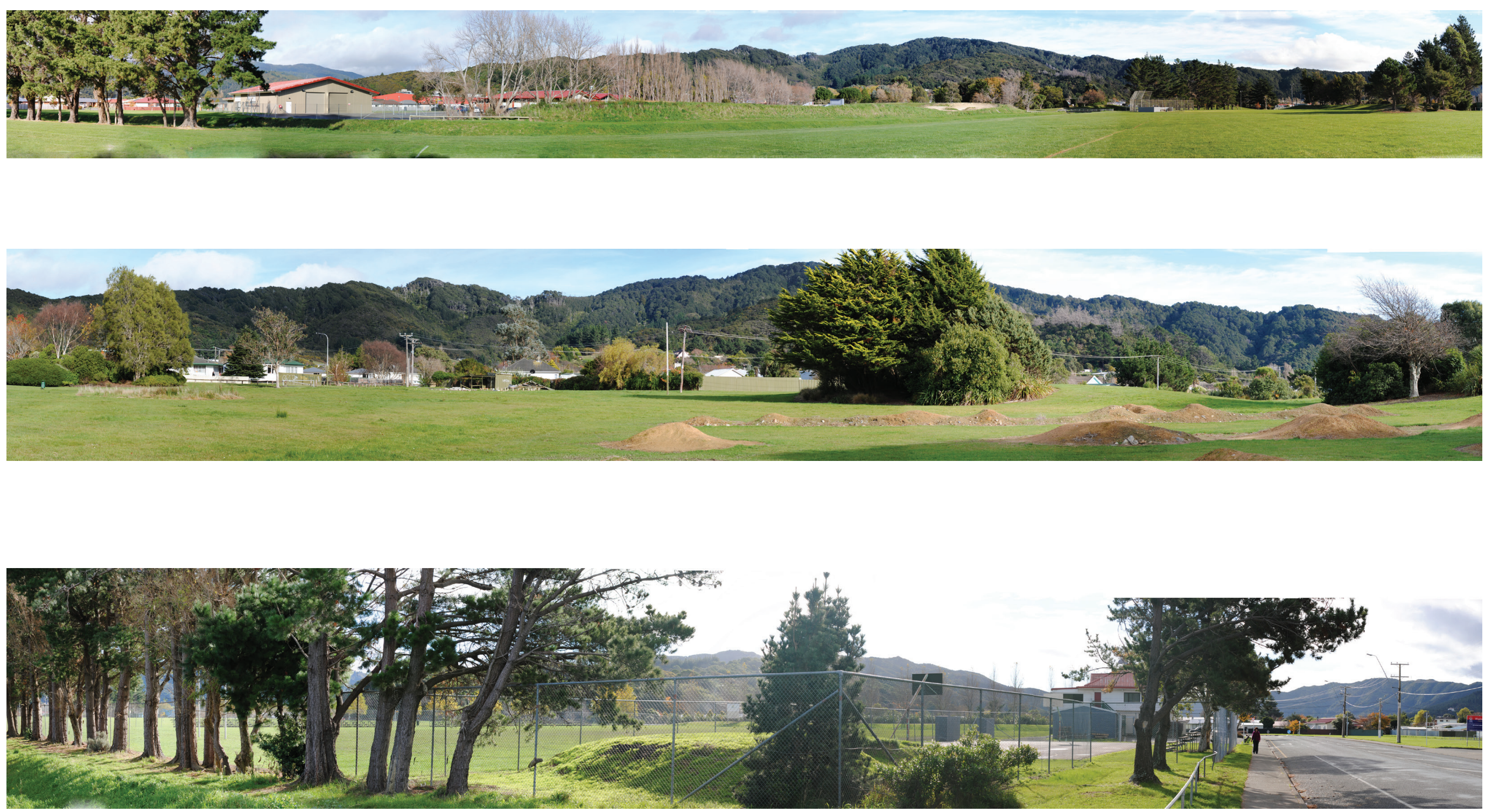



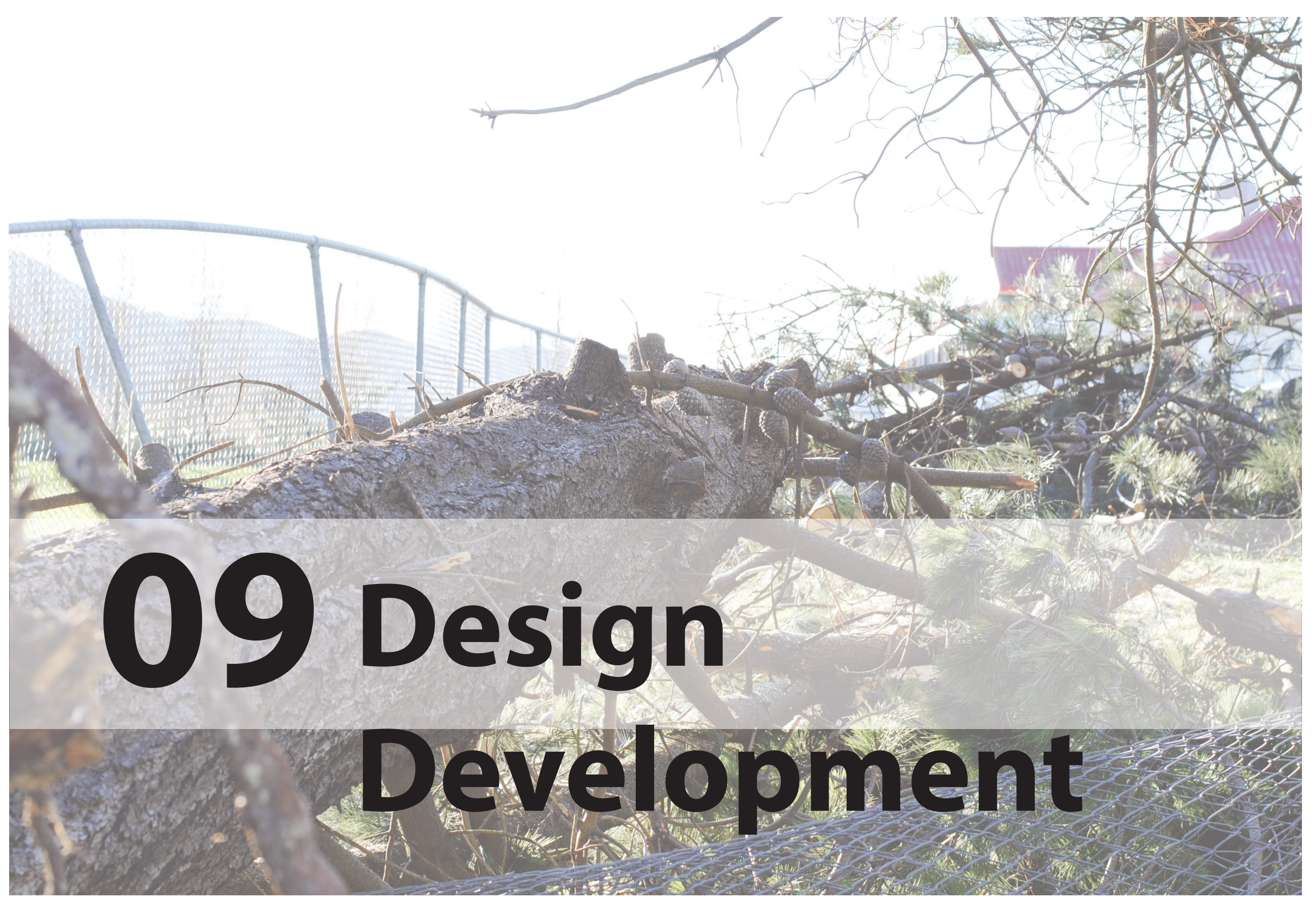




\section{Initial Design Developments}

\section{Design Development}

This section draws from the previous chapters 6,7 $\& 8$ and discusses design developments conducted leading to a developed design. This iterative process, consisted of a series of negotiations between; orientations of the site; connections through the site; program of sports facility and its relationship to the field; relationship between landscape, artificial landscape and building; visual connections to the surrounding landscape and community. In addition to continuous design revision, as part of this process, the overall design was re-evaluated at various stages based on reflection and feedback from critique at; the 6 month design review in July, a quick fire critique in September, and 8 month review in October. This design progression is outlined below.

Initial design development consisted of a series of drawings and overlays which explored the area of the site, compared to the program intended to occupy it and test some of the limitations of what was possible to include in the design (fig 122).

\section{Month Review}

The first design (see page 102 \& 103), developed for the 6 month review, was based on the 'three fields' organisational diagram developed in design trials, which guides the relationship between elements of program on the site of Wise Park. In this initial design the site is organised into a dense concentration of sports fields, a multi storey social space is concentrated between these fields with an adjacent sports hall and teaching spaces. A central field is raised with the dual purposes of, allowing the space beneath to be used for indoor sports, and to allow the field to cross the river, a formal move which bridges between the two sides and provides crossing points, improving connectivity on the site.

The design at this stage was understood as a broad arrangement of the main programmatic elements; Teaching + Social + Fields + Indoor sports hall, these were organised on the site as large blocks of program. This was a first attempt to mediate between the different orientations of the site and its awkward shape / bend. This design also began to explore how the experience of a spectator could be multiplied through an engagement with multiple games and activities. This concept was explored in the form of a raised platform which cuts through the site, bridges the river, and passes multiple fields and a central block of social and teaching program. This platform affords views to activities along both sides in three sections, allowing a spectator moving along its length to engage with the activities of six different environments. The potential for views of the surrounding landscape from the sidelines of the sports fields was also explored as a way to connect with the local context and add another level of engagement.

The arrangement on site is quite tight, maximising the amount of field area while accommodating other elements of program. While an efficient use of space, this arrangement is somewhat restrictive, limiting flexibility in the arrangement of program that a looser fit would provide. There was also a concern with the quality of space that placement of an indoor sports hall and teaching spaces underneath sports fields would provide particularly in regard to light conditions.
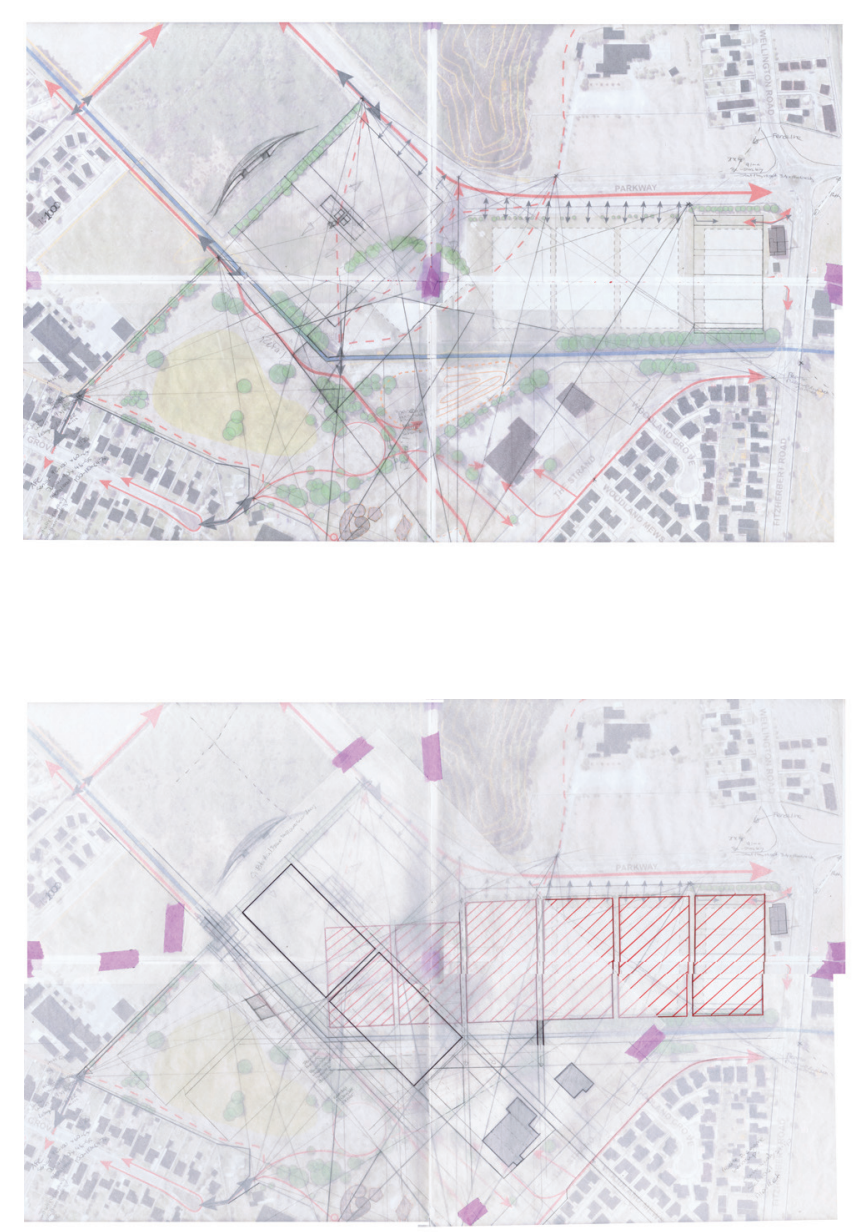

Above \& Next Page

Figure 122: Initial design developments explored the limitations of site. 


\section{Initial Design Developments (Continued)}
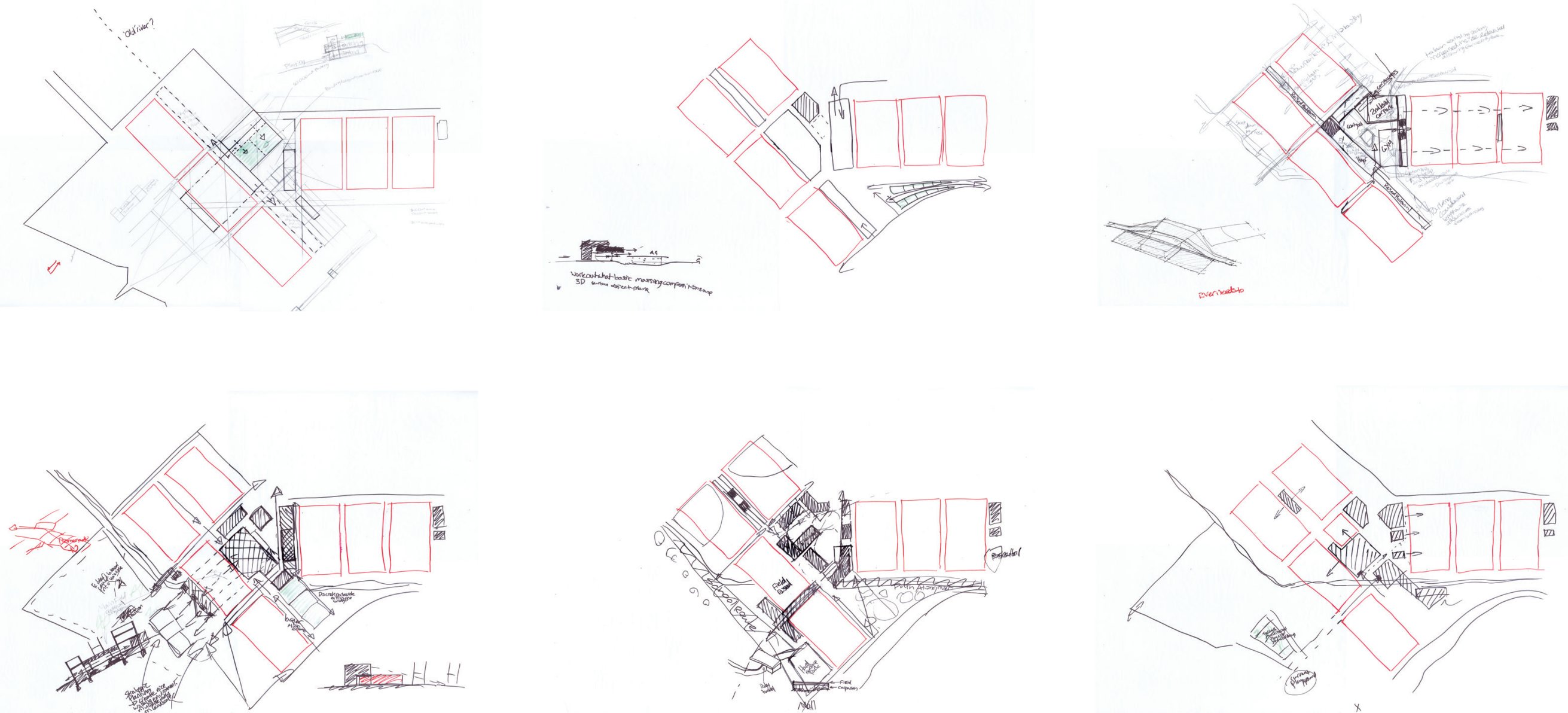


\section{Design at Six Month Review}

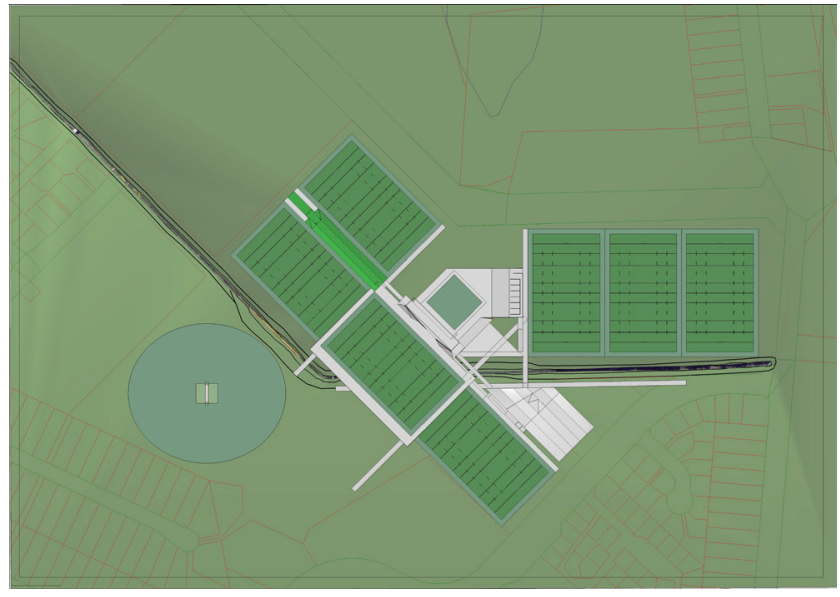

Figure 123: Site Plan showing distribution of fields and central core of social and teaching program

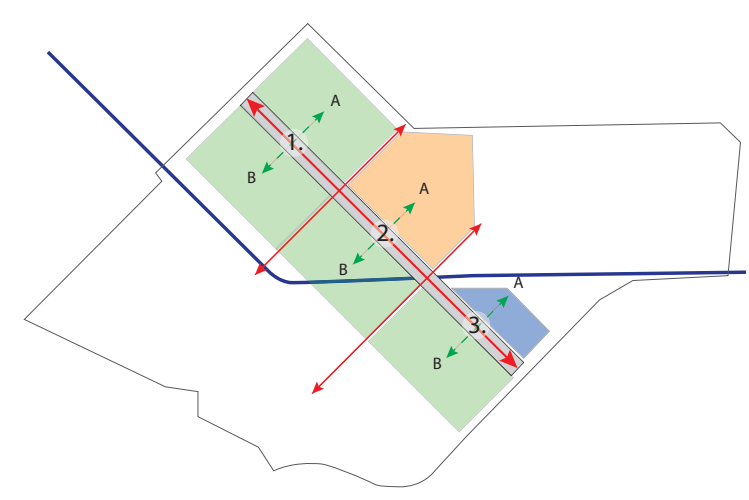

Figure 124: Central viewing platform multiplies spectator engagement by connecting with multiple areas of activity along a linear path.

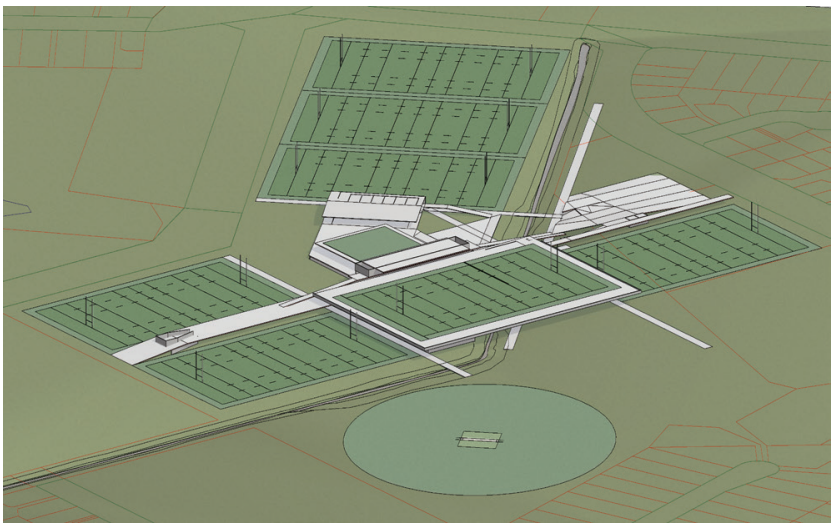

Figure 125: Aerial view looking East - Central field raised to bridge across river.

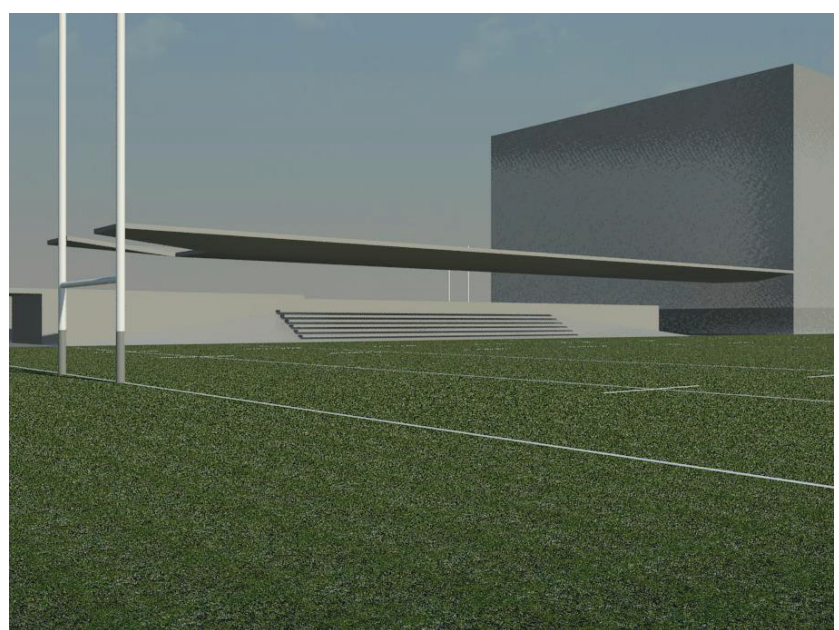

Figure 127: View across North-Western field - Viewing platform stretches along length of the field. 


\section{Design at Six Month Review (Continued)}

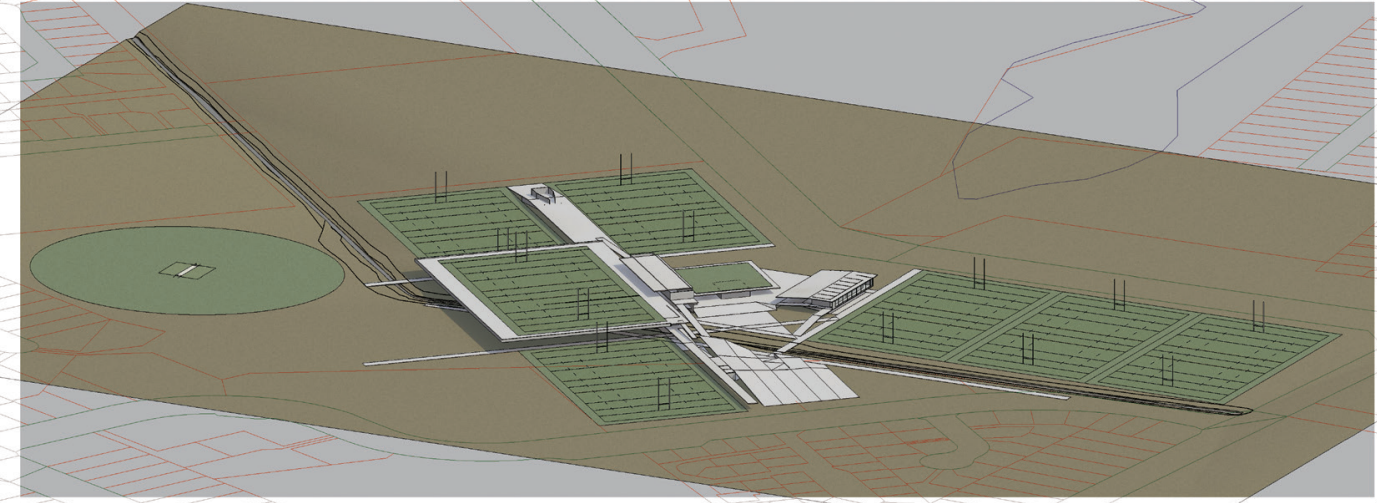

Figure 128: Aerial view looking North-West

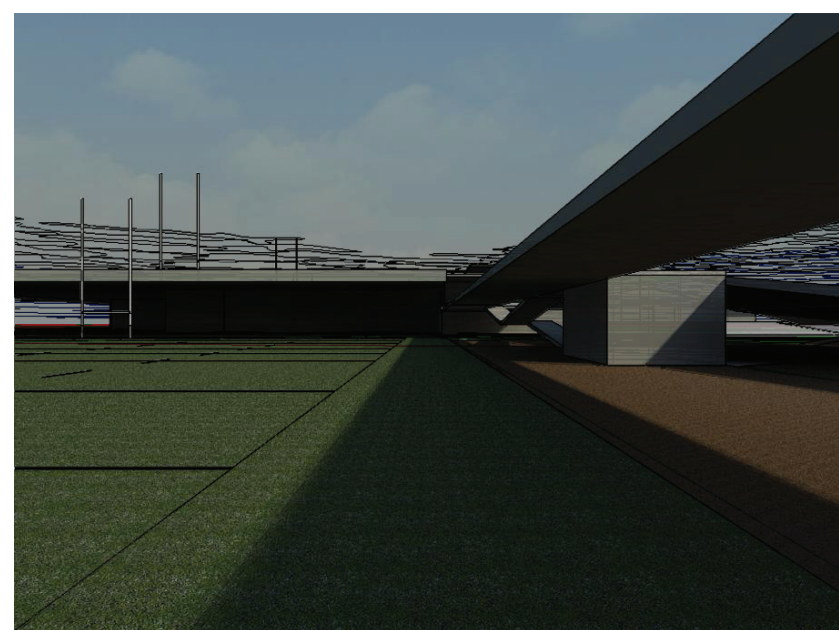

Figure 129: View from South-East field looking NorthWest towards raised field - Viewing platform passing overhead allows space for additional program below.

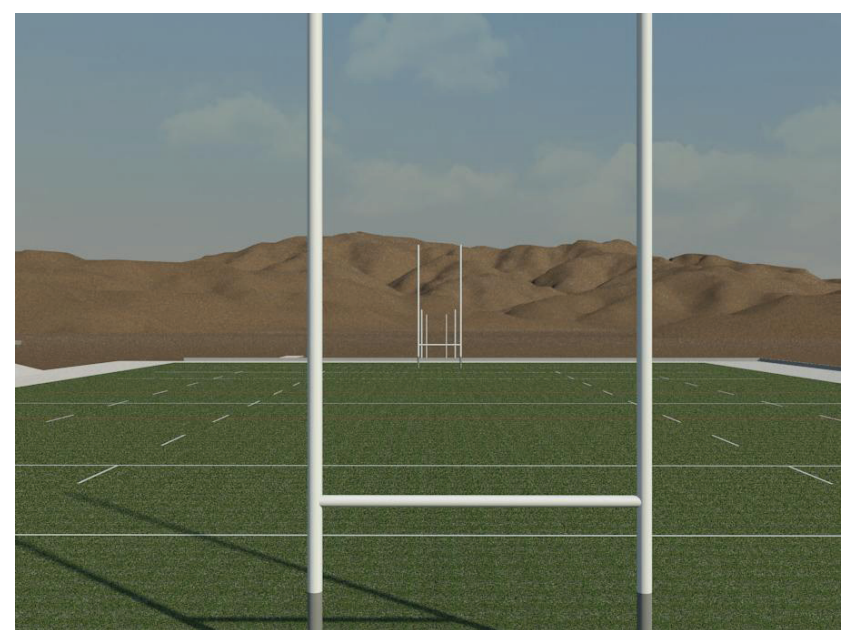

Figure 130: View South East from central, raised, field towards hills which define Wainuiomata.

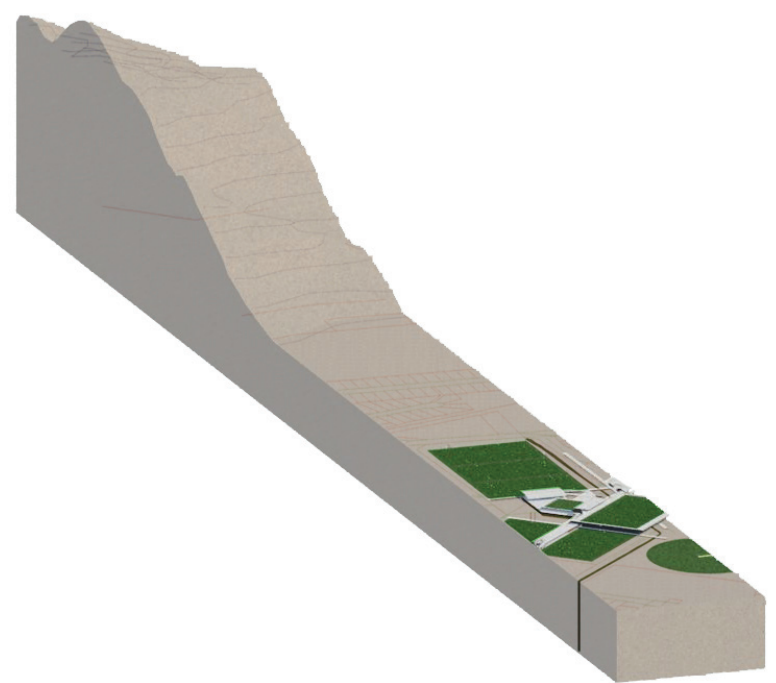

Figure 131: Visual Connection to Eastern hills

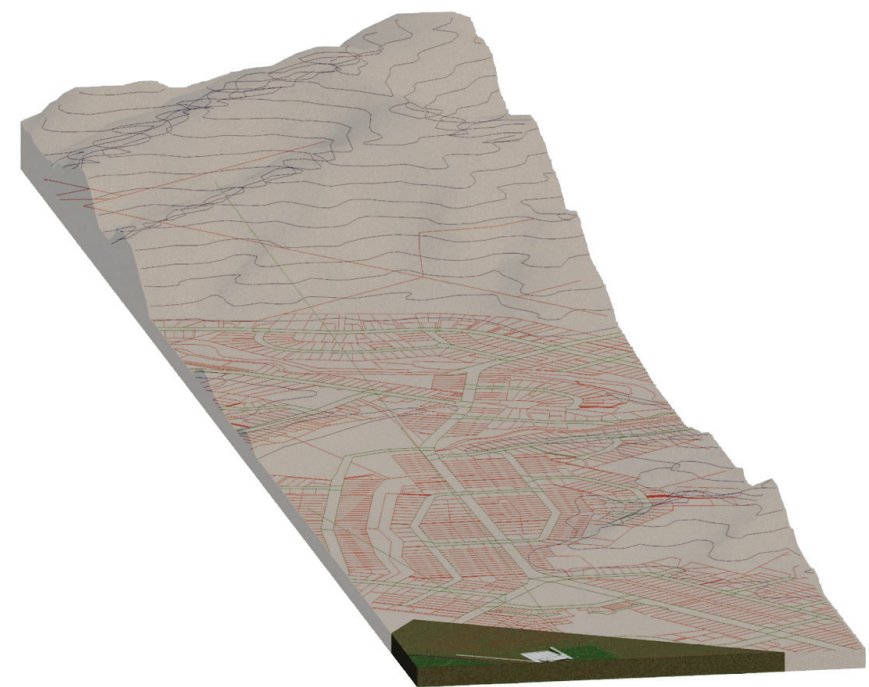

Figure 132: Visual Connection to Southern Hills and local context. 


\section{Development - Massing And Orientation Of Program}

After receiving feedback on this initial design it was decided that maximising field space worked against the design intentions, of achieving a closer relationship between the field and building. Maximising the amount of field space, relies on those fields being used, and would disperse activity along the site instead of concentrating it around the building. The tight arrangement also was not well suited for providing easy access through the site. As a response to these concerns a looser arrangement of program was explored and the central field and other elements of program were re oriented to provide better visual connection to the local context and to funnel people into main routes through the site, improving access (figs $133 \&$ 134). The landscape also began to be explored as another building element, with the old path of the river through the site explored as means of connecting with the past and providing variety to make the place attractive for a range of activities.
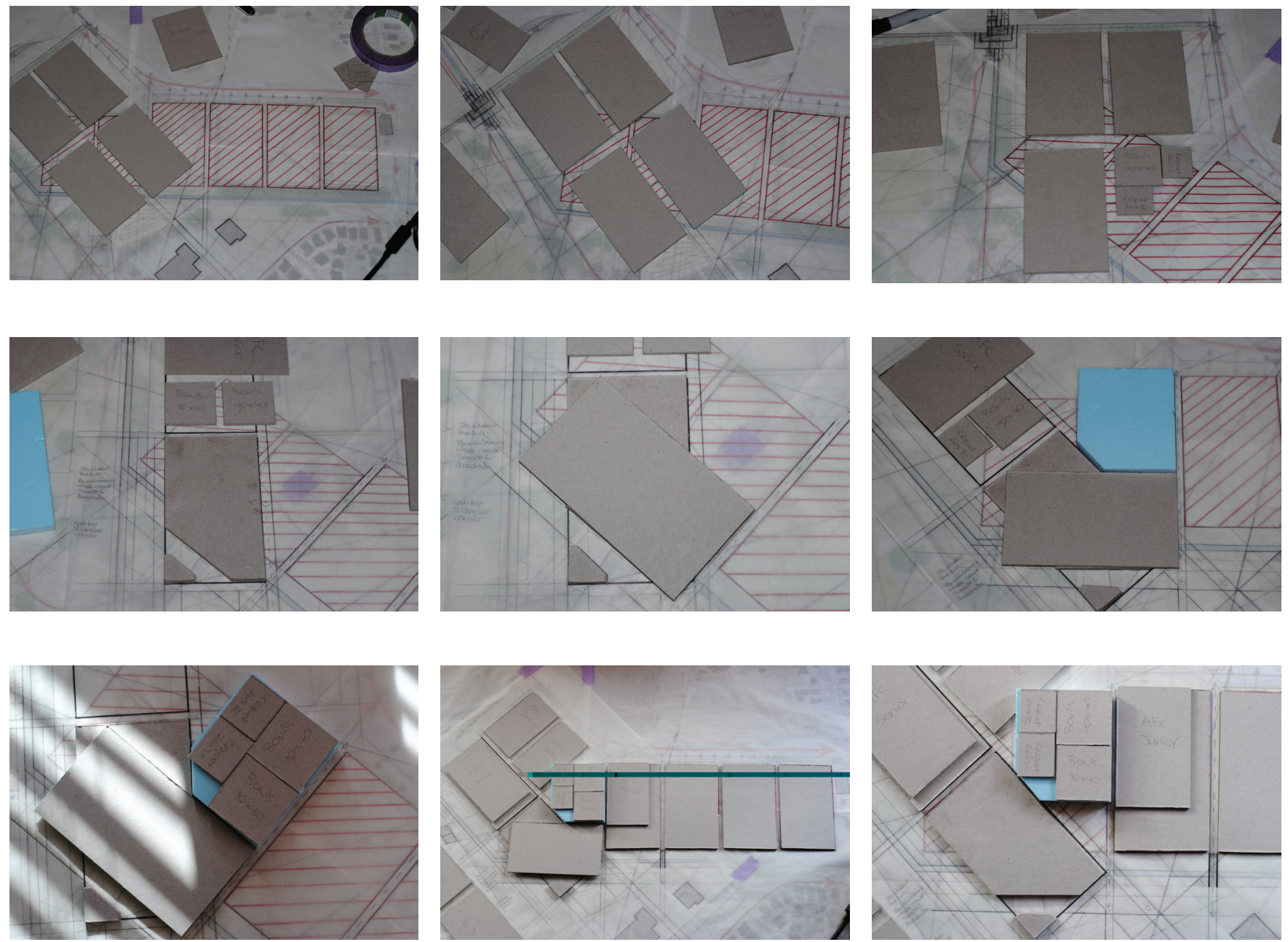

Figure 133: Massing of fields and program explored options and reorientation of main field 


\section{Massing And Orientation Of Program}
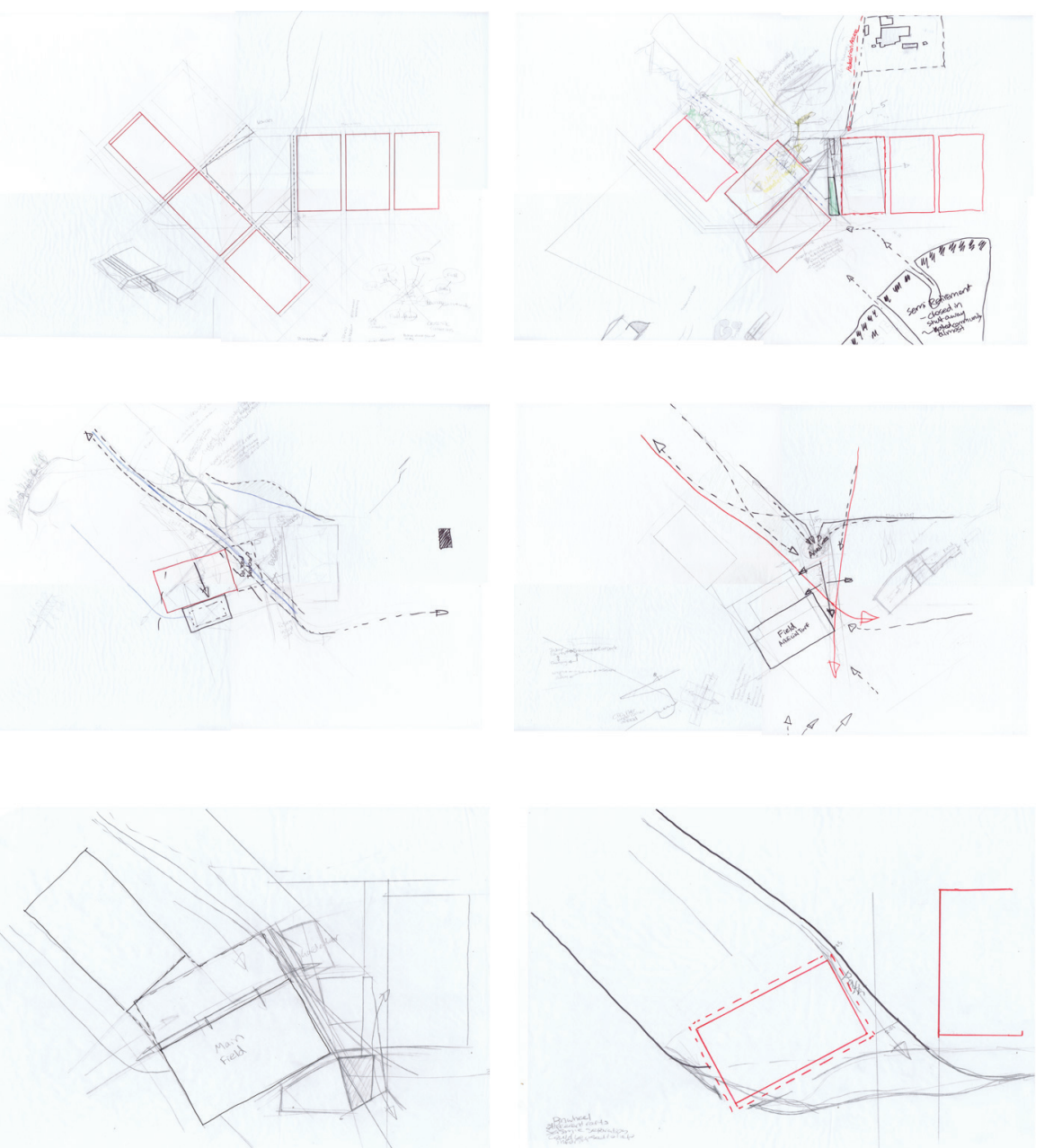

Figure 134: Further development explored a looser arrangement of program and the incorporation of landscape as a design element.

\section{September Critique}

The design presented at the September critique implemented a number of changes (see pages 106 $\&$ 107). The amount of fields accommodated was reduced to three, a central raised artificial pitch and two training / secondary pitches. These fields were oriented so that the sidelines had a visual con-

nection to the wider Wainuiomata context. Other elements of program were concentrated between these fields, in two main blocks, focusing around a main social space along the length of the artificial field, with views to two fields and the wider context, and the indoor sports hall which was moved to face towards the Eastern Hills and fields. The main artificial field was lowered and the space beneath used for car parking. This design began to explore a formal language of overlapping planes, where the building was understood as an extension of the field plane. A manipulation of the landscape was also introduced through the inclusion of hills to provide elevation for spectators viewing games, and as a formal device providing a fluid connection between the ground plane of the field and the elevated plane to the artificial turf. A fluid connection into the social space was also implemented through the inclusion of a grand stand with flows directly from the field into the space. 


\section{Design at September Critique}

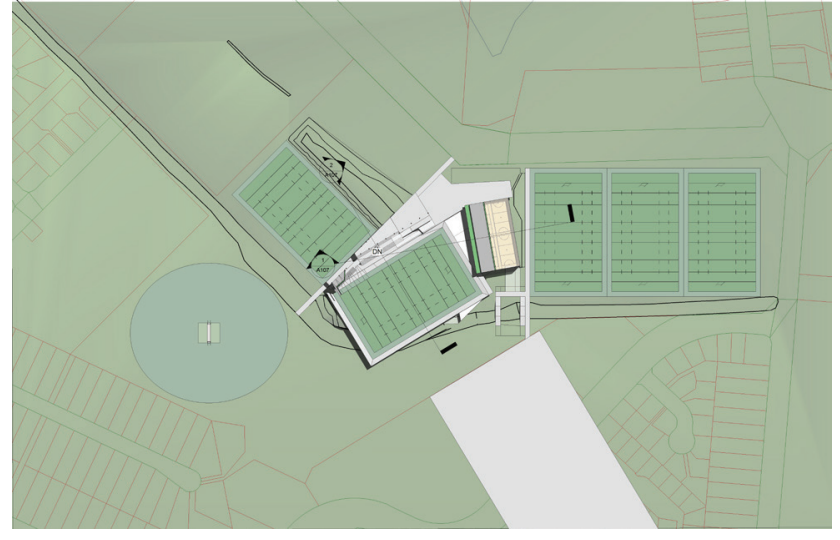

Figure 135: Site Plan - Demonstrating new arrangement of fields and program. Artificial hills are introduced as an additional design element.

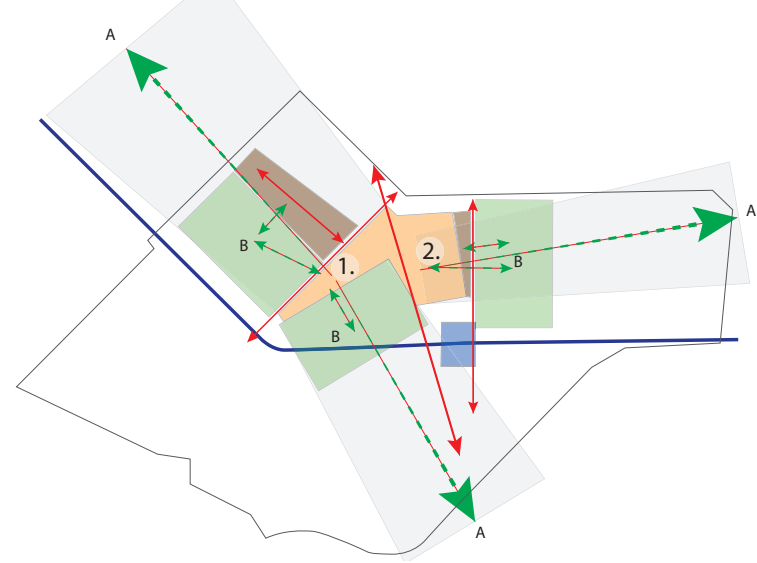

Figure 136: Diagram Of New Layout - Program is re-oriented and concentrated into two blocks with views of, $A$ the wider context and $B$ the sports field.

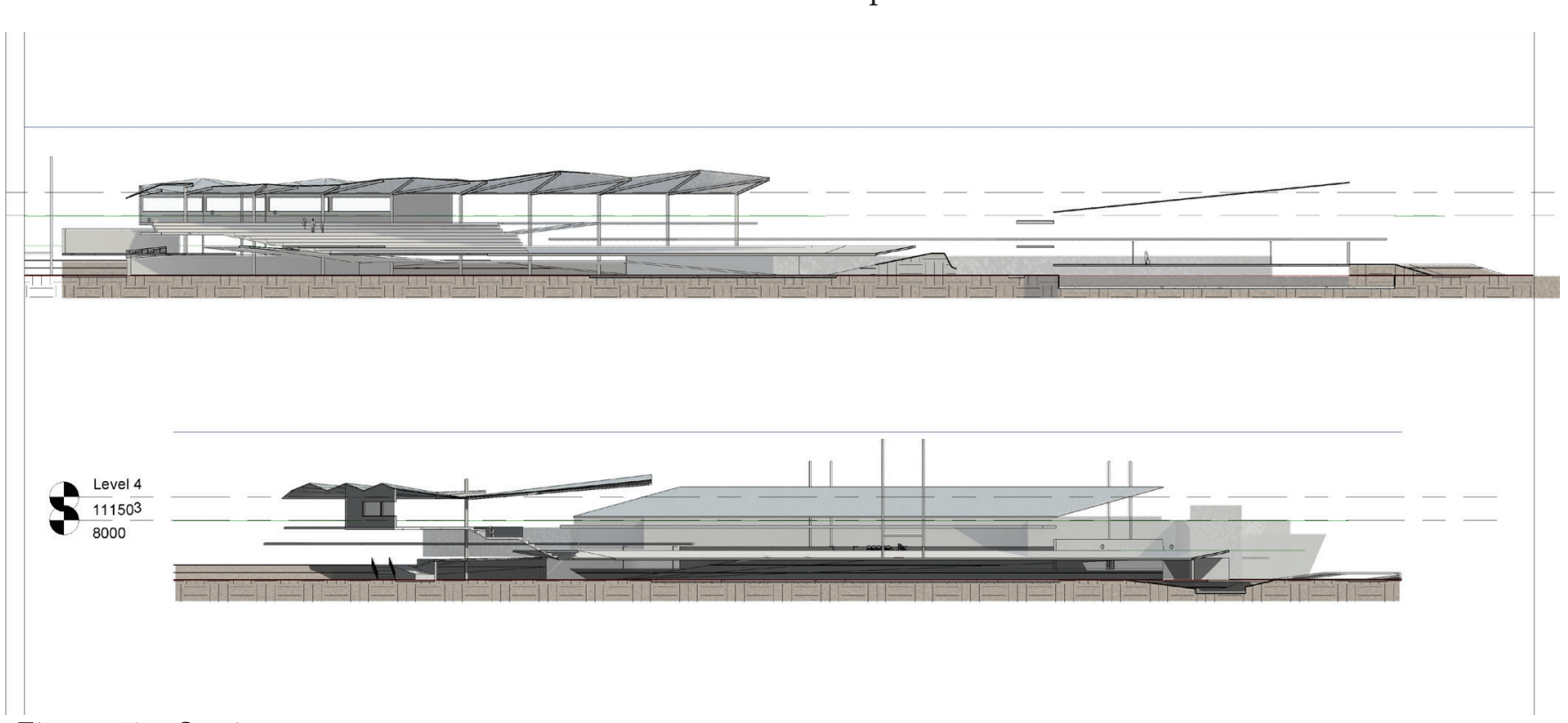

Figure 137: Sections
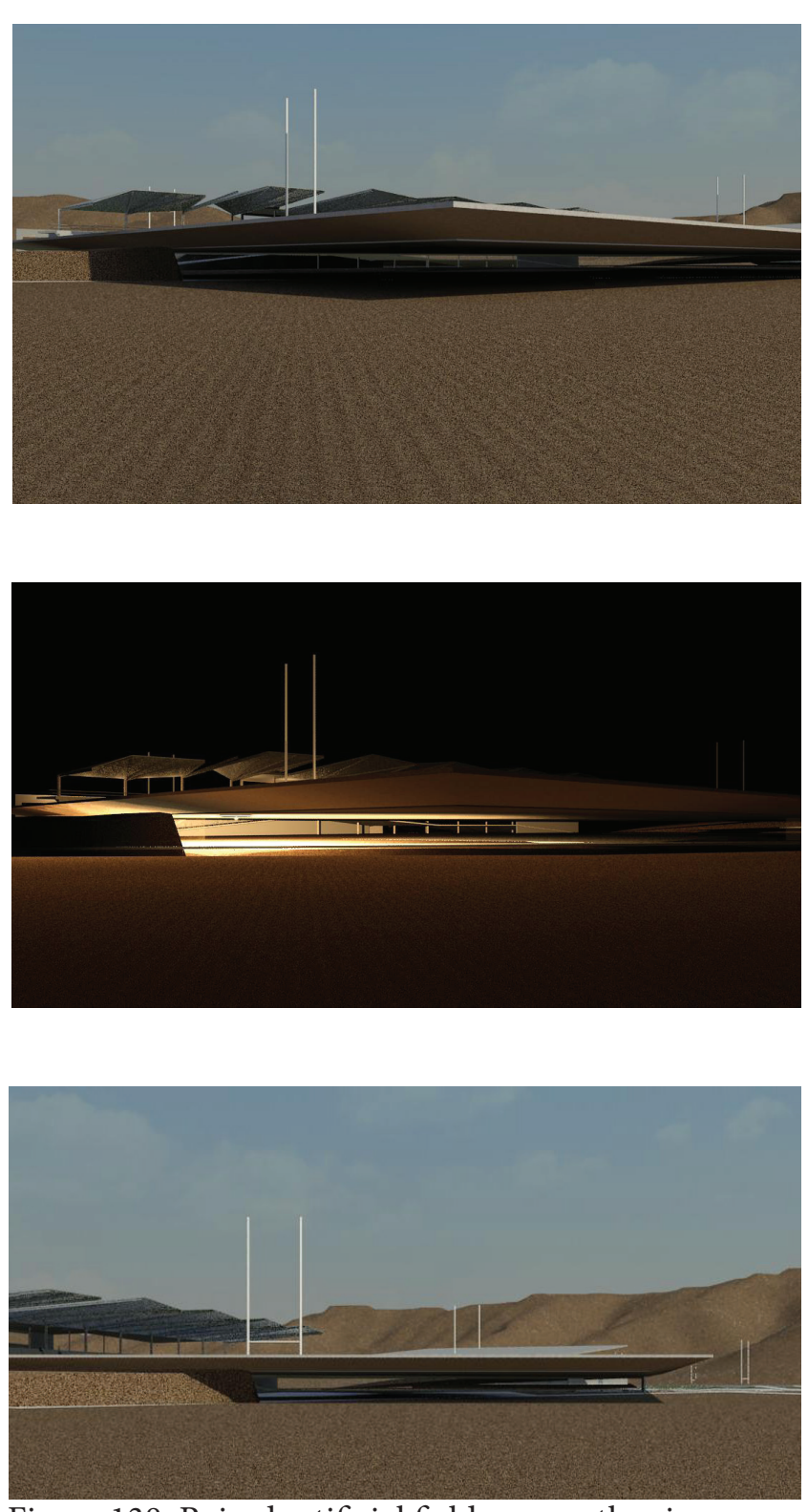

Figure 138: Raised artificial field crosses the river 


\section{Design at September Critique (Continued)}

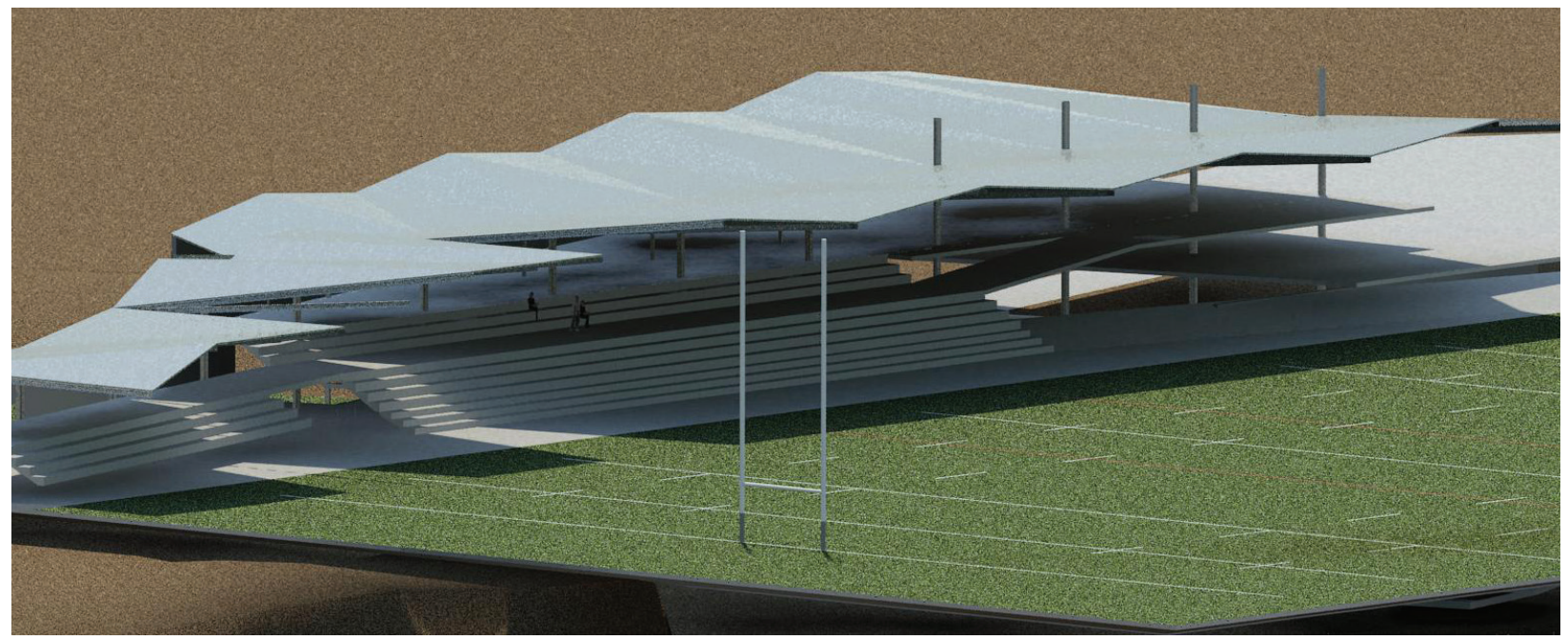

Figure 139: Main Social Area consists of a series of split levels to increase the visual connection to the field.

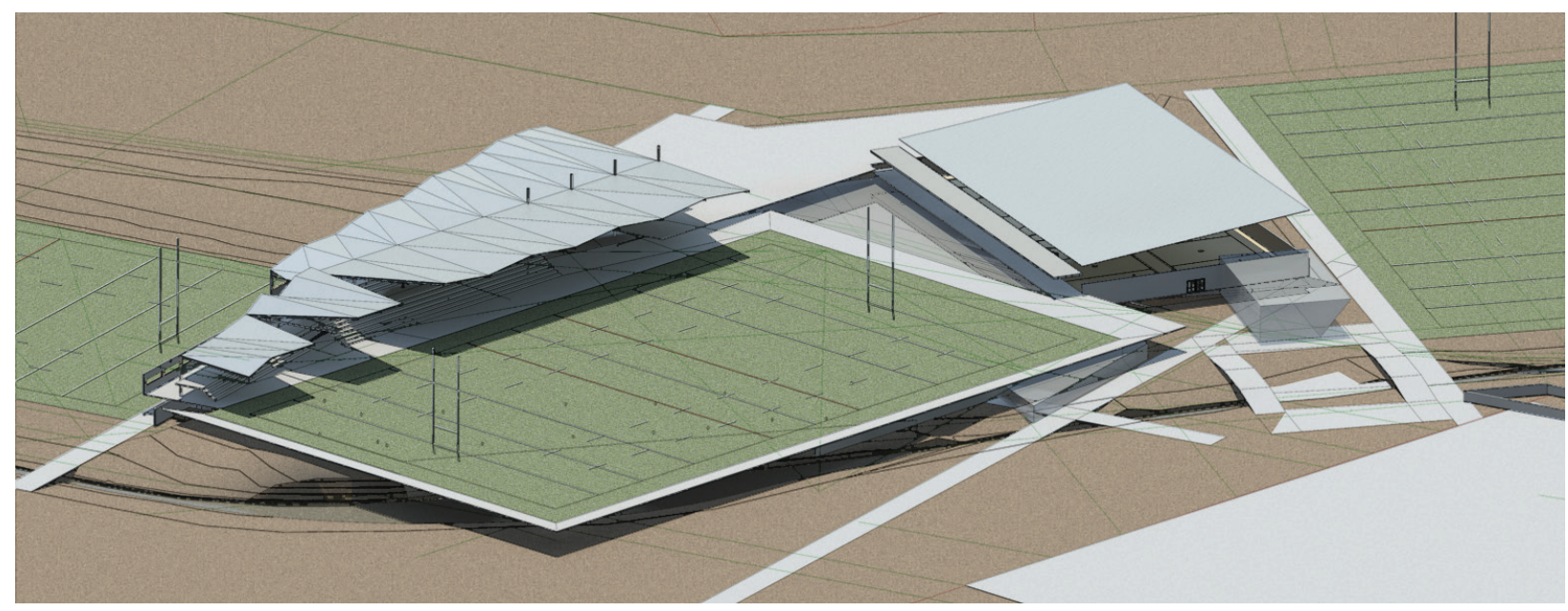

Figure 141: General arrangement on site

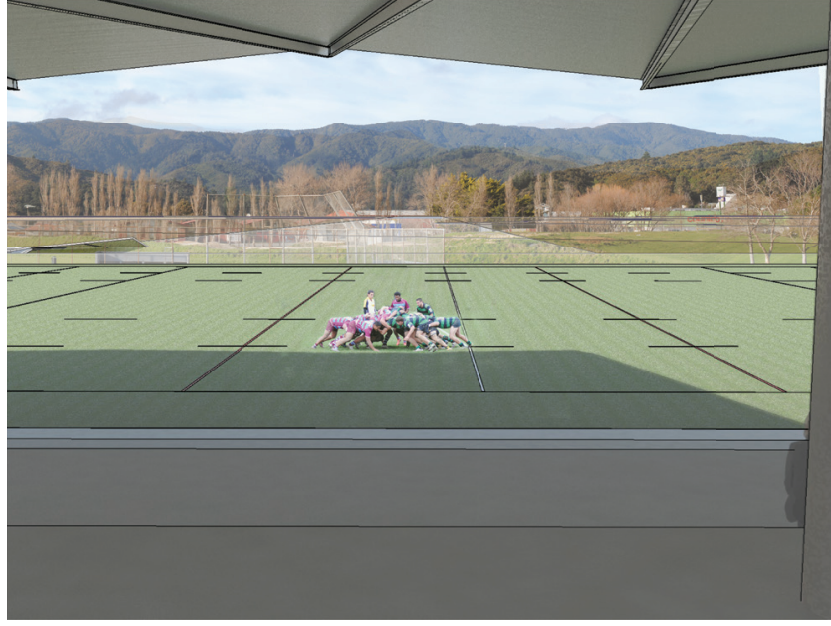

Figure 140: View South from Main Social Area

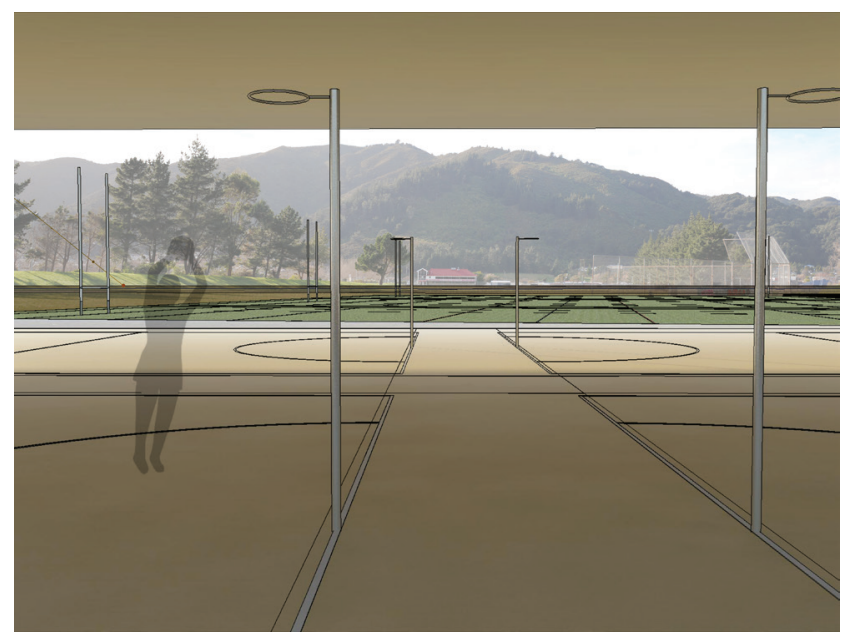

Figure 142: View East from Indoor Sports Hall 



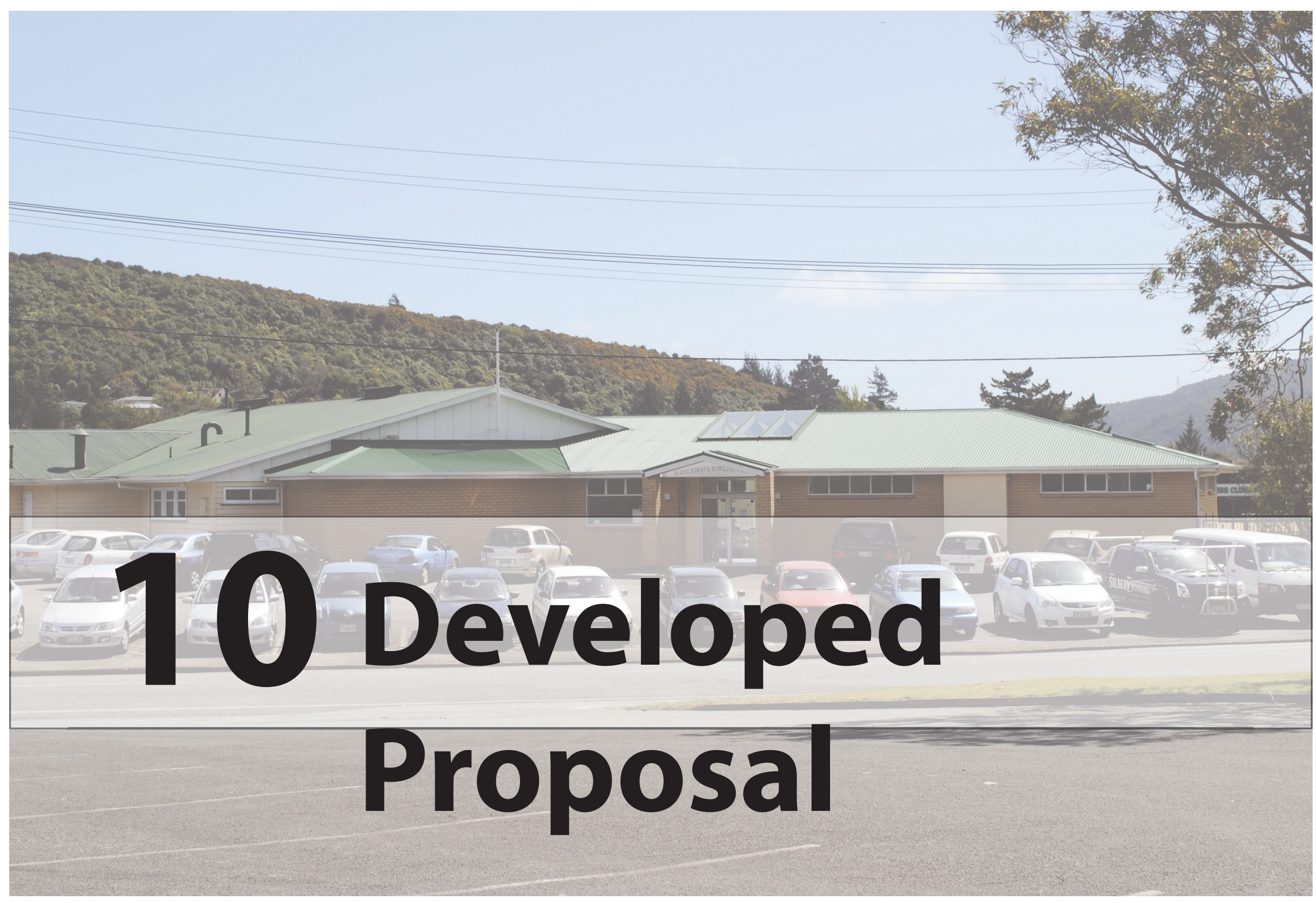





\section{Developed Design}

This chapter summarises developed design outcomes resulting from the research undertaken in this thesis. It will include the following:

- Location Plan (City Wide Scale)

- Site Plan \& Photographs (Social Context)

- Site Plan \& Photographs (Existing Conditions)

- Site Plan \& Diagrams (General Arrangement)

- 3D Overview of Site

- Section Relationship to Landscape

- General Plans \& Sections

- Detail Plans / Sections (Main Clubroom Block)

- Renders_(Connection to context \& approaches to site)

This chapter ends with a discussion of the final design outcom and reflection on the design research process undertaken. 


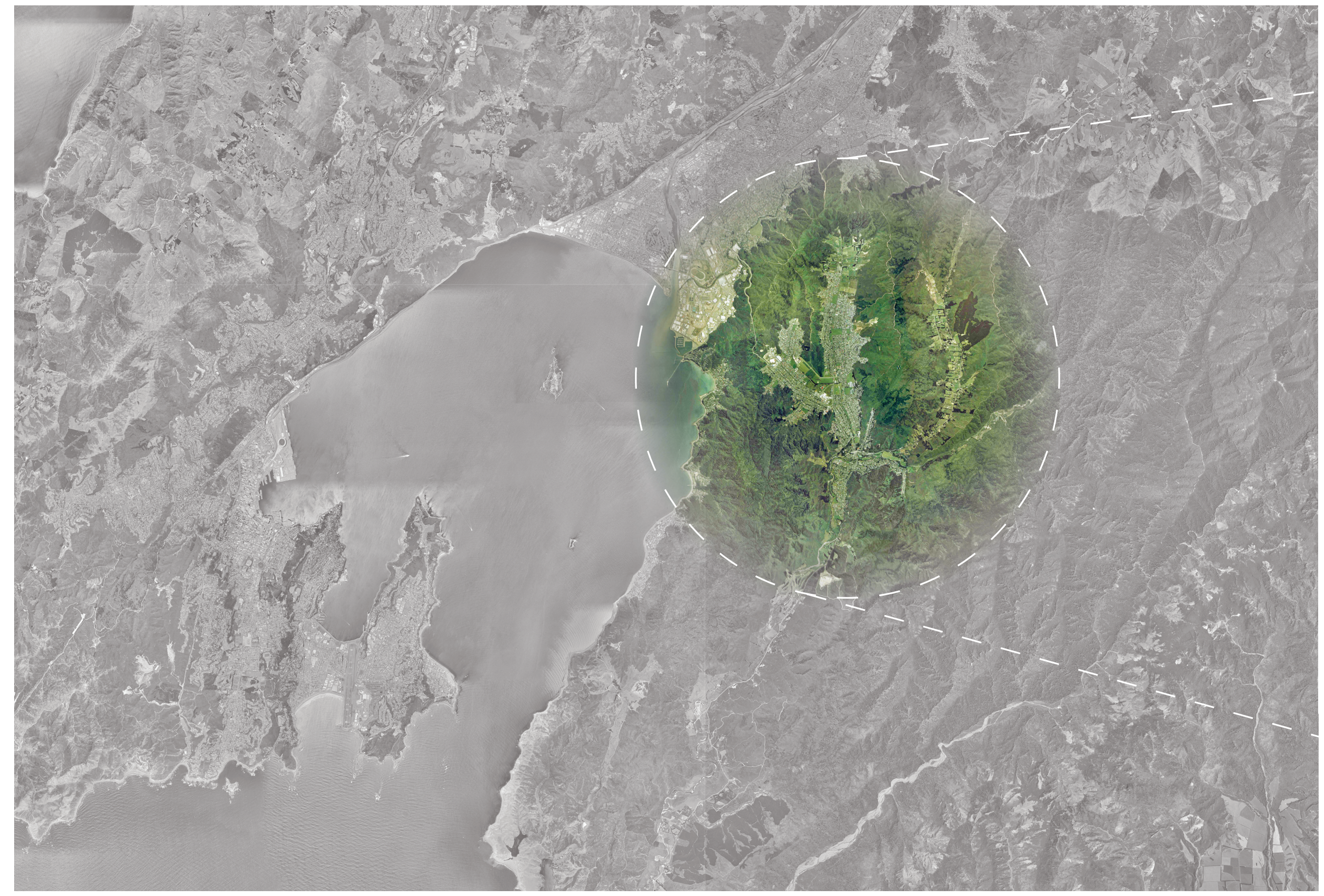




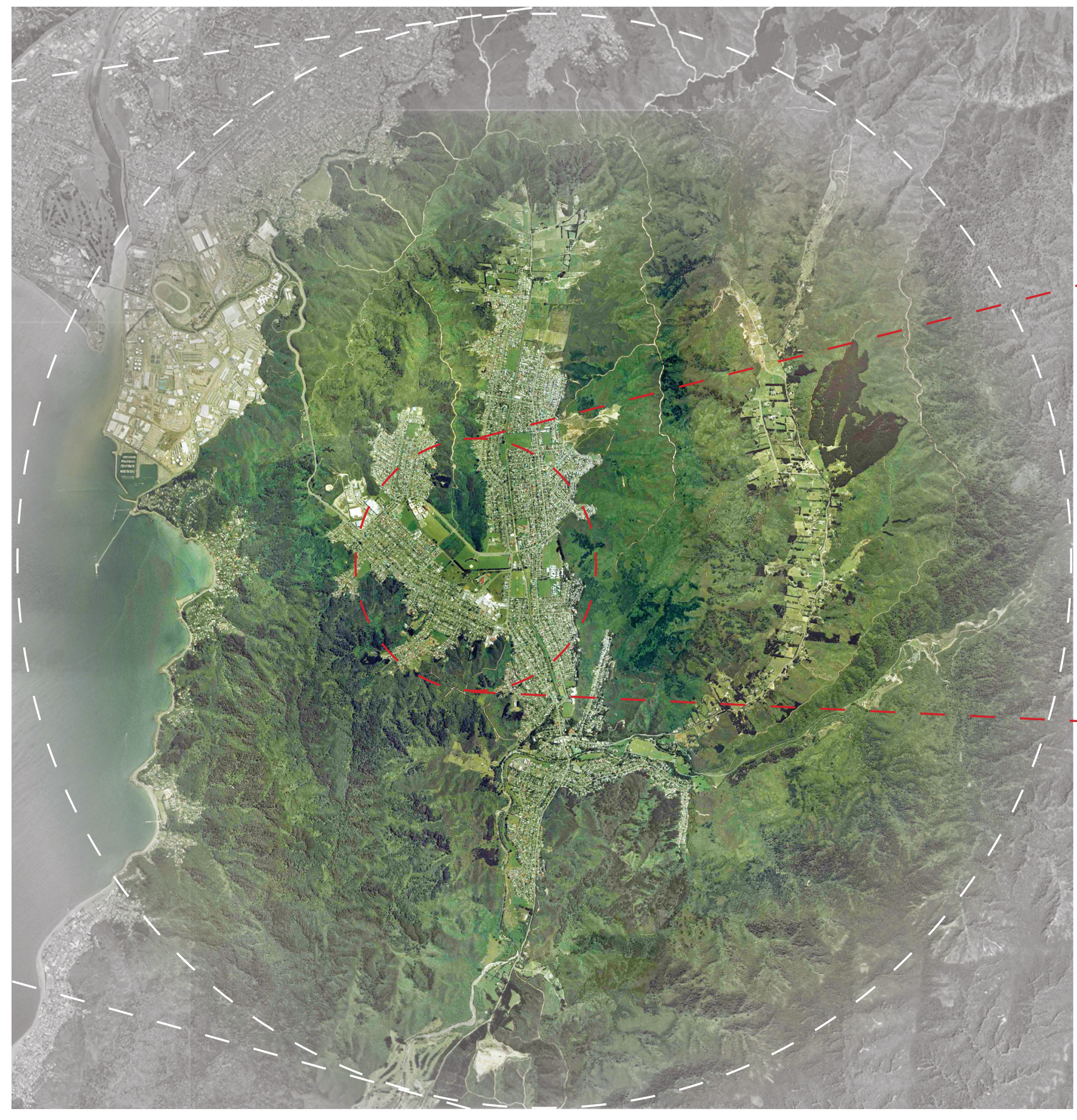

\section{Location of Site}

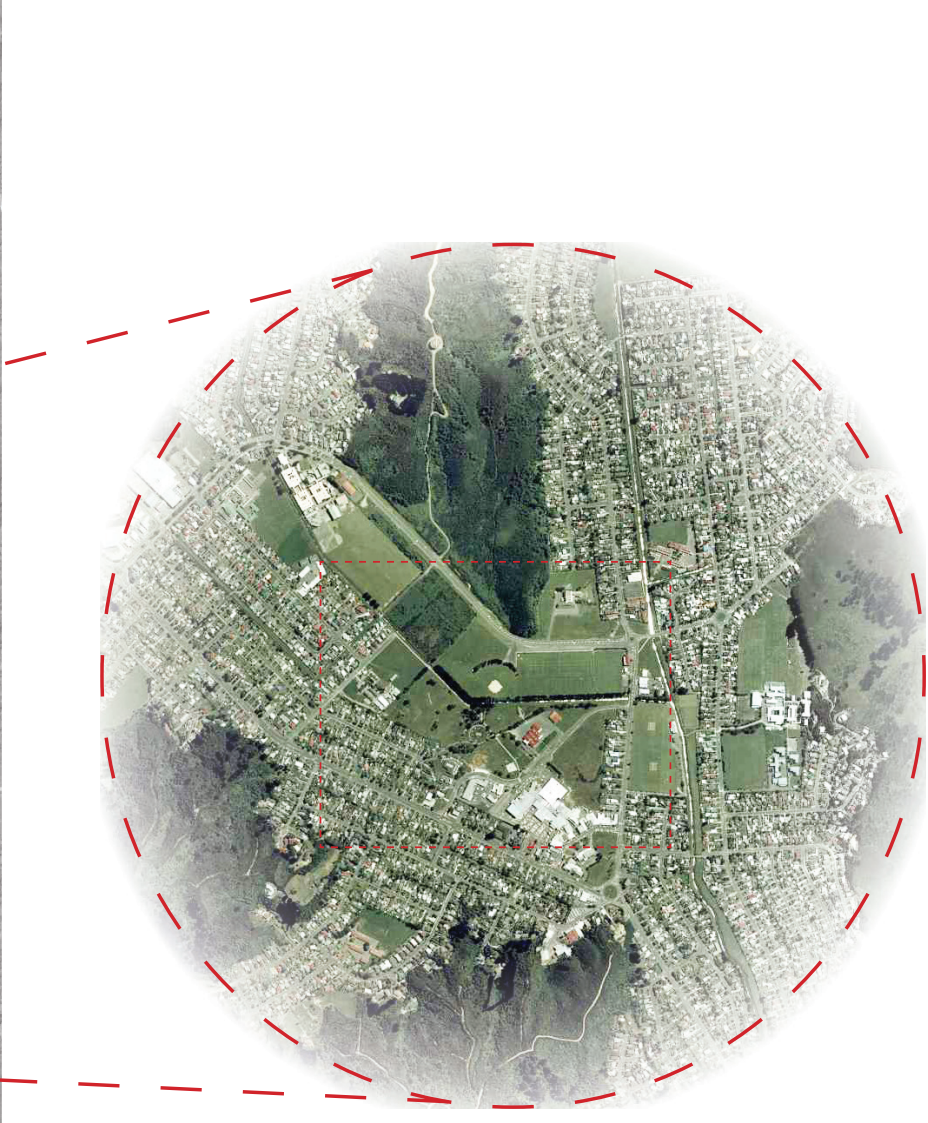

Above

Figure 143: Wise Park and Immediate Context Image sourced from google earth (Google Earth. 2012)

Previous Page

Figure 144: Wainuiomata is Located to the East of Lower Hutt and the Wellington Harbour Image adapted from orthophoto (LINZ)

Left

Figure 145: Location of Site, Wise Park, In Central Wainuiomata

Image adapted from orthophoto (LINZ) 


\section{Social Context}

Centres of community activity near Wise Park include:

1. Wainuiomata Intermediate School

2. Wainuiomata High School

3. Path to Firebreak

4. Parkway Primary School

5. St Claudine Thevenet School

6. Wainuiomata Marae

7. Shops on The Strand

8. Wainuiomata Mall

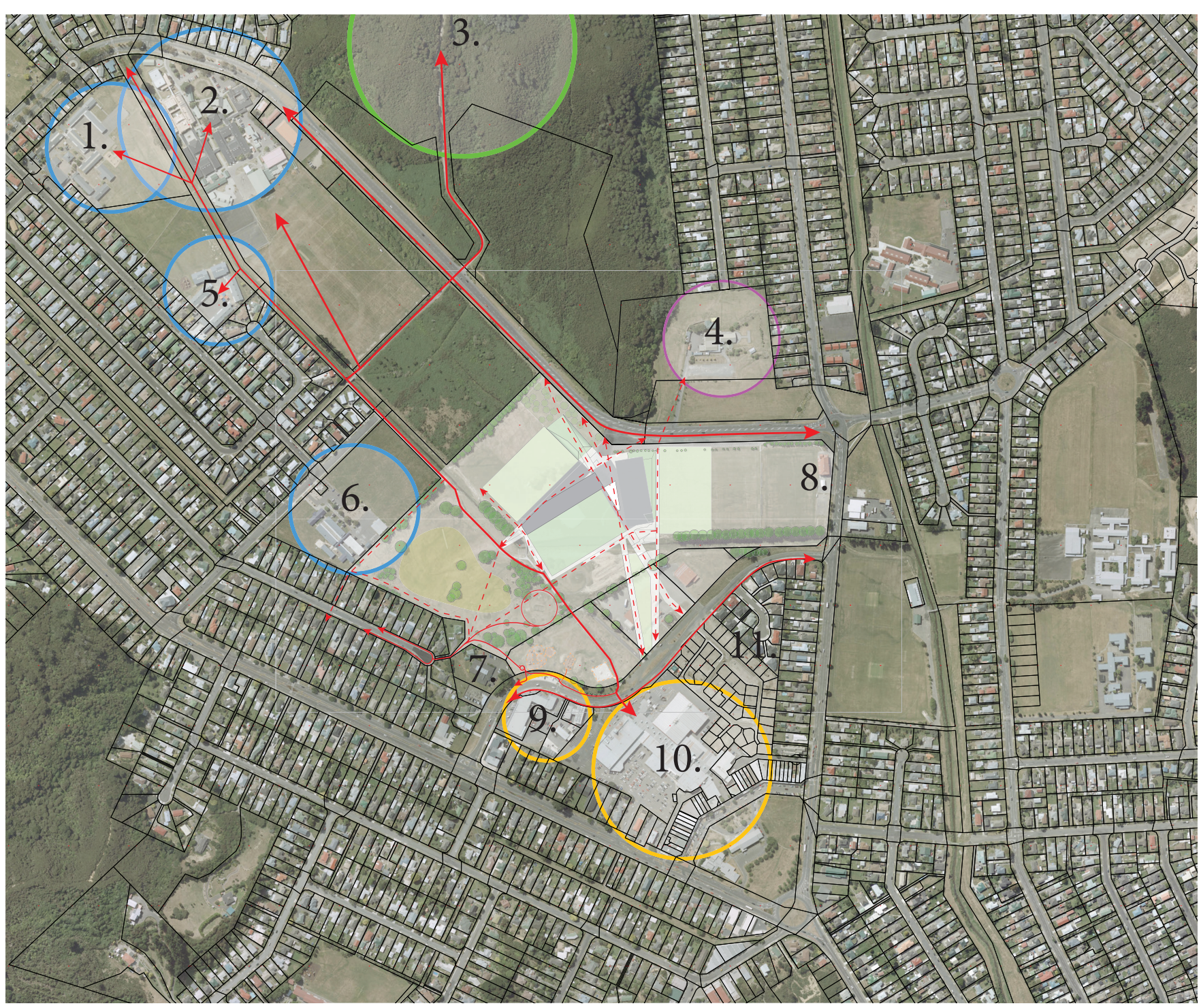

Above

Figure 146: Site Plan - Social Context

Background image source: Google Earth (Google Earth. 2012)
Opposite Page

Figure 147: Photographs of Context 


\section{Photographs of Context}

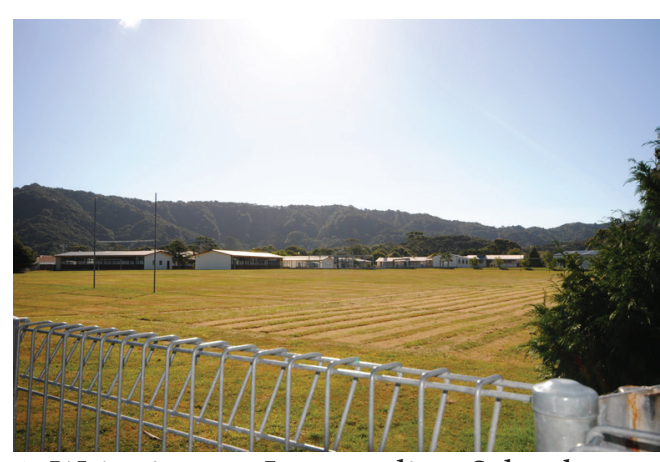

1. Wainuiomata Intermediate School

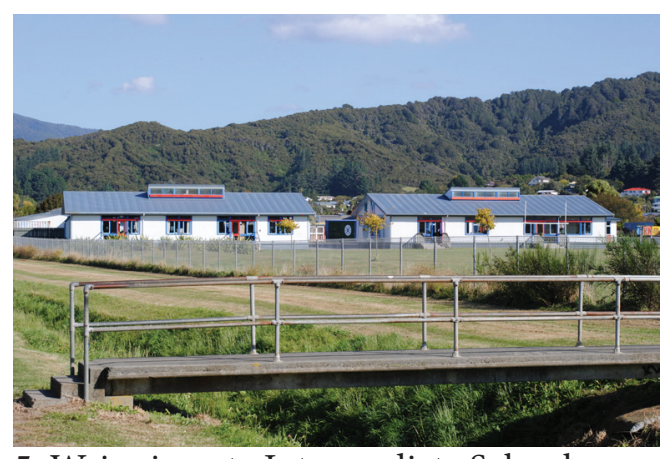

5. Wainuiomata Intermediate School

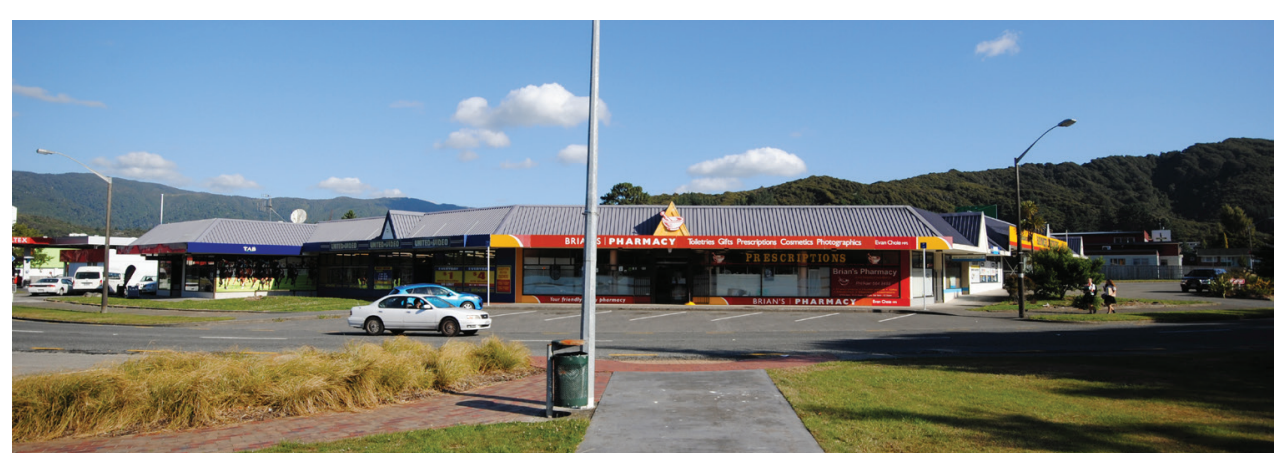

9. The Strand - Shops

2. Wainuiomata High School

7. Medical Centre
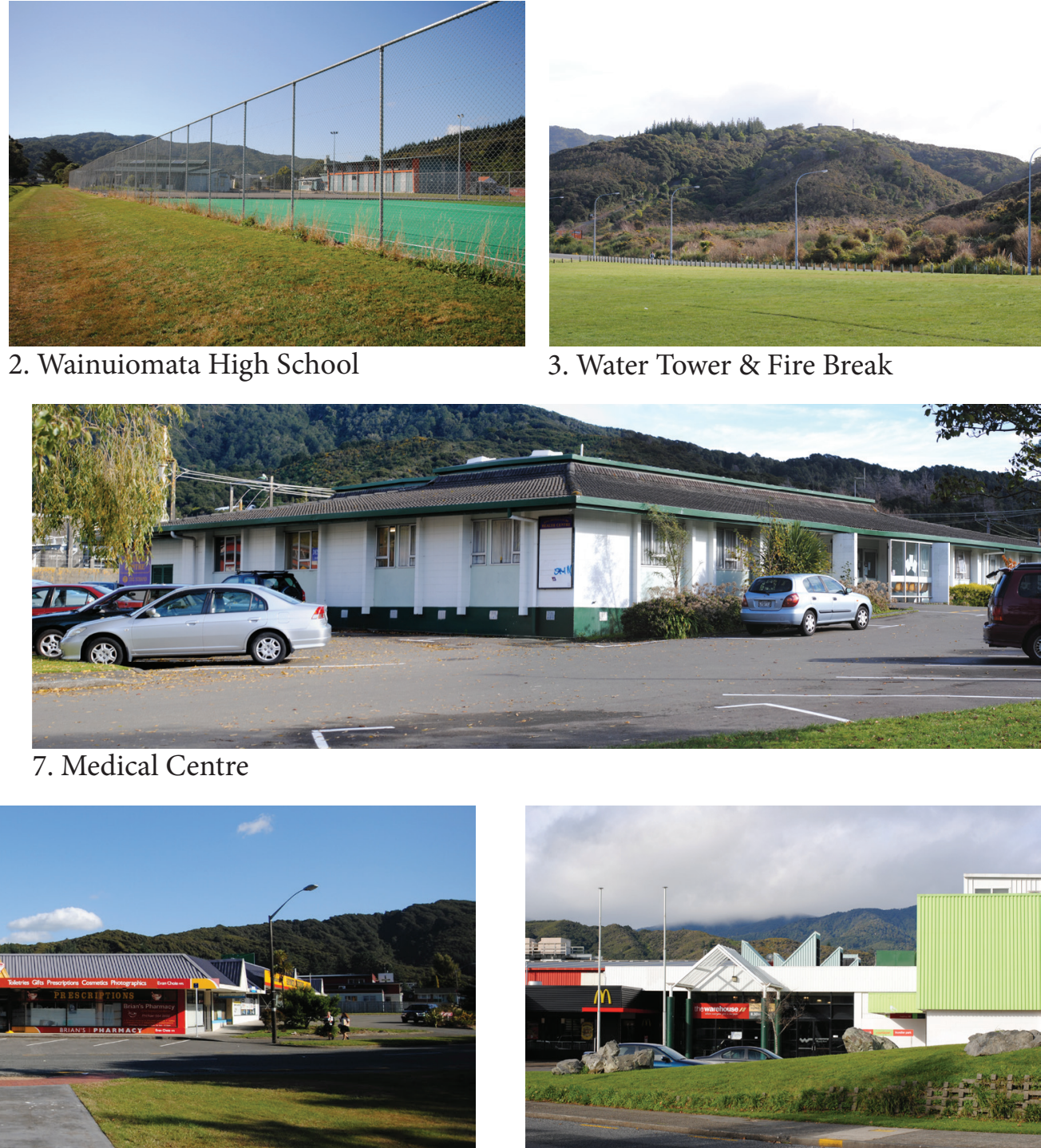

10. Wainuiomata Mall

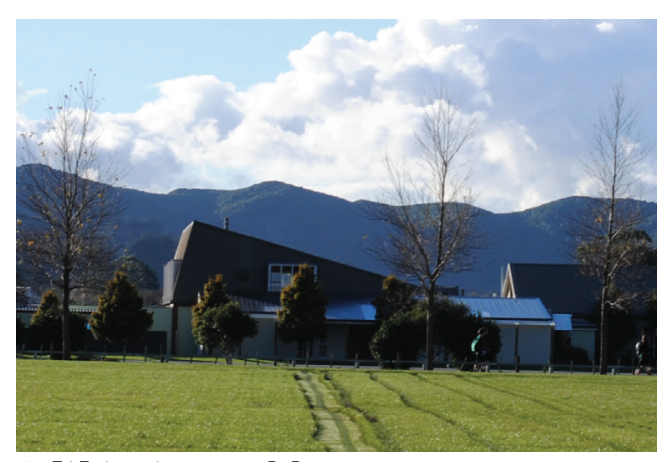

4. Wainuiomata Marae

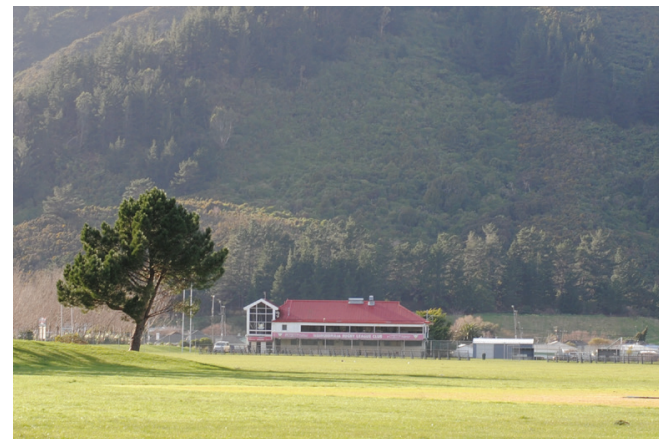

8. Wainuiomata Rugby League Club

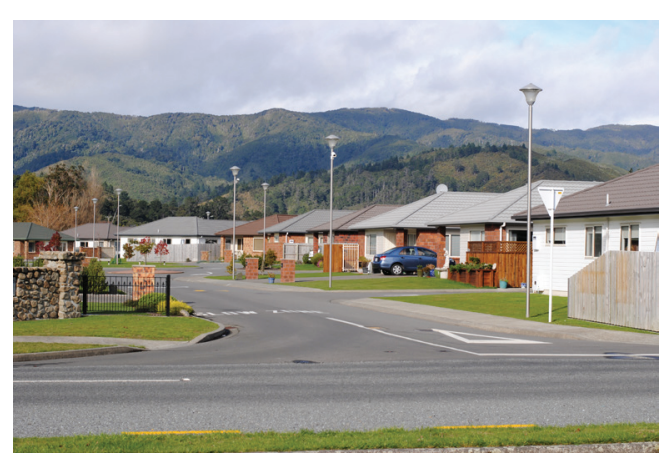

11. Semi-Retirement Village 


\section{Site Plan - Existing Site Conditions}

Wise Park Points of Interest:

1. Training Field (Including Flood Lights)

2. Softball Diamond

3. Recycling Centre

4. Rugby League Fields

5. Path Along River (School Route)

6. Bridge

7. BMX Track

8. Wainuiomata Bush Fire Service

9. 'Swampy' under utilised land

10.Playground

11. Skate Park

12. The Fitzroy Tavern \& Super Liquor Wainuiomata

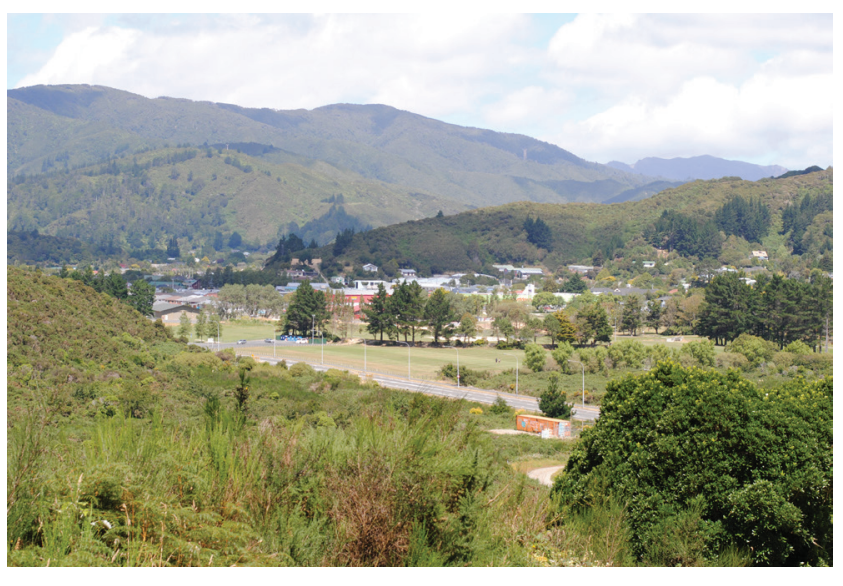

Figure 148: View of Site Looking South from Fire Break

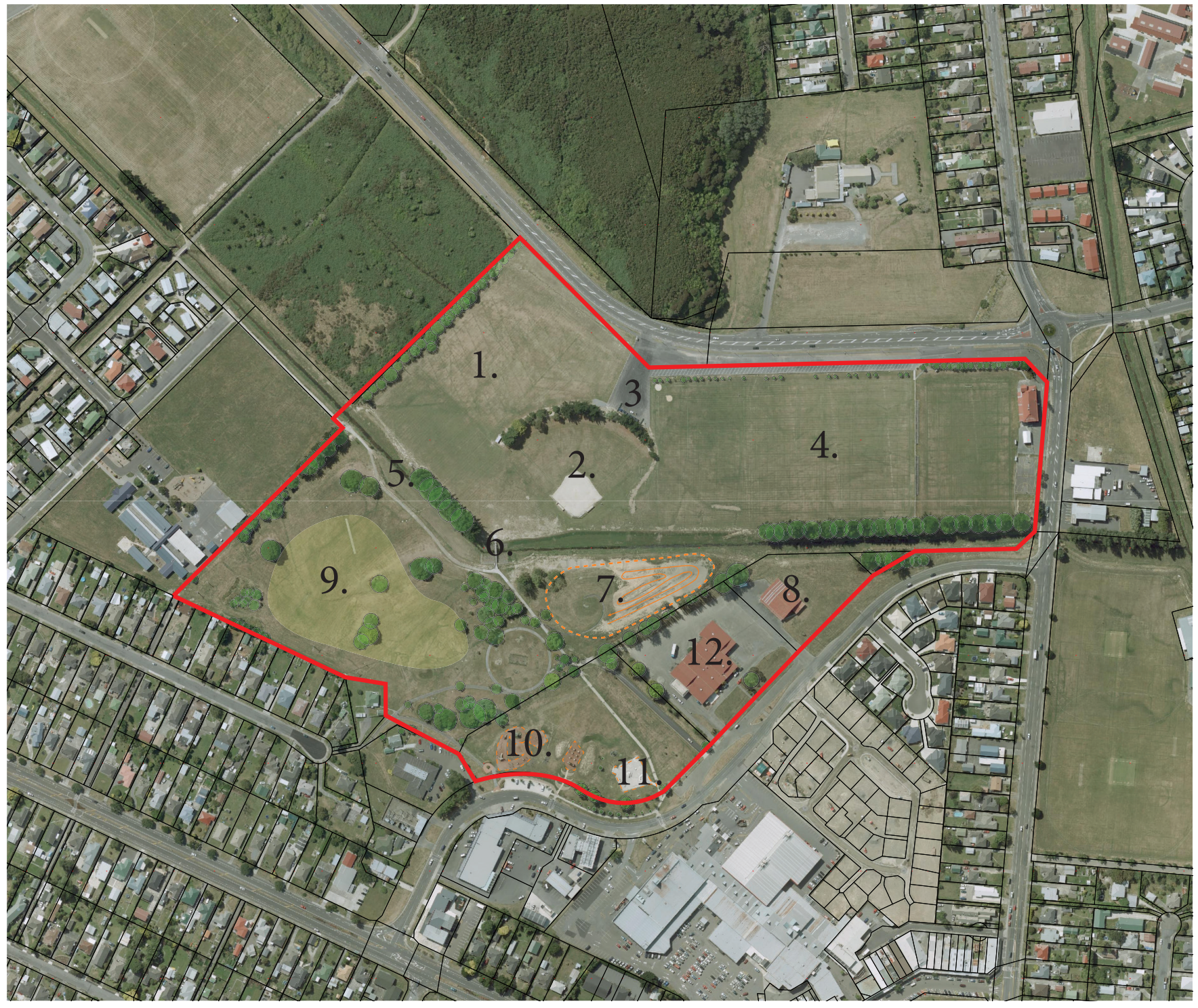

Above

Figure 149: Site Plan - Existing Site Conditions

Background image source: Google Earth (Google Earth. 2012)
Opposite Page

Figure 150: Photographs of Existing Site 
Photographs of Existing Site

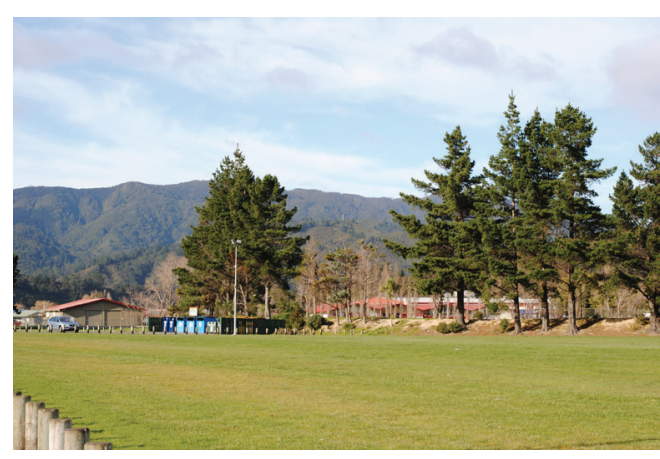

1. Training Field

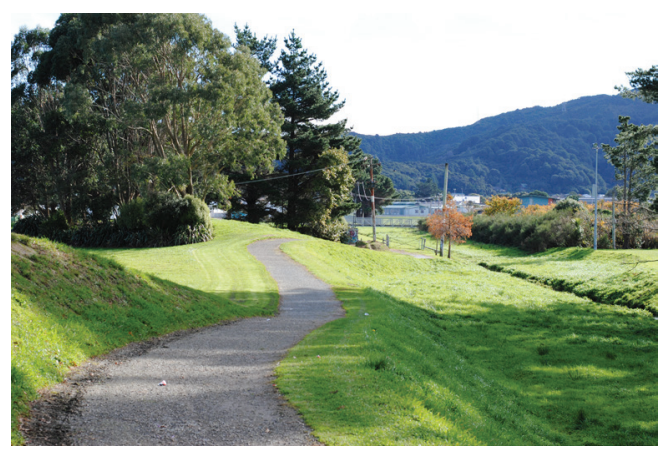

5. Path Along River (School Route)

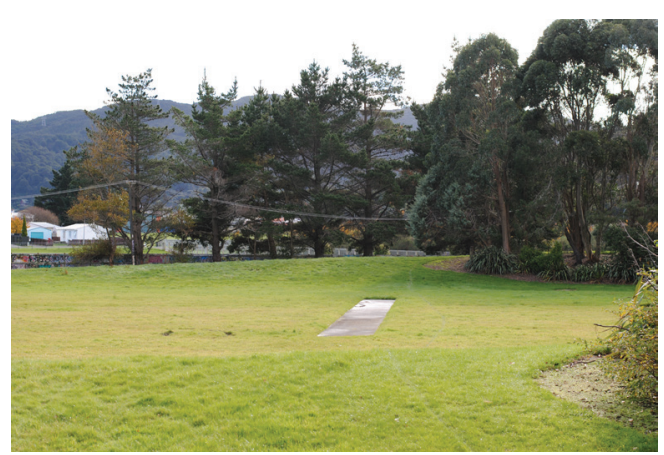

9. Underutilised Land

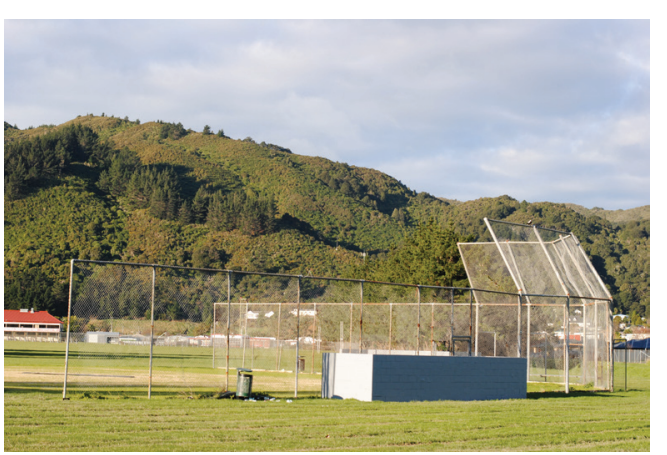

2. Softball Diamond

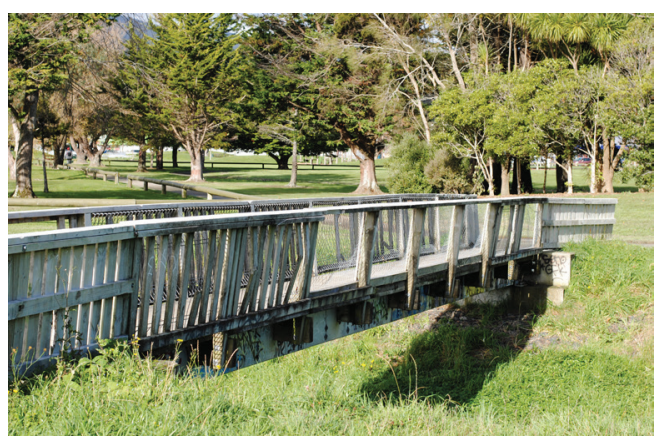

6. Bridge

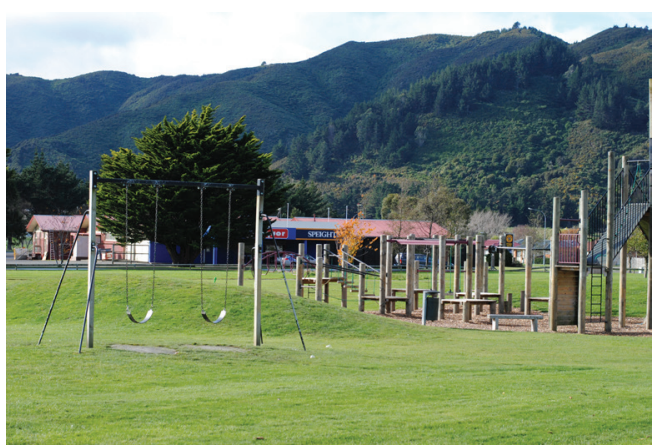

10. Playground

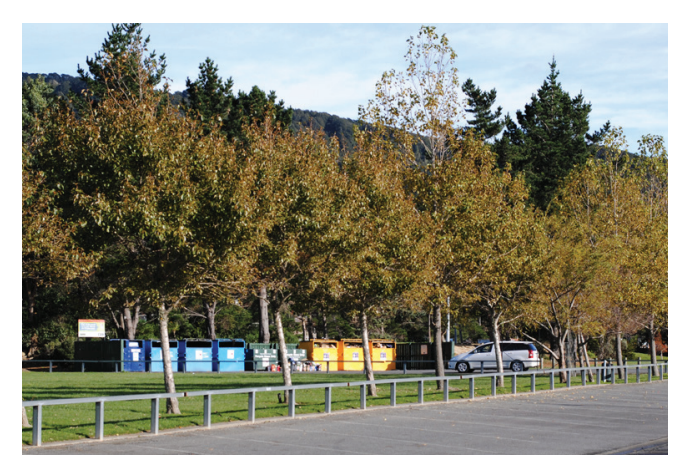

3. Recycling Centre

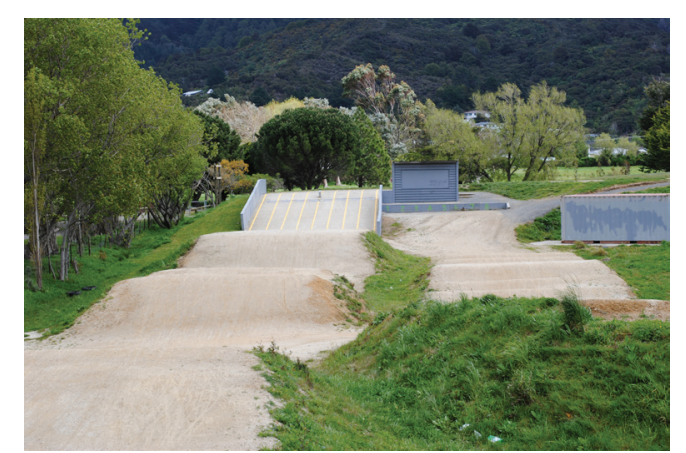

7. BMX Track

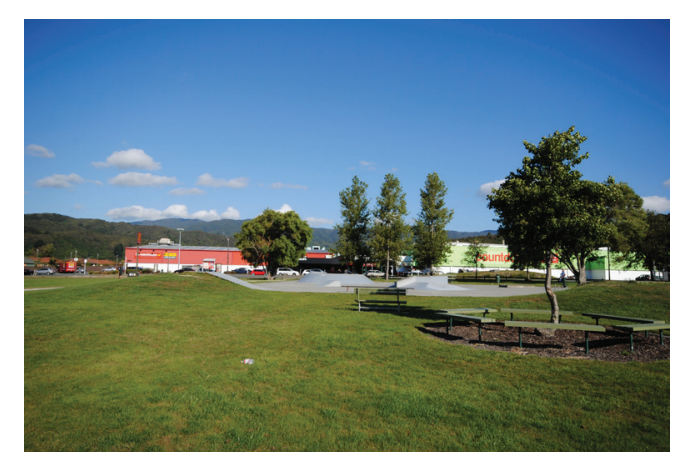

11. Skate Park

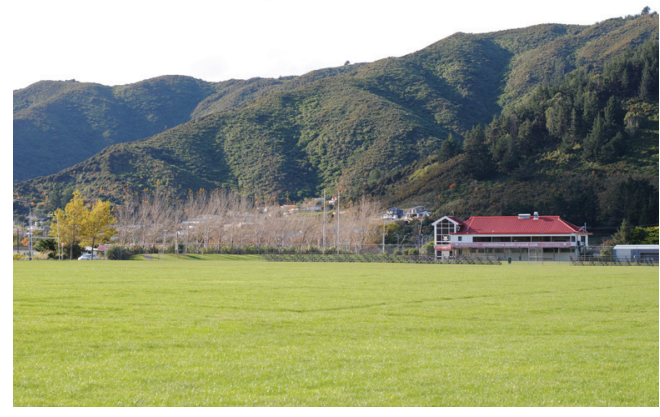

4. Rugby League Fields

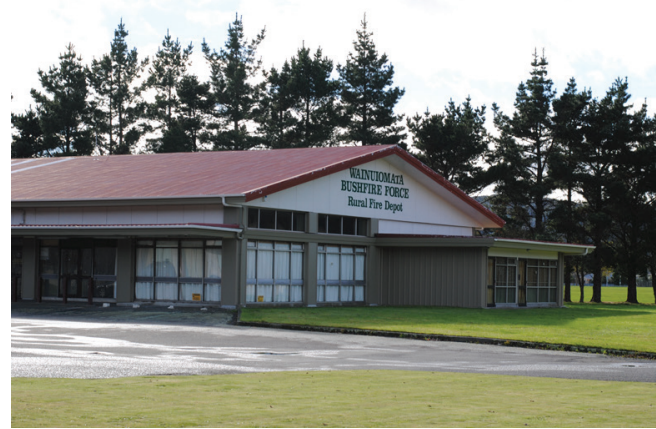

8. Wainuiomata Bush Fire Service

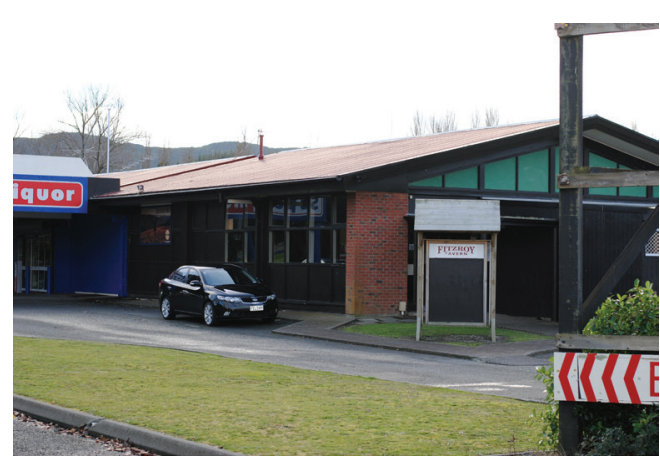

12. The Fitzroy Tavern \& Super Liquor 


\section{Site Plan - General Arrangement}

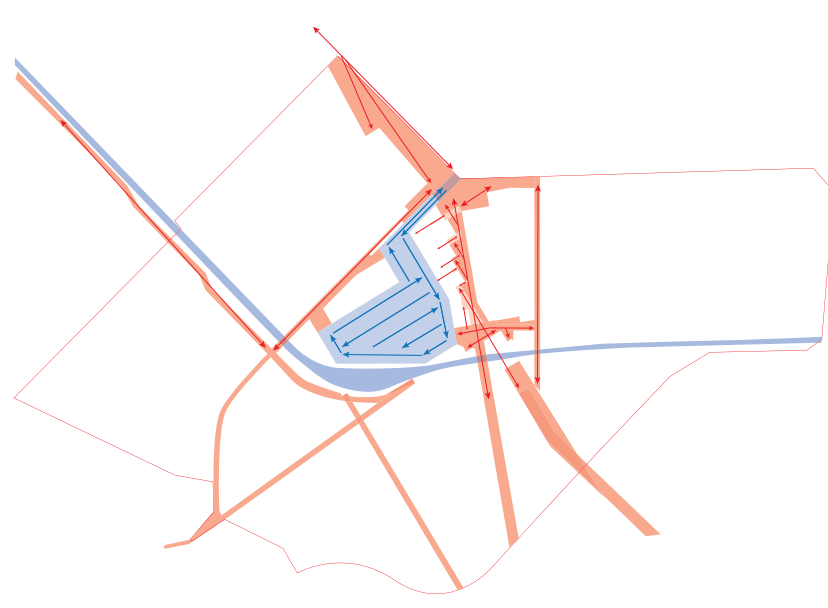

Figure 151: Pedestrian (Red) \& Vehicular (Blue) Circulation and connections through site. River through site shown in blue.

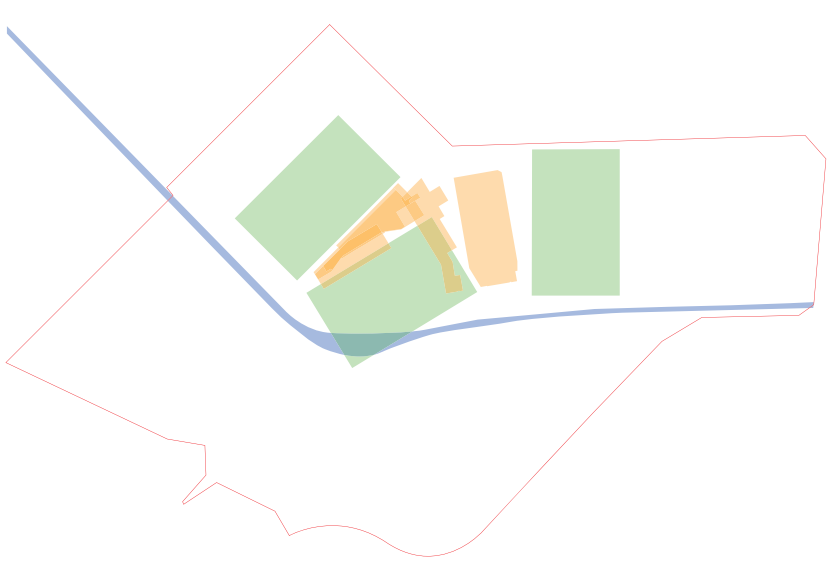

Figure 152: Three main blocks of program (Orange) are distributed between three fields (Green). River through site shown in blue.

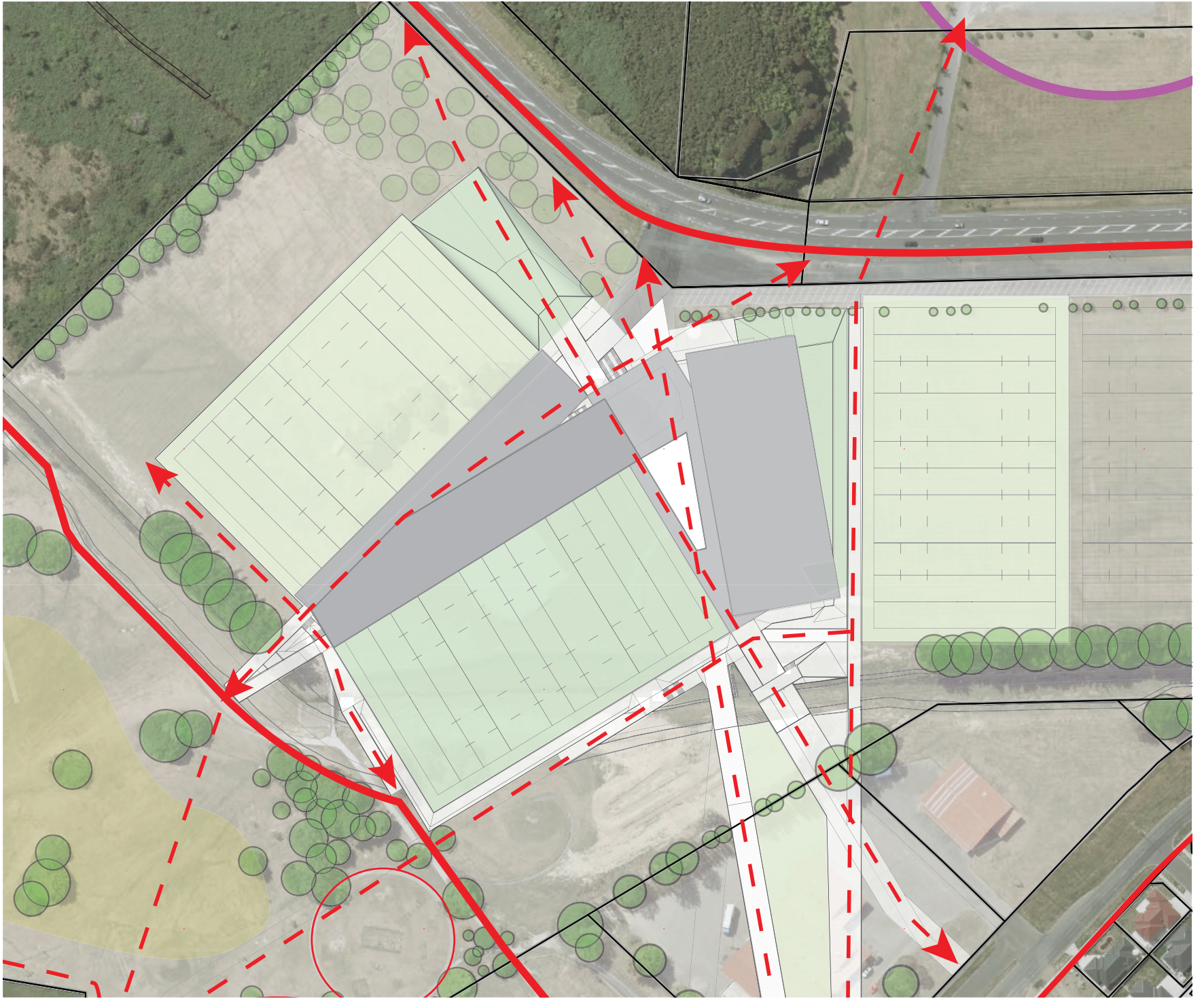

Figure 153: Site Plan - General Arrangement and Connections Through Site

Background image source: Google Earth (Google Earth. 2012) 


\section{D Overview Of Site}

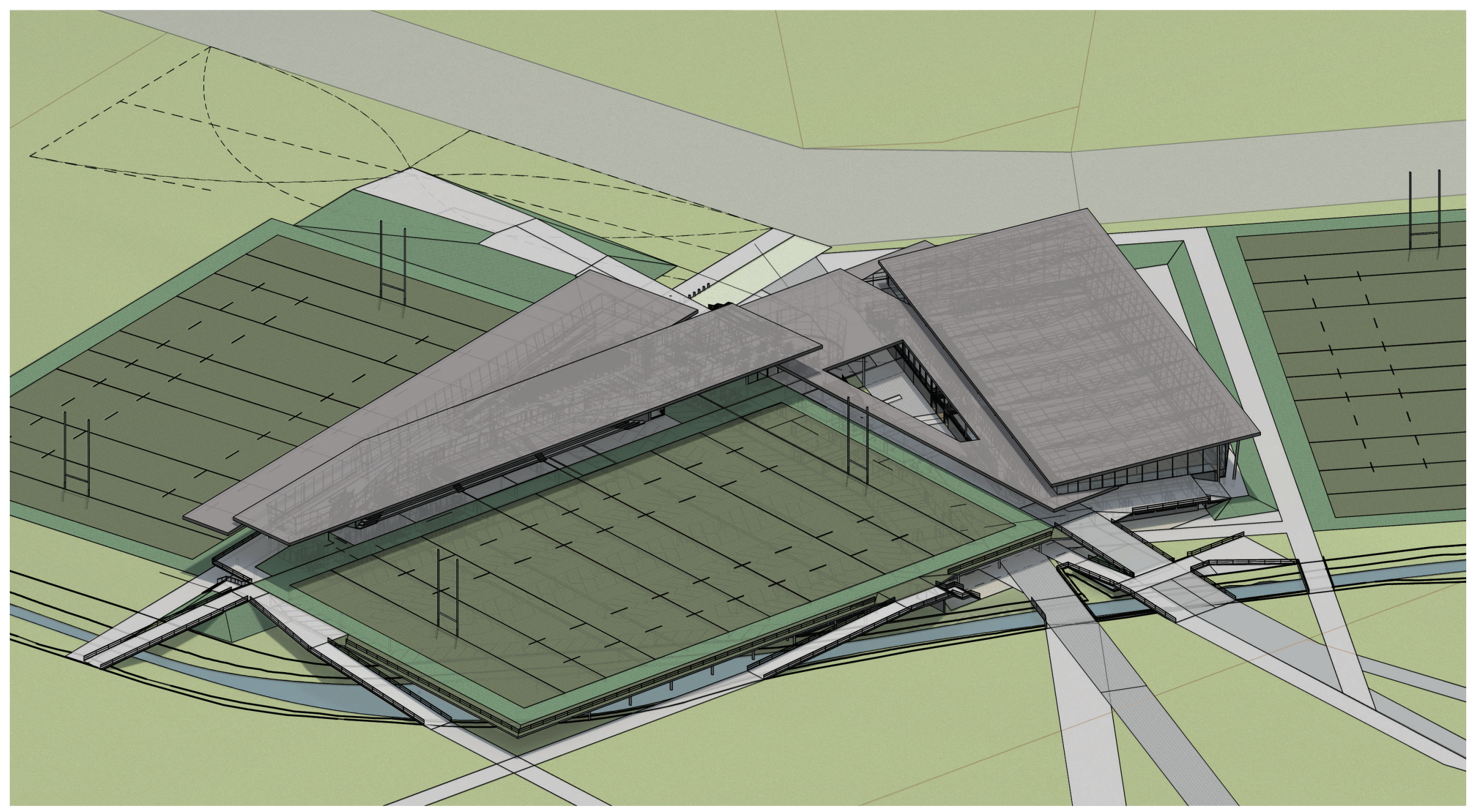

Figure 154: General Arrangement - Overlapping planar roof forms are derived from the planar nature of the sports field 


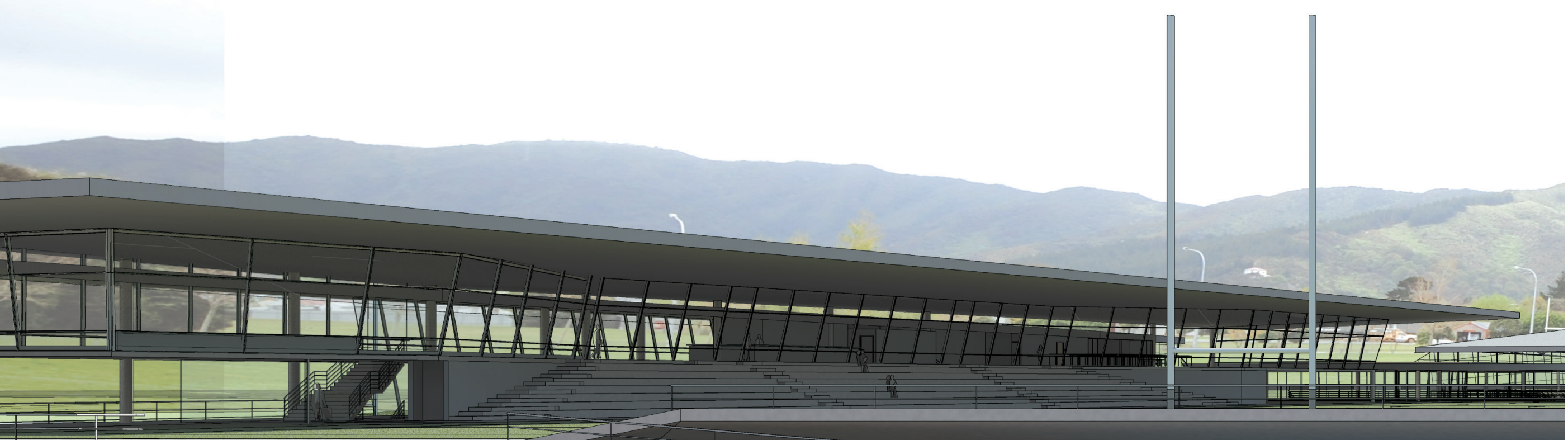
五 


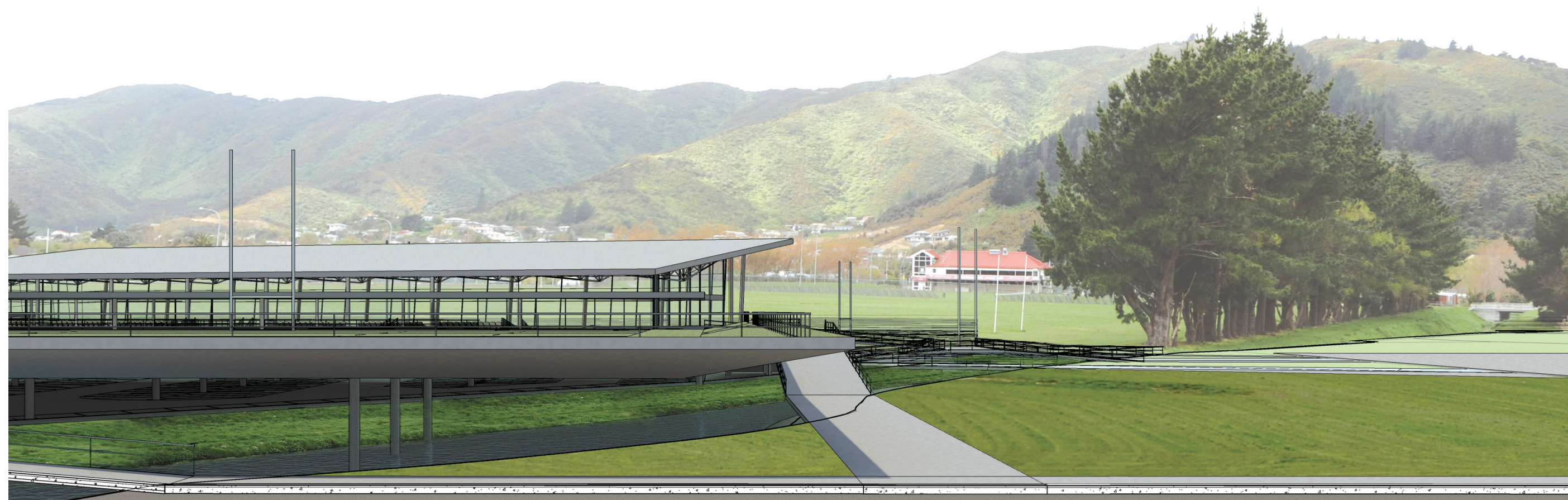




\section{Ground Floor Plan}

The ground floor contains five main areas:

1. Training Field- This field supplements the main artificial turf field, providing space for training and some games.

2. Utility Block- This contains; changing facilites which service both the training field and the main field above, lecture theatre, plant rooms, storage space, and vertical circulation. 3. Parking - This is placed centrally, underneath the raised main field. Easy access to playing areas, ground level program and vertical circulation is facilitated through the placement of multiple entrances.

4. Central Core - This area links the main entrance to teach ing spaces and library and sports hall. Vertical circulation provides access to the 1st floor sports field, viewing areas and training facilities.

5. Indoor Sports Hall: A large open hall with retractable seating. This is orientated to provide views to and from the distant hills and adjacent sports fields. Changing rooms and storage areas are provided to service this area.

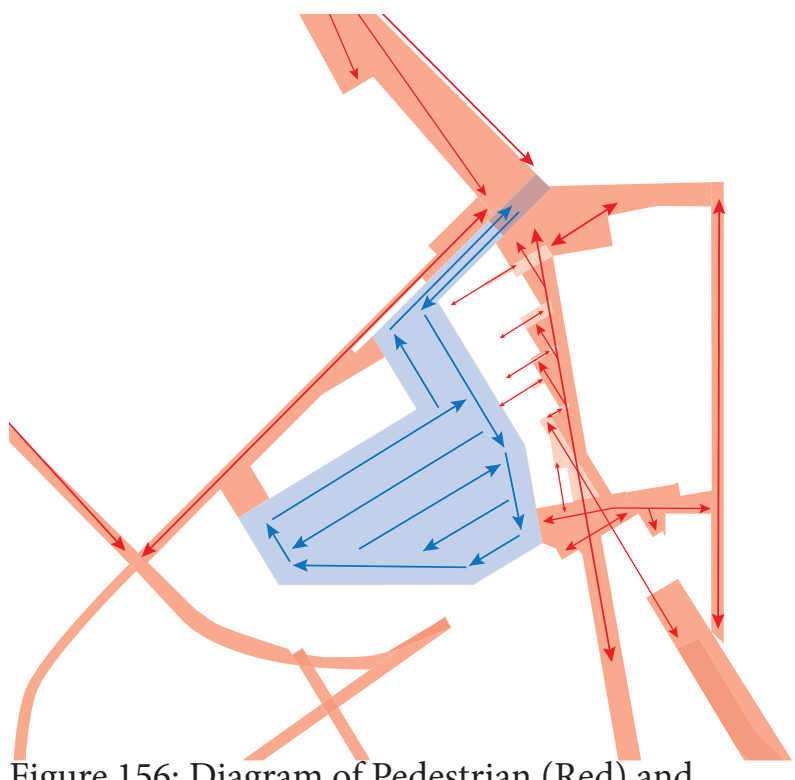

Figure 156: Diagram of Pedestrian (Red) and Vehicular (Blue) Circulation

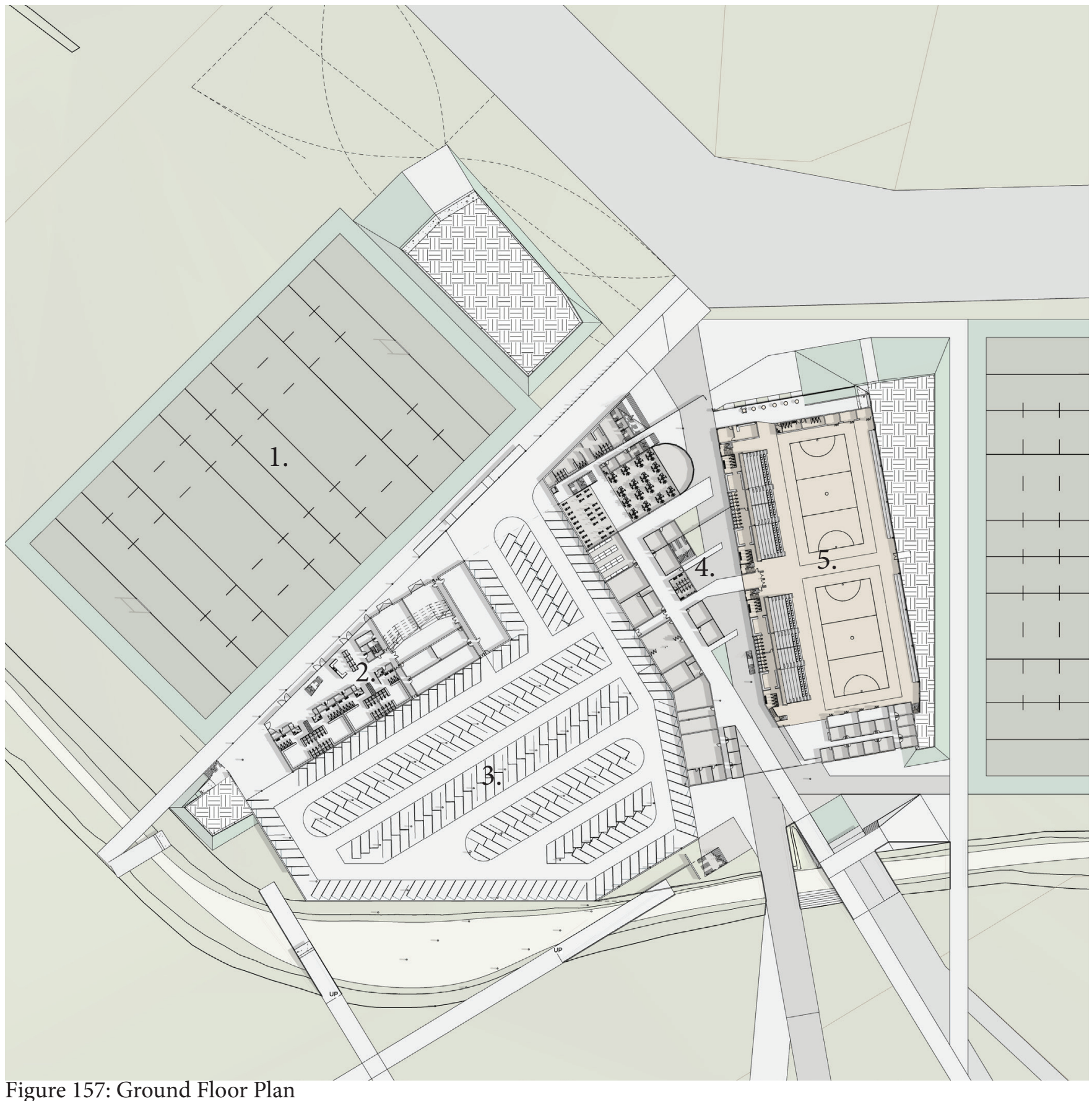

Figure 157: Ground Floor Plan 


\section{First Floor Plan}

The first floor contains:

1. Main sports field- this has an artificial turf enabling its use in all weather

2. Warm up Area - This is placed adjacent to the main field and recovery suite.

3. Viewing Areas- These are provided along the length of the main field, and areas which look down into the sports hall and the training field.

4. Grandstand - This is placedto optimise views of the main field and leads up to the social area above.

5. Central Foyer - This area connects 'public' areas of the teaching program, lecture theatre, library, and seminar room. It has views of the training field and connects to the social space above via a ramp and stairs.

6. Recovery Suite - This area has rooms suitable for recovery after matches and trainings including, physio room, spa and cryotherapy pool, and a recovery lounge.

7. Artificial Landscape - This formally links between the ground plane and the first floor plane providing a fluid connection up to the main field and through the site.

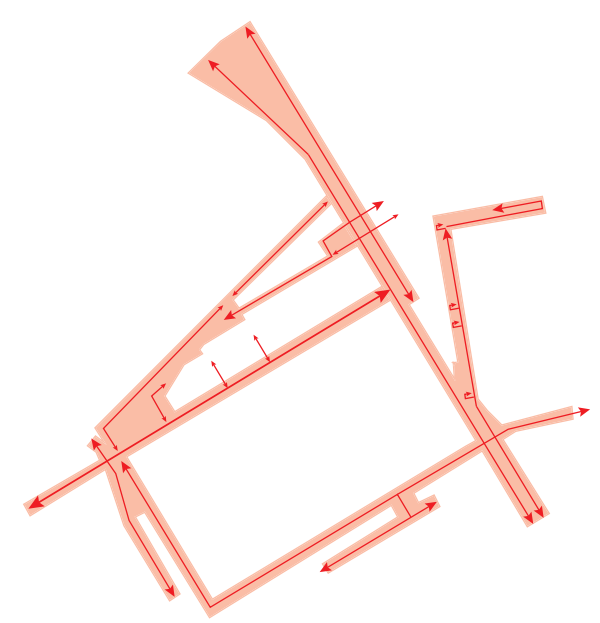

Figure 158: Diagram of Pedestrian Circulation

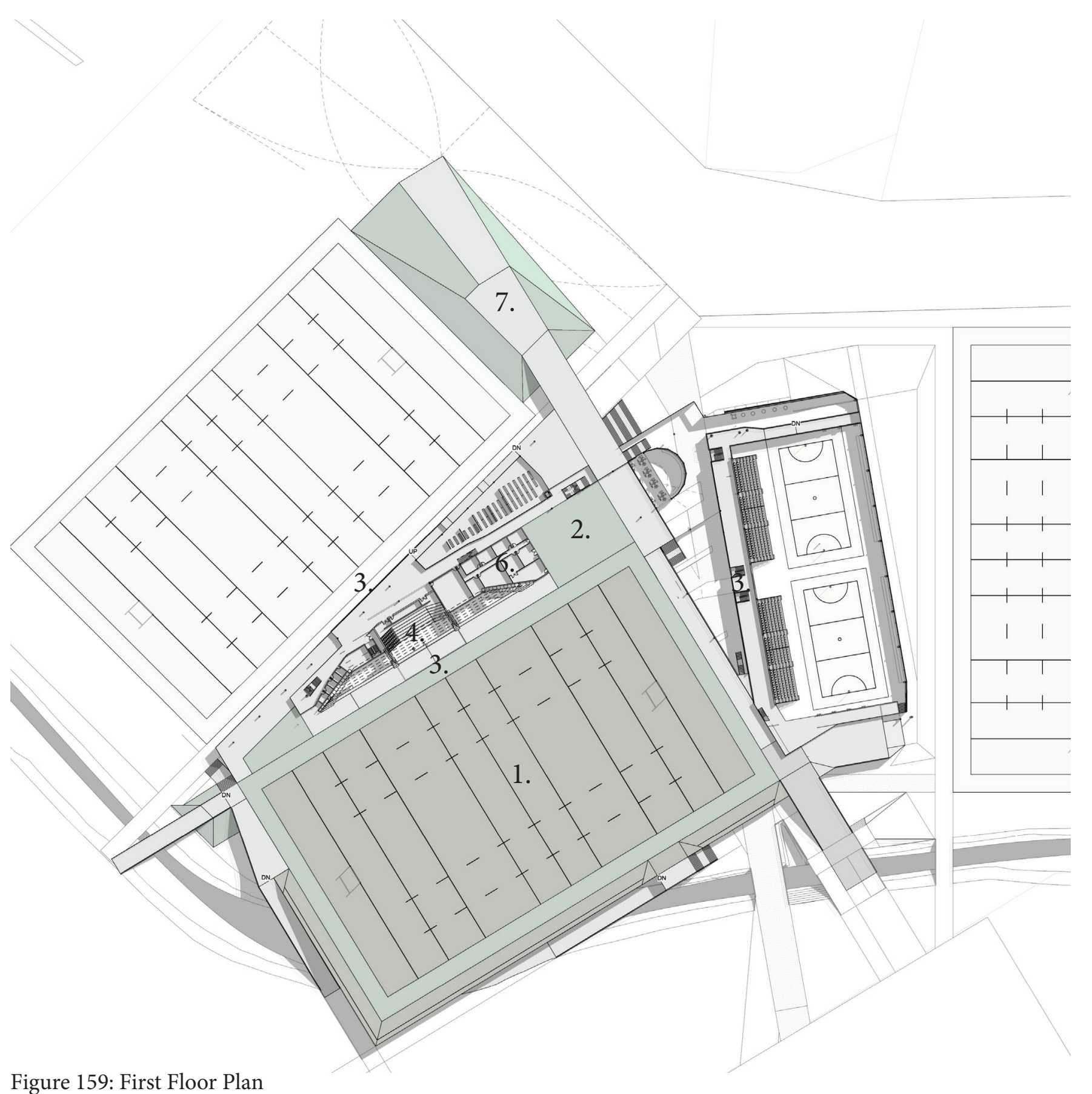




\section{Second Floor Plan}

The second floor contains:

1.The Main Social Area - This area is open and able to accomodate a range of layouts for different types of functions and events.It is positioned to provide views along its length to the main field and training field. 2.Central core- This contains a bar, kitchen and toilet areas.

3.Grandstand - This provides further viewing space while linking the field to the social area. The grandstand cuts back into the building allowing views of the field from further within the building.

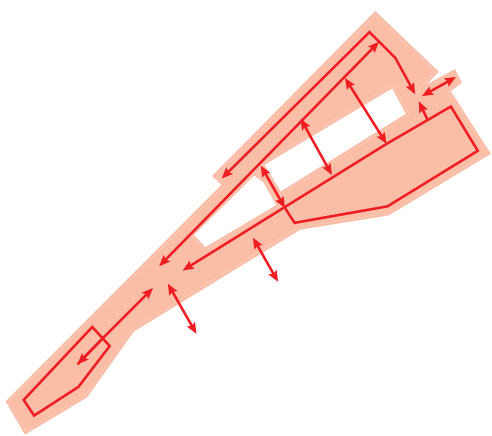

Figure 160: Diagram of Pedestrian Circulation

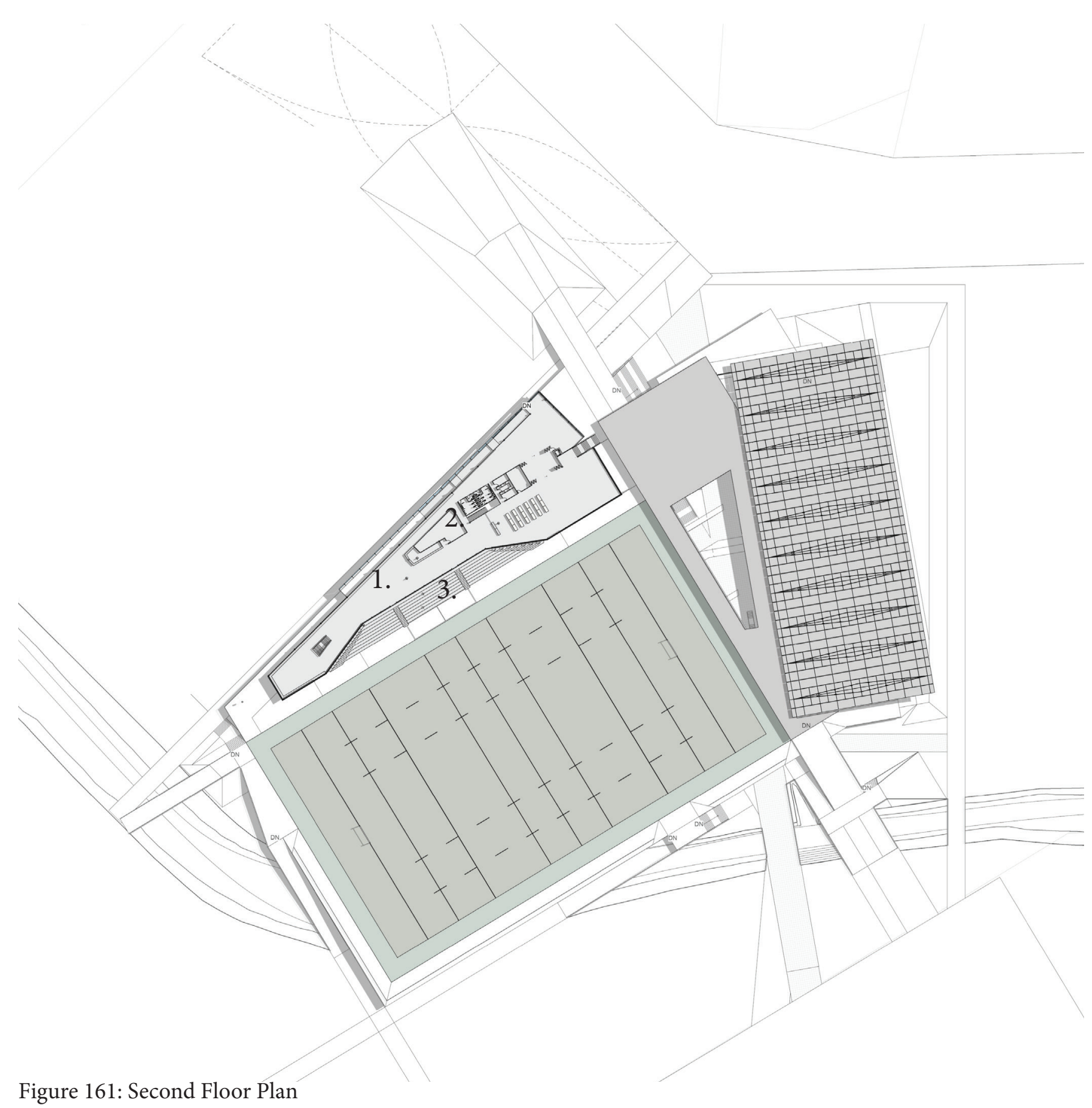




\section{Roof Plan}

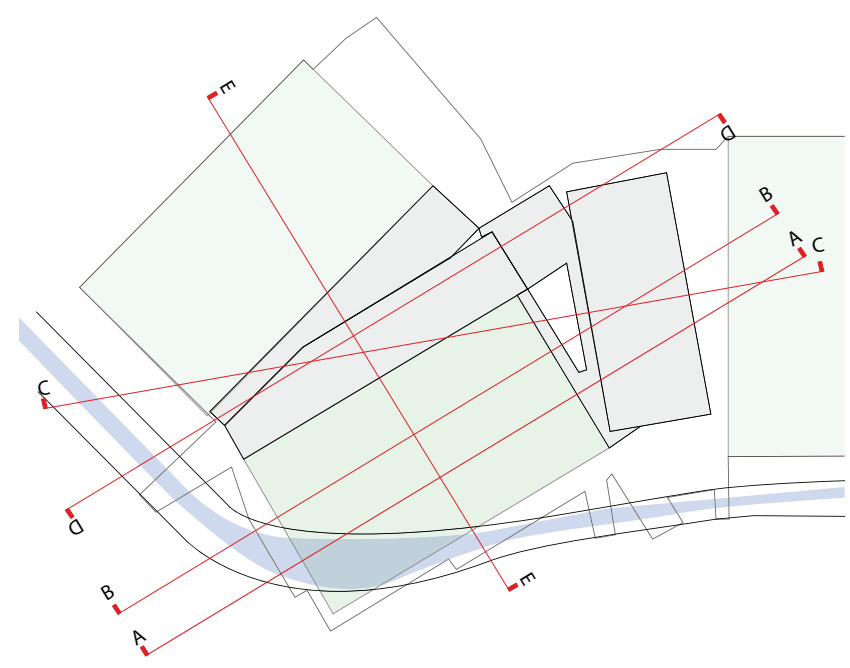

Figure 162: Section Drawing Location Diagram

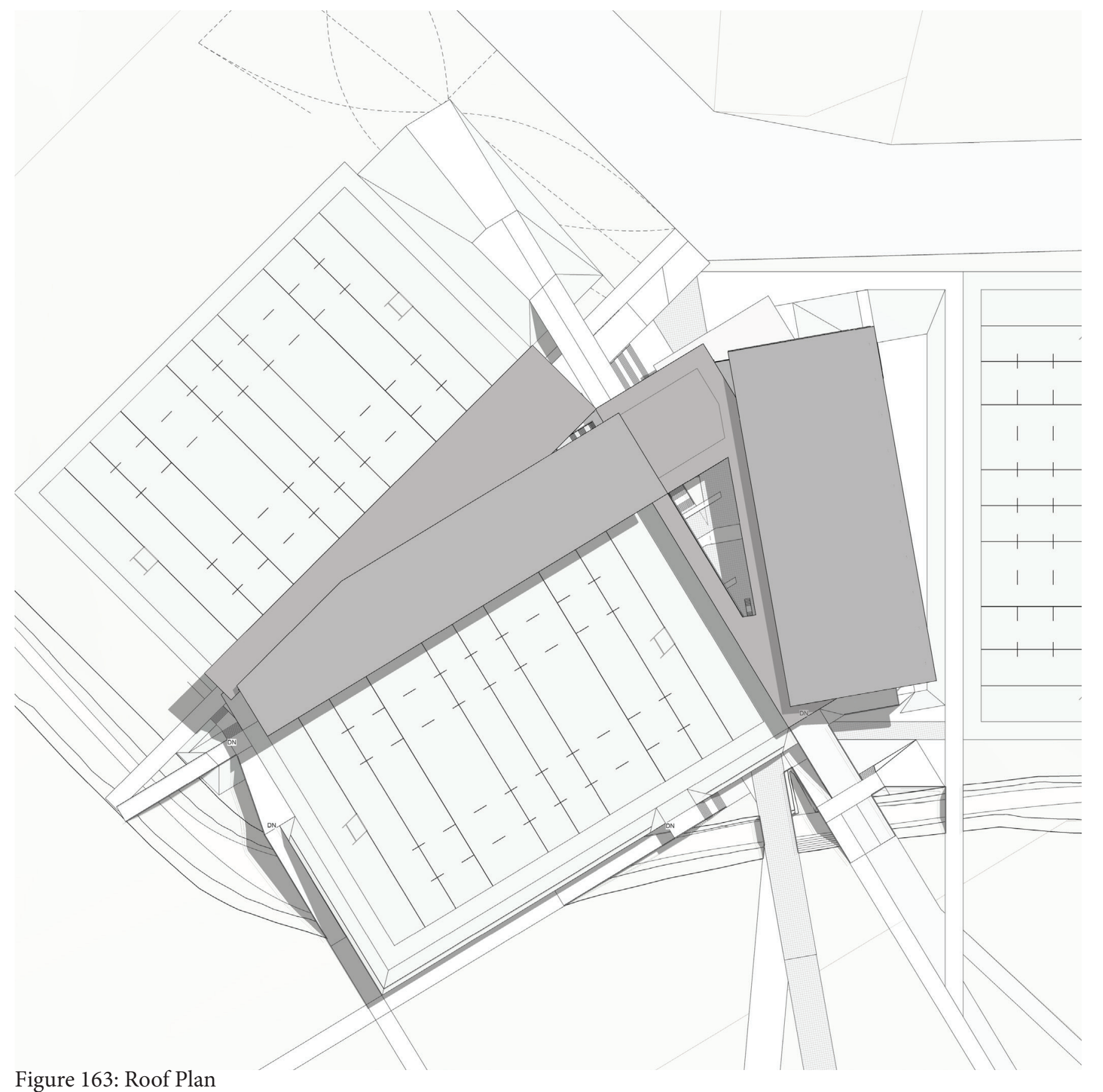


Figure 164: Section A - A
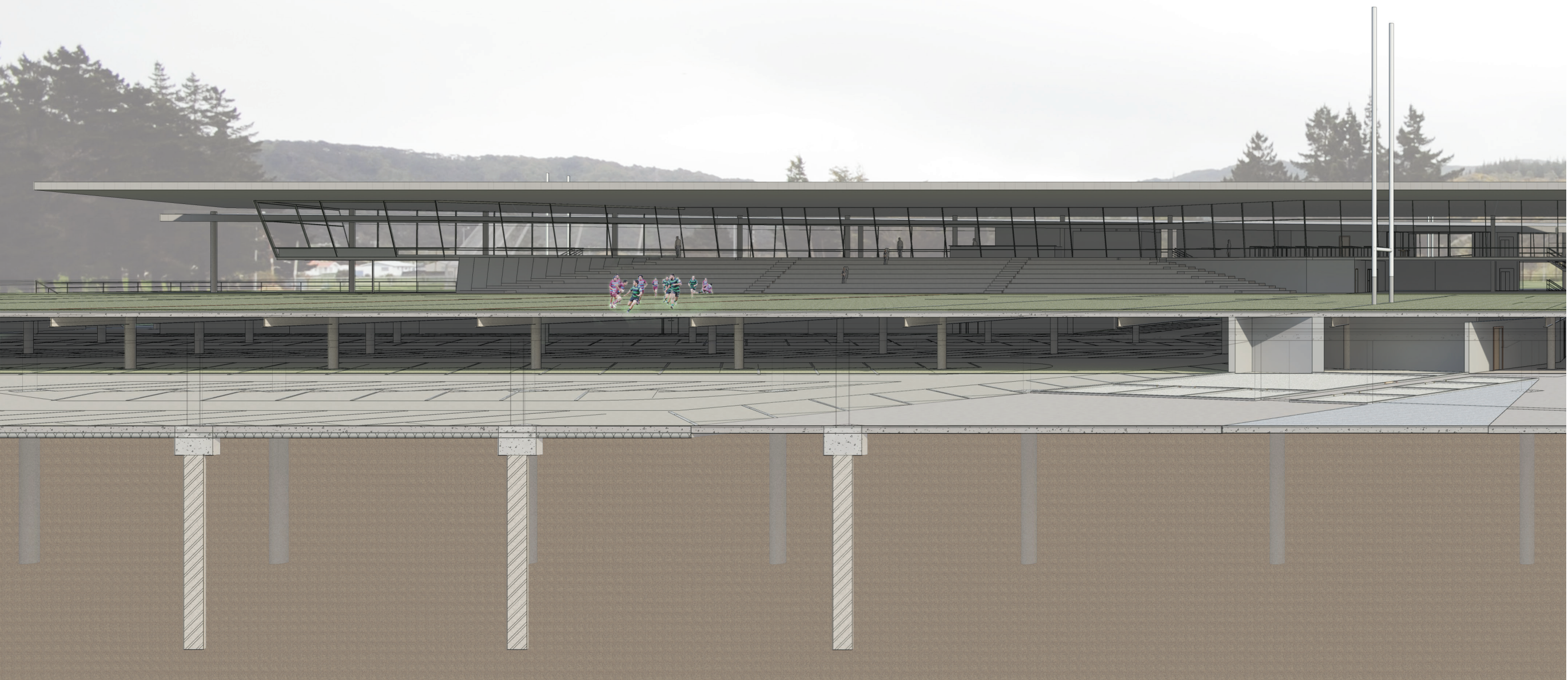


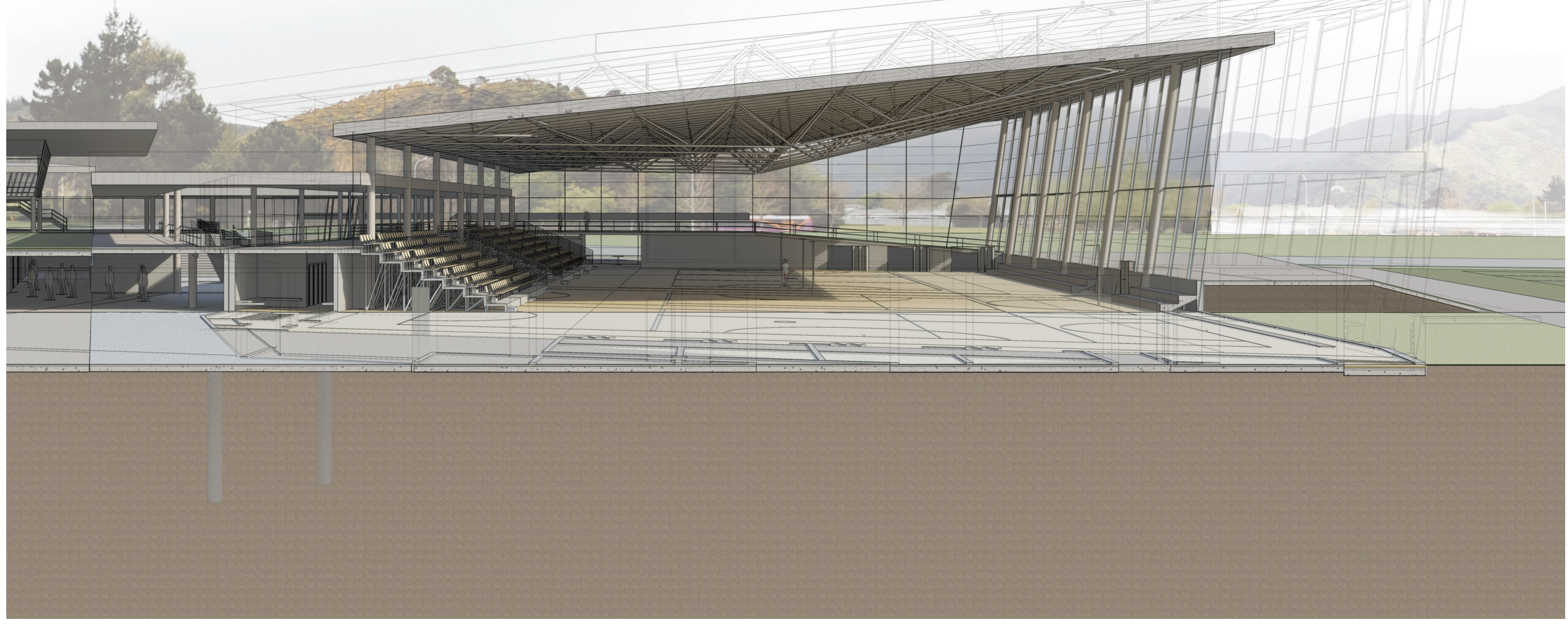



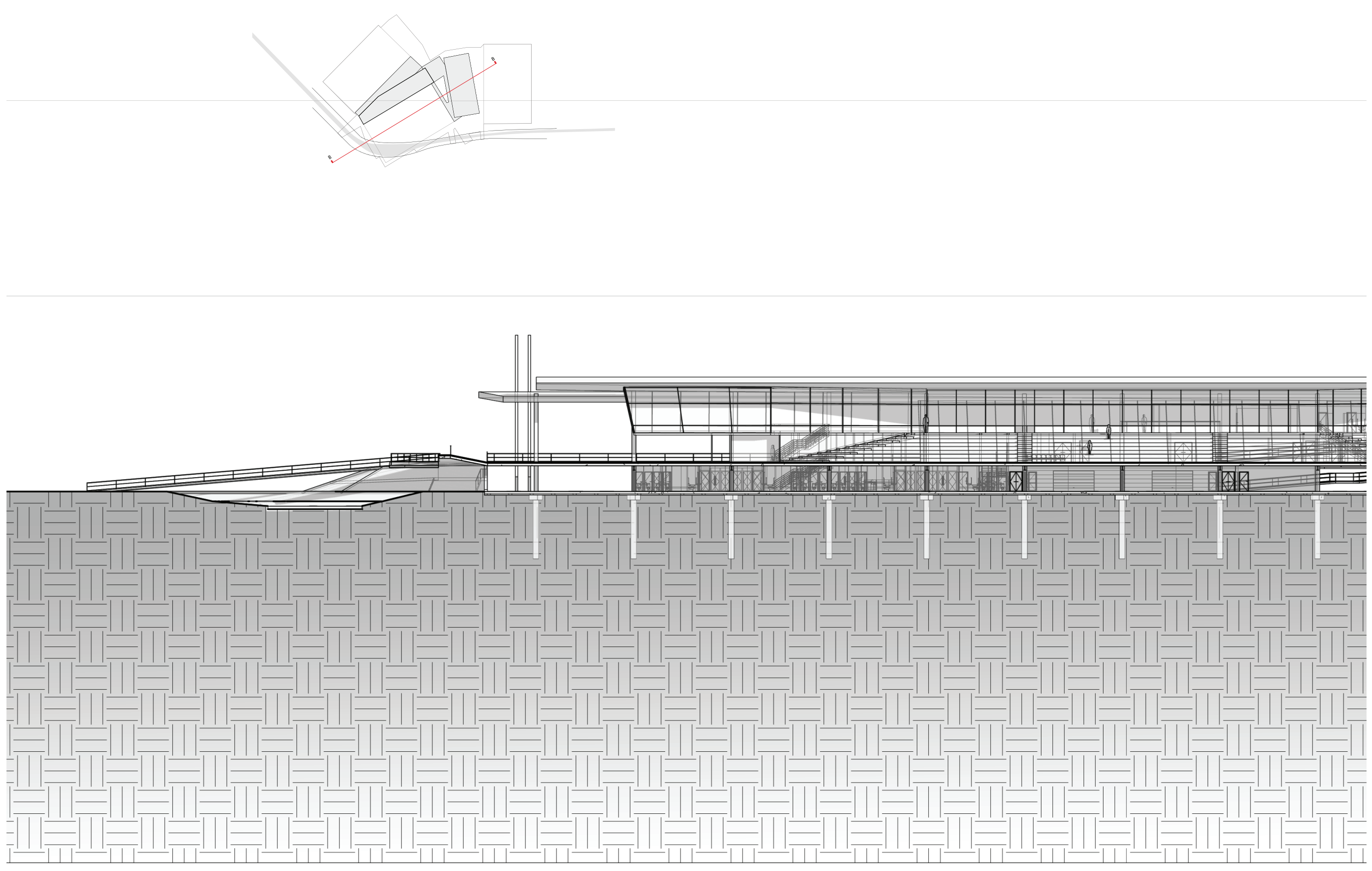


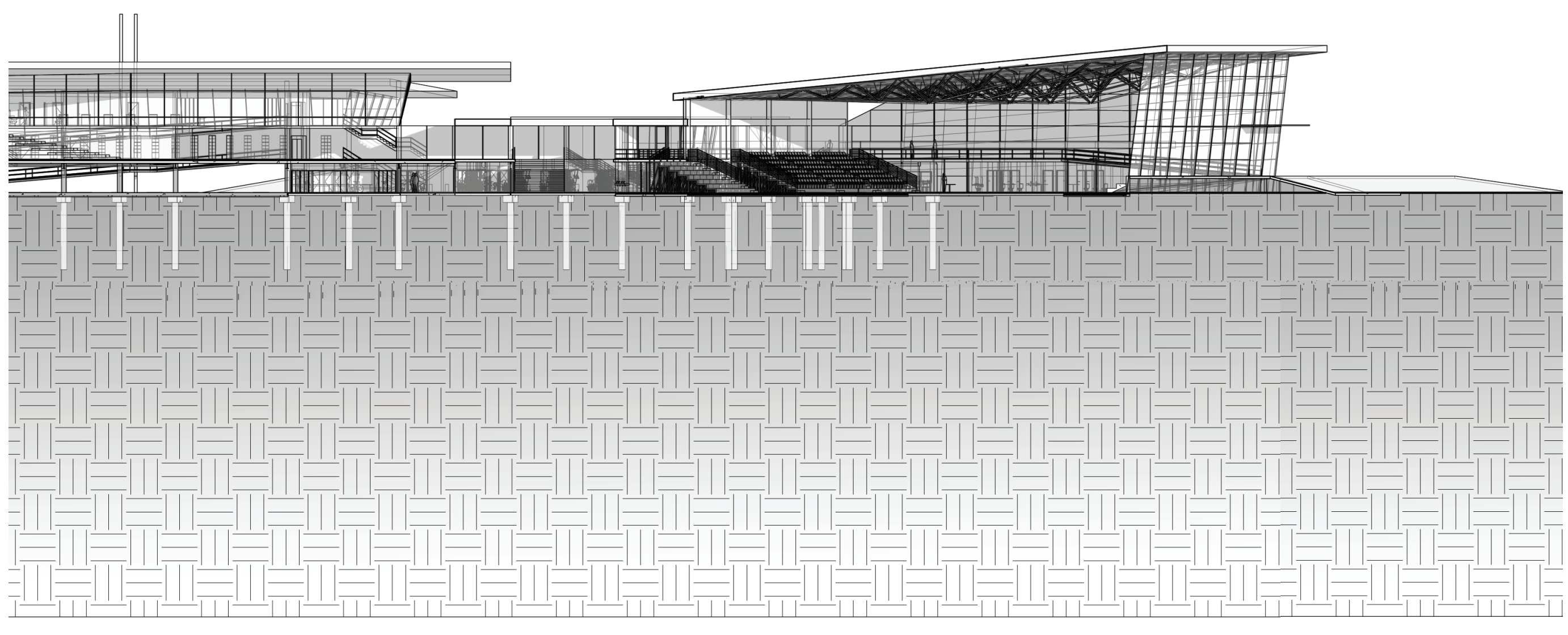



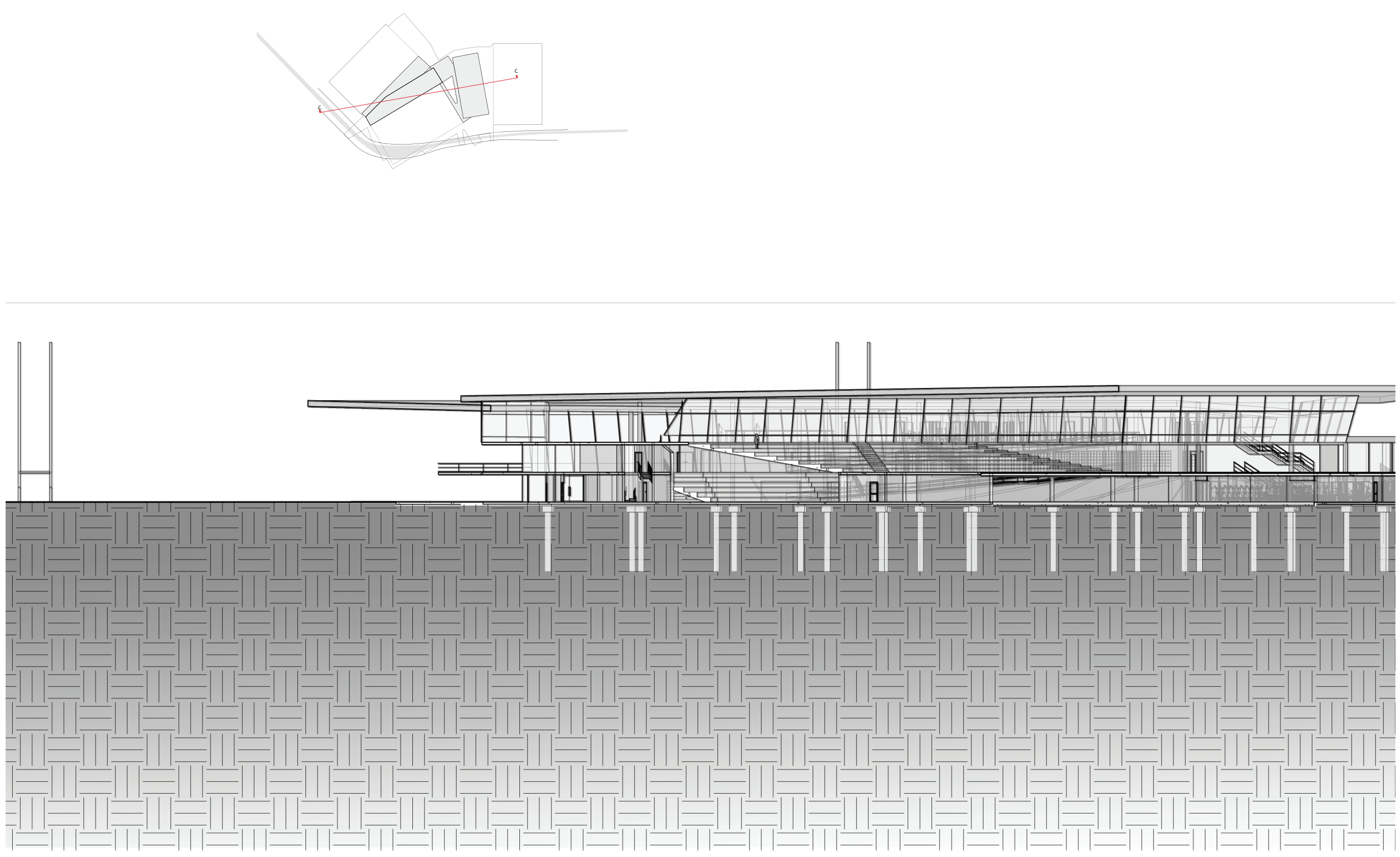


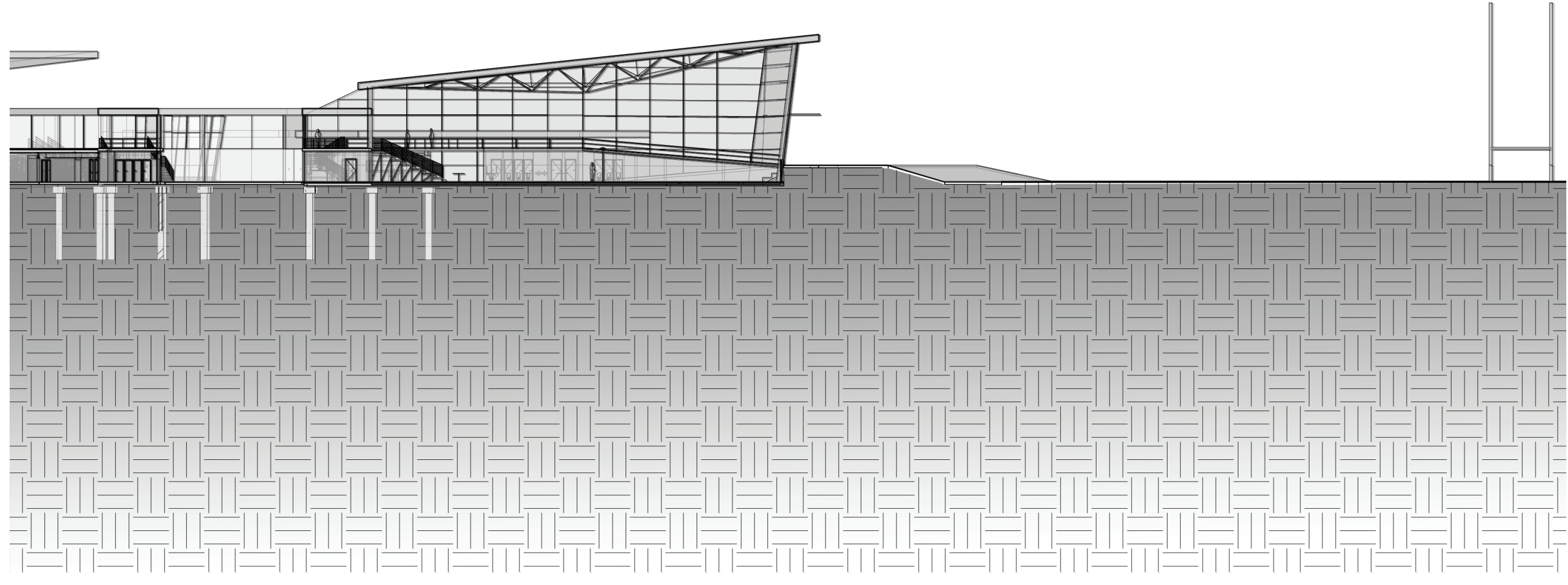



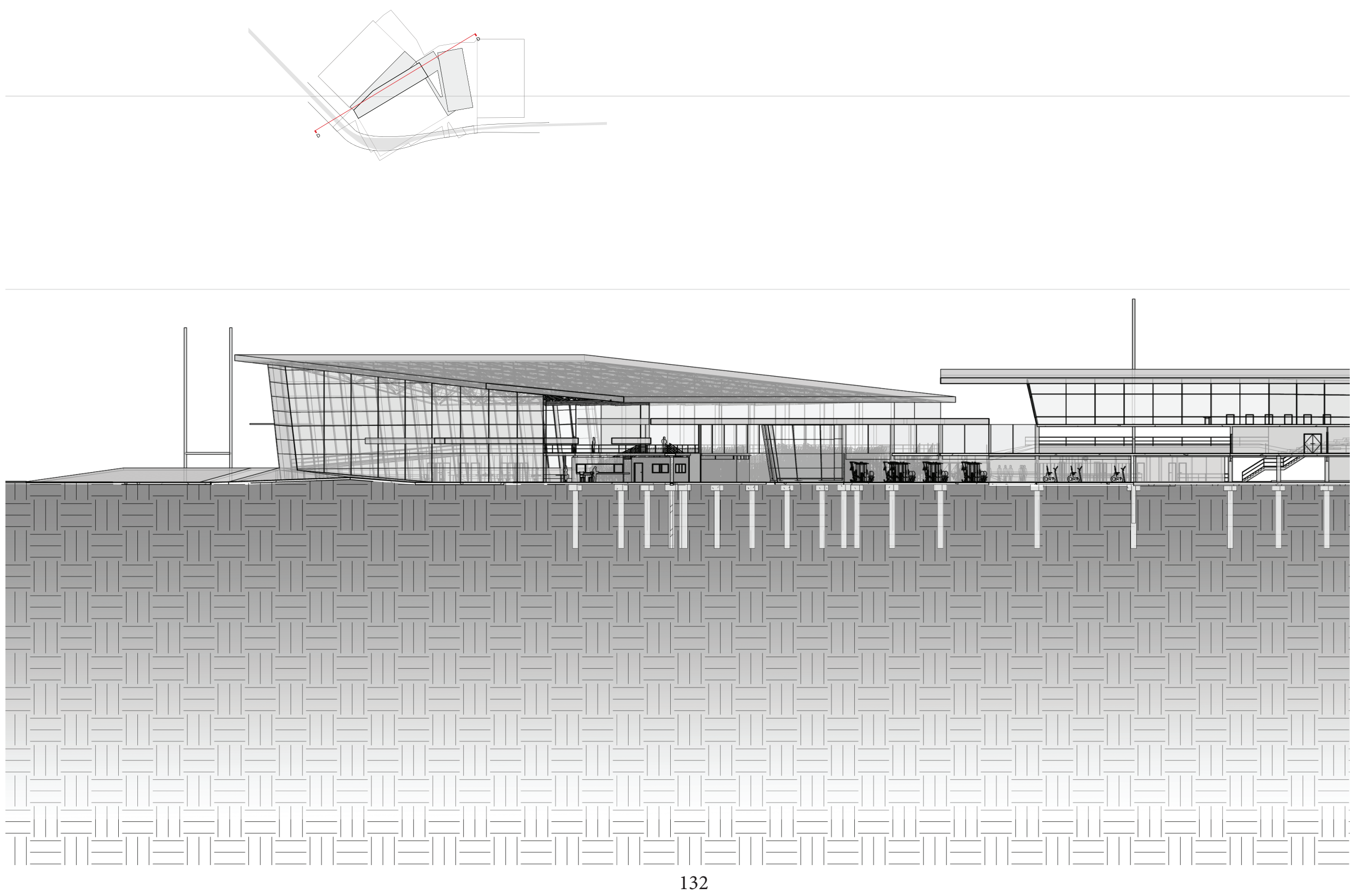


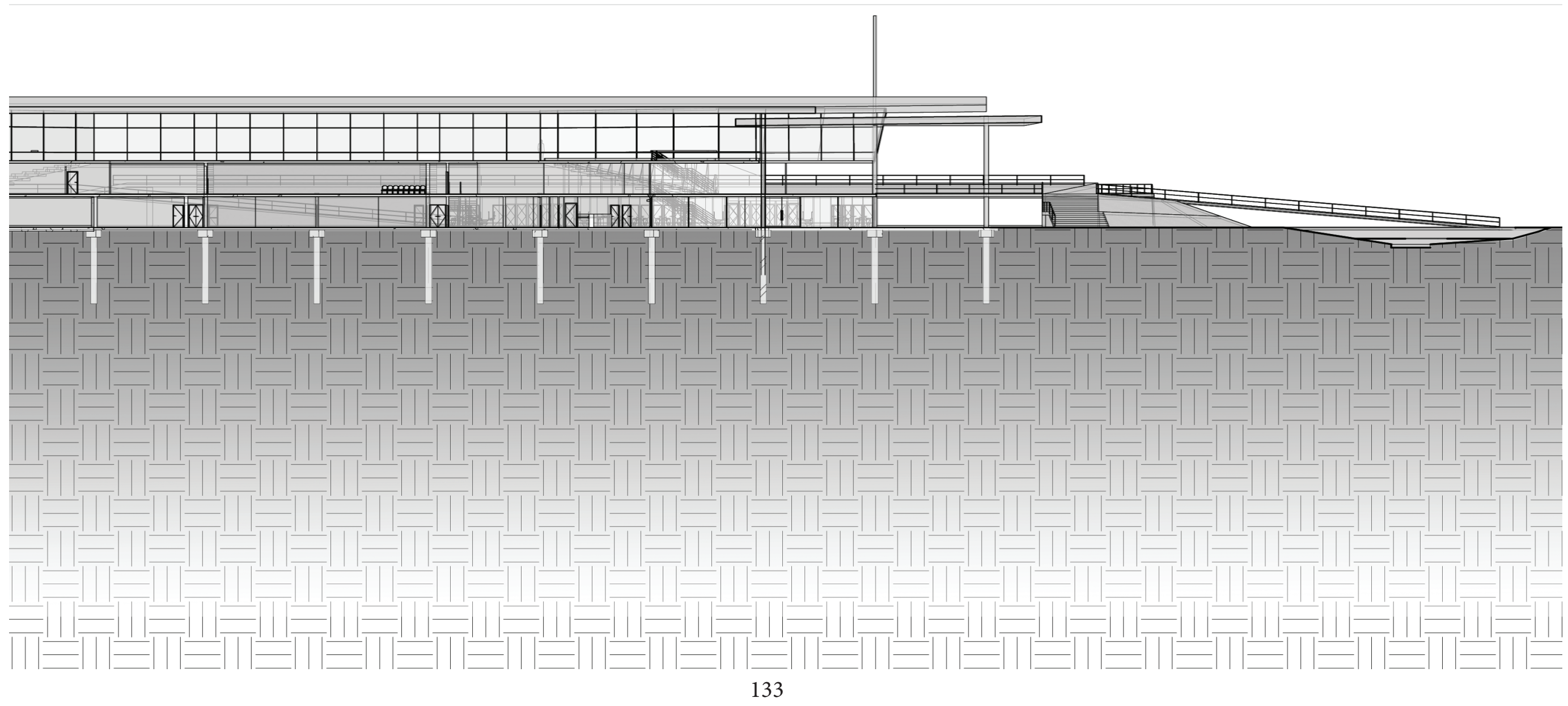




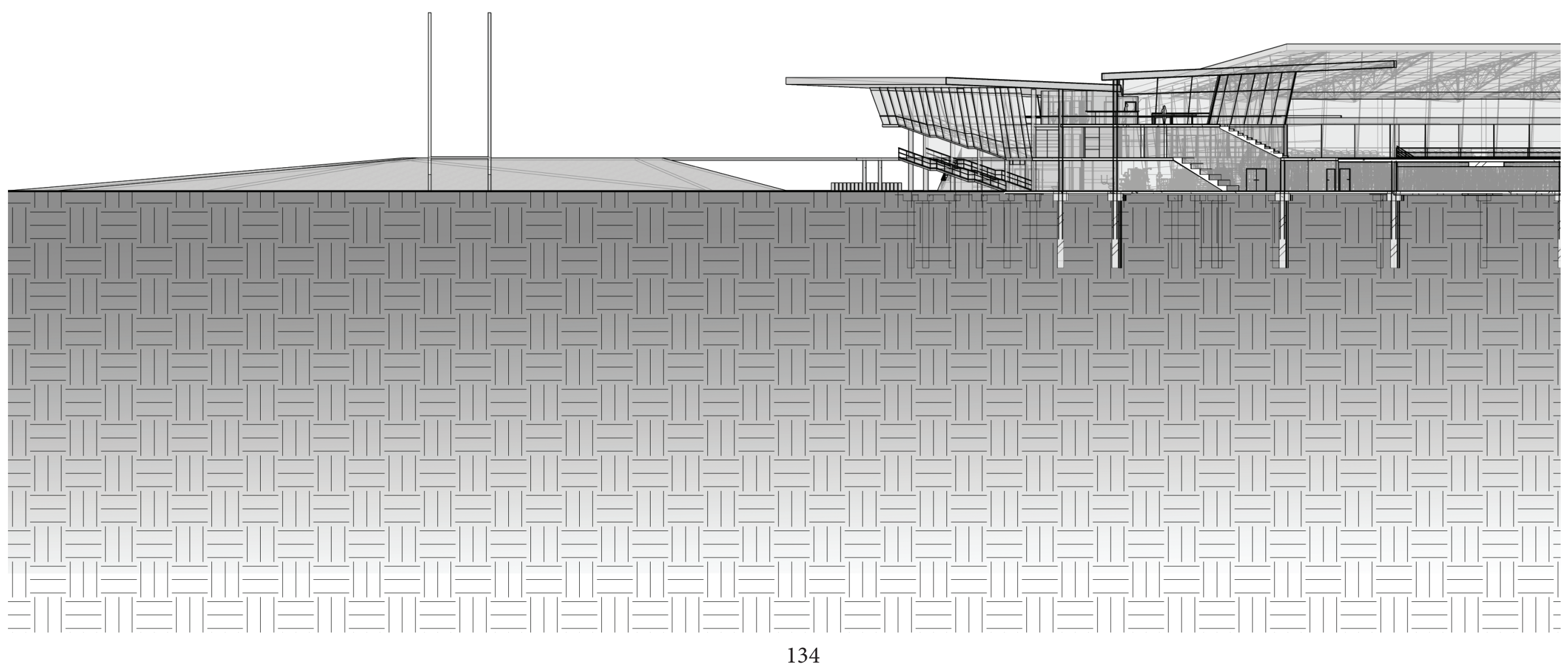




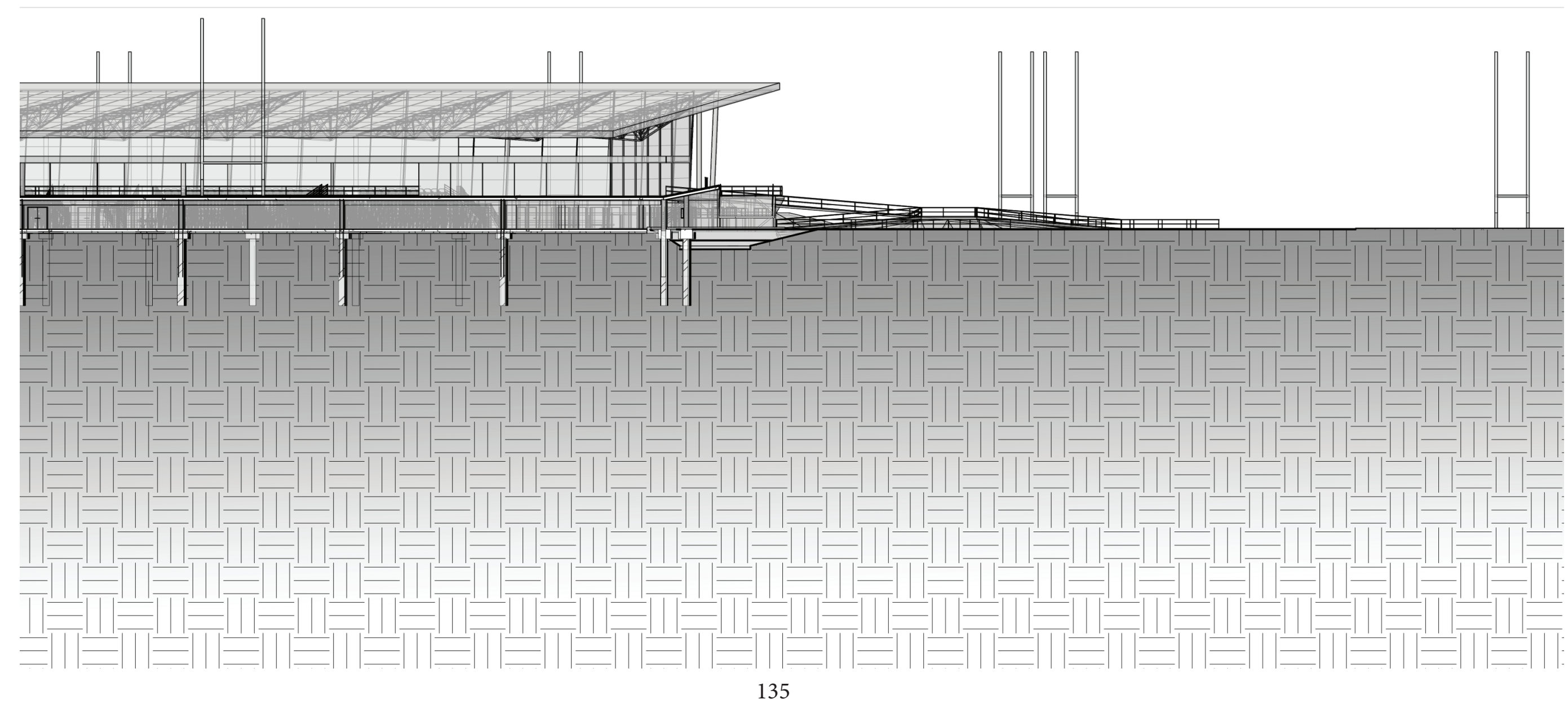




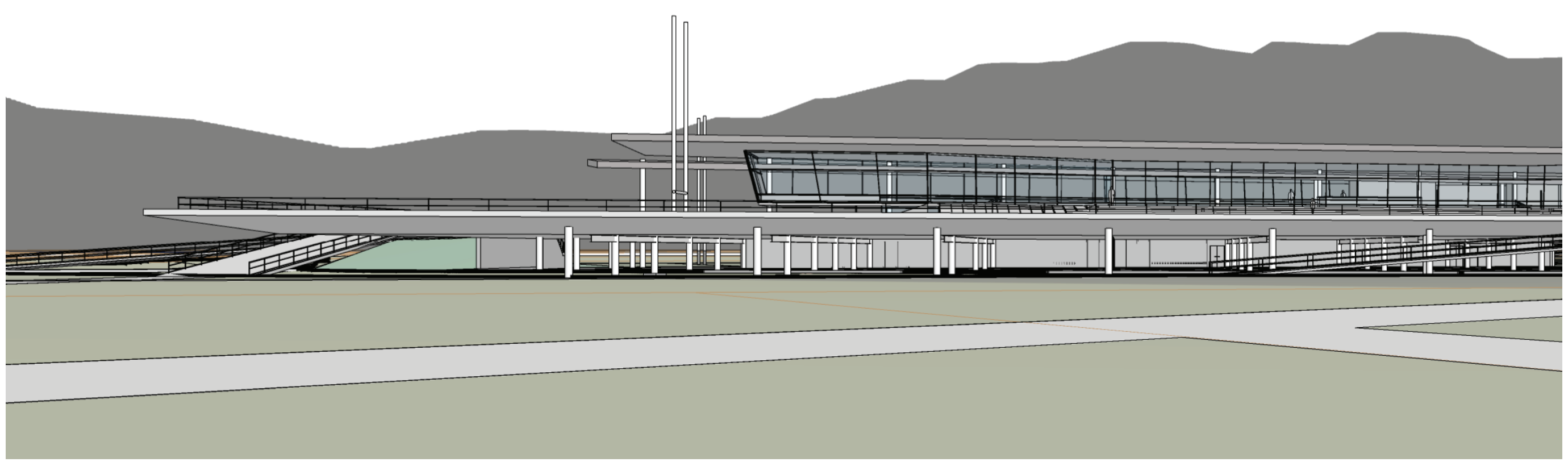




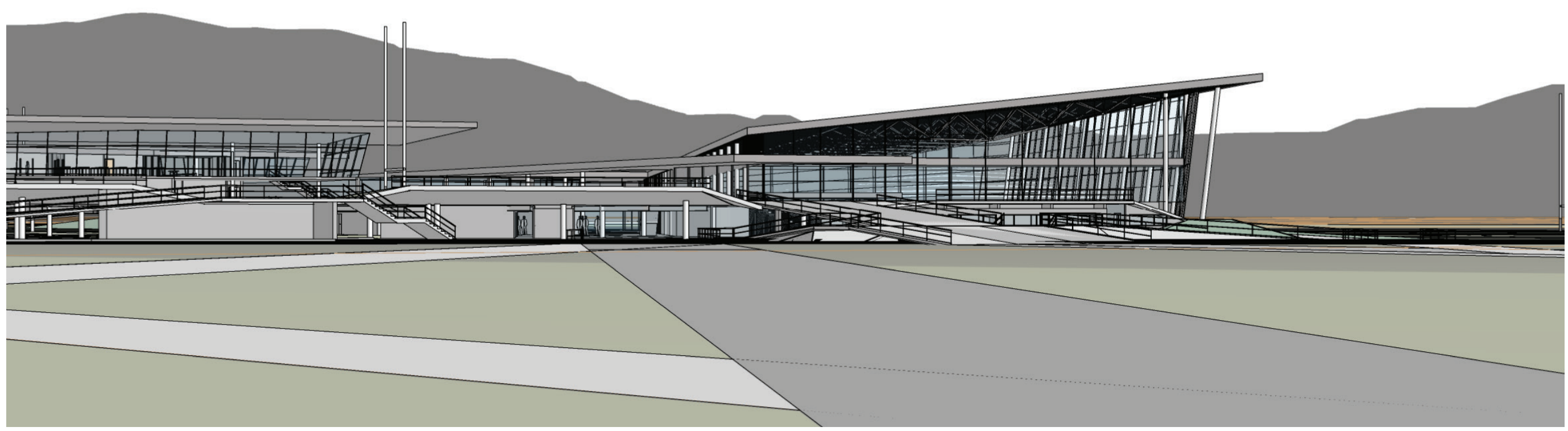




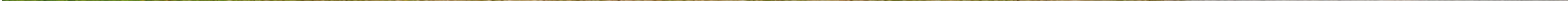




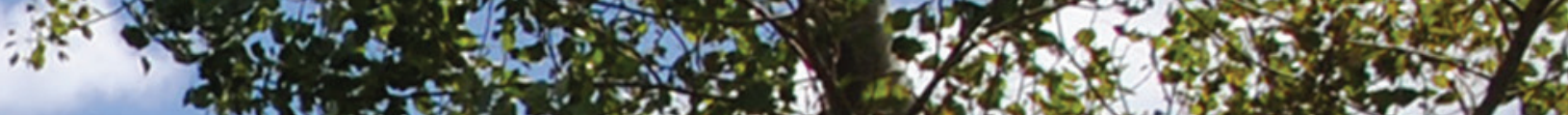

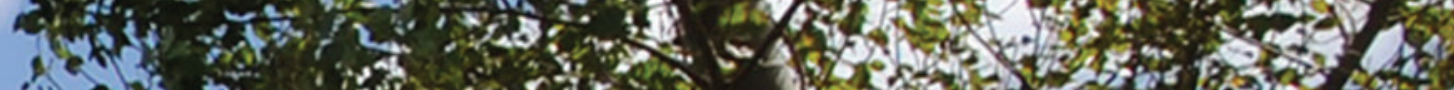

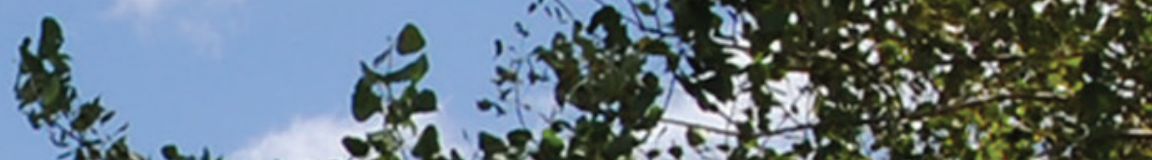

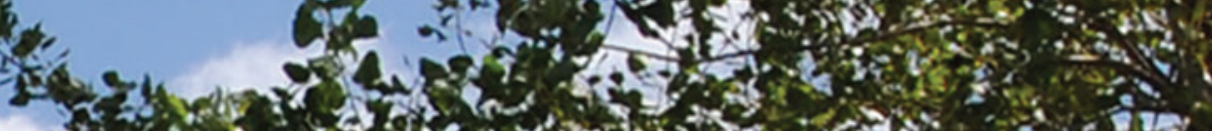

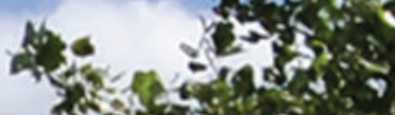

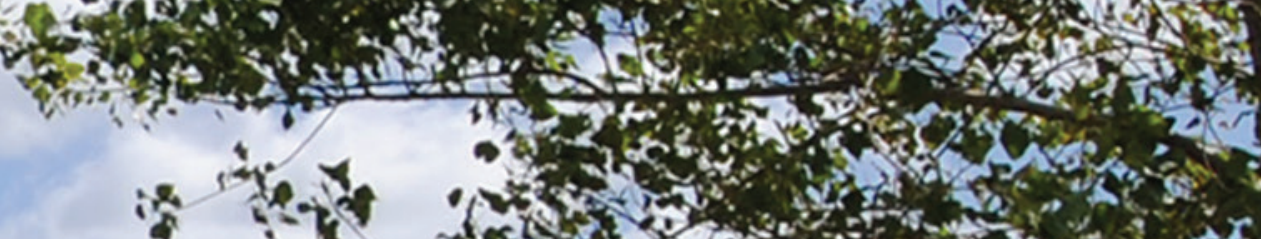 \\ का \\ riscos. \\ $-\infty, 0$.}

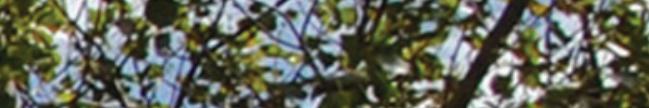

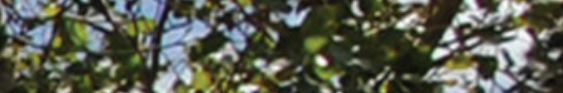
woy and 15 象, and 40 and 0 in 110

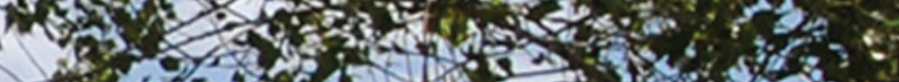

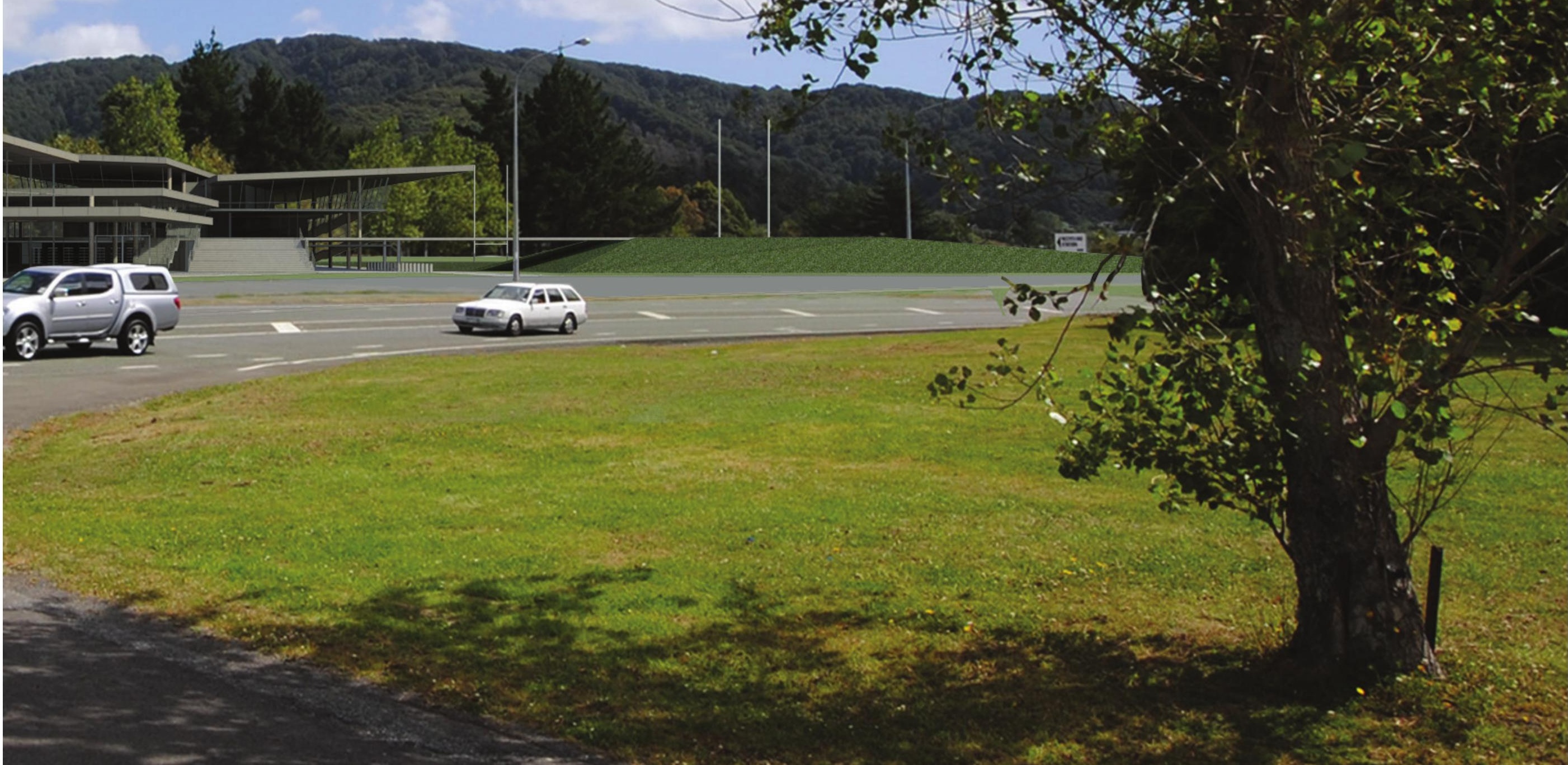




\section{Detailed Plan Ground Floor}

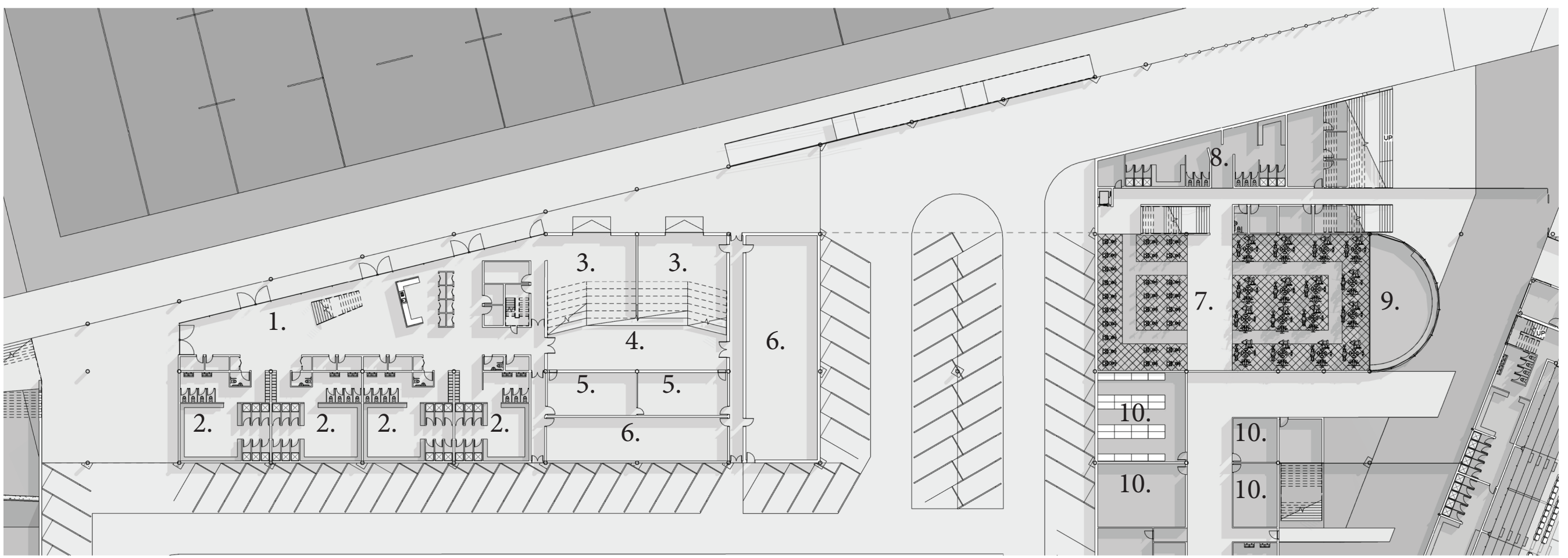

Figure 172: Detailed ground floor plan.

2. Changing Rooms

3. Storage

4. Lecture Theatre

5. Ancilary Rooms

6. Plant
7. Gym

8. Gym WC \& Changing

9.Reception Area

10.Teaching Spaces 


\section{Detailed Plan First Floor}

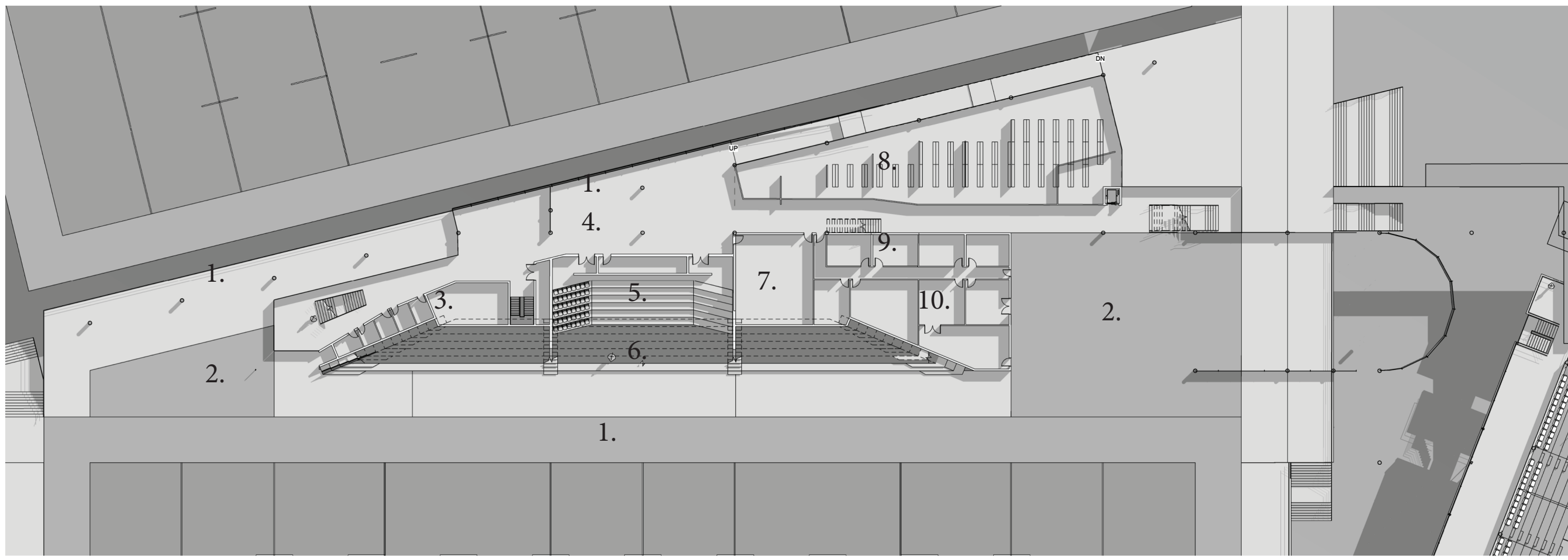

Figure 173: Detailed first floor plan.

1. Viewing Areas

2. Warm Up Areas

3. Storage

4. Central Foyer - This area connects 'public' areas of the

teaching program.

5. Lecture Theatre
6. Grandstand - This is placed to optimise views of the main field and leads up to the social area above.

7. Seminar Room

8.Library

9. Offices

10. Recovery Suite - Includes, physio room, spa and cryo-

therapy pool, and a recovery lounge. 


\section{Detailed Plan Second Floor}

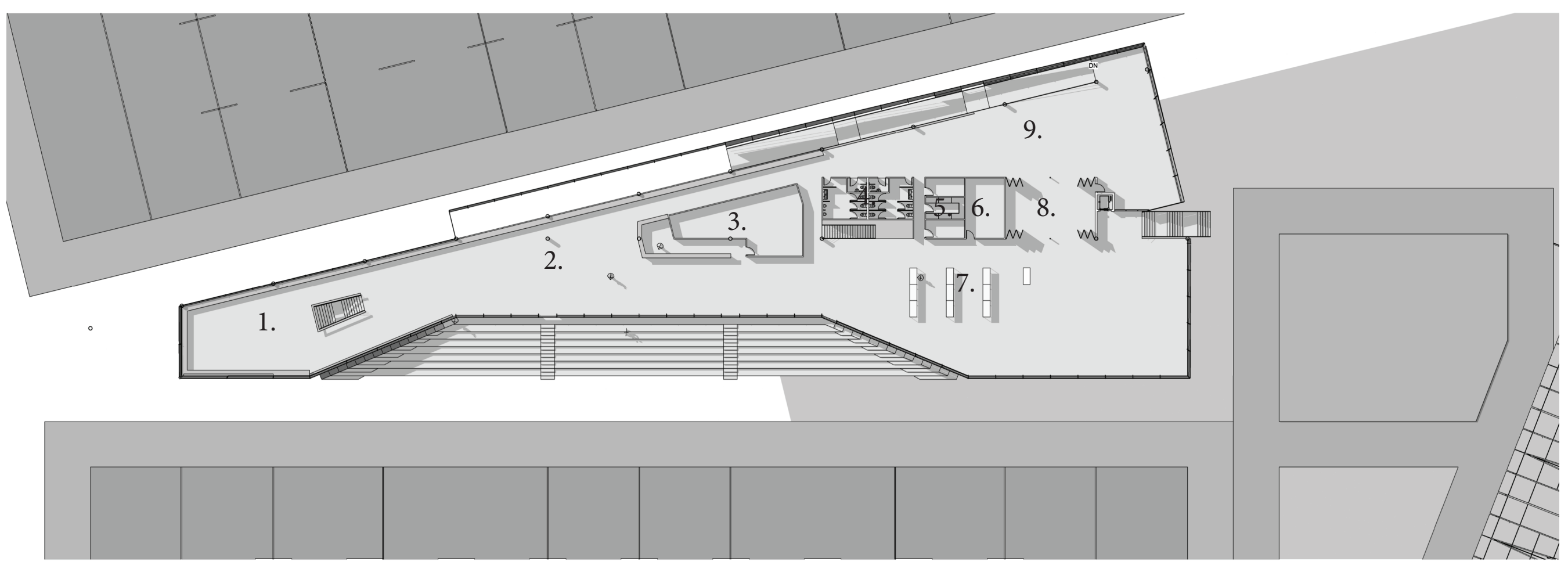

\section{Above}

Figure 174: Detailed first floor plan.

\section{Right Corner}

Figure 175: Diagram showing areas with view of field.
Second Floor:

1. Smaller Viewing Area (Social Space 1)

2. Bar Area (Social Space 2)

3. Bar \& Kitchen

4. Toilets

5. Storage

6. Office

7. Large Social Area (Social Space 2)

8. Multifuncional space (Opens up to make one big area)

9. Breakout space (Social Space 3)

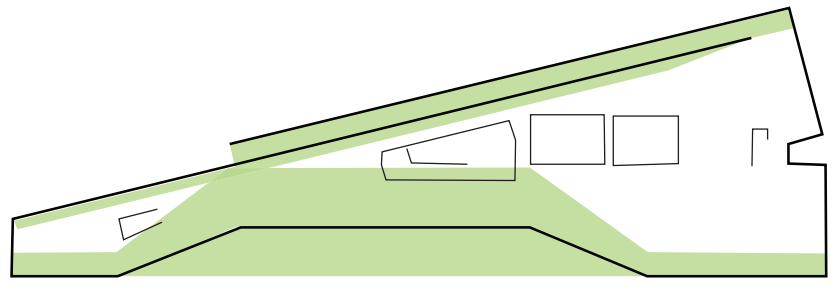




\section{Detailed Section E-E}

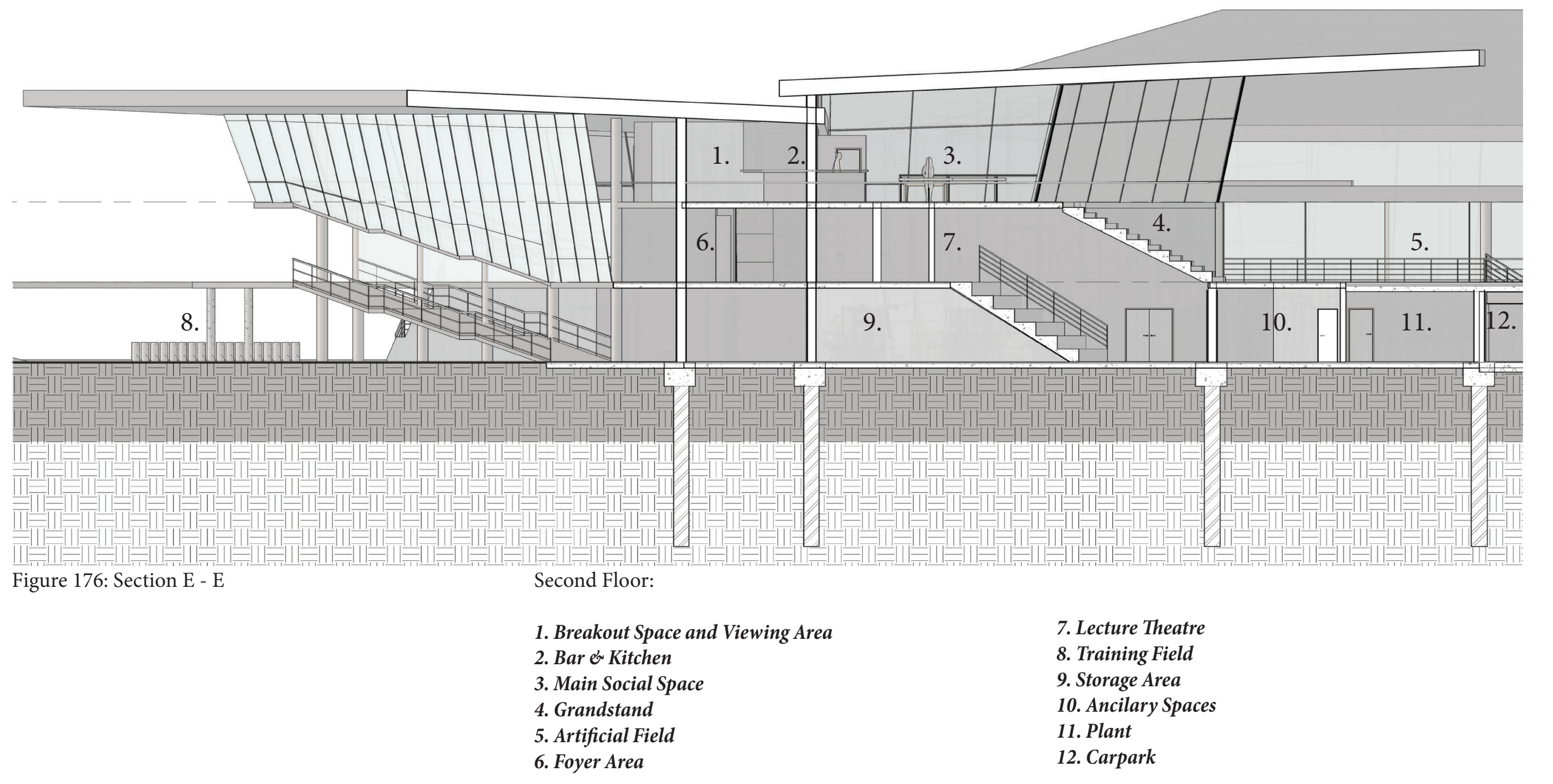


Western (Riverside) approach to facility

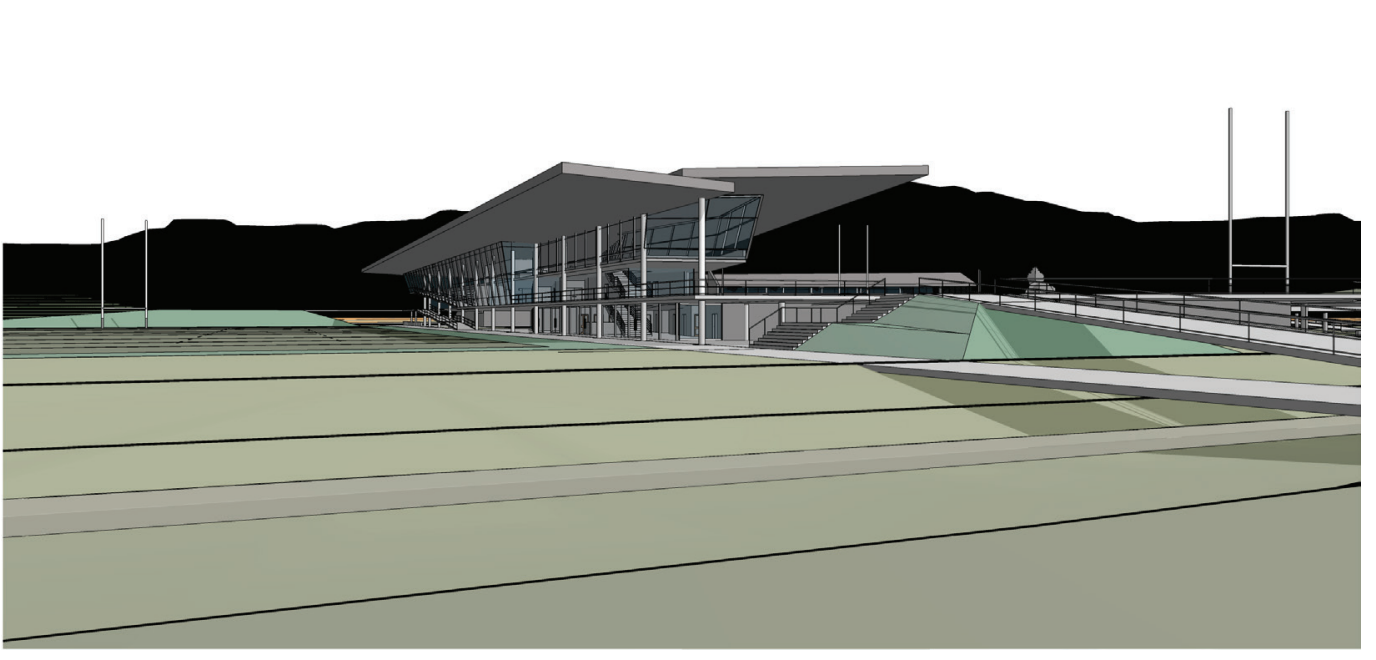

Figure 177: View 1 - Riverside approach

Figure 179: View 3 - Crossing the river towards clubrooms

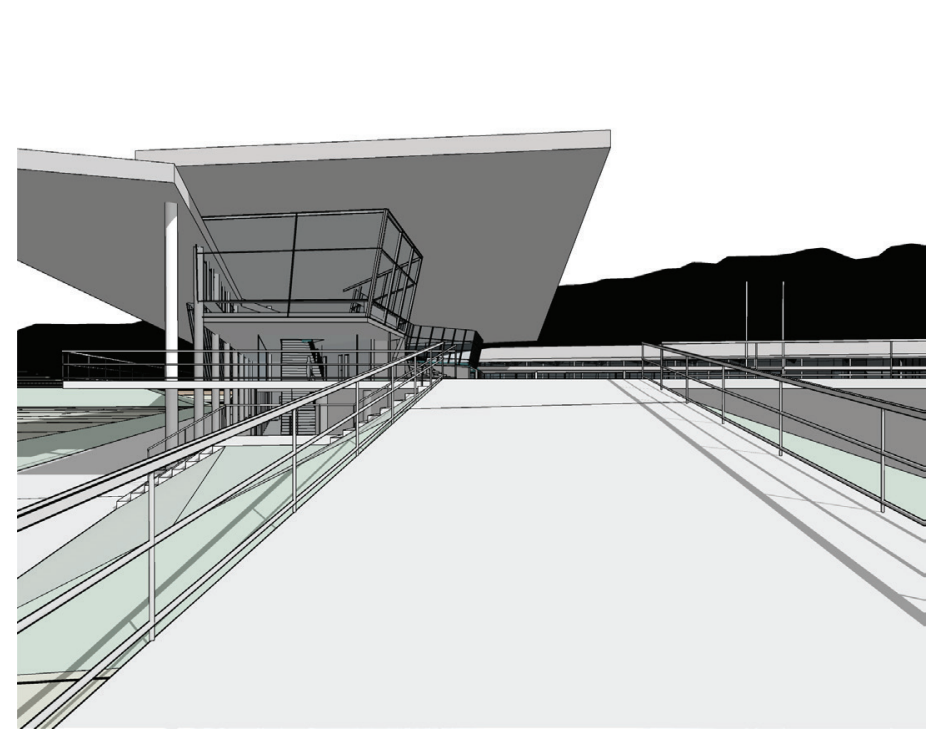

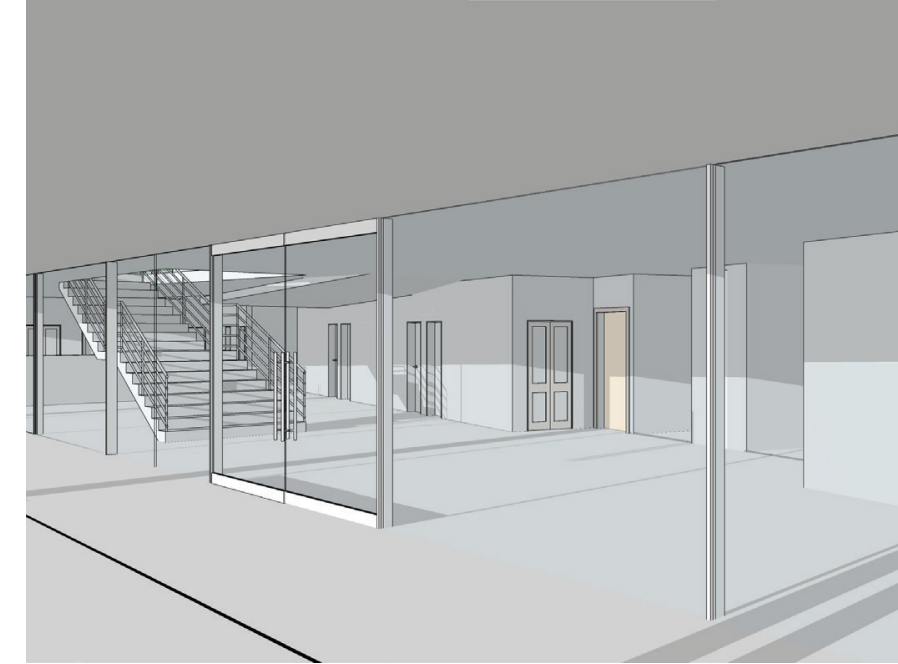

Figure 178: View 2 - Ground floor access to changing rooms.
Figure 180: View 4 - 1st floor sidelines and grandstand

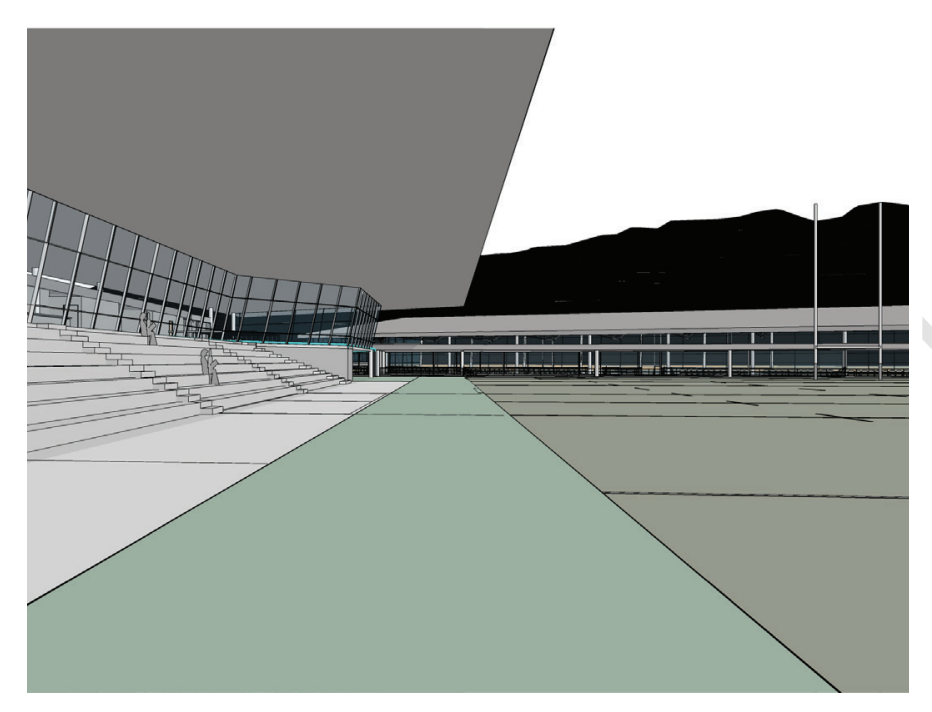

Figure 181: Location Plan showing views for pages

$146 \& 147$

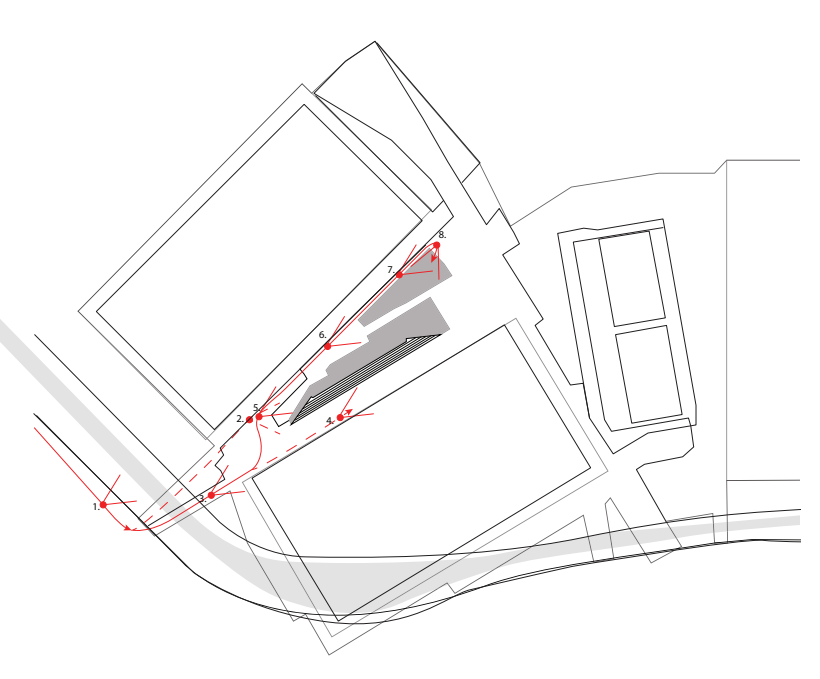




\section{Approach to social space via ramp}

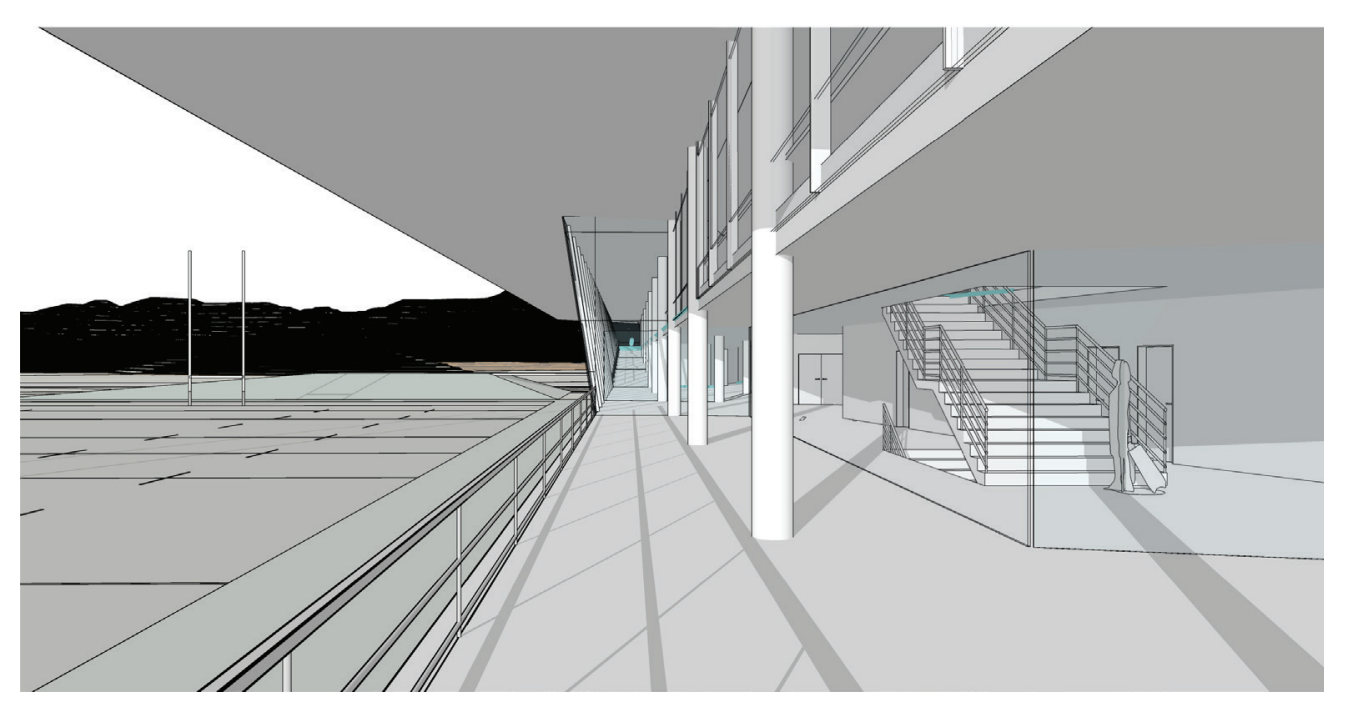

Figure 182: View 5 - Viewing area with training field on left and stairs to social space above on right

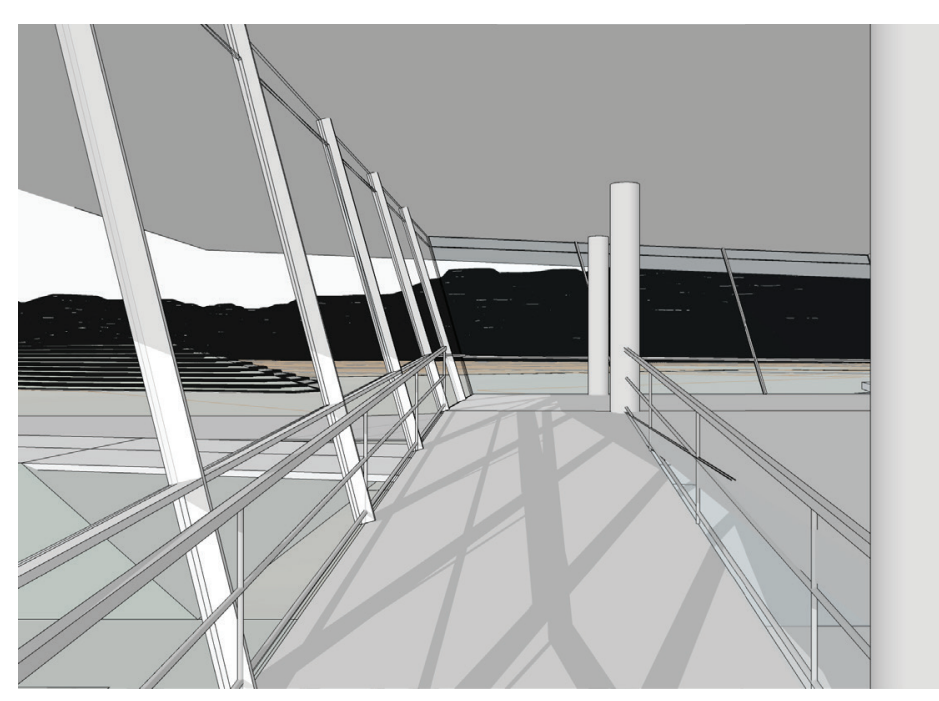

Figure 183: View 7 - Ramp to social space

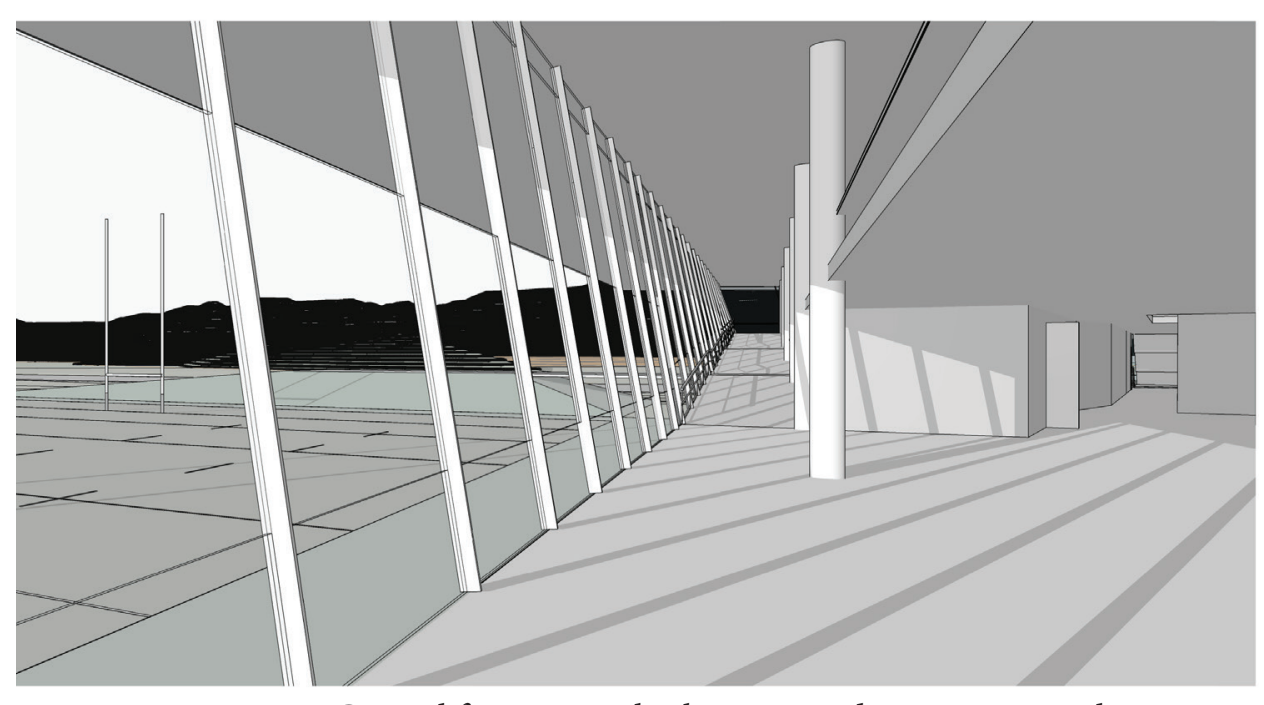

Figure 184: View 6 - Central foyer space looking towards ramp to social space

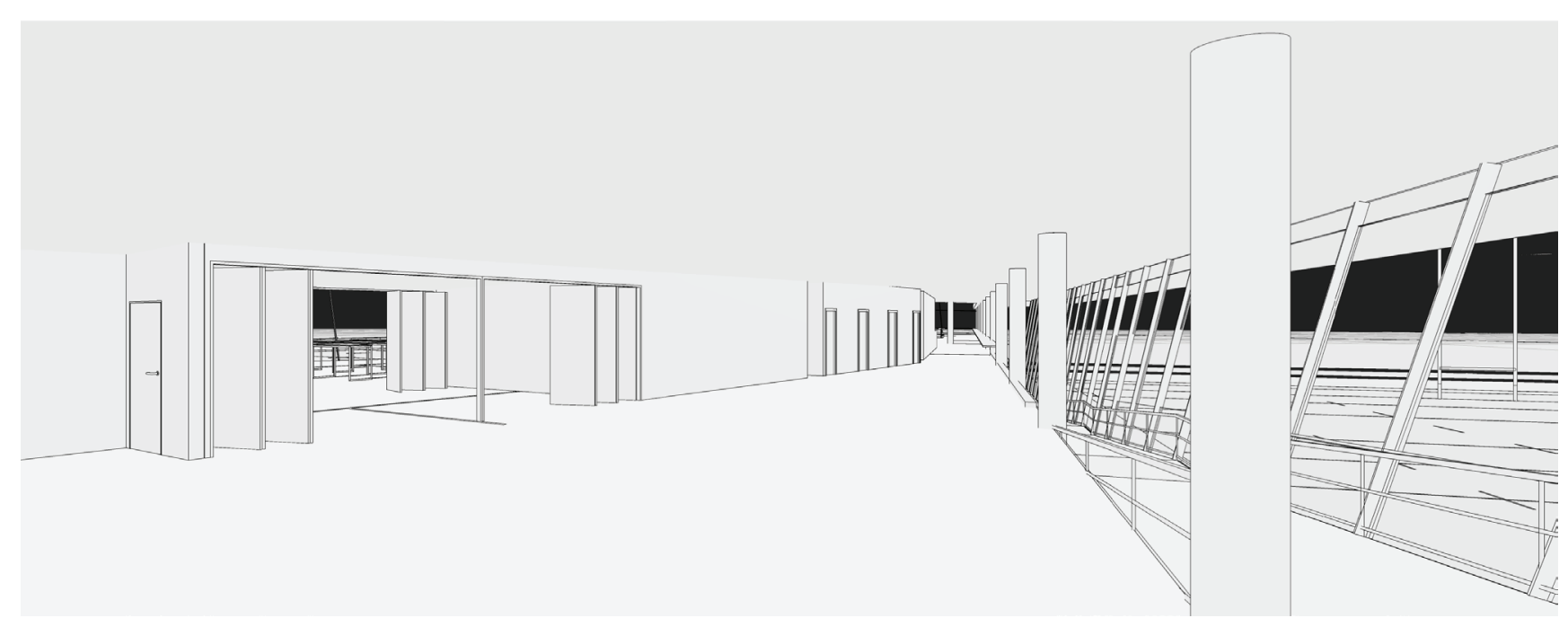

Figure 185: View 8 - Breakout area of social space 


\section{Southern approach from mall}

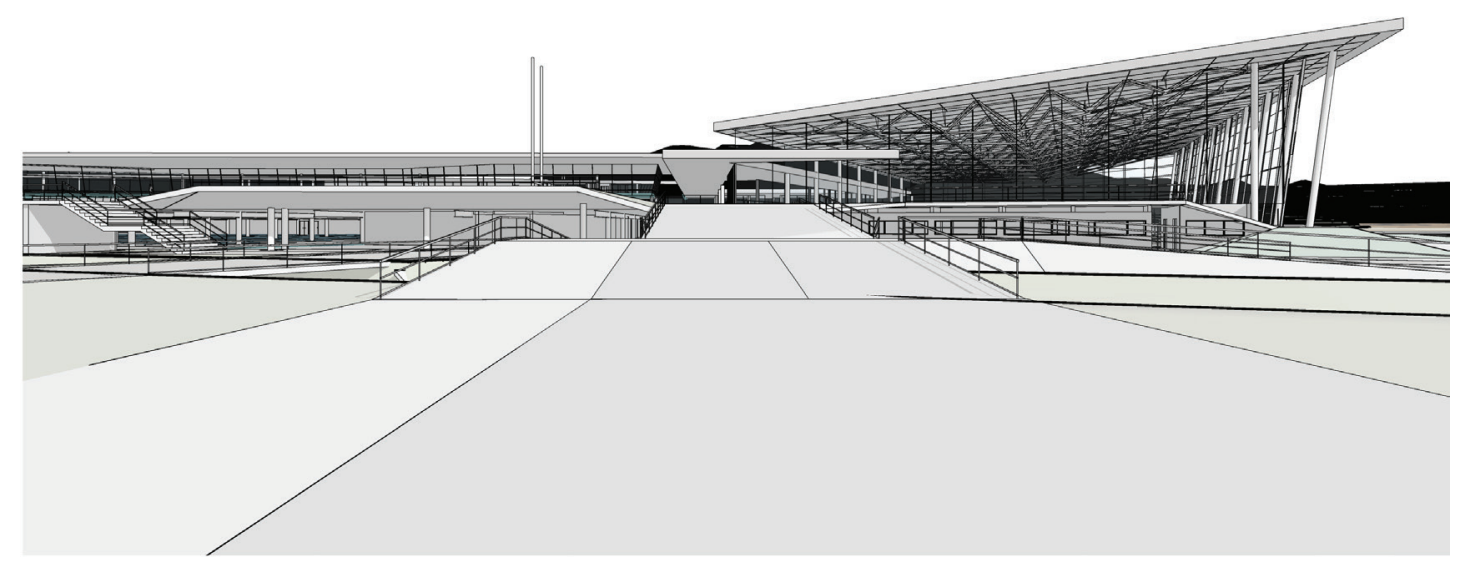

Figure 186: View 9 - Approach from the South

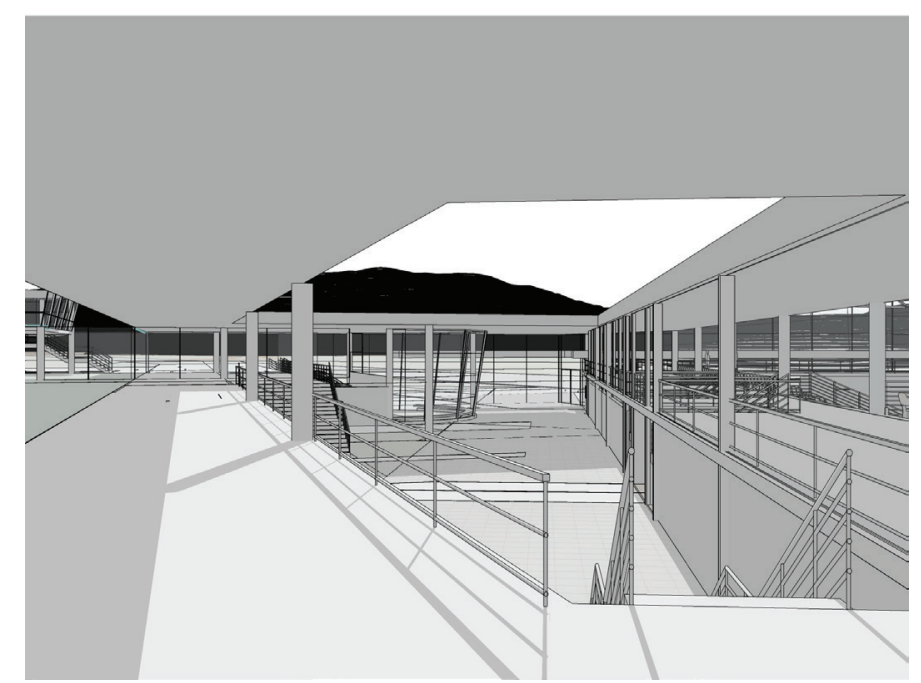

Figure 188: View 11. Looking down into Courtyard

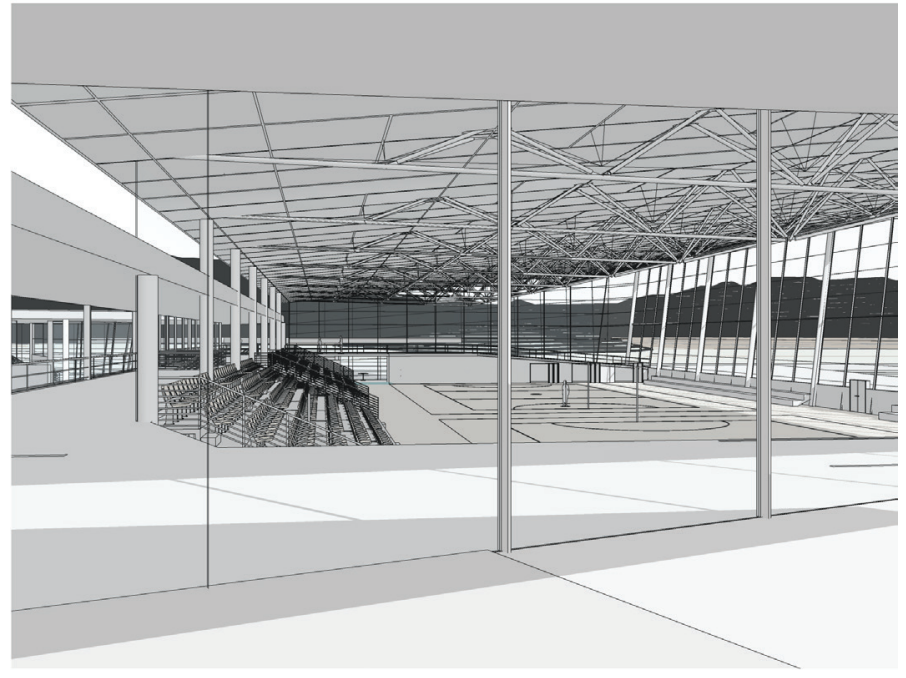

Figure 187: View 10 - Looking down into Indoor Hall

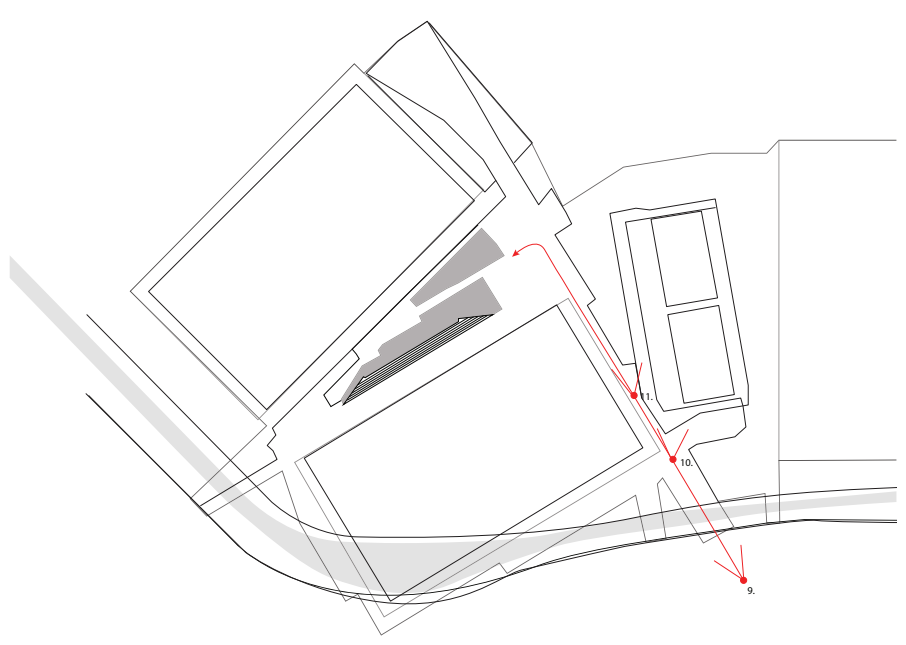

Figure 189: Southern approach views 


\section{Northern approaches}

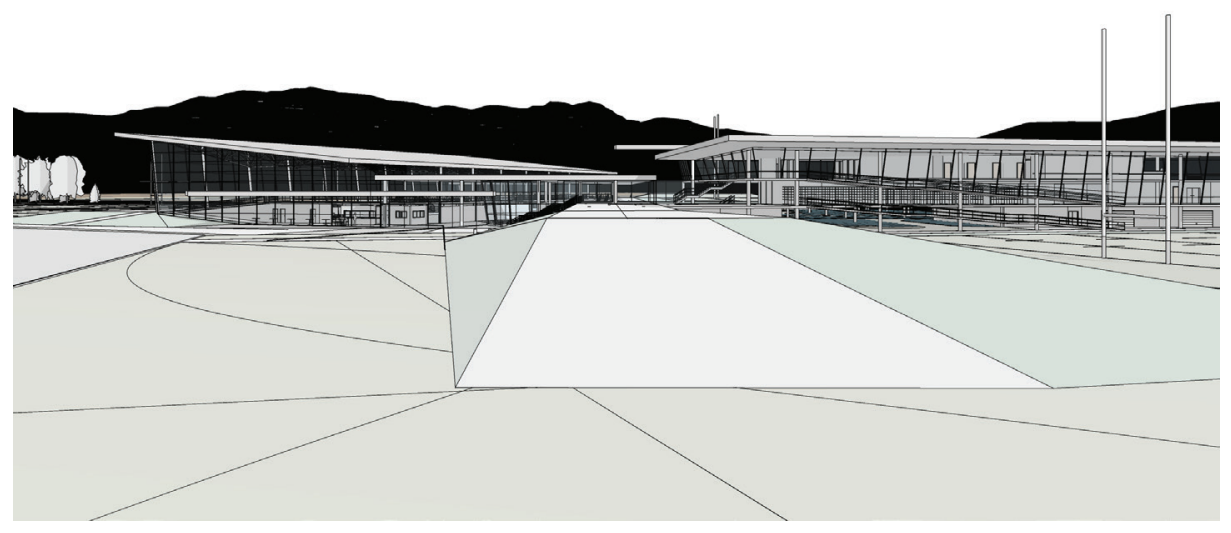

Figure 190: View 12 - Approach from North West

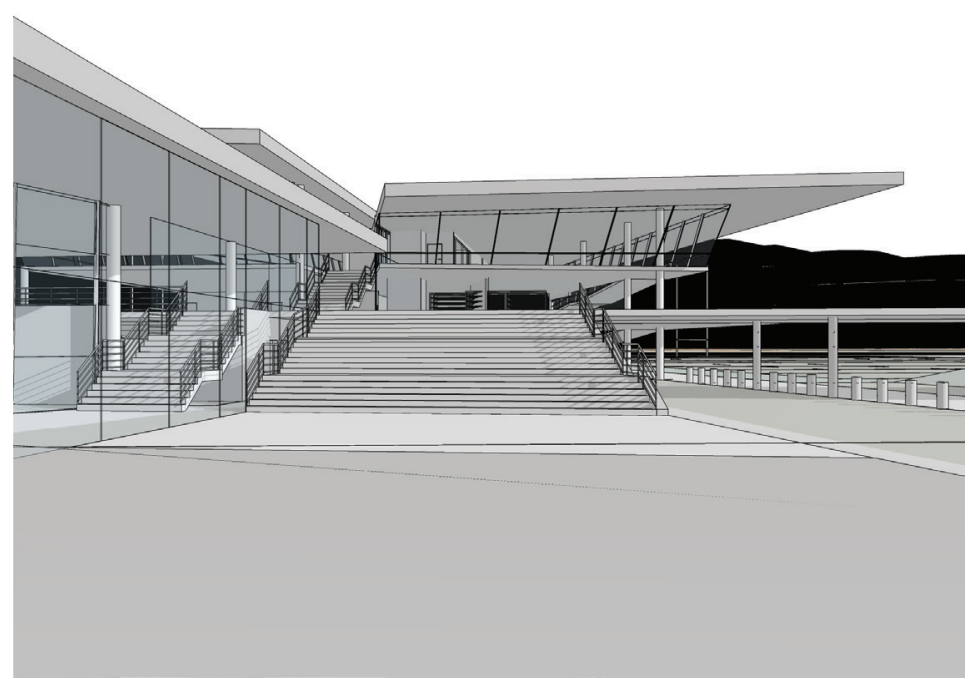

Figure 192: View 14 - Approach to main stairs from North East

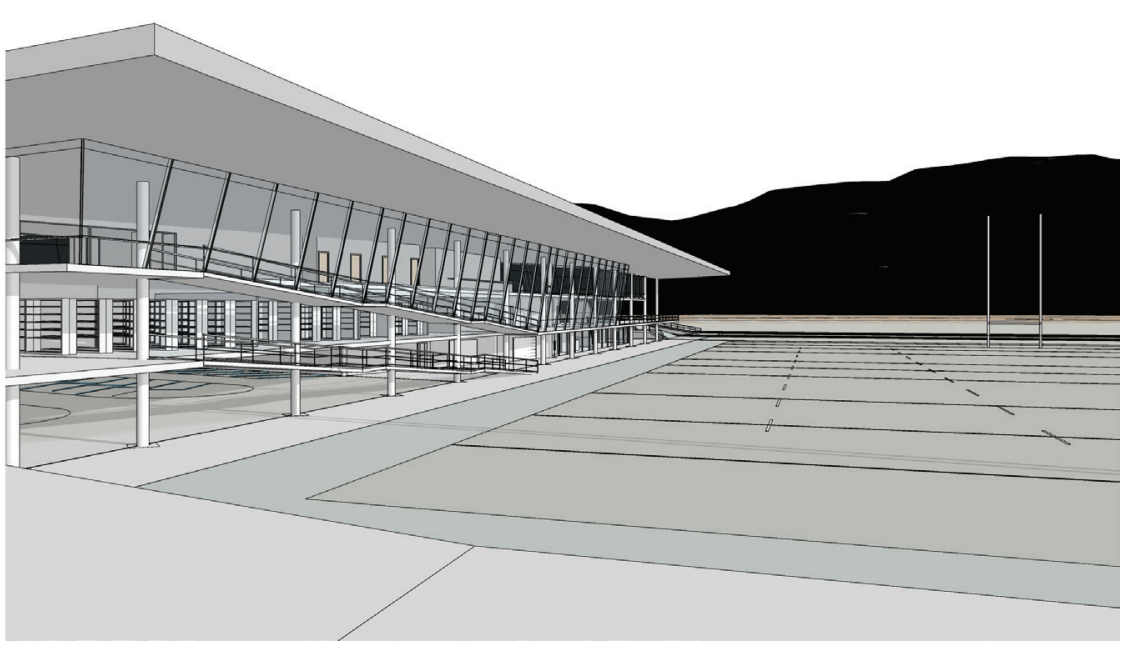

Figure 191: View 13- Looking down from hill

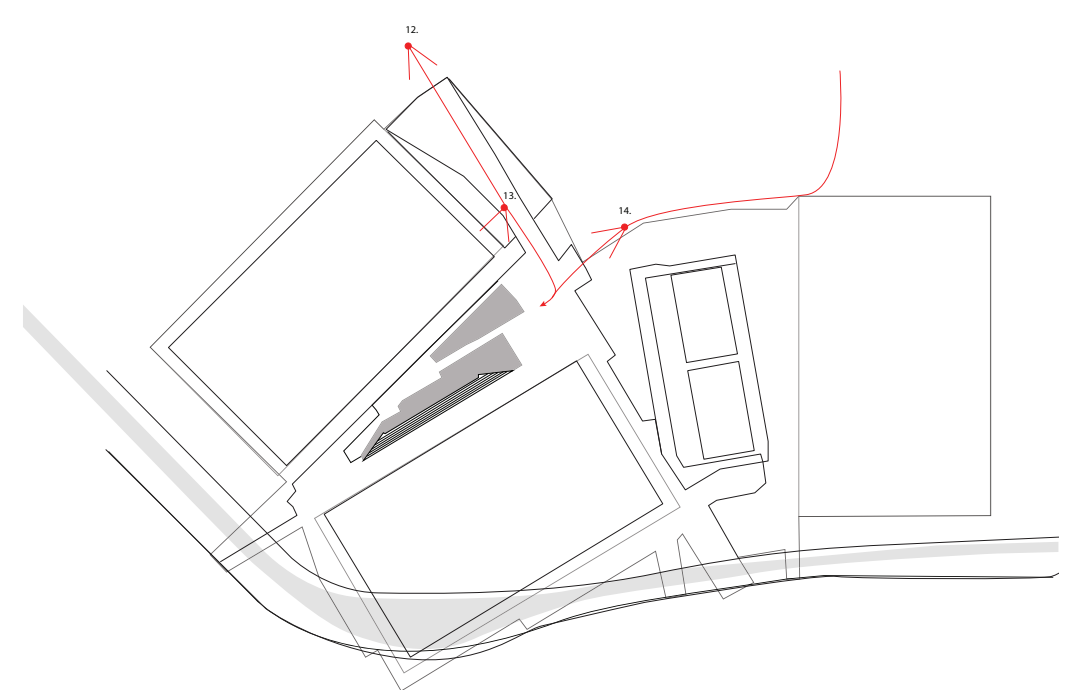

Figure 193: Northern approach views 


\section{Main social space / clubrooms}

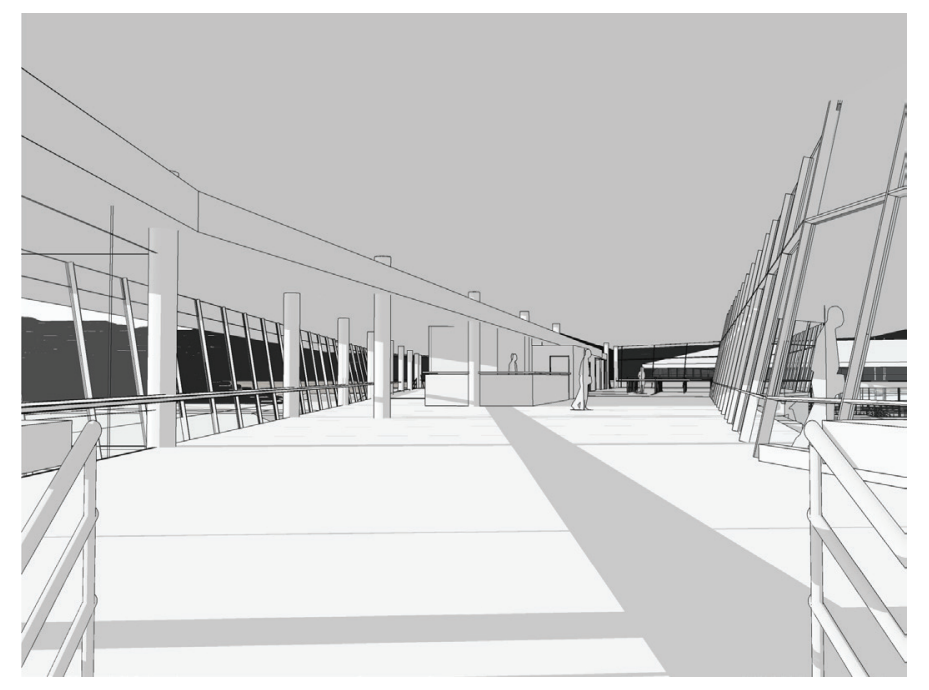

Figure 194: View 15- Top of stairs looking into main social space

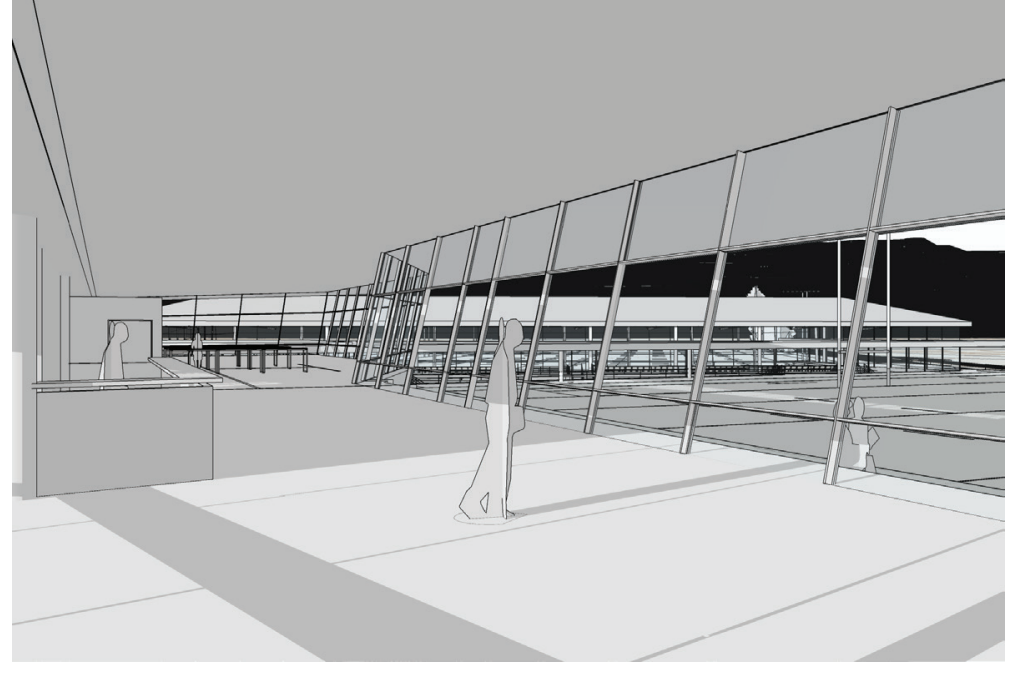

Figure 195: View 16 - Bar area of main social space

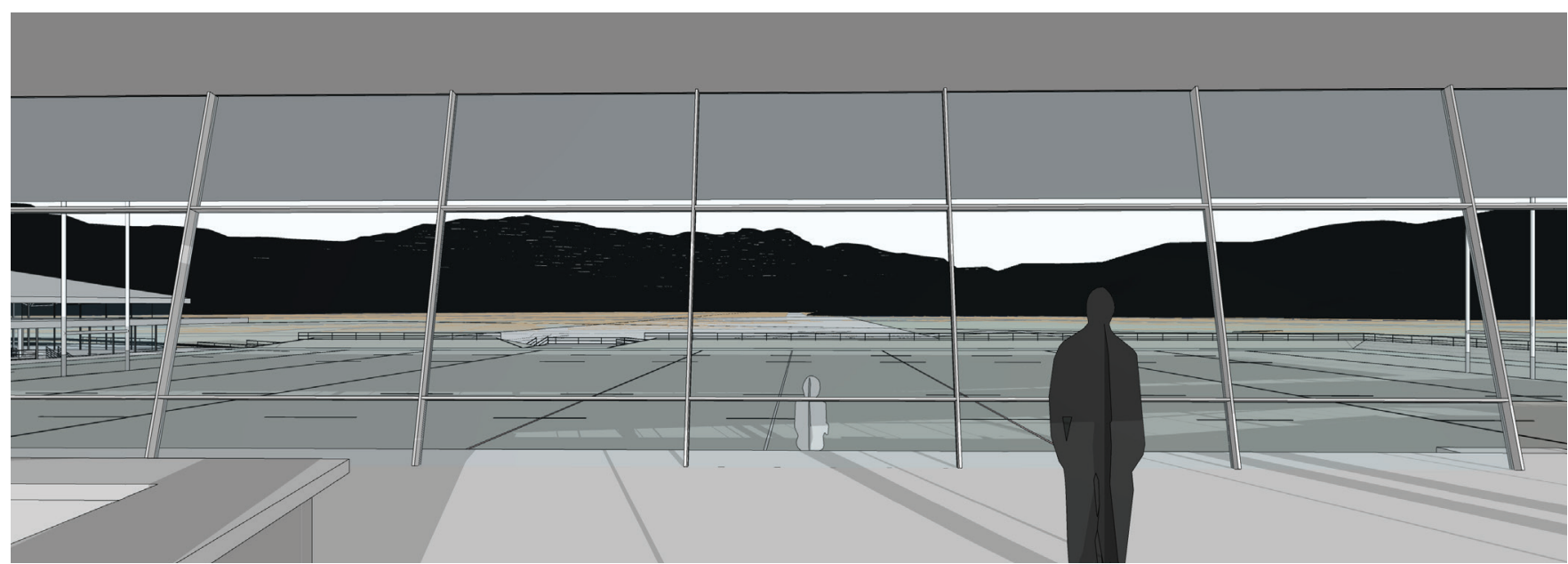

Figure 196: View 17 - View of field and landscape from bar area

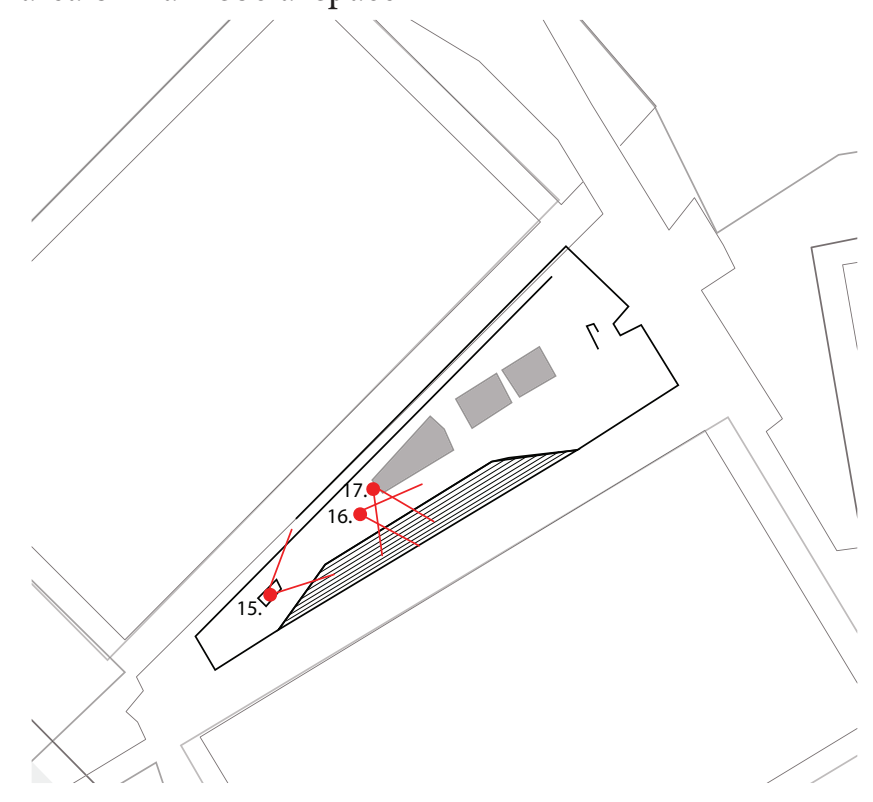

Figure 197: Location plan showing views 
Indoor Sports Hall

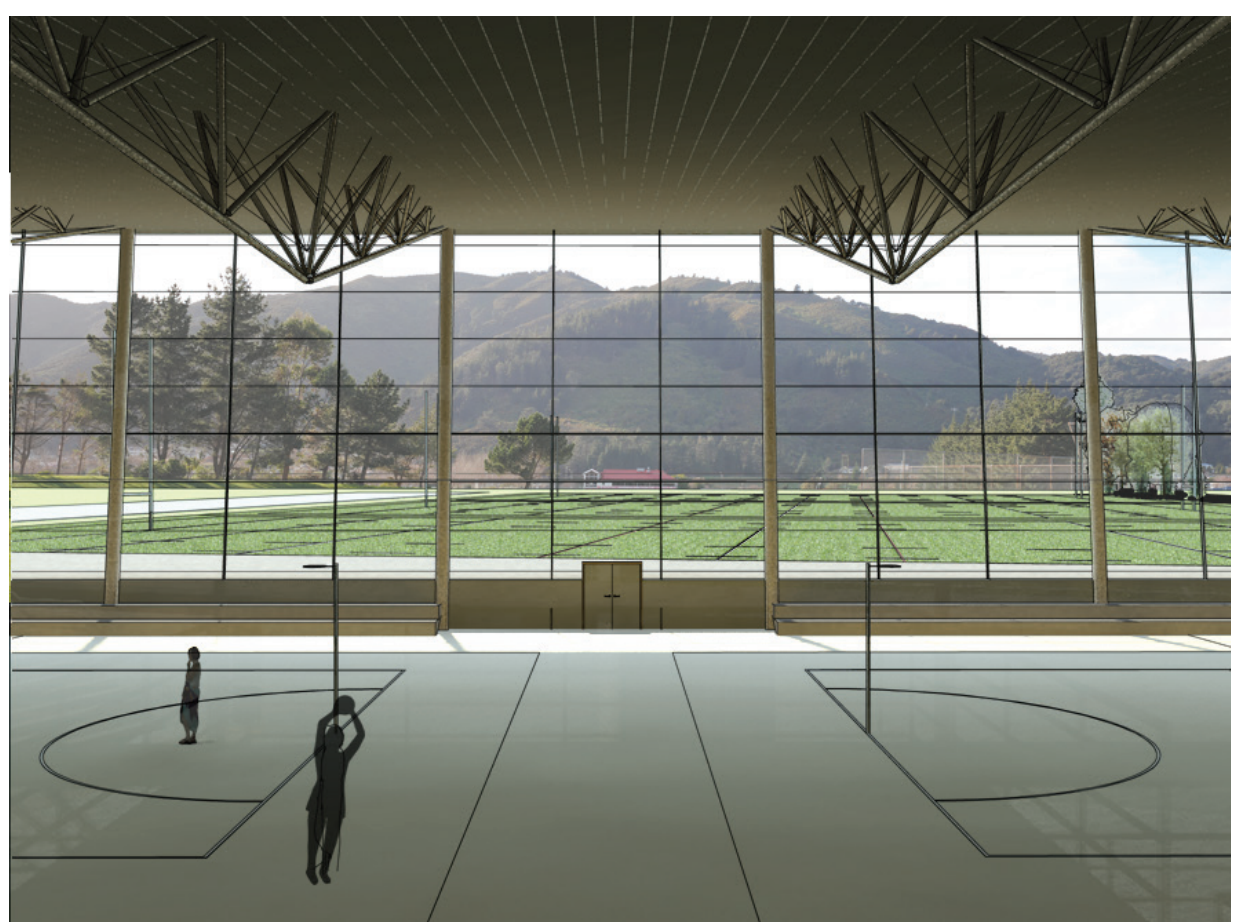

Figure 198: View from spectator area of Indoor Sports Hall

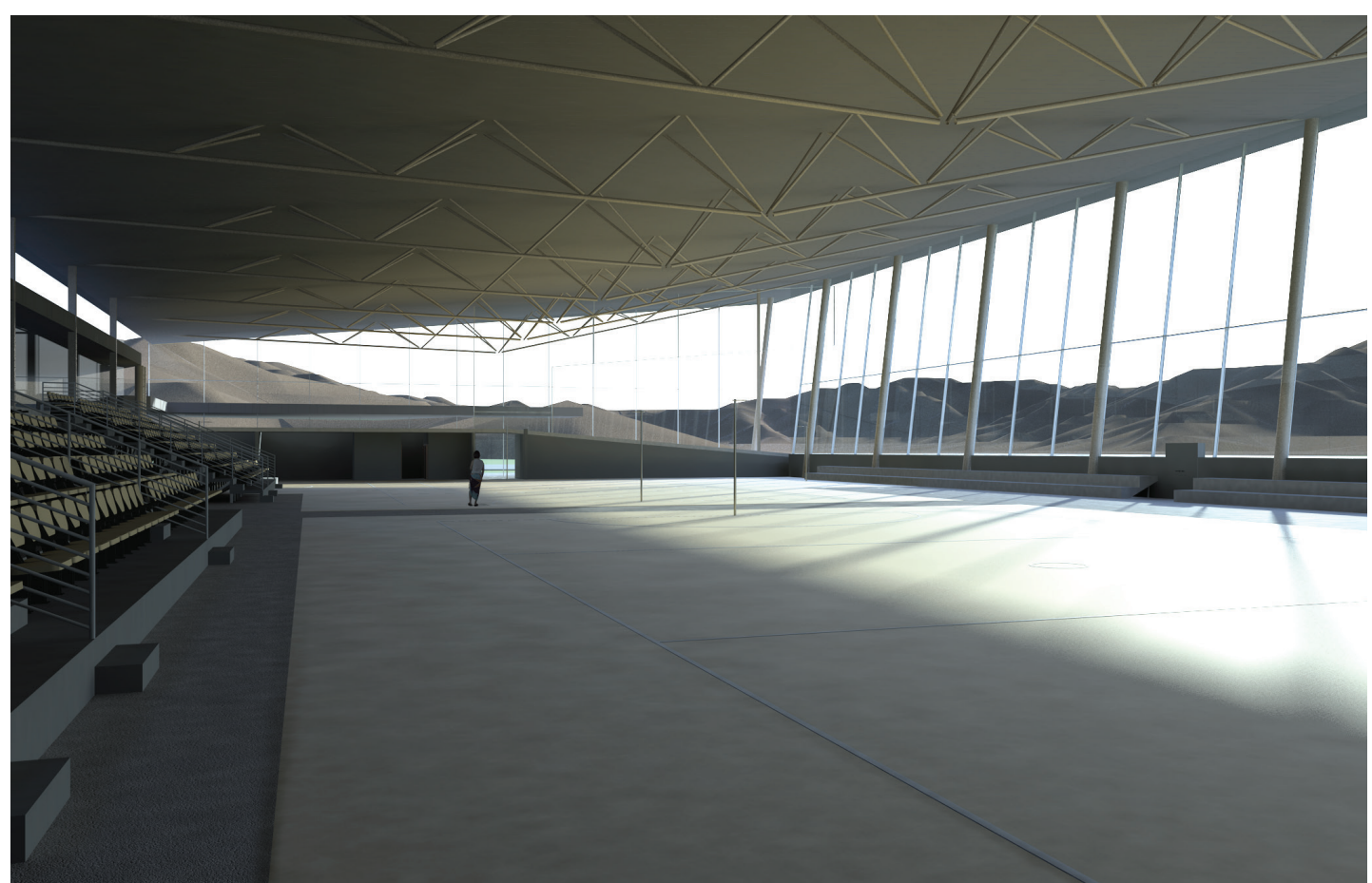

Figure 199: View from ground floor of Indoor Sports Hall 


\section{Discussion}

The final design developed for this thesis uses knowledge derived from research conducted on the Wainuiomata community, and its relationship with sport, to deliver a design which offers a new understanding of how Architecture's relationship with the Sports Field can be reconsidered to intensify (social) connections between sport and community. The final outcome of this research process is a design for a sports and education facility in Wainuiomata which increases the opportunities for social engagement by pursuing a closer relationship between architecture and the sports field.

Research conducted on the Wainuiomata community was used to build an understanding of a number of factors which affect the relationship between sport, community, and the use of sports facilities. The final design developed responds to these factors, outlined in the brief (see pg $80-81$ ), which have an effect on the use of these social spaces. The design is a negotiation between these factors, the conditions of site, and social/physical context.

\section{Physical arrangement}

The building is designed to have a close proximity, and to open directly onto the field. A closer relationship between the clubrooms and the sports field is achieved through the design of a long social space which occupies the length of the field. This layout enables views of the game from many places within the clubroom itself, seating space is provided via terraces which cut back into the clubrooms, these are shaped to allow views of the entire field while also enabling views from further back within the centre of the clubroom itself, all the way to the bar so people can continue watching while waiting.

\section{Program}

Sports clubs are traditionally only used during the evenings and weekends. The introduction of additional program, in the form of a tertiary education campus, with a focus on sport, and a gym which is accessible to the public, ensures use of the facilities throughout the day. While also providing wider benefits to the local community in the form of fitness/ health and improved education opportunities.

\section{Weather}

The design responds to a lack of all weather facilities in Wainuiomata by incorporating an artificial turf on its main field, shelter is also provided to spectators through the extension of the roof to cover spectator areas, the field can also be viewed from within the club itself. This enables games and training in any weather and allows for more intensive use of the grounds.

\section{Visual connections}

This design responds to local context by inverting the traditional stadium form by concentrating spectator spaces between multiple fields instead of splitting them to surround a single field. This concentrates the social space of sport and gives the opportunity to engage with the wider community by establishing a visual relationship with the city and wider context. The main social space and the sports hall are oriented to enhance this visual connection to the surrounding landscape and the rest of the community. A judicious use of glass on the exterior of the building enables a level of transparency into the building to make activity within visible from the outside encouraging people to participate in social activities. The layout of the clubrooms concentrates amenities and provides shelter for spectators and allows spectators to consume alcohol within the club space without impacting their ability to watch and enjoy the game.

Form

Formally the building consists of a series of overlapping planes which form the ground, $1^{\text {st }}$ and $2^{\text {nd }}$ floors of the building as well as the roof. The planar nature of the building is derived from that of the sports field itself. The building is designed to have a closer relationship with the field of play. This is taken to the extreme where the building is treated as an extension of this field, blurring the lines between interior and exterior spaces where these planes overlap. Within these planes there exist three types of conditions, the natural, the artificial, and a hybrid of the two.

\section{Functionality}

The building is required to accommodate a range of events of varying sizes, so that a wide range of groups can use it. As a response to this the main social space has been designed so that it can be divided into a number of different size spaces, with the ability to open it up into one large space. The Indoor Sports Hall can similarly be divided to host two basketball / netball games, or four training courts. Retractable seating is provided to accommodate spectators for games, while allowing more space for activities when not required.

\section{Site and connection to context}

On an urban scale the facility addresses the lack of connectivity which exists in the site of Wise Park, despite its central location at the junction between three main branches of the Wainuiomata Valley and 
its position between multiple nodes of community activity, the Wainuiomata Marae, the Rugby League Club, The Fitzroy Tavern, Wainuiomata Intermediate \& High School as well as a number of primary schools, The Wainuiomata Mall and Central shopping area \& community centre. The site is split into two parts by a waterway which was altered to facilitate drainage. Currently there is only one bridge which crosses this divide creating a very narrow bottleneck on what is otherwise a large central site. There are also no defined paths on the north side of the river, which means that in order to cross the bridge a person has to pass through a grassy field which is often quite wet and muddy.

The design addresses this issue by approaching it in a diagrammatic fashion. Desire lines through the site were mapped out, linking the various nodes of community activity. Potential layouts for a series of fields were also explored diagrammatically to test a series of arrangements and orientations. These two explorations were then combined by using a strategy of funnelling which concentrated the various desired routes into three main movement channels which focus pedestrians into major routes which flow either side of the main blocks of program as well as through the middle. This strategy enabled a negotiation between the spatial requirements of program and movement channels through the site.

\section{Reflection}

The aim of this thesis is to explore how Architecture's relationship with the Sports Field can be reconsidered to intensify (social) connections between sport and community. This is achieved through the design of a community sports facility which employs a closer physical, formal, and visual relationship between building and sports field. It also encourages activity throughout the day by integrating the programs of sports club room, and a tertiary education campus. An analysis of existing relationships and interconnections within the sporting community of Wainuiomata was used to build an understanding of these relationships and to highlight what was missing that could be incorporated into a new facility. A design was then developed which responded to these understandings. On reflection this research is successful in exploring how the design of a sports facility can intensify (social) connections between sport and community however there are a number of areas in which this research could have been improved:

\section{Research Process}

This research was a two part process which involved research for design which analysed connections between sport and community, and research through design which used knowledge developed in the earlier study to inform a design brief, tests and developments. This process by design was very open with the intention that research conducted on the local community would point towards a design response. This process of data collection was more time consuming than originally anticipated, in part due to the limited sources of data available. While this process was useful, and interesting, it was inefficient and delayed the research through design stage.
I think that if the key issues for the design to respond to were identified earlier the project could have benefited from a more thorough series of design experiments to test different options. Ultimately this process could have been structured better, however going into the project it was difficult to anticipate what to expect.

Initially this thesis was a response to the state of the Wainuiomata Sporting community. Wainuiomata was observed to have a strong sporting tradition but its facilities are in decline. It was hypothesized that part of the problem was that there is quite a large number of sports clubs, each with their own facilities that they struggled to maintain. An answer to this was to bring these different clubs together in a single facility and to see what type of building would result. In short the thesis was initially conceived as a study of program of local sports clubs which would be conducted through a combination of observations and interviews with representatives of the different clubs. This data was to be mapped / diagrammed to allow comparisons between clubs to allow their programs to be combined and to allow other programs to be introduced. The intended outcome was to see how the quality of sporting facilities in local communities i.e. Wainuiomata could be improved. It was assumed that bringing these groups together would be an improvement.

Once the project started it became obvious that my initial methodology was flawed. An analysis of existing facilities was not going to provide a good basis for combining sports clubs. The clubs and the community in general exist in a state of flux due to changing demographics and a range of other influences. This means that the existing facilities are not 
necessarily reflective of what is required or will be in the future. There is also the looming question of the role played by existing facilities - which would not just disappear. The relationship between the field and the sports club itself began to present itself as a more important cause for concern. The field and the architecture of the clubroom share a kind of reciprocal / symbiotic relationship. Sports clubs rely on social activity and interaction in order to continue operating in their role of promoting and supporting sporting activities. The field and the games which are played on it play an important role in attracting people to games and the clubrooms themselves. Without this initial attraction the clubrooms are mostly empty with only a few regulars coming back. During the period of my investigations problems affecting the use of fields such as extreme weather conditions were observed in the form of drought and heavy rain both of which made grounds unusable throughout the season. Ground cancellations exacerbate the problems which clubs have in attracting people to the clubrooms.

The initial design methodology similarly did not cope with what I perceive as being a core issue with community sports architecture - The large amount of down time when nobody is using the space. A similar problem exists with the field itself which is a large are of public land which for the most part is sparingly used and only for limited purposes. Simply bringing sports clubs together at the prime times when their facilities are being used any way would just exaggerate existing problems with the sports environment with expanded premises which would still lie abandoned throughout the day. In a roundabout way this links back to a part of the initial method which looked at other programs which could be introduced to supplement the existing. The thesis was no longer about combining programs but about introducing new programs and activities to the sports field through an architectural design. These could be tested in the design of a new facility which filled gaps existing in the existing community which would be revealed through an analysis of the community in general and its relationship with sport.

\section{Diagrams}

While diagrams did serve a useful purpose in my design process their use was less prominent that what was originally intended. For the purposes of this research diagrams were initially conceived as a means of visualising the 'invisible' networks and interrelations between sports clubs and the wider community. The intention was that through translating this information into a visual format it could then be understood and utilised as part of the architectural medium. During this process however it became clear to me that (perhaps unsurprisingly) that this merely resulted in visual representation of data. While this was useful for developing an understanding of local history and context this contained no agency in itself to generate design outcomes. Diagrams used in this fashion were not so useful for generating a design brief however they were useful to condense contextual information to allow it to be more readily understood by others. The issue is that in order to arrive at that point I already had to process the information and so in many ways the value of this process was limited from a design point of view. What I found more useful in the design process was not so much the use of diagrams, but instead understanding the building as a diagram. The final design of the building operates a diagram, in the sense that it takes a number of factors which relate to the social environment of sports and specifies how they combine, to create a building which multiplies these social effects.

\section{Limitations}

Due to the scale of the design the developed design was resolved to the level where the relationship between elements of program are well established however each of these areas in themselves would require further development at a detailed level. This was considered to be outside the scope of the project.

There are biases which exist in the research process, due to my role in the research process both in the collection of data and design responses which have shaped the nature of design, focusing it towards areas which I believed to be important. Similarly this research was limited in its response to community due to its focus on the Wainuiomata Rugby Club, time constraints meant that only this club was analysed in detail. This means that data gathered is biased towards the relationships observed at the rugby club, for the purposes of this research they were assumed to be representative of a wider New Zealand conditions however further research would need to be conducted to verify this on a wider scale.

Given the scale of the design there are a number of aspects of the design which given time could have been further developed, these included: 


\section{Connection to local context}

While the building is effectively a response to local context in terms of its program and organisation on site there is a general lack of the development at the fringes of the site due to a focus on the relationship between field and building. The treatment of connections to landscape, river, and the street itself are all areas which could have used more development. The intention was that landscape could have been used to mediate between the street and the site, facilitating transition into the site from pedestrian routes. Paths through the site also displace the existing BMX track and Fitzroy Tavern. The intention was to relocate these elements or redesign them to better integrate with the wider design.

\section{Structure and Materiality}

Because the focus of the design was on exploring a social agenda some aspects of the design such as structure and materiality were not explored in detail. These areas would require further development if the project were to be realized.

\section{Viability}

In reviews there were concerns about the viability of the design due to cost, and the scale of the development. I feel that the project is justified as a response to real problems which exist in the community and will be made worse in the future with a proposed increase to the local population.

\section{Conclusion}

The aim of this thesis is to explore how Architecture's relationship with the Sports Field can be reconsidered to intensify (social) connections between sport and community. This is achieved through the design of a community sport \& education facility which employs a closer physical, formal, and visual relationship between building and sports field. 


\section{Appendix}

Appendix 1: Sources of Data

Information was gathered from a number of sources including:

- Statistics New Zealand Census data from 1986 to 2006

- Usually Resident Population

○ Ethnicity

○ Religious Affiliation

- Personal Income

- Societies.govt.nz

- Financial statements for incorporated societies (including sports clubs)

- Dates clubs were incorporated

- Wainuiomata Historical Society

- Newspaper clippings covering articles on sports clubs

- Books on early Wainuiomata

- Pamphlet about history of Wainuiomata

- Book about community involvement in building of swimming pool, 'If you want a pool, build it ....... yourselves'
- Wainuiomata Community Library

- Local News Paper Archive - Valley News, Wainuiomata News, The Courier

- Association Football Club $25^{\text {th }}$ Jubilee publication

- Rugby Football Club $50^{\text {th }}$ Jubilee publication

- Old Wainuiomata Maps

- http://www.digitalnz.org/

- Historic Photographs of rugby club

- Historic Aerial photographs (showing Wainuiomata development over time)

\section{- Wainuiomata Rugby Football Club}

- Photographs and observations / sketches

- Occupation patterns

- Physical / material characteristics of place

- Anecdotal information

- Rugby Football Club 50 $50^{\text {th }}$ Jubilee publication (History of Club)

- Various Plans of the building and alterations, built \& unbuilt 
Appendix 2: Financial accounts of Wainuiomata Sports Clubs

All financial data for sports clubs used in this study was obtained from the 'Societies and Trusts Online' website (Ministry of Business, 2014) and was accessed using the 'search for an incorporated society' function found under the Online services tab on their home page. Data obtained about each sports club was taken from a number of financial account documents found under entries for each individual club. These documents have been individually listed below but for simplicity references are given for each individual club listing, where these documents can be found, and not each individual document. Data taken from these documents was entered into an excel table to aid in comparisons between years and clubs.
WAINUIOMATA ASSOCIATION FOOTBALL CLUB INCORPORATED

\section{Number: 217040}

\begin{tabular}{|c|c|c|c|c|}
\hline 圈 & 24-JAN-2011 11:22:48 & $\underline{10059937191}$ & Annual Accounts - 2010 & $\underline{152.8 \mathrm{~Kb}}$ \\
\hline 橉 & $\underline{02-D E C-2008 ~ 16: 37: 31}$ & 10053689508 & Annual Accounts - 2008 & $311.6 \mathrm{~Kb}$ \\
\hline 图 & 21-NOV-2006 11:26:56 & 10052869810 & Annual Accounts - 2006 & $\underline{61 \mathrm{~Kb}}$ \\
\hline 圈 & 21-NOV-2006 11:26:25 & 10052869821 & Annual Accounts - 2005 & $\underline{86.9 \mathrm{~Kb}}$ \\
\hline 8 & 24-NOV-2004 15:33:05 & 10047104042 & Annual Financial Statements for 2004 & $147.3 \mathrm{~Kb}$ \\
\hline 橉 & 25-FEB-2004 09:05:45 & 10045570500 & Annual Financial Statements For 2003 & $\underline{93.2 \mathrm{~Kb}}$ \\
\hline 橉 & 05-AUG-2003 11:06:31 & $\underline{10044396189}$ & Annual Financial Statements For 2002 & $102.2 \mathrm{~Kb}$ \\
\hline 图 & 01-FEB-2002 14:46:41 & 10040526001 & Annual Financial Statements For 2001 & \\
\hline
\end{tabular}

(Ministry of Business, 2013a)

\section{WAINUIOMATA BOWLING CLUB INCORPO-}

\section{RATED}

\section{Number: 217044}

\begin{tabular}{|l|l|l|l|l|}
\hline 圈 & $\underline{22-J U N-2012 ~ 16: 04: 10}$ & $\underline{10061126136}$ & $\underline{\text { Annual Accounts - 2012 }}$ & $\underline{712.6 \mathrm{~Kb}}$ \\
\hline 圈 & $\underline{13-D E C-201111: 35: 10}$ & $\underline{10060803738}$ & $\underline{\text { Annual Accounts - 2010 }}$ & $\underline{203.2 \mathrm{~Kb}}$ \\
\hline 橉 & $\underline{13-D E C-201111: 34: 06}$ & $\underline{10060803727}$ & $\underline{\text { Annual Accounts - 2011 }}$ & $\underline{138.1 \mathrm{~Kb}}$ \\
\hline
\end{tabular}

(Ministry of Business, 2013b) 


\section{WAINUIOMATA CRICKET CLUB INCORPORATED}

Number: 215967

\begin{tabular}{|c|c|c|c|c|}
\hline 9 & 31-AUG-2012 09:25:57 & $\underline{10061247980}$ & Annual Accounts - 2012 & $\underline{127.4 \mathrm{~Kb}}$ \\
\hline 里 & 27-AUG-2010 14:02:28 & $\underline{10059509609}$ & $\underline{\text { Annual Accounts - } 2010}$ & $\underline{201.4 \mathrm{~Kb}}$ \\
\hline 有 & $\underline{\text { 04-SEP-2008 14:06:35 }}$ & $\underline{10056470835}$ & Annual Accounts - 2008 & $\underline{224.8 \mathrm{~Kb}}$ \\
\hline 争 & 23-APR-2007 16:23:27 & $\underline{10052089695}$ & Annual Accounts - 2006 & $\underline{59.1 \mathrm{~Kb}}$ \\
\hline 8 & 07-APR-2006 16:28:44 & $\underline{10050927213}$ & Annual Accounts - 2005 & $\underline{12.6 \mathrm{~Kb}}$ \\
\hline 幽 & 07-APR-2006 16:27:48 & $\underline{10050927202}$ & $\underline{\text { Annual Financial Statements For } 2003}$ & $\underline{29.9 \mathrm{~Kb}}$ \\
\hline 圈 & 07-APR-2006 16:27:07 & $\underline{10050927199}$ & Annual Accounts - 2005 & $\underline{29.4 \mathrm{~Kb}}$ \\
\hline
\end{tabular}

(Ministry of Business, 2012a)

\section{WAINUIOMATA CROQUET CLUB INCORPORATED}

Number: 585577

\begin{tabular}{|c|c|c|c|c|}
\hline 9 & 18-JUN-2012 10:45:51 & 10061119312 & Annual Accounts - 2012 & $105.9 \mathrm{~Kb}$ \\
\hline 屎 & 31-MAY-2011 09:37:05 & 10060322682 & Annual Accounts - 2011 & $\underline{82.7 \mathrm{~Kb}}$ \\
\hline 89 & $\underline{\text { 02-JUN-2010 16:53:40 }}$ & $\underline{10059336410}$ & Annual Accounts - 2010 & $\underline{111.8 \mathrm{~Kb}}$ \\
\hline 棌 & 25-JUN-2009 09:04:43 & $\underline{10057831666}$ & Annual Accounts - 2009 & $131.6 \mathrm{~Kb}$ \\
\hline 90 & 12-MAY-2008 10:59:55 & $\underline{10055823350}$ & Annual Accounts - 2008 & $\underline{73.6 \mathrm{~Kb}}$ \\
\hline 9 & 17-DEC-2007 11:15:05 & $\underline{10055263926}$ & Annual Accounts - 2006 & $\underline{31.1 \mathrm{~Kb}}$ \\
\hline 橉 & 25-MAY-2007 11:33:21 & 10053970161 & Annual Accounts - 2007 & $\underline{35.4 \mathrm{~Kb}}$ \\
\hline
\end{tabular}

(Ministry of Business, 2013c) 


\section{WAINUIOMATA RUGBY FOOTBALL CLUB INCORPORATED}

\section{Number: 216045}

\begin{tabular}{|c|c|c|c|c|}
\hline 图 & 18-DEC-2013 21:14:04 & & Upload of Financial Statement for 2012 & $1721.7 \mathrm{~Kb}$ \\
\hline 圈 & 30-OCT-2013 10:52:30 & & Upload of Financial Statement for 2013 & $2108.3 \mathrm{~Kb}$ \\
\hline 圈 & 30-OCT-2013 10:37:23 & & Upload of Financial Statement for 2013 & $\underline{48.2 \mathrm{~Kb}}$ \\
\hline 圈 & 05-APR-2013 15:42:36 & & Upload of Financial Statement for 2011 & $1556.6 \mathrm{~Kb}$ \\
\hline 80 & 09-NOV-2012 16:21:02 & 10061386910 & Annual Accounts - 2012 & $1506.4 \mathrm{~Kb}$ \\
\hline 圈 & 25-MAR-2011 11:52:08 & 10060186358 & Annual Accounts - 2010 & $\underline{2024.6 \mathrm{~Kb}}$ \\
\hline 圈 & 30-JAN-2009 10:39:18 & 10057117313 & Annual Accounts - 2008 & $139.6 \mathrm{~Kb}$ \\
\hline 圈 & 30-JAN-2007 12:07:01 & 10052277276 & Annual Accounts - 2006 & $110.5 \mathrm{~Kb}$ \\
\hline
\end{tabular}

(Ministry of Business, 2013d)

\section{WAINUIOMATA RUGBY FOOTBALL LEAGUE CLUB INCORPO-}

\section{$\underline{\text { RATED }}$}

\section{Number: 217681}

\begin{tabular}{|l|l|l|l|l|}
\hline 18-DEC-2012 13:45:43 & $\underline{\text { Upload of Financial Statement for 2011 }}$ & $\underline{2476.5 \mathrm{~Kb}}$ & \\
\hline 橉 & $\underline{\text { 28-FEB-2012 11:14:22 }}$ & $\underline{\text { Upload of Financial Statement for 2010 }}$ & $\underline{2538.4 \mathrm{~Kb}}$ & \\
\hline 橉 & $\underline{14-F E B-2011 ~ 20: 21: 14}$ & $\underline{\text { Upload of Financial Statement for 2009 }}$ & $\underline{142.5 \mathrm{~Kb}}$ & \\
\hline $\mathbf{1 0}$ & $\underline{18-F E B-200923: 37: 24}$ & $\underline{\text { Upload of Financial Statement for 2008 }}$ & $\underline{61 \mathrm{~Kb}}$ & \\
\hline
\end{tabular}

(Ministry of Business, 2012b) 


\section{WAINUI SOFTBALL CLUB INCORPORATED}

Number: 218021

\begin{tabular}{|c|c|c|c|c|}
\hline 圈 & 06-NOV-2006 12:44:10 & $\underline{10052799045}$ & Annual Accounts - 2005 & $\underline{87.1 \mathrm{~Kb}}$ \\
\hline 图 & 31-OCT-2006 10:10:27 & $\underline{10052839456}$ & Annual Accounts - 2006 & $\underline{62.3 \mathrm{~Kb}}$ \\
\hline 圈 & 14-APR-2005 09:55:36 & $\underline{10046622369}$ & Annual Financial Statements for 2004 & $\underline{76.9 \mathrm{~Kb}}$ \\
\hline 图 & 17-SEP-2003 13:45:20 & 10044787890 & Annual Financial Statements For 2003 & $\underline{69.5 \mathrm{~Kb}}$ \\
\hline 圈 & 08-NOV-2002 09:17:38 & 10042868334 & Annual Financial Statements For 2002 & $\underline{56.5 \mathrm{~Kb}}$ \\
\hline 圈 & 07-SEP-2001 11:05:14 & 10038744950 & Annual Financial Statements For 2001 & $\underline{63.3 \mathrm{~Kb}}$ \\
\hline
\end{tabular}

(Ministry of Business, 2006) 
Association Football Club Income Sources

\begin{tabular}{|c|c|c|c|c|c|c|c|c|c|c|c|c|c|}
\hline & 2012 & 2011 & 2010 & 2009 & 2008 & 2007 & 2006 & 2005 & 2004 & 2003 & 2002 & 2001 & 2000 \\
\hline Bar Trading & & & 9,679 & 8,913 & 7,738 & 9,056 & 5,051 & 5,238 & 6,492 & 4,765 & 4,647 & 4,154 & 3,786 \\
\hline Grants & & & 28,740 & 16,434 & 19,318 & 25,811 & 7,952 & 4,795 & 29,466 & 19,444 & 19,613 & 16,316 & 12,628 \\
\hline Subscriptions & & & 21,706 & 17,886 & 14,440 & 11,209 & 8,453 & 7,873 & 8,606 & 9,444 & 8,126 & 13,756 & 14,245 \\
\hline Other & & & 11,155 & 7,235 & 2,413 & 2,613 & 1,041 & 1,371 & 4,930 & 2,667 & 2,170 & 1,484 & 4,586 \\
\hline Total & 0 & 0 & 71280 & 50468 & 43909 & 48689 & 22497 & 19277 & 49494 & 36320 & 34556 & 35710 & 35245 \\
\hline \multicolumn{14}{|c|}{ Bowling Club Income Sources } \\
\hline & 2012 & 2011 & 2010 & 2009 & 2008 & 2007 & 2006 & 2005 & 2004 & 2003 & 2002 & 2001 & 2000 \\
\hline Bar Trading & 58,519 & 71,503 & 52,758 & & & & & & & & & & \\
\hline Grants/Gaming & 16,569 & 18,175 & 26,073 & & & & & & & & & & \\
\hline Subscriptions & 17,504 & 17,676 & 19,751 & & & & & & & & & & \\
\hline Other & 14,910 & 29,995 & 15,707 & & & & & & & & & & \\
\hline Total & 107502 & 137349 & 114289 & 0 & 0 & 0 & 0 & 0 & 0 & 0 & 0 & 0 & 0 \\
\hline \multicolumn{14}{|c|}{ Rugby League Income Sources } \\
\hline & 2012 & 2011 & 2010 & 2009 & 2008 & 2007 & 2006 & 2005 & 2004 & 2003 & 2002 & 2001 & 2000 \\
\hline Bar Trading & & 5,320 & 4,455 & 3,858 & 26,646 & & & & & & & & \\
\hline Grants & & 43,217 & 26,368 & 21,759 & 23,852 & & & & & & & & \\
\hline Subscriptions & & 5,161 & 3,514 & 0 & 0 & & & & & & & & \\
\hline Other & & 4,622 & 14,377 & 10,411 & 2,679 & & & & & & & & \\
\hline Total & 0 & 58320 & 48714 & 36028 & 53177 & 0 & 0 & 0 & 0 & 0 & 0 & 0 & 0 \\
\hline
\end{tabular}


Cricket Club Income Sources

\begin{tabular}{|c|c|c|c|c|c|c|c|c|c|c|c|c|c|}
\hline & 2012 & 2011 & 2010 & 2009 & 2008 & 2007 & 2006 & 2005 & 2004 & 2003 & 2002 & 2001 & 2000 \\
\hline Bar Trading & 2,529 & 9,418 & 9,405 & 5,218 & 6,581 & 8,580 & 4,114 & 5,156 & 6,683 & 13,591 & & & \\
\hline $\begin{array}{l}\text { Sponsors \& } \\
\text { grants }\end{array}$ & 34302 & 19543 & 19422 & 26887 & 19839 & 22368 & 6537 & 42478 & 24487 & 10539 & & & \\
\hline Subscriptions & 5368 & 6120 & 6645 & 8590 & 7780 & 8720 & 8930 & 8325 & 8190 & 11180 & & & \\
\hline Other & 5,994 & 7,331 & 5,638 & 10,137 & 8,928 & 7,003 & 6,323 & 41,224 & 4,918 & 7,988 & & & \\
\hline Total & 48193 & 42412 & 41110 & 50832 & 43128 & 46671 & 25904 & 97183 & 44278 & & 0 & 0 & 0 \\
\hline \multicolumn{14}{|c|}{ Croquet Club Income Sources } \\
\hline & 2012 & 2011 & 2010 & 2009 & 2008 & 2007 & 2006 & 2005 & 2004 & 2003 & 2002 & 2001 & 2000 \\
\hline Clubrooms & 716 & 1119 & 1078 & 1255 & 1747 & 1376 & 1060 & & & & & & \\
\hline Grants & 2000 & 2000 & & & 1500 & & 1300 & & & & & & \\
\hline Subscriptions & 2570 & 2770 & 2860 & 2940 & 2839 & 3420 & 3380 & & & & & & \\
\hline Other & 3324 & 3956 & 3983 & 3312 & 4299 & 3983 & 4372 & & & & & & \\
\hline Total & 8610 & 9846 & 7921 & 7506 & 10385 & 8779 & 10112 & 0 & 0 & 0 & 0 & 0 & 0 \\
\hline \multicolumn{14}{|c|}{ Rugby Union Income } \\
\hline & 2012 & 2011 & 2010 & 2009 & 2008 & 2007 & 2006 & 2005 & 2004 & 2003 & 2002 & 2001 & 2000 \\
\hline Bar Trading & 62870 & 95734 & 111531 & 59921 & 77824 & 59516 & 48242 & & & & & & \\
\hline Grants \& WRFU & 70459 & 96980 & 43824 & 57873 & 45637 & 135454 & 69548 & & & & & & \\
\hline Subscriptions & 5887 & 4279 & 4525 & 5222 & 7820 & 4704 & 3769 & & & & & & \\
\hline Other & 32264 & 72369 & 14097 & 8908 & 23995 & 24878 & 19437 & & & & & & \\
\hline Total & 171480 & 269362 & 173977 & 131924 & 155276 & 224551 & 140996 & 0 & 0 & 0 & 0 & 0 & 0 \\
\hline \multicolumn{14}{|c|}{ Wainui Softball Club } \\
\hline & 2012 & 2011 & 2010 & 2009 & 2008 & 2007 & 2006 & 2005 & 2004 & 2003 & 2002 & 2001 & 2000 \\
\hline \multicolumn{14}{|l|}{ Bar Trading } \\
\hline Grants & & & & & & & 1195 & 4873 & 4092 & 3325 & & 4454 & 400 \\
\hline Subscriptions & & & & & & & 8067 & 2608 & 2755 & 5742 & 4284 & 4757 & 4052 \\
\hline Other & & & & & & & 2398 & 1923 & 2008 & 2458 & 1677 & 1933 & 3176 \\
\hline Total & 0 & 0 & 0 & 0 & 0 & 0 & 11660 & 9404 & 8855 & 11525 & 5961 & 11144 & 7628 \\
\hline
\end{tabular}




\begin{tabular}{l}
\hline Nga Purapura Areas \\
\hline Ground Floor \\
\hline First Floor/ Mezzanine \\
Total \\
Break down of spaces \\
\hline Ground Floor \\
\hline Reception \\
Atrium \\
Kakano \\
Sports Hall \\
Toilets \\
\hline Teaching Spaces \\
\hline Shower \\
Gym \\
\hline Nutrition Class \\
\hline Cafe \\
Plant \\
Circulation / Other \\
\hline First Floor/ Mezzanine \\
\hline Warm \\
\hline
\end{tabular}

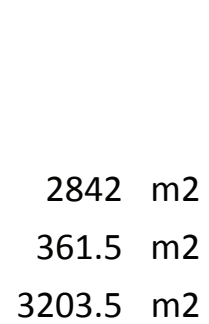

$18 \mathrm{~m} 2$

$192 \mathrm{~m} 2$

$\mathrm{m} 2$

$1554 \mathrm{~m} 2$

$66.125 \mathrm{~m} 2$

$112 \mathrm{~m} 2$

$101.5 \mathrm{~m} 2$

$420 \mathrm{~m} 2$

$100 \mathrm{~m} 2$

$12.25 \mathrm{~m} 2$

$21 \mathrm{~m} 2$

$245.125 \mathrm{~m} 2$

$49.5 \mathrm{~m} 2$

$66 \mathrm{~m} 2$

Admin

Offices

Plant

Circulation / Other

\begin{tabular}{|rr|}
\hline & $\begin{array}{l}\text { Proportional to } \\
\text { Wainuiomata } \\
\text { population }\end{array}$ \\
\hline $89 \%$ & $8952.3 \quad \mathrm{~m} 2$ \\
$11 \%$ & $1138.725 \quad \mathrm{~m} 2$ \\
$100 \%$ & $10091.03 \quad \mathrm{~m} 2$
\end{tabular}

Percentage of Total

$1 \%$

$6 \%$

$49 \%$

$2 \%$

$3 \%$

$3 \%$

$13 \%$

$3 \%$

$0 \%$

$1 \%$

$8 \%$

$2 \%$

$2 \%$

$1 \%$

$4 \%$

$2 \%$
$56.7 \mathrm{~m} 2$

$604.8 \mathrm{~m} 2$

$0 \mathrm{~m} 2$

$4895.1 \mathrm{~m} 2$

$208.2938 \mathrm{~m} 2$

$352.8 \mathrm{~m} 2$

$319.725 \mathrm{~m} 2$

$1323 \mathrm{~m} 2$

$315 \mathrm{~m} 2$

$38.5875 \mathrm{~m} 2$

$66.15 \mathrm{~m} 2$

$772.1438 \mathrm{~m} 2$

$155.925 \mathrm{~m} 2$

$207.9 \mathrm{~m} 2$

$138.6 \mathrm{~m} 2$

$433.125 \mathrm{~m} 2$

$203.175 \mathrm{~m} 2$

\section{Population}

Otaki (2006 census)

5466

Wainuiomata (2006 census)

17,214

Wainuiomata/Otaki

3.15 


\section{References}

(UNStudio), B. v. B. a. C. B. (2010). Diagrams. In M. Garcia (Ed.), The Diagrams of Architecture (pp. 222-227). West Sussex, UK: John Wiley \& Sons Ltd.

Alexander, V. (2000). Tales from the Swamp. Wainuiomata: Wainuiomata Historical Museum Society Inc.

Allen, S. (1998). Diagrams Matter. ANY, 15-19.

Allen, S. (2009a). IX_From Object to Field: Field Conditions in Architecture + Urbanism. In S. Allen (Ed.), Practice: Architecture, Technique + Representation (2nd ed., pp. 217-243). New York: Routledge.

Allen, S. (2009b). Notations and Diagrams: Mapping the Intangible. In S. Allen (Ed.), Practice: Architecture, Technique + Representation (2nd ed., pp. 40-69). New York: Routledge.

ArchDaily. (2013). ASB Sports Centre / Tennent + Brown Architects. Retrieved 13 February, 2014, from http://www.archdaily.com/405384/ asb-sports-centre-tennet-brown-architects/

Architects, B. T. (1981). The Manhattan Transcripts. from http://www.tschumi.com/projects/18/

Associates, B. J. Wise Park Wainuiomata - A landscape evaluation and explanation of proposals for Wise park, Wainuiomata.

Bale, J. (1993). The Spatial Development of the Modern Stadium. International Review for the Sociology of Sport, 28(2-3), 121-133. doi: $10.1177 / 101269029302800204$

Bale, J. (2001). Sport, Space and the City. Caldwell, N.J: Blackburn Press.

Brass, J. (2012a). Nga Purapura, Te Wananga o Raukawa: Figure 3. Architecture NZ(4), 58-64.
Brass, J. (2012b). Nga Purapura, Te Wananga o Raukawa: Figure 6. Architecture $N Z(4), 58-64$.

Brown, S. F. (2013). Epilogue: the not-so-hidden complexity of the sportcommunity connection. Sport in Society: Cultures, Commerce, Media, Politics, 17(1), 134-138. doi: 10.1080/17430437.2013.828898

Brown, T. (2012). Nga Purapura. Retrieved 13 February, 2014, from http:// www.tennentbrown.co.nz/

Creswell, J. W. (2003). Research Design: Qualitative, Quantitative and Mixed Method Approaches. Thousand Oaks, California: Sage.

Culley, P. P., John. (2009). Sports Facilities and Technologies. New York: Routledge.

Deleuze, G. (1988). Foucault (S. Hand, Trans.). Minneapolis: University of Minnesota Press.

Deleuze, G., Guattari, F., \& Massumi, B. (1987). Thousand Plateaus : Capitalism and Schizophrenia Retrieved from http://VUW.eblib.com/patron/FullRecord.aspx?p=310185

Department of Internal Affairs. (2012, 01-Jul-2012). Venues and numbers by territorial authority as at 30 June 2012 Retrieved 8 February, 2014, from https://www.dia.govt.nz/Pubforms.nsf/URL/ListofVenue 01\%20July\%202012.pdf/\$file/ListofVenue 01\%20July\%20 2012.pdf

Derrida, J. (1976). Of grammatology. Baltimore: Johns Hopkins University Press.

Digital NZ. (2014). Digital NZ. Retrieved 17 February, 2014, from http:// www.digitalnz.org/records?text=wainuiomata

Downton, P. (2003). Design Research. Melbourne: RMIT University Press.

Easton, P. (2013, 12 May). Wainuiomata rugby ground a 'mud bath', The Dominion Post. Retrieved from http://www.stuff.co.nz/dominion-post/ 
news/hutt-valley/8786374/Wainuiomata-rugby-ground-a-mud-bath

Eichberg, H. (1993). New Spatial Configurations of Sport? Experience from Danish Alternative Planning. International Review for the Sociology of Sport, 28(2-3), 245-262. doi: 10.1177/101269029302800212

Eisenman, P. (1999). Diagram Diaries. New York: Universe Publishing.

Eisenman, P. (2010). Diagram: An Original Scene of Writing. In M. Garcia (Ed.), The Diagrams of Architecture (pp. 92-103). West Sussex, UK: John Wiley \& Sons Ltd.

Emmons, p. (2006). Embodying networks: bubble diagrams and the image of modern organicism. The Journal of Architecture, 11(4), 441-461. doi: $10.1080 / 13602360601037867$

Flowers, B. (2011). Stadiums: Architecture and the Iconography of the Beautiful Game. The International Journal of the History of Spot, 28(8-9), 1174-1185. doi: 10.1080/09523367.2011.567770

Foucault, M. (1975). Discipline and Punish: The Birth of the Prison. New York: Random House.

Frank, S. S., Silke (2010). Introduction: Football, space and the built environment. In S. F. S. Steets (Ed.), Stadium Worlds: Football, space and the built environment (pp. 1-16). New York: Routledge.

Garcia, M. (2010). Introduction: History and Theories of the Diagrams of Architecture. In M. Garcia (Ed.), The Diagrams of Architecture (pp. 18-45). West Sussex, UK: John Wiley \& Sons Ltd.

Garritzmann, W. D. a. U. (2010). Diagramming the Contemporary: OMA's Little Helper in the Quest for the New. In M. Garcia (Ed.), The Diagrams of Architecture (pp. 228-235). West Sussex, UK: John Wiley \& Sons Ltd.

Hassan, D. (2013). Sport and communities: an introduction. Sport in Society, 17(1), 1-5. doi: 10.1080/17430437.2013.828903
Hight, C. (2009). Meeting the New Boss: After the Death of Theory. Architectural Design, 79(1), 40-45. doi: 10.1002/ad.808

Hutt City Council. (2012). Long Term Integrated Community Facilities Plan. Retrieved 9 February 2014, from http://www.huttcity.govt.nz/Documents/Have\%20your\%20say/Long\%20Term\%20Integrated\%20Facilities\%20Plan\%202012.pdf

Hutt City Council. (2013a). Draft Urban Growth Strategy. Retrieved from http://www.huttcity.govt.nz/Documents/a-z/Draft\%20Urban\%20 Growth\%20Strategy.pdf.

Hutt City Council. (2013b). GIS Viewer. Retrieved 17 February, 2013, from http://gisviewer.huttcity.govt.nz/silverlightviewer/?Viewer=HCC Viewer

Hutt City Council Policy Comittee. (2013). DEM10-10-7 - 13/834 - Proposal to Revoke Part of Hugh Sinclair Park and to Grant a Right of Way. Hutt City Council Website: Retrieved from http://infocouncil.huttcity.govt.nz/Open/2013/08/PC 01082013 AGN AT.PDF.

John, G. S., Rod; Vickery, Ben. (2013). Stadia: The Populous Design and Development Guide (5th ed.). New York: Routledge.

Keneally, J. M. K. B. M. (1982). Wainuiomata - These Passing Years. Churton Park, Wellington: Colonial Associates.

Kubo, M., \& Prat, R. (2005). Seattle Public Library, OMA/LMN. Michigan: Actar.

Kural, R. (2010). Changing spaces for sports. Sport in Society: Cultures, Commerce, Media, Politics, 13(2), 300-313. doi: $10.1080 / 17430430903523002$

LINZ. (2011, 20 November). bq32a fy 04 05. Retrieved 17 February, 2014, from http://ortho.linz.govt.nz/high res_jpg/2004 05 jipg_high res/ bq32a fy 04 05.jpg 
McCormack, D. (2012). Geography and abstraction: Towards an affirmative critique. Progress in Human Geography, 36(6), 715-734. doi: doi:http://dx.doi.org/10.1177/0309132512437074

McCredie, P. (2013a, 05 Aug). ASB Sports Centre / Tennent + Brown Architects: Eastern Sports Chamber. ArchDaily Retrieved 16 February, 2014, from http://ad009cdnb.archdaily.net/wp-content/uploads/2 013/07/51ed371de8e44e67170000ce_asb-sports-centre-tennentbrown-architects-_asb_sports centre eastern_sports chamber.jpg

McCredie, P. (2013b, 05 Aug). ASB Sports Centre / Tennent + Brown Architects: Sports Centre Entry. ArchDaily Retrieved 16 February, 2014, from http://ad009cdnb.archdaily.net/wp-content/uploads/2013/0 7/51ed3738e8e44e67170000cf asb-sports-centre-tennent-brownarchitects-_asb sports centre entry.jpg

McCredie, P. (2013c, 05 Aug). ASB Sports Centre / Tennent + Brown Architects: View from Mt Vic. ArchDaily Retrieved 16 February, 2014, from http://ad009cdnb.archdaily.net/wp-content/uploads/2013/07 151ed3796e8e44e67170000d2_asb-sports-centre-tennent-brownarchitects-_asb sports centre view from mt vic.jpg

McCredie, P. (2013d, 05 Aug). ASB Sports Centre / Tennent + Brown Architects: View of Courts. ArchDaily Retrieved 16 February, 2014, from http://ad009cdnb.archdaily.net/wp-content/uploads/2013/07/51e d3765e8e44eff9f0000d8 asb-sports-centre-tennent-brown-architects-_asb sports centre interior view of courts.jpg

McCredie, P. (2013e, 30 July ). Nga Purapura/Tennent+Brown: image 3. ArchDaily Retrieved 16 February, 2014, from http://ad009cdnb.archdaily. net/wp-content/uploads/2013/07/51ec35e1e8e44eff9f000086 nga-purapura-tennent-brown nga purapura image 3.jpg

McCredie, P. (2013f, 30 July ). Nga Purapura/Tennent+Brown: image 4. ArchDaily Retrieved 16 February, 2014, from http://ad009cdnb.archdaily. net/wp-content/uploads/2013/07/51ec35e4e8e44e6717000082 nga-purapura-tennent-brown nga purapura image 4.jpg
McCredie, P. (2013g, 30 July ). Nga Purapura/Tennent+Brown: image 6. ArchDaily Retrieved 16 February, 2014, from http://ad009cdnb.archdaily. net/wp-content/uploads/2013/07/51ec3604e8e44eff9f000087 nga-purapura-tennent-brown nga purapura image 6.jpg

McCredie, P. (2013h, 30 July ). Nga Purapura/Tennent+Brown: image 9. ArchDaily Retrieved 16 February, 2014, from http://ad009cdnb.archdaily. net/wp-content/uploads/2013/07/51ec3643e8e44ee48a000096 nga-purapura-tennent-brown nga purapura image 9.jpg

Ministry of Business, I. a. E. M. (2006, 06-NOV-2006). WAINUI SOFTBALL CLUB INCORPORATED 218021. Retrieved 8 February, 2014, from http://www.societies.govt.nz/pls/web/DBSVWCO.View Company?a $n=784305 F 2640 B A 9 F 8 B A 1308$ AD028827E6\&cn=218021\&ut=C\#doc1

Ministry of Business, I. a. E. M. (2012a, 31-AUG-2012). WAINUIOMATA CRICKET CLUB INCORPORATED 215967. Retrieved 8 February, 2014, from http://www.societies.govt.nz/pls/web/DBSVWCO.View Comp any?an $=784305 F 2640$ BA9F8BA1308AD028827E6\&cn $=215967 \& u t=C$

Ministry of Business, I. a. E. M. (2012b, 18-DEC-2012). WAINUIOMATA RUGBY FOOTBALL LEAGUE CLUB INCORPORATED 217681. Retrieved 8 February, 2014, from http://www.societies.govt.nz/pls/ web/DBSVWCO.View Company?an=784305F2640BA9F8BA1308AD 028827E6\&cn $=217681 \& u t=C$

Ministry of Business, I. a. E. M. (2013a, 09-MAY-2013). WAINUIOMATA ASSOCIATION FOOTBALL CLUB INCORPORATED 217040. Retrieved 8 February, 2014, from http://www.societies.govt.nz/pls/web/ DBSVWCO.View Company?an=784305F2640BA9F8BA1308AD02882 7E6\&cn $=217040 \& u t=C$

Ministry of Business, I. a. E. M. (2013b, 16-JUL-2013). WAINUIOMATA BOWLING CLUB INCORPORATED 217044. Retrieved 8 February, 2014, from http://www.societies.govt.nz/pls/web/DBSVWCO.View Comp any? $\mathrm{an}=784305 \mathrm{~F} 2640 \mathrm{BA} 9 \mathrm{~F} 8 \mathrm{BA} 1308 \mathrm{AD} 028827 \mathrm{E} 6 \mathrm{kn}=217044 \& \mathrm{ut}=\mathrm{C}$ 
Ministry of Business, I. a. E. M. (2013c, 11-JUL-2013). WAINUIOMATA CROQUET CLUB INCORPORATED 585577. Retrieved 8 February, 2014, from http://www.societies.govt.nz/pls/web/DBSVWCO.View Comp any?an=784305F2640BA9F8BA1308AD028827E6\&cn $=585577 \&$ ut $=C$

Ministry of Business, I. a. E. M. (2013d, 18-DEC-2013). WAINUIOMATA RUGBY FOOTBALL CLUB INCORPORATED 216045. Retrieved 8 February, 2014, from http://www.societies.govt.nz/pls/web/DBSVWCO. View Company?an=784305F2640BA9F8BA1308AD028827E6\&cn $=2$ $\underline{16045 \& u t=C}$

Ministry of Business, I. a. E. M. (2014). Societies and Trusts Online. Retrieved 8 February, 2014, from http://www.societies.govt.nz/cms

Miskell, B. (2012). Hutt Landscape Study 2012: Landscape Character Description.

Neufert, E., \& Neufert, P. (2000). Architects' Data (B. Baiche \& N. Walliman Eds. 3rd ed.). Oxford: Blackwell Science.

Nicholson, M. B., Kevin; Hoye, Russell. (2013). Sport, community involvement and social support. Sport in Society: Cultures, Commerce, Media, Politics, 17(1), 6-22. doi: 10.1080/17430437.2013.828696

O'Hara, Y. (2002). If you want a pool, build it yourselves (M. Wright Ed.). n.p: n.p.

Pai, H. (2010). Scientific Management and the Birth of the Functional Diagram. In M. Garcia (Ed.), The Diagrams of Architecture (pp. 64-79). West Sussex, UK: John Wiley \& Sons Ltd.

Pickering, T. (1984). Wainuiomata Association Football Club Incorporated, 1959-1984 : 25th anniversary celebrations, Easter weekend.

Purapura, N. (2013). Our Facility. Retrieved 13 February, 2014, from http:// www.ngapurapura.maori.nz/facility/our-facility

Putnam, R. D. (2001). Bowling Alone. New York: Simon \& Schuster.
Sheard, R. (2005). The Stadium: Architecture for the New Global Culture. Singapore: Tuttle.

Somol, R., \& Whiting, S. (2002). Notes around the Doppler Effect and Other Moods of Modernism. Perspecta, 33, 72-77. doi: 10.2307/1567298

Somol, R. E. (1999). Dummy Text, or the Diagrammatic Basis of Contemporary Architecture. In P. Eisenman (Ed.), Diagram Diaries (pp. 6-25). New York: Universe Publishing.

Speaks, M. (2002). Theory was interesting... but now we have work. Architectural Research Quarterly, 6(3), 209-212. doi: 10.1017/ S1359135503001714

Statistics New Zealand. (2009, 20 May 2009). 2006 Census Meshblock Dataset. Retrieved 8 February, 2013, from http://www.stats. govt.nz/Census/2006CensusHomePage/MeshblockDataset. aspx?tab=DownloadStatistics New

Victoria University: Research Policy Group. (2007). Human Ethics Policy. Retrieved 17 February, 2014, from http://www.victoria.ac.nz/law/pdf/ human-ethics-policy.pdf

Vidler, A. (2000). Diagrams of Diagrams: Architectural Abstraction and Modern Representation. Representations(72), 1-20. doi: $10.2307 / 2902906$

Vidler, A. (2001). Diagrams of Utopia. In C. W. de Zegher, Mark (Ed.), The Activist Drawing: Retracing Situationist Architectures from Constant's New Babylon to Beyond (pp. 93-104). New York: The Drawing Center.

Vidler, A. (2006). What is a Diagram Anyway. In S. E. Cassara, Peter (Ed.), Peter Eisenman: Feints (pp. 19-27). Milan: Thame \& Hudson.

Wainuiomata AFC. (2012). Wainuoimata AFC. Retrieved 10 February, 2014, from http://www.foxsportspulse.com/club info.cgi?c=1-4205112061-0-0\&sID=213432 
Wainuiomata Rugby Football Club. (1996). Wainuiomata Rugby Football Club Incorporated : 50th jubilee 1946-1996 : Easter weekend 1996.

Wainuiomata Rugby Football Club. (2013a). Archived Plans. Wainuiomata Rugby Club Archive.

Wainuiomata Rugby Football Club. (2013b). Wainuiomata Rugby Football Club: Sponsors. Retrieved 9 February, 2014, from http://www. sportsground.co.nz/wainuiomatarugby/92673/

Wainuomata Lions Rugby League Club. (2012). Wainuiomata Lions Rugby League Club. Retrieved 10 February, 2014, from http://www.foxsportspulse.com/club info.cgi?c=1-4979-86700-0-0\&sID=173854

Wellington City Council. ASB Sports Centre: Associated Services. Retrieved 9 February, 2014, from http://wellington.govt.nz/recreation/asbsports-centre/about-the-sports-centre/associated-services

Wellington City Council. ASB Sports Centre: Facility \& Opening Hours. Retrieved 9 February, 2014, from http://wellington.govt.nz/recreation/ asb-sports-centre/about-the-sports-centre/facility-and-opening$\underline{\text { hours }}$

Wood, P. (2012). Nga Purapura, Te Wananga o Raukawa. Architecture NZ(4), 58-64.

Zealand. (2013). Census of Population and Dwellings Statistics 1986-1991 [Excell File]. Tennent + Brown Architects. (2013a, 05 Aug). ASB Sports Centre / Tennent + Brown Architects: 1st Floor Plan. Arch Daily. Retrieved 16 February, 2014, from http://ad009cdnb.archdaily.net/wp-content/uploads/2013/07/51ed37c0e8e44eff9f0000 da asb-sports-centre-tennent-brown-architects- plan.png

Tennent + Brown Architects. (2013b, 05 Aug). ASB Sports Centre / Tennent + Brown Architects: Floor Plan. Arch Daily. Retrieved 16 February, 2014, from http://ad009cdnb.archdaily.net/wp-content/uploads/2 013/07/51ed37a9e8e44ee48a0000e6 asb-sports-centre-tennentbrown-architects-_plan2.png
Tennent + Brown Architects. (2013c, 05 Aug). ASB Sports Centre / Tennent + Brown Architects: Site Plan. Arch Daily. Retrieved 16 February, 2014, from http://ad009cdnb.archdaily.net/wp-content/uploads/2 013/07/51ed37cfe8e44e67170000d4_asb-sports-centre-tennentbrown-architects- site.png

Tennent + Brown Architects. (2013d). Basketball Court Layout. Retrieved 17 Feb, 2014, from http://wellington.govt.nz/ /media/recreation/asbsports-centre/files/basketball.pdf

Tennent + Brown Architects. (2013e). Exhibition Court Layout. Retrieved 17 Feb, 2014, from http://wellington.govt.nz/ /media/recreation/asbsports-centre/files/retractable-seating.pdf

Tennent + Brown Architects. (2013f). Futsal, Handball and Korfball Court Layout. Retrieved 17 Feb, 2014, from http://wellington.govt.nz/ / media/recreation/asb-sports-centre/files/futsal-handball-korfball. pdf

Tennent + Brown Architects. (2013g, 30 July ). Nga Purapura/ Tennent+Brown: Floor Plan. ArchDaily Retrieved 16 February, 2014, from http://ad009cdnb.archdaily.net/wp-content/uploads/2013/0 7/51ec36a8e8e44eff9f000089 nga-purapura-tennent-brown_nga purapura floor plan.png

Tennent + Brown Architects. (2013h, 30 July ). Nga Purapura/ Tennent+Brown: Mezzanine Plan. ArchDaily Retrieved 16 February, 2014, from http://ad009cdnb.archdaily.net/wp-content/uploads/20 13/07/51ec36a4e8e44eff9f000088 nga-purapura-tennent-brown nga_purapura mezz_plan.png

Tennent + Brown Architects. (2013i, 30 July ). Nga Purapura/ Tennent+Brown: Site Plan. ArchDaily Retrieved 16 February, 2014 from http://ad009cdnb.archdaily.net/wp-content/uploads/2013/07 /51ec36c7e8e44ee48a000099 nga-purapura-tennent-brown nga purapura site plan.png 
Tennent + Brown Architects. (2013j). Volleyball Court Layout. Retrieved 17 Feb, 2014, from http://wellington.govt.nz/ /media/recreation/asbsports-centre/files/volleyball.pdf

Tomlinson, A. M., Andrei S.; Young, Christopher. (2003). Introduction: Mapping Sports Space. American Behavioral Scientist, 46(11), 14631475. doi: 10.1177/0002764203252812

Tschumi, B. (2010). The Diagrams of Bernard Tschumi. In M. Garcia (Ed.), The Diagrams of Architecture (pp. 194-203). West Sussex, UK: John Wiley \& Sons Ltd.

van Ingen, C. (2003). Geographies of Gender, Sexuality and Race: Reframing the Focus on Space in Sport Sociology. International Review for the Sociology of Sport, 38(2), 201-216. doi: 10.1177/1012690203038002004 


\section{List of Figures}

List of Figures

Figure 1 Central Wainuiomata and surrounding hills as viewed from the Wainuiomata Hill Road summit

Figure 2 The sporting community is split between Architecture and the Sportsfield. 11

Figure 3 A closer relationship between architecture and the field will concentrate the sporting community, intensifying the social effects of sport.

Figure 4 Diagram of Research Process 13

Figure 5 Manhattan Transcripts Diagrams (B.T. Architects, 1981)

Figure $6 \quad$ Nodes of Sporting Activity in Wainuiomata

Figure 7 Books now compete with an expanded range of media types

Figure 8 Uniform flexibility allows collections to encroach upon public space (Kubo and Prat, p. 14)

Figure 9 The social program of the library is also expanding

Figure 10 Compartmentalised Flexibility contains expansion to defined areas (Kubo and Prat, p.15)

Figure 11 Program is categorised spatially in coloured bands and consolidated (Kubo and Prat, p. 18)
Figure 12 Program is reshuffled into compartments of stability and instability 24

Figure 13 Diagram of View Shafts Determines Alignment of Spaces

Figure 14 Final Composition of Program 25

Figure 15 Ground Floor Plan-Circulation branches from central atrium.

Figure 16 Mezzanine Plan - Viewing platform and Admin area overlook Sports Hall and Atrium space. (Architects, 2013h) 27

Figure 17 Site Plan - Landscape elements act as a threshold separating the building from the main road. (Architects, 2013i) 27

Figure 18 Main Entrance - Bridge crossing wetland facilitates transition between street and building. (Brass, 2012a, p. 61)28

Figure 19 Conceptual Sketch - Building organised into functional areas in accordance with Te Whare Tapa Wha holistic model of Maori health. (Wood, 2012, p. 64)28

Figure 20 Spaces throughout the building link back visually to the central Atrium aiding in orientation. (McCredie, 2013f) 28

Figure 21 Tall atrium contains a pre fab 'Kakano' reflection space with a distinctive form which helps orient visitors to the building. (McCredie, 2013e)

29
Figure 22 Gym provides open space for a range of training activities. (McCredie, 2013h) 29

Figure 23 Colour coded markings in Sports Hall accommodate a range of sports. Suspended basketball hoops prevent obstruction at ground level. (McCredie, 2013g)29

Figure 24 Retractable seating in Sports Hall enables flexible use of space. (Brass, 2012b, p. 62)

Figure 25 Ground Floor Plan - Hall space split into two large areas which can accomodate a range of sports and activities. (Architects, 2013a)

31

Figure 26 Upper Floor Plan- Supplementary programmes occcupy space at either end of the sports halls. (Architects, 2013b)31

Figure 27 Site Plan - Building is located adjacent to Cobham Drive a major arterial route which links the city to the airport (Architects, 2013c)

Figure 28 Exhibition Court Layout - Retractable seating can be arranged to provide viewing areas for games and events (Architects, 2013j)

Figure 29 Basketball Court Layout

Figure 30 Futsal, Handball and Korfball Court Layout (Architects, 2013e)

Figure 31 Volley Ball Court Layout 
Figure 32 Development of the sportsfield intensifies its use by the public. (Google Earth. 2009, 2012)

Figure 33 ASB occupies a prominent position at the end of Evans Bay and is visible from accross the harbour (McCredie, 2013b) 33

Figure 34 Eastern Sports Hall - The use of allows for large unobstructed playing areas. (McCredie, 2013d)

Figure 35 Main Entrance - The concrete panels of the facade open out to reveal the entrances to the sports halls and cafe. (McCredie, 2013a)

Figure 36 Sports Hall - Nets and colour coded markings allow the space to accommodates a range of sporting activities. (McCredie, 2013c)

33

Figure 37 Location of Wainuiomata - The Wainuiomata Valley is defined by a network of hills which separate it from the rest of the Hutt City (LINZ, 2011)

Figure 38 The centre of Wainuiomata has shifted North over time

Figure 39 Plan of proposed new tunnel and development for Wainuiomata area (Alexander, 2000, p. 91)
Figure 40 Map of Wainuiomata - Sports Clubs are clustered around three main areas; Wise Park and Brian Heath Park, William Jones Park, and Brian Heath Park. Images obtained from(LINZ, 2011)(Hutt City Council, 2013b)

Figure 41 Photo Survey of Sports Clubs Facilities and Grounds in Wainuiomata.

Figure 42 Wainuiomata Rugby League Club 45

Figure 43 Wainuiomata Bowls Club 45

Figure 44 Wainuiomata Croquet Club 45

Figure 45 WainuiomataRugby Football Club 45

Figure 46 Wainuiomata Cricket Club 45

Figure 47 Wainuiomata Association Football Club 45

Figure 48 The activities of Sports Clubs are split between a number of associated sports grounds - a number of these clubs also have an association with each other through the Wainuiomata SportsVille programme.

Figure 49 Diagram of club Relationships with Sports Grounds- Sports activities are distributed geographically throughout Wainuiomata, there are three clusters where activities of a number of clubs are concentrated.
Figure 50 Diagrams showing sources of sponsorship and grant money for Wainuiomata League, Union, and Football Clubs primarily comes from businesses based outside of Wainuiomata. (AFC, 2012; W. L. R. L. Club, 2012; W. R. F. Club, 2013b) 47

Figure 51 Diagram of pokie machine numbers in the local community - pokies fund sports clubs in an indirect way through grants from Gaming Trusts. The bowling club owns its own machines. (Affairs, 2012)

Figure 52 Rugby League Income Sources - The majority of the clubs income comes from grants.

Figure 53 Croquet Income Sources - The Croquet Club operates on a very low budget and is mainly financed through fundraising and subscriptions.

Figure 54 Cricket Income Sources - The Cricket Club gets the majority of its income from grants, which is supplemented by bartrading, subscriptions and other sources

Figure 55 Bowls Income Sources - The Bowling Club makes most of its money from bar trading, which is supplemented by subscriptions, grants and other sources.49

Figure 56 Rugby Income Sources - Roughly half of the Rugby Club's income comes from bar trading, followed closely by grants then other fundraising. 
Figure 57 Football Income Sources - The Football Club is financed primarily through subscriptions and grants, this is supplemented by a fairly low but steady income from bar trading.

49

Figure 58 Diagram of Wainuiomata's stages of development as it has progressively expanded from the original settlement in Homedale Village. (Continued page 43) 50

Figure 59 The number of Sports Clubs registered in Wainuiomata has expanded over time resulting in increased competition for members and the division of the sporting community.

52

Figure 60 A social and developmental history of the Wainuiomata Rugby Club, Association Football Club, and the Wainuiomata Pool were mapped spatially over time, in reference to the simultaneous expansion of Wainuiomata. (Continued on page 46 \&47)

Figure 61 Wainuiomata Population Growth - Figures taken from Boffa Jackman Study (Associates, p. 6) + Census data from 1986 to 2006 (Zealand, 2009, 2013). 56

Figure 62 The average age of population is increasing

Figure 63 Wainuiomata is becoming more Ethnically Diverse
Figure 64 Wainuiomata is becoming less religious 57

Figure 65 The percentage of population above 15 with no qualifications varies throughout different areas of Wainuiomata, reaching as high as $37.5 \%$ in some cases (Zealand, 2009).

Figure 66 Wainuiomata has a high proportion of population above 15 with no qualifications of any kind, even compared to other Lower Hutt suburbs (Zealand 2009).

Figure 67 The majority of Wainuiomata residents are not currently engaged in full or part time study (Zealand, 2009).

Figure 68 Population density in Wainuiomata is fairly low, however there are severa clusters, generally towards the fringes and more recently developed areas, where the population is higher than in other areas.

Figure 693 3 representation of population density in Wainuiomata.

Figure 70 Site 1:2000 Showing the Rugby Club top right and adjacent William Jones Park centre. West of the park is the Wainuiomata Squash Club. The Swimming Pool and Bowling Club are north of the Rugby Club. (Hutt City Council, 2013b) 63

Figure 71 Photos - Connection to Immediate Context
Figure 72 Photo Survey of External Appearance 64

Figure 73 Photo Survey of the rugby grounds at William Jones Park

Figure 74 Photo Survey of the rugby grounds at William Jones Park

Figure 75

Figure 76 Senior Team 'Camp' - Informal layout of chairs and tables

Figure 77 High School Function - Space maintained for regulars by the bar while the rest of the area is organised for highschool dinner

Figure 78 Old Timers Day - Dense arrangement to accomodate more people

Figure 79 Senior Prize Giving - Formal Dinner Arrangement - Entrance to club controlled by bouncer

Figure 80 Before Senior 1st Game: Tables by corner windows occupied

Figure 81 Seniors Players Return: Tables towards the centre begin to be used.

Figure 82 After Senior 1st Game: People concentrated around bar, corner windows, and childrens area

Figure 83 Later in the night: Majority of tables occupied, band playing and dance floor in use

69 
Figure 84 After Premier Game: Large amounts of people around bar, edges of seated areas occupied

Figure 85 Density of Occupation Throughout the Day

Figure 86 Graphic Evolution of the Ruby Club (Continued page 62)

Figure 87 Expansion Of Program Over Time. 72

Figure 88 Rugby Club Program Sorted By Area72

Figure 89 Rugby Club Expansion Over Time 72

Figure 90 Growth In Team Numbers Over Time 72

Figure 91 Registered Rugby Players 2012, 2011, 2010 \& 2009

Figure 92 Corner windows provide views of the field from within the rugby club. 73

Figure 93 Typical distribution of spectators observing premier team 73

Figure 94 Trees provide natural shelter during games

Figure 95 Post match spectator movements 73

Figure 96 Diagrams of player and spectator behavior in relation to site.

Figure 97 Permeable Facade

Figure 98 Corner Opening to Field
Figure 99 Mezzanine Floors

86

Figure 100 Visual Connections

Figure 101 Surface developed from views of field 87

Figure 102 Club blended into landscape

Figure 103 Sports club masses re arranged to occupy length of field

Figure 104 Unfolding of rugby club program. (Google Earth)

Figure 105 Organisational strategy - Three fields with program concentrated in between intensifying social space and multiplying views.

Figure 106 Space above field used for additional program

Figure 107 Raised field allows additional program underneath

Figure 108 Sketch of 'three fields' organisation strategy, utilising the space beneath the field.

90

Figure 109 Sites considered for design Source: (Hutt City Council, 2013b)

Figure 110 Pedestrian routes through and around Frederick Wise Park - A 'river' splits the park into two sections North and South, this divide is crossed by a single bridge which creates a bottle nexk withing the park.
Figure 111 View East towards Rugby League Fields and Club Rooms, framed by surrounding landscape.

Figure 112 Figure Ground - with pedestrian paths 94

Figure 113 Zones

Figure 114 Pedestrian Routes - through and around the site.

95

Figure 115 Diagram of ideal connections / desire lines through Wise Park

Figure 116 Zones with figure ground

Figure 117 Overlay of historic plot areas and original river course.

Figure 118 Boffa Jackman \& Associates proposal for wise park. (Associates, p. 25)

95

Figure 119 Panorama of sports fields on North side of river

Figure 120 Panorama of 'under utilised area' 96

Figure 121 Panorama from Fitzherbert road bridge - looking west with Semi-Retirement Village to the left, River/Stormwater drainage centre, Rugby League Club, Basketball Court and Sports Fields to the right.

Figure 122 Initial design developments explored the limitations of site. 100 
Figure 123 Site Plan showing distribution of fields and central core of social and teaching program

Figure 124 Social space concentrated between other areas of program

Figure 125 Central viewing platform multiplies spectator engagement by connecting with multiple areas of activity along a linear path.

Figure 126 Aerial view looking East - Central field raised to bridge across river. 102

Figure 127 View across North-Western field - Viewing platform stretches along length of the field.

Figure 128 Aerial view looking North-West 103

Figure 129 View from South-East field looking North-West towards raised field - Viewing platform passing overhead allows space for additional program below.103

Figure 130 View South East from central, raised, field towards hills which define Wainuiomata.

Figure 131 Visual Connection to Eastern hills103

Figure 132 Visual Connection to Southern Hills and local context.

Figure 133 Massing of fields and program explored options and reorientation of main field 104
Figure 134 Further development explored a looser arrangement of program and the incorporation of landscape as a design element.

105

Figure 135 Site Plan - Demonstrating new arrangement of fields and program. Artificial hills are introduced as an additional design element.

106

Figure 136 Sections 106

Figure 137 Diagram Of New Layout - Program is re-oriented and concentrated into two blocks with views of, $A$ the wider context, and B the sports field. 106

Figure 138 Raised artificial field crosses the river 106

Figure 139 Main Social Area consists of a series of split levels to increase the visual connection to the field.

Figure 140 General arrangement on site 107

Figure 141 View South from Main Social Area107

Figure 142 View East from Indoor Sports Hall107

Figure 143 Wise Park and Immediate Context113

Figure 144 Wainuiomata is Located to the East of Harbour Lower Hutt and the Wellington

Location of Site, Wise Park, In Central 113 114
Figure 147 Photographs of Context

Figure 148 View of Site Looking South from Fire Break

Figure 149 Site Plan - Existing Site Conditions 116

Figure 150 Photographs of Existing Site

Figure 151 Pedestrian (Red) \& Vehicular (Blue) Circulation and connections through site. River through site shown in blue.118

Figure 152 Three main blocks of program (Orange) are distributed between three fields (Green). River through site shown in blue.

Figure 153 Site Plan - General Arrangement and Connections Through Site

Figure 154 General Arrangement - Overlapping planar roof forms are derived from the planar nature of the sports field 119

Figure 155 Relationship to site

Figure 156 Diagram of Pedestrian (Red) and Vehicular (Blue) Circulation

Figure 157 Ground Floor Plan

Figure 158 Diagram of Pedestrian Circulation123

Figure 159 First Floor Plan

Figure 160 Diagram of Pedestrian Circulation124

Figure 161 Second Floor Plan

124 
Figure 162 Section Drawing Location Diagram125

Figure 163 Roof Plan

Figure 164 Section A - A

Figure 165 Section B - B

Figure 166 Section C - C

Figure 167 Section D - D

Figure 168 Section E- E

Figure 169 Approach from South, looking North 136

Figure 170 Approach from school route, along river, looking East.

Figure 171 Approach from Marae, looking South West.

Figure 172 Detailed ground floor plan. 142

Figure 173 Detailed first floor plan. 143

Figure 174 Detailed first floor plan. 144

Figure 175 Diagram showing areas with view of field.

Figure 176 Section E- E

Figure 177 View 1 - Riverside approach 146

Figure 178 View 3 - Crossing the river towards clubrooms

146

Figure 179 View 4 - 1st floor sidelines and grandstand
Figure 180 View 2 - Ground floor access to changing rooms.

Figure 181 Location Plan showing views for pages $119 \& 120$

146

Figure 182 View 5 - Viewing area with training field on left and stairs to social space above on right

147

Figure 183 View 7 - Ramp to social space 147

Figure 184 View 8 - Breakout area of social space 147

Figure 185 View 6 -Central foyer space looking towards ramp to social space 147

Figure 186 View 9 - Approach from the South148

Figure 187 View 11. Looking down into Courtyard 148

Figure 188 View 10 - Looking down into Indoor Hall 148

Figure 189 Southern approach views

Figure 190 View 12 - Approach from North West 149

Figure 191 View 14 - Approach to main stairs from North East

149

Figure 192 View 13- Looking down from hill 149

Figure 193 Northern approach views

149

Figure 194 View 17 - View of field and landscape from bar area
Figure 195 View 15- Top of stairs looking into main social space

Figure 196 View 16 - Bar area of main social space 150

Figure 197 Location plan showing views 150

Figure 198 View from spectator area of Indoor Sports Hall

Figure 199 View from ground floor of Indoor Sports Hall 
